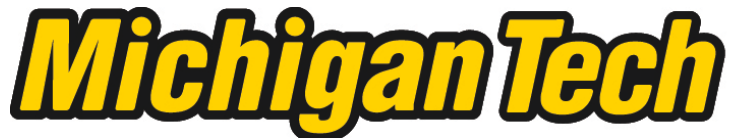 \\ Michigan Technological University Create the Future Digital Commons @ Michigan Tech
}

2013

\section{Volcanic processes and human exposure as elements to build a risk model for Volcan de Fuego, Guatemala}

Rüdiger P. Escobar Wolf

Michigan Technological University

Follow this and additional works at: https://digitalcommons.mtu.edu/etds

Part of the Geology Commons

Copyright 2013 Rüdiger P. Escobar Wolf

\section{Recommended Citation}

Escobar Wolf, Rüdiger P., "Volcanic processes and human exposure as elements to build a risk model for Volcan de Fuego, Guatemala", Dissertation, Michigan Technological University, 2013.

https://doi.org/10.37099/mtu.dc.etds/638

Follow this and additional works at: https://digitalcommons.mtu.edu/etds

Part of the Geology Commons 


\title{
VOLCANIC PROCESSES AND HUMAN EXPOSURE AS ELEMENTS TO BUILD A RISK MODEL FOR VOLCÁN DE FUEGO, GUATEMALA
}

\author{
By \\ Rüdiger P. Escobar Wolf
}

\begin{abstract}
A DISSERTATION
Submitted in partial fulfillment of the requirements for the degree of DOCTOR OF PHILOSOPHY

In Geology
\end{abstract}

MICHIGAN TECHNOLOGICAL UNIVERSITY

2013

(C) 2013 Rüdiger P. Escobar Wolf 

This dissertation has been approved in partial fulfillment of the requirements for the Degree of DOCTOR OF PHILOSOPHY in Geology.

Department of Geological and Mining Engineering and Sciences

Dissertation Advisor: Dr. William I. Rose

Committee Member: Dr. Gregory P. Waite

Committee Member: Dr. Simon Carn

Committee Member: Dr. Kathleen Halvorsen

Department Chair: Dr. John S. Gierke 



\section{Table of Contents}

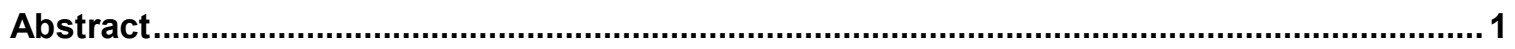

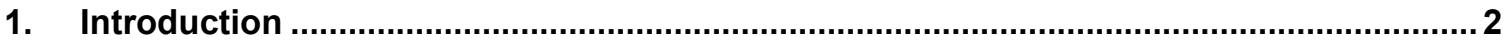

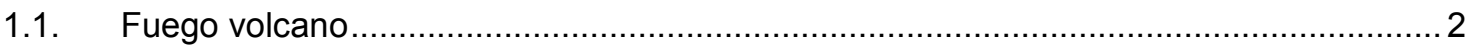

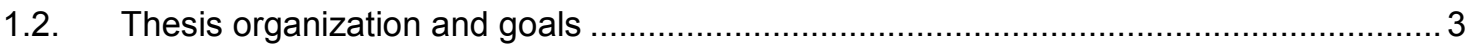

\section{Mapping the products and characterizing the volcanic processes during the current}

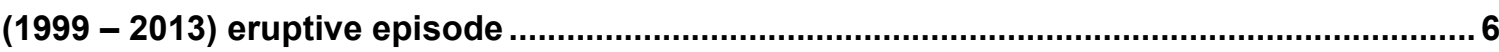

2.1. Volcanic activity and eruptive products during the 1999 to 2013 eruptive episode ......... 6

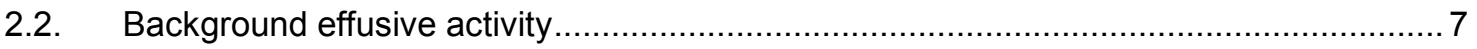

2.3. Small scale background explosive activity ......................................................... 13

2.4. Rockfall during background activity and deposits in the "proximal active areas" ..........20

2.5. Effusive activity during large (above background) eruptions ...................................... 25

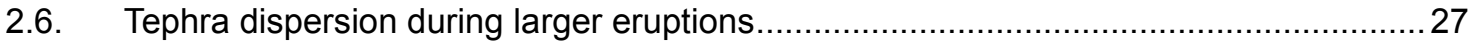

2.7. Pyroclastic flows and surges generated during larger eruptions ................................... 30

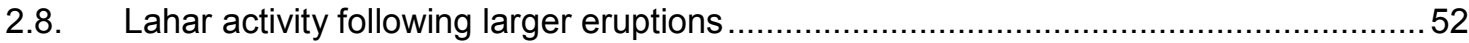

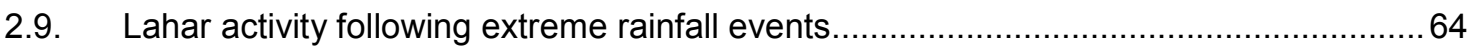

2.10. Summary of volcanic activity from 1999 to 2013: inventory of events and deposits .....69

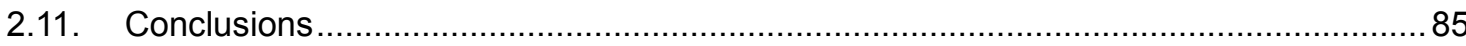

3. Comparison of the current $(1999-2013)$ eruptive episode with previous eruptions at Fuego volcano, and revision of the volcanic facies model. .....................................................8 8

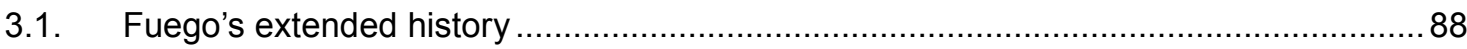

3.2. Documentation of the previous (up to the 1970s) eruptive activity ............................. 88

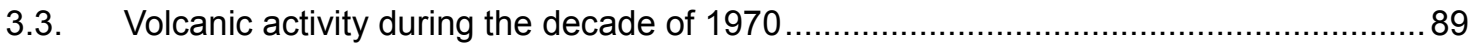

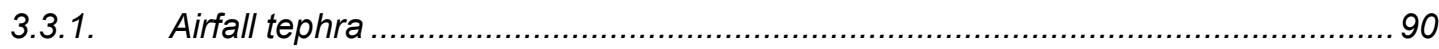

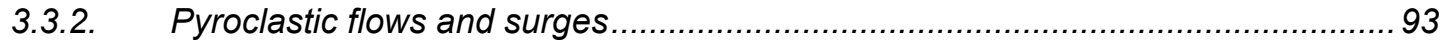

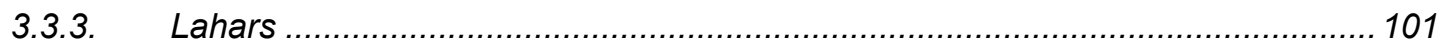

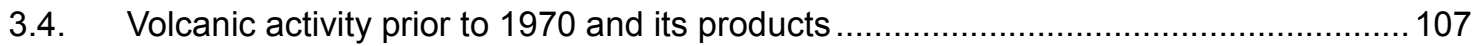

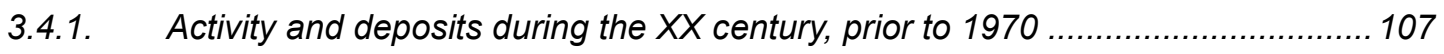


3.5. Mapping and dimensions of deposits erupted during the 1970's

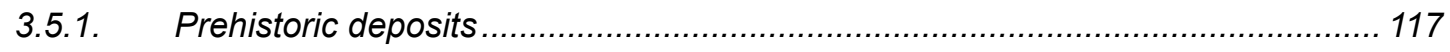

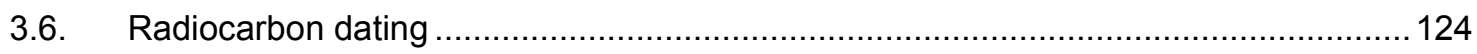

3.7. A revised and expanded facies model for Fuego ...................................................... 127

3.8. Evolution of Fuego volcano through time....................................................... 133

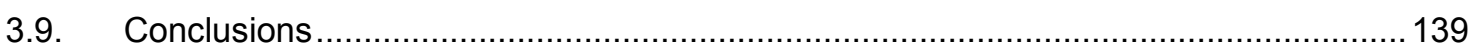

4. People's expectation of future eruptive crises at Fuego volcano and their willingness

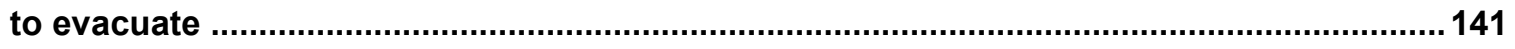

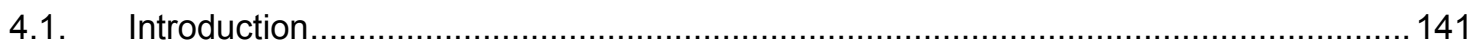

4.1.1. Risk and evacuations at Fuego volcano ..................................................... 141

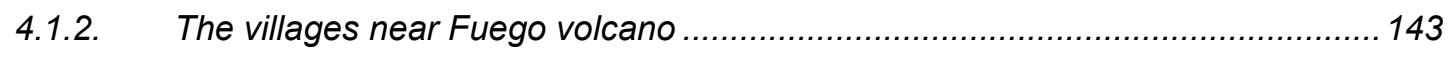

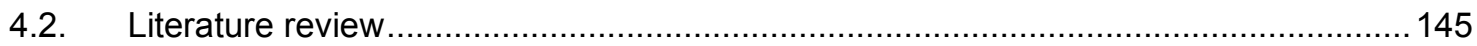

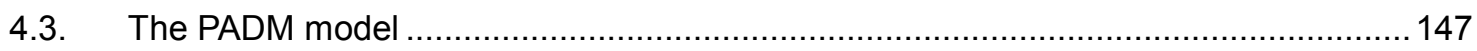

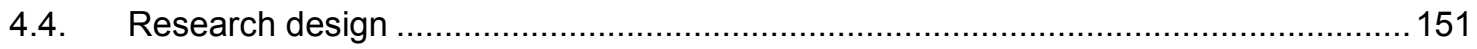

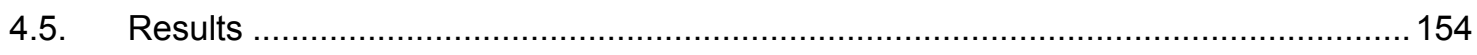

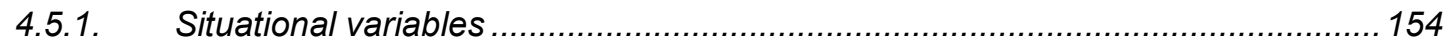

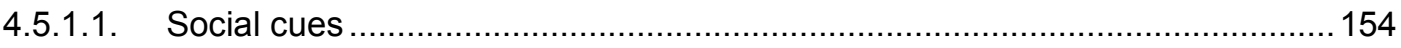

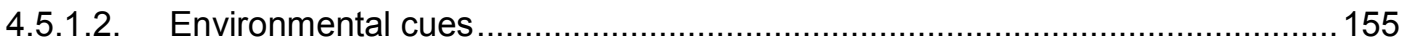

4.5.2. Population previous experience and demographics ....................................... 156

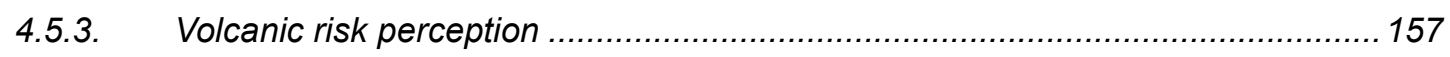

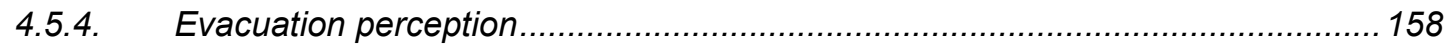

4.5.5. Stakeholder perception: trust in authorities and perception of self-efficacy ........ 160

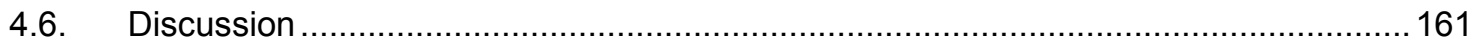

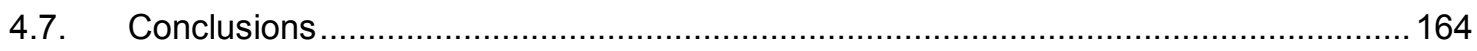

5. Elements for building a risk model at Volcan de Fuego: final considerations about

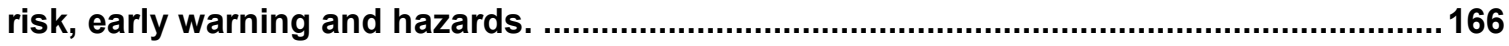

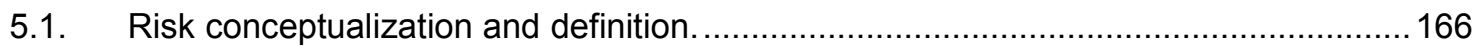

5.2. Risk management through early warning systems. ............................................. 169

5.3. People's vulnerability in the context of an early warning system..............................172 
5.4. Hazard elements to consider as part of a risk model for Fuego volcano..................... 180 5.5. Concluding remarks on potential future crises, and opportunities and challenges to

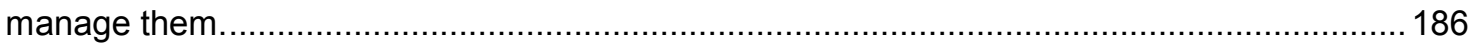

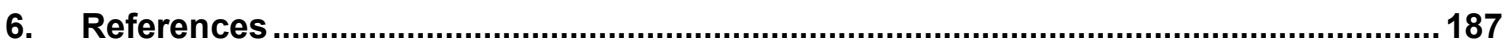

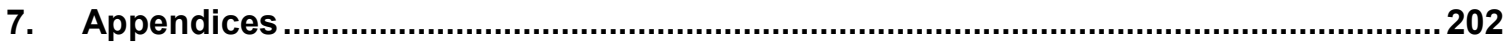





\section{Abstract}

The activity of Fuego volcano during the 1999 - 2013 eruptive episode is studied through field, remote sensing and observatory records. Mapping of the deposits allows quantifying the erupted volumes and areas affected by the largest eruptions during this period. A wide range of volcanic processes results in a diversity of products and associated deposits, including minor airfall tephra, rockfall avalanches, lava flows, and pyroclastic flows. The activity can be characterized by long term, low level background activity, and sporadic larger explosive eruptions. Although the background activity erupts lava and ash at a low rate $\left(\sim 0.1 \mathrm{~m}^{3} / \mathrm{s}\right)$, the persistence of such activity over time results in a significant contribution $(\sim 30 \%)$ to the eruption budget during the studied period. Larger eruptions produced the majority of the volume of products during the studied period, mainly during three large events (May 21, 1999, June 29, 2003, and September 13, 2012), mostly in the form of pyroclastic flows. A total volume of $\sim 1.4 \times 10^{8} \mathrm{~m}^{3}$ was estimated from the mapped deposits and the estimated background eruption rate. Posterior remobilization of pyroclastic flow material by stream erosion in the highly confined Barranca channels leads to lahar generation, either by normal rainfall, or by extreme rainfall events.

A reassessment of the types of products and volumes erupted during the decade of 1970's allows comparing the activity happening since 1999 with the older activity, and suggests that many of the eruptive phenomena at Fuego may have similar mechanisms, despite the differences in scale between. The deposits of large pyroclastic flows erupted during the 1970's are remarkably similar in appearance to the deposit of pyroclastic flows from the $1999-2013$ period, despite their much larger volume; this is also the case for prehistoric eruptions. Radiocarbon dating of pyroclastic flow deposits suggests that Fuego has produced large eruptions many times during the last $\sim 2$ $\mathrm{ka}$, including larger eruptions during the last 500 years, which has important hazard implications.

A survey was conducted among the local residents living near to the volcano, about their expectations of possible future crises. The results show that people are aware of the risk they could face in case of a large eruption, and therefore they are willing to evacuate in such case. However, their decision to evacuate may also be influenced by the conditions in which the evacuation could take place. If the evacuation represents a potential loss of their livelihood or property they will be more hesitant to leave their villages during a large eruption. The prospect of facing hardship conditions during the evacuation and in the shelters may further cause reluctance to evacuate. A short discussion on some of the issues regarding risk assessment and management through an early warning system is presented in the last chapter. 


\section{Introduction}

\subsection{Fuego volcano}

Fuego volcano is located on the northern part of the Central American Volcanic Arc (CAVA) in Guatemala (see figure 1.1 A). Fuego reaches an elevation of $\sim 3800$ masl, and is drained by multiple drainages, locally known as "barrancas". Seven of these barrancas usually receive the products of Fuego's activity (see figure 1.1 B). Fuego is also surrounded by a series of small villages with populations between 30 and 8,000 inhabitants (see also figure $1.1 \mathrm{~B}$ ).
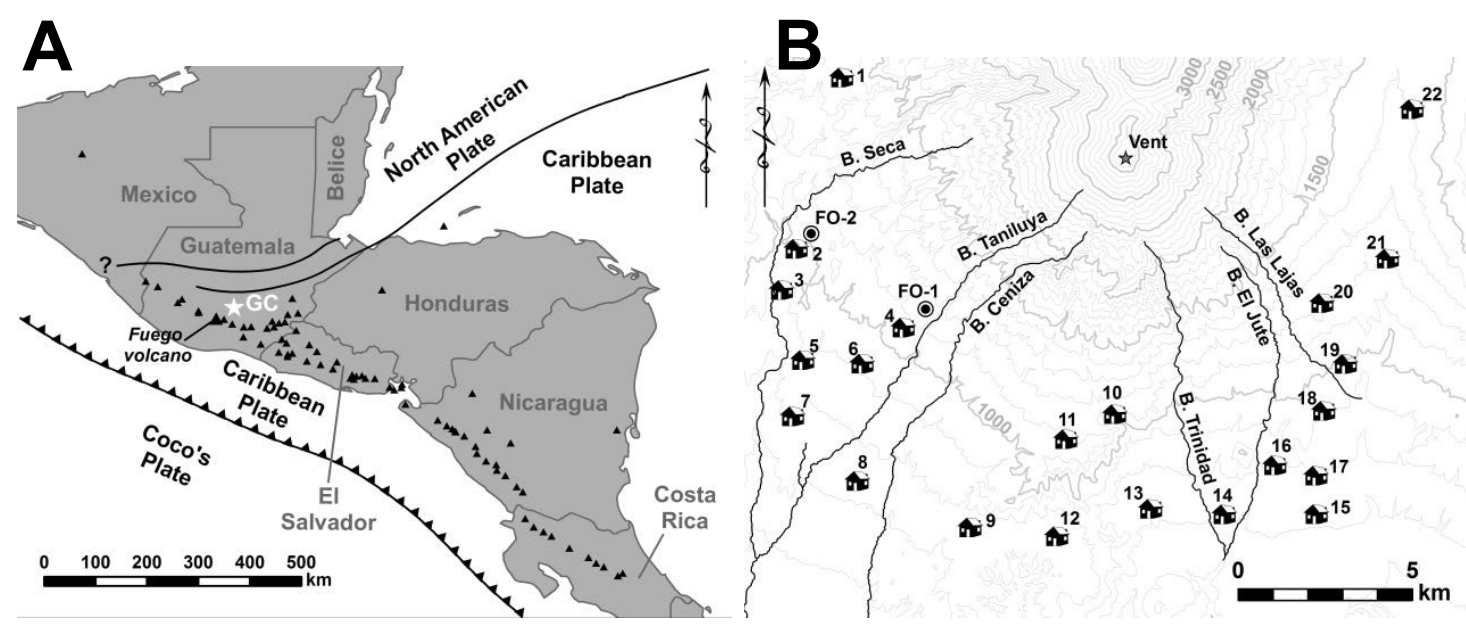

Figure 1.1. A Regional tectonics and location of Fuego volcano within the Central American Volcanic Arc (represented by the small black triangles). The white star labeled GC represents Guatemala City. B Fuego volcano and nearby communities. FO-1 and FO-2 correspond to INSIVUMEH's observatories OVFUEGO - I (in Panimache I) and OVFUEGO - II (in Sangre de Cristo). Barrancas are shown by black lines. Elevation contours are shown in gray at a $100 \mathrm{~m}$ elevation interval, with thicker contours every $500 \mathrm{~m}$ and labeled accordingly. Villages are labeled with numbers according to the following key: 1. San Pedro Yepocapa. 2. Sangre de Cristo. 3. Palo Verde. 4. Panimache I. 5. El Porvenir. 6. Morelia. 7. Yucales. 8. Asuncion Osuna. 9. Los Diamantes. 10. La Rochela. 11. Ceilan. 12. Chuchu. 13. Guadalupe - El Zapote. 14. La Trinidad 15 de Octubre. 15. Sabana Grande. 16. La Reina. 17. El Rodeo. 18. San Miguel Los Lotes. 19. San Jose Las Lajas. 20. La Reunion. 21. Santa Augusta. 22. Alotenango.

Geochemically, Fuego has been dominated by basaltic and basaltic-andesitic products, but some of the older rocks are more silicic (Chesner and Rose, 1984, Halsor and Cherner, 1997). Figure 1.2 shows a TAS rock classification diagram including pre-1999 rock compositions, as well as rock compositions from the 1999 - 2013 episode, published by Berlo et al. (2012). The interstitial glass and melt inclusion compositions are also much more silicic than the whole rock chemistry, suggesting that these samples have undergone extensive crystallization and melt evolution. Fuego's activity has been documented in historical records dating back to the early $16^{\text {th }}$ century, 
including several large explosive eruptions. More recently Fuego entered a new episode of activity in May of 1999, which has continued through 2013.

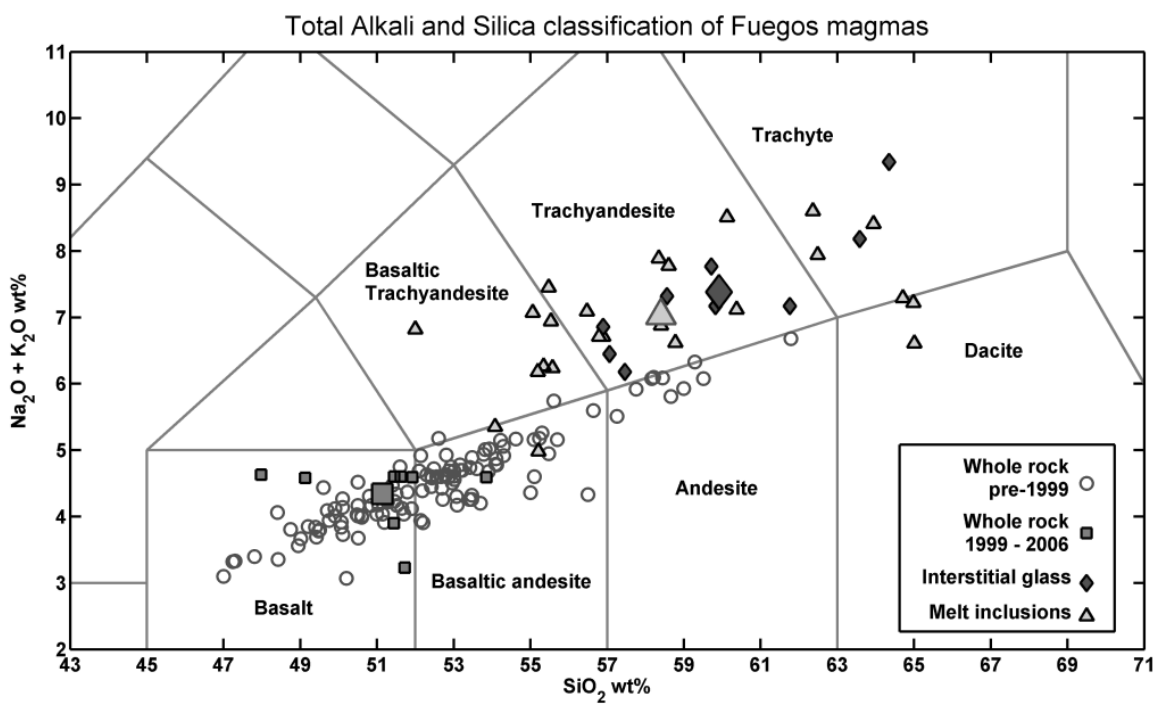

Figure 1.2 TAS volcanic rock classification diagram. Geochemical data for the $1999-2006$ samples (whole rock, interstitial glass and melt inclusions) are from Berlo et al. (2012). Geochemical data for older (pre-1999) whole rock compositions are from the RU_CAGeochem database (http://www.iedadata.org/doi?id=100263).

\subsection{Thesis organization and goals}

The main goals of this thesis are:

- To characterize the low to moderate level eruptions at Fuego volcano, by mapping and describing the processes and resulting deposits of the eruptive activity during the $1999-$ 2013 eruptive period.

- To compare and contrast the products and processes of the low and moderate level eruptive activity, with products and processes of much larger magnitude eruptions that have previously happened at Fuego.

- To investigate the perception and expectations that people living near to Fuego have in relation to potential future volcanic crisis, in the context of and early warning system.

- To link the findings of the research described in the previous goals, to a risk model for Fuego volcano. 
This thesis is divided in five chapters, starting with this introduction. The second chapter describes and characterizes the eruptive activity during the 1999 - 2013 episode, focusing on mapping the deposits and quantifying the erupted volumes, based on observatory records, extensive fieldwork and remote sensing data. A description of the products and the processes that generated them is also provided, and an estimation of the erupted volumes (all given as bulk values) is included. The activity is divided in different types and analyzed separately, according to the processes generating it. Based on the compiled catalog of eruptions from 1999 to 2013 a statistical analysis is performed on the data. Additional information on the methods and supplementary electronic files containing information generated during the research done for this chapter are also provided as electronic appendices, including the complete set of GIS deposits layers.

Although the description and analysis extends to a wide variety of phenomena, including the smaller scale and less hazardous types, the focus on a substantial part of the chapter is on phenomena that have a very high potentially to be hazardous and highly lethal, like pyroclastic flows and lahars. Despite the interest that the current activity of Fuego has sparked on the volcanological community, virtually no mapping and only a limited reporting of the eruptive activity has been published in the scientific literature. The chapter two aims to provide such information and sets the foundation to better understand the relatively low level activity at Fuego.

In the third chapter the pre-1999 eruptive activity and deposits are revisited, with the aim of comparing them to the current (post-1999) eruptive phenomena. Using Landsat imagery and aerial photography from the 1970's and early 1980's a detailed mapping of the volcanic deposits emplaced during the 1970's is presented. The excellent exposure of the deposits from previous eruptions, including those from the 1970's allows us to compare them with the deposits from the recent activity, which in many cases was directly observed as it happened in real time. The inferences drawn from the comparison of the deposits allows to generalize the conceptual models for many processes happening at Fuego at different magnitude scales (from small to very large eruptions), which sets the base a more detailed analysis of potential hazards. This comparison also highlights the rather intuitive notion that scale plays a key role in determining the severity of the hazard, but it also shows that relatively moderate events can still present a significant hazard.

The fourth chapter explores the perception and expectations that people living close to the volcano have about future potential volcanic crises. Based on a survey conducted on 8 villages around the volcano, people are inquired about their perception of the volcanic risk, their selfefficacy confronting that risk, their trust in authorities, and their expectations about the development of a future crisis. This information is put in context of their previous experience and 
demographic background. The central idea of this chapter is to compare all those variables and see how they may affect people's responses to hypothetical evacuation scenarios.

On chapter 5 , a discussion is presented about the possible elements that should be taken into account for building a risk model for Fuego volcano. The discussion of different theoretical approaches to risk, early warning and volcanic crises management is initially presented, followed by the application of the concepts to the Fuego case. The discussion is set within the practical constraints of current risk and volcanic crisis management practices. A series of key issues, identified and analyzed in the previous chapters are discussed in more detail at this point, but within a specific hazard, vulnerability and risk context. The potential paths that a crisis may take and the potential responses that people will engage in during the different scenarios are also considered. The challenging process of deciding what scenario or scenarios should the risk analyst and risk managers focus on during a crisis, and how this relates to the hazard information provided for the risk analysis (e. g. as defined by a set of hazard maps) are also discussed.

The crisis management aspect is analyzed from the three different perspective of CONRED, INSIVUMEH and the local population. The current warning and crises management procedures by CONRED and INSIVUMEH are also discussed in the context of a crisis at Fuego. The issue of uncertainty in the decision making process is also analyzed for the Fuego case, and a hypothetical event tree is used as an example explore how some of the main finding throughout the thesis (e. g. the importance of pyroclastic flow over-banking and the negative perceptions linked to evacuating) could be incorporated to such an analysis framework. The chapter is finished with a concluding remark on potential future crises and some of the most pressing issues that should be dealt with before a potentially lethal crisis happens. 


\section{Mapping the products and characterizing the volcanic processes during the current (1999 - 2013) eruptive episode}

\subsection{Volcanic activity and eruptive products during the 1999 to 2013 eruptive episode}

Fuego volcano became active after several years of dormancy on May 21, 1999 producing a violent explosive eruption, and has since then remained active up to the time of this writing (June 2013). The activity at Fuego during the 1999 to 2013 eruptive episode can be broadly divided in two main levels: a persistent low level background activity, and sporadic "above the background" explosive eruptions of larger size, some of them triggering crises that involved the evacuation of people from the nearby communities. The low level activity has become a normal background state, virtually persisting over the whole eruptive episode and alternating between effusive lava flow and small size transient explosive eruptions. Products of the low level explosive activity include small gas and tephra clouds (and associated proximal tephra deposits), ballistic projectiles, and small rockfalls and avalanches, whereas products from the effusive activity include short lava flows emplaced on the upper cone near the vent, but also persistent rockfalls and avalanches of small volume.

Larger (above the background) eruptions produce larger amounts of air-fall tephra, ballistic projectiles, pyroclastic density currents and surges, and lava flows. The exact classification of these larger eruptions is not straightforward, as they seem to display a variety of eruptive phenomena that are difficult to group under a single of the classical types of eruptions; with some of them fitting into the description of "violent Strombolian" eruptions, but others producing what could be described as Merapi type pyroclastic flows.

Rainfall, especially after pyroclastic flow producing eruptions, commonly triggers lahars. Additionally to lahars generated by normal rainfall events, two extreme rainfall events in October 2005 and May - June 2010 affected the area, triggering landslides and debris flows on steeps slopes on Fuego volcano and other high slope terrains in the region, and causing extensive sedimentation and deposition of laharic material downstream. The normal and extreme rainfall events have also caused erosion on prior volcanic deposits, especially on pyroclastic flow deposits emplaced during the current eruptive episode.

Despite the extensive basic documentation on the activity, the eruptive episode has not been systematically characterized for its entire duration. Although studies, like those published by Webley et al. (2008) and Lyons et al. (2009) detail the characteristics of the activity during some periods of the eruptive episode, most of the 1999 to 2013 period has not been studied in detail, 
beyond the collection of direct data by the observatories. No complete catalog of the "larger than normal" eruptions has been compiled for the whole period, and the deposits of these eruptions and from the background activity has not been mapped in detail, as hasn't been the case for deposits and erosion related to normal and extreme rain events during this period.

The low level activity at Fuego volcano is important from three perspectives: 1. Many of the volcanic processes are the same as those happening during larger eruptions (e. g. the generation of lahars and pyroclastic flows). Observing the processes during the low level activity will help us understand similar processes occurring during larger eruptions. 2. The persistence of low level activity over a long period of time can contribute significantly to the overall eruptive volumetric budget, becoming an important edifice building process. 3 . Despite the relatively small size of the eruptions during the low level activity period, some of the most explosive events can still represent a hazard for the population (e. g. if the September 13, 2012 pyroclastic flows would have been directed in a different channel); for this reason studying such eruptions and their products is also important from a hazard characterization point of view.

In this chapter I address some of these issues, presenting a complete catalog of large eruptions and a characterization of the background activity during the entire period. The deposits produced by this activity are mapped and a detailed description of the observed volcanic processes that generated them is also presented. A wide variety of sources that documented the activity over the 1999 to 2013 period, mainly provided by the Instituto Nacional de Sismologia, Vulcanologia, Meteorologia e Hidrologia (INSIVUMEH; National Institute of Seismology, Vulcanology, Meteorology, and Hydrology), and the Coordinadora Nacional para la Reduccion de Desastres (CONRED; National Coordination Agency for Disaster Reduction), has been analyzed to infer the volcanic processes and describe the evolution of the activity. Research published in the academic literature by several authors over the same period of time is also used for the analysis. Aerial photography and satellite imagery, together with fieldwork form the base for the mapping. A description of the documentation sources and the methods is given on appendix 2.1.

\subsection{Background effusive activity}

Effusive background activity is characterized by lava effusion from one or more summit area vents. The lava advance usually only for short distances on the very steep slopes (average slopes between $30^{\circ}-40^{\circ}$ ) before disintegrating and generating rockfalls. In some instances, as it was the case for the lava flows erupted from February through August of 2002 on the east flank 
(towards the headwaters of the Las Lajas and El Jute Barrancas) the lava flows collapsed when flowing over a $\sim 20 \mathrm{~m}$ subvertical cliff, producing a cascade of incandescent blocks and hot debris that deposited on the downslope terrain. Flow front collapses also happen in cases where the underlying terrain does not have such an abrupt discontinuity, e. g. on the headwaters of the Seca, Taniluya and Ceniza Barrancas. Flow front collapse in both cases is probably caused by the transition from ductile to brittle behavior of the lava flow core under high strain rates, and it may be in part related to the substrate instability and failure, promoted by the steep slopes. The fundamental mechanism limiting lava flows length is therefore heat loss causing a change in the rheological behavior of the lava, and could therefore be considered an extension of the classical "cooling limited" mechanism, but in the case of flows on steep and unstable slopes, cooling does not cause flow front arrest, but flow front collapse. Similar cases of flow front collapse have been described by Borgia et al (1983), Cigolini et al. (1984), Borgia and Linneman (1990), and Linneman and Borgia (1993) for lava flows at Arenal volcano, and by Lodato et al. (2007) for lava flows erupted during the $2002-2003$ Stromboli eruption.

Lava flow textures seen in high resolution aerial and satellite visible imagery range from aa' to blocky. In some flows a transition from a smoother aa' to a grainier block texture is apparent downslope along the flow. Some flows develop the typical structures of channelized aa' lava flows, with lateral levees bounding a central channel. Other flows appear not to show a well developed channel and levee structure but a rather simple lobate morphology, transitioning laterally into the surrounding debris of the upper cone slopes. Some of the channelized flows leave behind high levees and a relatively low channel, suggesting drainage of the channels after the lava supply from the source was cut, either by diversion of the lava to a different flow or by cessation of the effusion. In some cases roofing of the lava flow channel leads to lava tube formation, especially during prolonged and slightly higher effusion rate background activity, resulting in dark gaps in the incandescent footprint of the flows, as seen both in the field at night, or in the thermal channels of remote sensing imagery. Individual flows commonly overlap to form elongated composite flows and flow fields.

Lava flows erupted during background effusive activity usually extend only a few hundred meters from their respective vents. The median length recorded by the INSIVUMEH observatory for lava flows from 2005 through 2007 (not including those associated with larger eruptions) was $300 \mathrm{~m}$, although there is a high variability, with lava flows at times reaching a length close to $1 \mathrm{~km}$, especially in the case of intermediate levels of activity between background effusive activity and larger eruptions (see figure 2.1). 

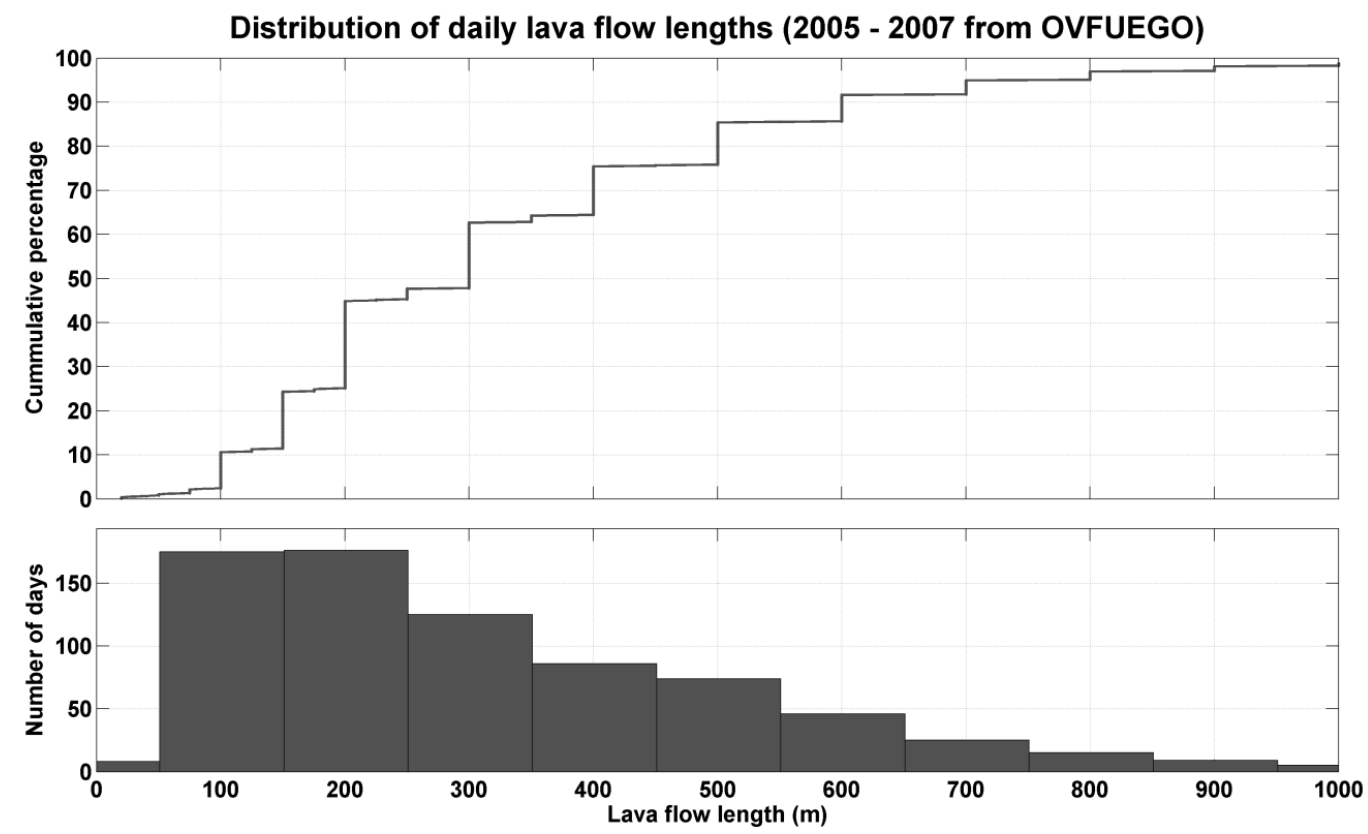

Figure 2.1. Distribution of daily mean lava flow lengths as recorded by the OVFUEGO - I, observatory.
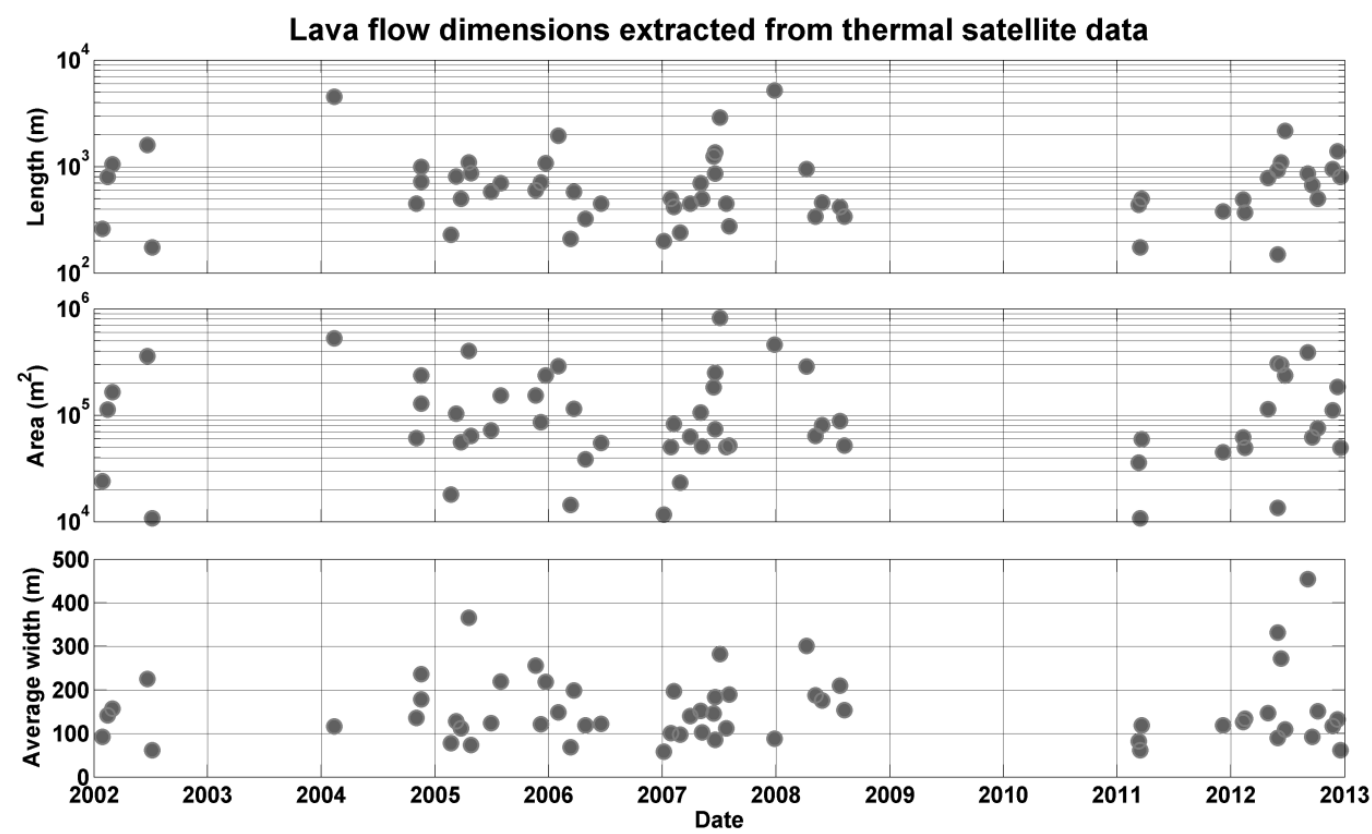

Figure 2.2. Lava flow dimensions inferred from thermal anomalies mapped on satellite imagery.

The INSIVUMEH dataset is based on visual estimations made by the OVFUEGO observatory staff from a distance of $\sim 7.6 \mathrm{~km}$, and the potential errors could be significant (e. g. $>100 \mathrm{~m}$ ), 
however this dataset represents the most complete set of lava flow lengths for the studied period. Flow dimensions extracted from thermal satellite sensors broadly agree with the INSIVUMEH dataset (see figure 2.2 and supplementary video files in appendix 2.2).

Thermal bands used for this study include short wave infrared (SWIR) and thermal infrared (TIR) bands, with can be used isolated or simultaneously to identify hot spots. Thermal bands in ASTER (SWIR and TIR), Landsat (SWIR and TIR) and EO-1 ALI (SWIR) satellite data were analyzed to identify high radiance anomalies related to the recent deposits that were still hot at the time of the image acquisition. Most of the thermal anomalies associated to hot deposits were directly analyzed by visually inspecting the radiance maps linearly scaled to an 8 bit (256 values) color map, and choosing a radiance threshold value to define the deposit region as those pixels above the threshold. In cases when this method was compared with other methods (e. g. mapping the deposits from the visible high resolution orthophotos) the results were satisfactory. Some deposits with a relatively low temperature above the background were analyzed by applying anomaly enhancement and detection methods. The TIR bands will be more sensitive to lower temperature anomalies than SWIR bands, e. g. for deposits that have had more time to cool or which were emplaced at lower temperature, but such bands will offer a lower spatial resolution (e. g. $90 \mathrm{~m}$ for TIR bands vs. $30 \mathrm{~m}$ for SWIR bands for the ASTER images). TIR bands work better for night time images which are not affected by solar heating of the ground which can potentially mask deposits that are only slightly above the surrounding ground temperature. The use of multiple bands can help to better discriminate between the hot anomaly and the background, by using a band in the SWIR spectral range, as the contrast will be much stronger (Steffke and Harris, 2011).

For the more subtle thermal anomalies a spatially "contextual" anomaly detection method (e. g. Steffke and Harris) was applied, by calculating the mean and standard deviation of the radiance values of the pixels in a $3 \mathrm{~km}$ radius moving window centered over each pixel in the volcanic region, and comparing those statistics with the radiance values of the pixels over which the moving window was centered; pixels were classified by the number of standard deviation values they stood above the regional average radiance value. A threshold for the number of standard deviations above the mean can be chosen by trial and error, to flag pixels corresponding to "hot" (lava or pyroclastic material) deposits, and trying to balance sensitivity and specificity in the classification of pixels. Other anomaly enhancement techniques, including 2D image filtering through averaging and "unsharp" contrast enhancement (Marques, 2011; Gonzales et al. 2004) were applied to the lowest contrast anomalies in the images using Matlab. For subtle anomalies that were also elongated and narrow (e. g. $\sim 1$ pixel wide in the $90 \mathrm{~m}$ pixel TIR images) edge 
detection algorithms, including the "Sobel", "Prewitt", "Roberts", "Log", "Zero cross", and "Canny" methods (Marques, 2011; Gonzales et al. 2004) were also applied, but gave weaker results.

Flow widths measured on high resolution imagery range from $15 \mathrm{~m}$ (including $4 \mathrm{~m}$ wide levees and a $7 \mathrm{~m}$ wide central channel) for single narrow channelized aa flows, to $70-150 \mathrm{~m}$ for compound flows and flow fields produced by the repeated emplacement of individual. Flow widths derived from thermal satellite imagery seem to be wider on average, and this can be explained in part by the rather coarse resolution of these sensors: $60 \mathrm{~m}$ pixel for Landsat band 6 (which is resampled at $30 \mathrm{~m}$ using cubic convolution, for distribution by the USGS/EROS) and $90 \mathrm{~m}$ pixel for ASTER TIR bands, resulting in an overestimation of flow average widths by as much as one pixel diagonal length (85-127 m). Thermal signatures were observed in both thermal infrared Such overestimations will obviously also have an important impact on flow areas, especially for narrow and long flows, which is the most common occurrence. It is also possible that part of the hot areas shown in the thermal imagery correspond to hot debris that has been shed off laterally from the lava flows, or parallel to them from a source upslope.

Figure 2.3 shows a map of the thermal anomalies extracted from satellite imagery and considered to be associated with lava flows, stacked in a single image as semitransparent gray polygons (note the square pixelated nature of the polygons, inherited from the satellite images pixels). The pattern of lava flows following the topographic lows is very clear, and the discontinuity of some of the flows, perhaps caused by channel roofing, can also be seen in some cases. 


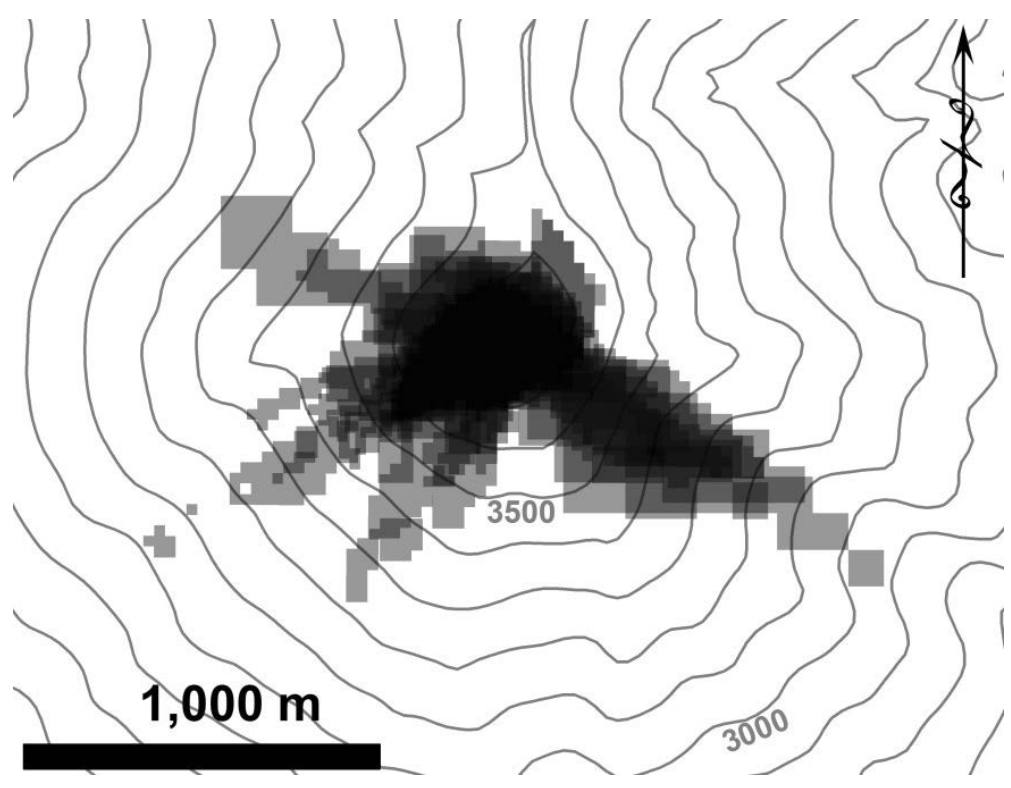

Figure 2.3. Map of thermal anomalies (stacked) near the Fuego vent, covering the 1999 to 2013 period. Elevation contours in meters above sea level, contour interval $100 \mathrm{~m}$.

Individual flow thicknesses are challenging to estimate, but they probably don't exceed a few meters. The relief of individual flows fall below the sensitivity of the February 2006 contour elevation map, as well as the sensitivity of SRTM and ASTER DEMs, which constrains the maximum value for such a relief to be less than $10 \mathrm{~m}$. Individual flow thicknesses may be as thin as 1 - $2 \mathrm{~m}$, which would be similar to lava flow thicknesses reported for equally steep slopes at Etna volcano by Walker (1967), and would be consistent with the model proposed by Kilburn (2004) for aa' and blocky lava flow, suggesting that the flow dynamic is determined by the fracturing of the flow at the front and the possible transition into the blocky flow regime, which on such steep slopes would result in total collapse and calving off blocks from the flow core.

Considering individual flow widths between 5 and $50 \mathrm{~m}$, and thicknesses between 1 and $10 \mathrm{~m}$, for the flows erupted during background effusive activity, such flows would have cross sectional areas between 5 and $500 \mathrm{~m}^{2}$, but typical values would probably be much closer to the lower end. Considering typical width and thickness values of 20 and $2 \mathrm{~m}$, respectively, resulting in a cross sectional area of $40 \mathrm{~m}^{2}$. Such dimensions broadly agree with those estimated by Lyons et al. (2009), although they assume a larger area $\left(60 \mathrm{~m}^{2}\right)$ for the average flow cross sectional area.

There are only a few indirect dataset from which flow advance rates and flow channel velocities can be estimated. The daily lava flow length data from the OVFUEGO observatory can be used to assess the daily changes in the length of the flows, by subtracting consecutive length values, 
resulting in daily negative (flow front retreat) and positive (flow front advance) values. Assuming that the length changes happened over an entire 24 hour period, the flow front advance rates can be estimated (see figure 2.4). The mean and median values obtained from a total of 295 (only positive) rates are $186 \mathrm{~m} /$ day and $100 \mathrm{~m} /$ day, respectively, which correspond to velocities of 0.002 and $0.001 \mathrm{~m} / \mathrm{s}$, but the maxima can be as high as $1000 \mathrm{~m} /$ day $(0.01 \mathrm{~m} / \mathrm{s})$. Using the cross sectional values discussed previously would give a range of lava flow volumetric rates between $0.01 \mathrm{~m}^{3} / \mathrm{s}$ and $5 \mathrm{~m}^{3} / \mathrm{s}$, and a mean value of ca. $0.1 \mathrm{~m}^{3} / \mathrm{s}$. This estimate is lower than the value obtained by Lyons et al. (2009), but such a discrepancy is to be expected, given the ranges of uncertainty in both the present study and that by Lyons et al. (2009).

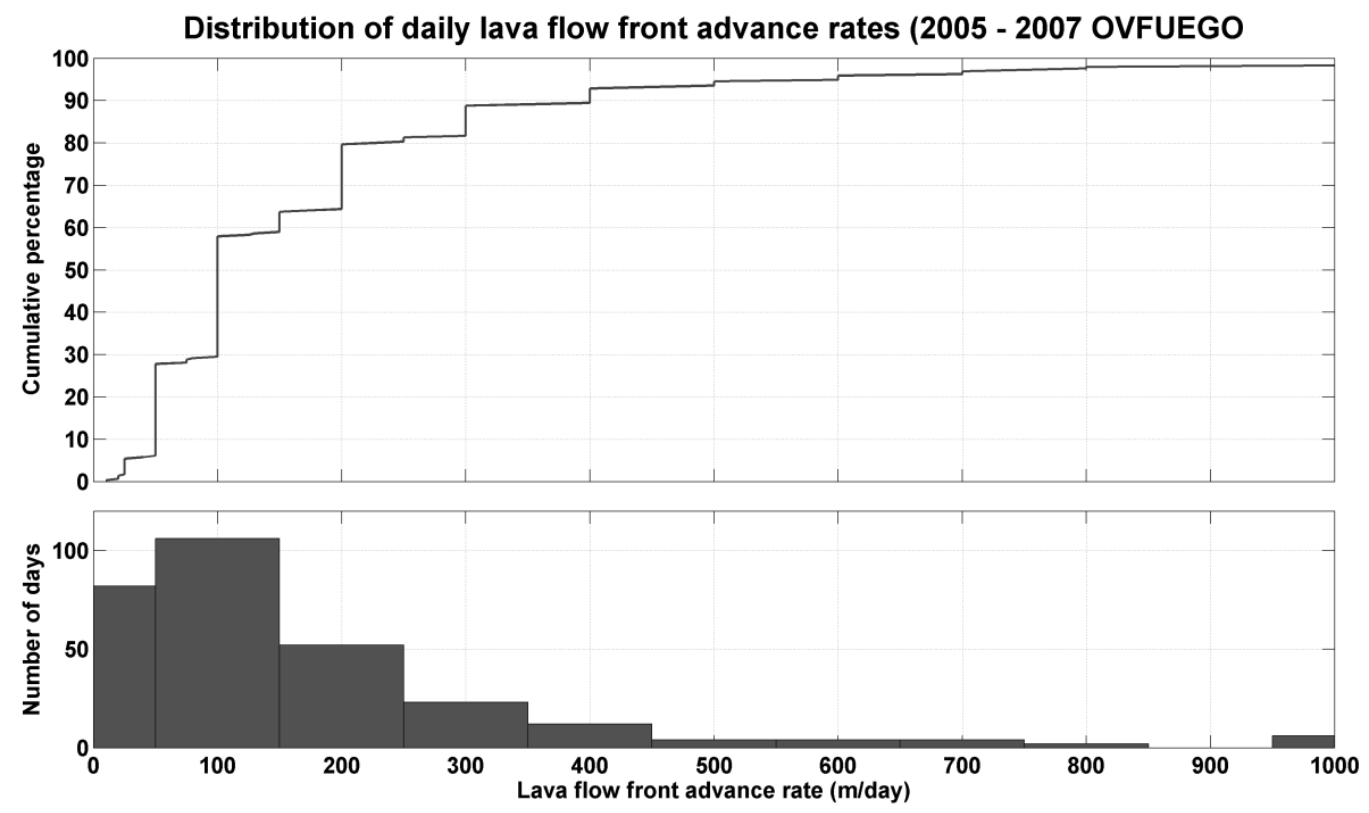

Figure 2.4. Lava flow front advance rates derived from daily flow lengths reported by the OVFUEGO - I observatory from 2005 to 2007.

\subsection{Small scale background explosive activity}

Small explosive eruptions during background activity include a wide range of styles, and possibly a corresponding variety of eruption mechanisms. Although individual events are at the lower end of the magnitudes for eruptive activity at Fuego $\left(<10^{4} \mathrm{~m}^{3}\right.$ per individual event), their high recurrence (several times a day) over virtually the whole eruptive episode could result in a significant cumulative contribution to the long term volume of erupted products at Fuego. This persistence in eruptive activity at Fuego is clearly visible in the thermal signature of the vent area over virtually the entire time since the initiation of the current eruptive episode in May of 1999 
(see supplementary video files in appendix 2.2). Activity styles range between extreme types, from low apparent viscosity magma producing "bubble bursts", which fit perfectly into the classical description of mild Strombolian activity, to much more impulsive and ash rich eruptions, which would more appropriately fit the description of the Vulcanian type. Between these extreme types there is a continuum spectrum of activity styles that can be challenging to classify.

The more powerful Vulcanian type eruptions eject fragmental material ranging in size from ash to blocks and bombs $>2 \mathrm{~m}$ in diameter. Observations during daylight show that these eruptions are characterized by the impulsive release of an initially dark gray cloud, in the form of "finger jets". The jets can have initial velocities $>100 \mathrm{~m} / \mathrm{s}$ as measured from video footage, but decelerate rapidly ( 1 second) to $<40 \mathrm{~m} / \mathrm{s}$, expanding into a turbulent convective cloud with the typical "cauliflower". Typically the cloud further slows to $<20 \mathrm{~m} / \mathrm{s}$, attaining a nearly constant velocity over the next few tens of seconds, following a typical behavior described by similar but smaller eruptions in 1978 by Wilson and Self (1980). This behavior is interpreted as showing the transition of the cloud from the initial high velocity (and momentum) jets, to a slower thermal convective cloud. After $30-60$ seconds the vertical velocity further decays, slowing down zero over the next minute or two, as the convective cloud reaches a level of neutral buoyancy and is dispersed by the wind. The ballistic blocks and bombs often reach elevations of $300-500 \mathrm{~m}$ above the crater level, landing at distances $>1.5 \mathrm{~km}$ and further rolling down the slope, in some cases, to distances $>2.5 \mathrm{~km}$. Video footage of explosive, ash rich, "Vulcanian" type eruptions can be found here: http://www.youtube.com/watch?v=nZgTOAVO4A4. See also Waite et al. (2013) and their supporting material for more video examples.
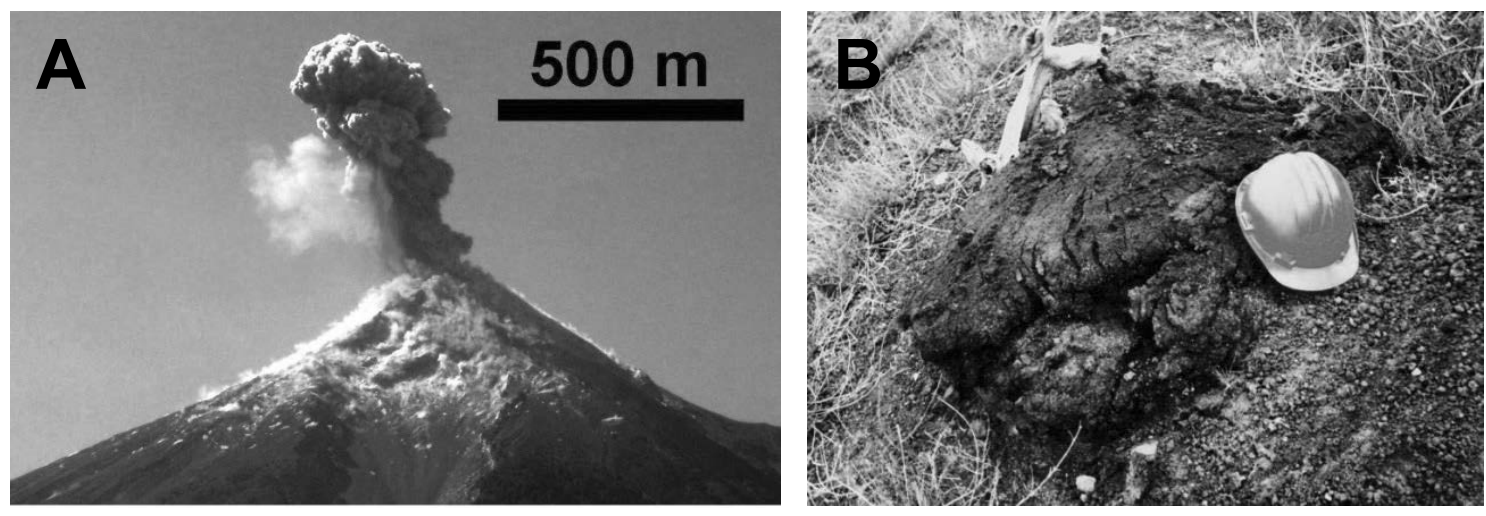

Figure 2.5. A. Typical ash rich background explosive eruption at Fuego. Notice the dust clouds forming on the upper cone slopes caused by ballistic projectile hitting the ground. B. Volcanic bomb erupted during background explosive activity at Fuego volcano in April of 2003, located $1.5 \mathrm{~km}$ to the NE of the active vent. 
Ash produced by the background explosive eruptions can be tracked as it remains suspended in the atmosphere by means of satellite imagery, aircraft reports, and from ground observations (e. g. from the INSIVUMEH observatories); such a tracking of ash clouds is done routinely by the Washington Volcanic Ash Advisory Center (VAAC)

(http://www.ssd.noaa.gov/VAAC/washington.html) for all active volcanoes within the jurisdiction of the VAAC, including Fuego volcano. Figure 2.6 shows the elevation and distance from Fuego volcano of ash clouds reported by the Washington VAAC for the 1999 to 2013 period.

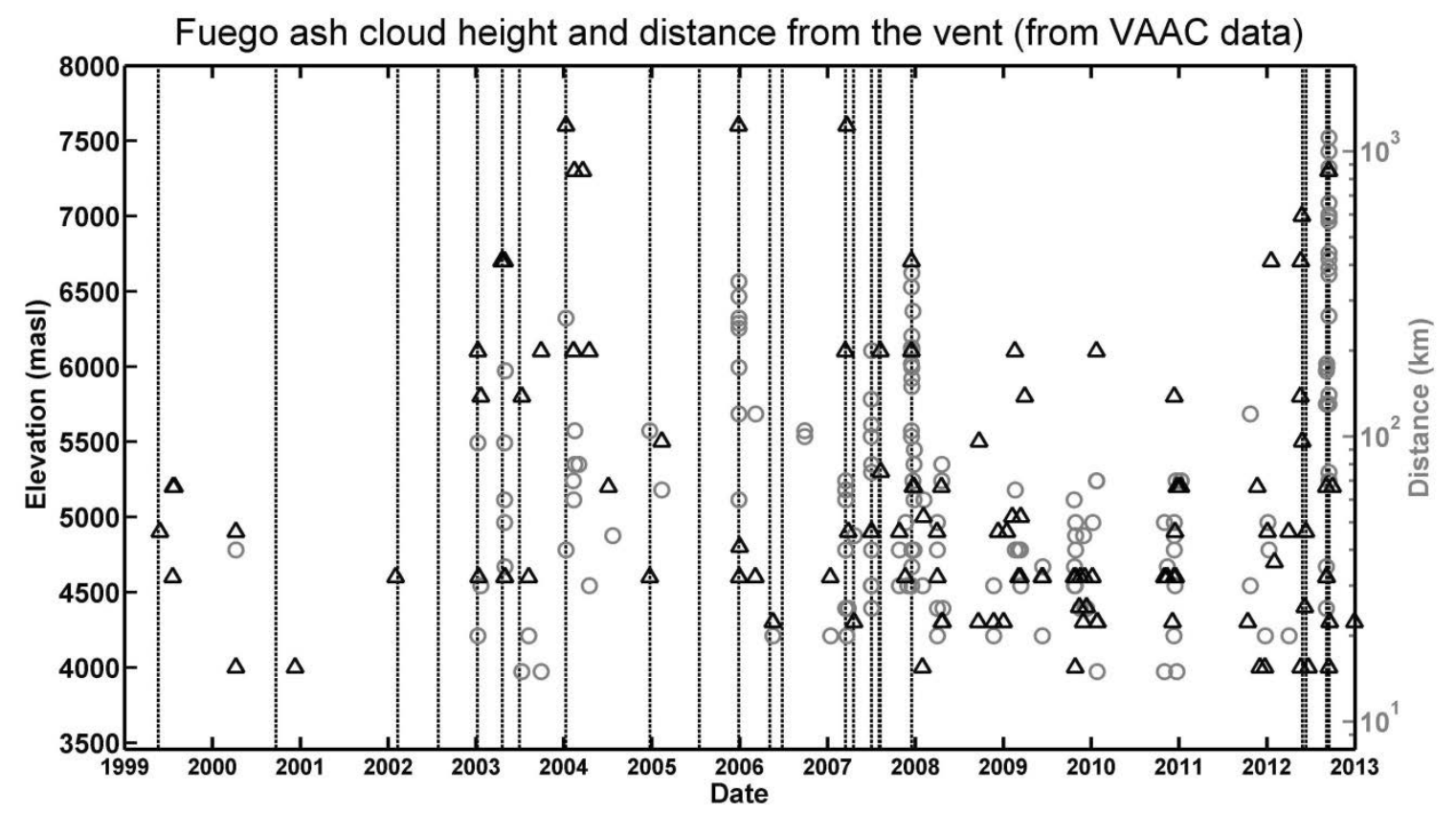

Figure 2.6. Fuego ash cloud height and distance from the vent. Black triangles represent elevation measured in meters above sea level, on the left axis, and gray circles represent horizontal distance from the vent measured in $\mathrm{kms}$, on the right axis. Vertical dotted lines represent the larger (above background) eruptions.

Ash clouds generated by explosive background activity usually rise up to $2 \mathrm{~km}$ above the vent ( 6000 masl) and can travel several tens of kms, being recognizable as ash clouds as far as 100 $\mathrm{km}$ from the vent, according to reports from the Washington VAAC. The ash clouds reported by the VAAC may have very low ash concentrations, and in most cases the ash falling to the ground will form a negligible, impossible to map deposit. The surprisingly long distance that this ash can reach suggests that at least a part of it must be fine (Rose and Durant, 2011). 
No cases of column collapse (sensu stricto) during background explosive eruptions have been observed or reported, implying that the erupted mixture of gas and pyroclasts either exists the vent at high velocity and immediately expands to reach positive buoyancy, or the mixture is already buoyant when erupted. However, rock fall avalanches, many times transitional to small pyroclastic flows, are often produced by the more vigorous Vulcanian eruptions, caused by the showering of the upper summit region by blocks and bombs from the eruption, and perhaps also by strong shaking and deformation of the upper edifice during the explosive eruptions.

On the other end of the activity style spectrum, mild Strombolian eruptions are much less powerful and produces little to no ash, with most of the erupted magma fragmenting into larger size ejecta, forming bombs, spatter and lapilli (see figure 2.7). This kind of activity tends to happen during periods of effusive activity, sometimes coevally from the same vent. Additional video footage examples can be found here: http://footage.shutterstock.com/clip-713875-stockfootage-erupting-volcano-in-central-america-volcano-fuego.html

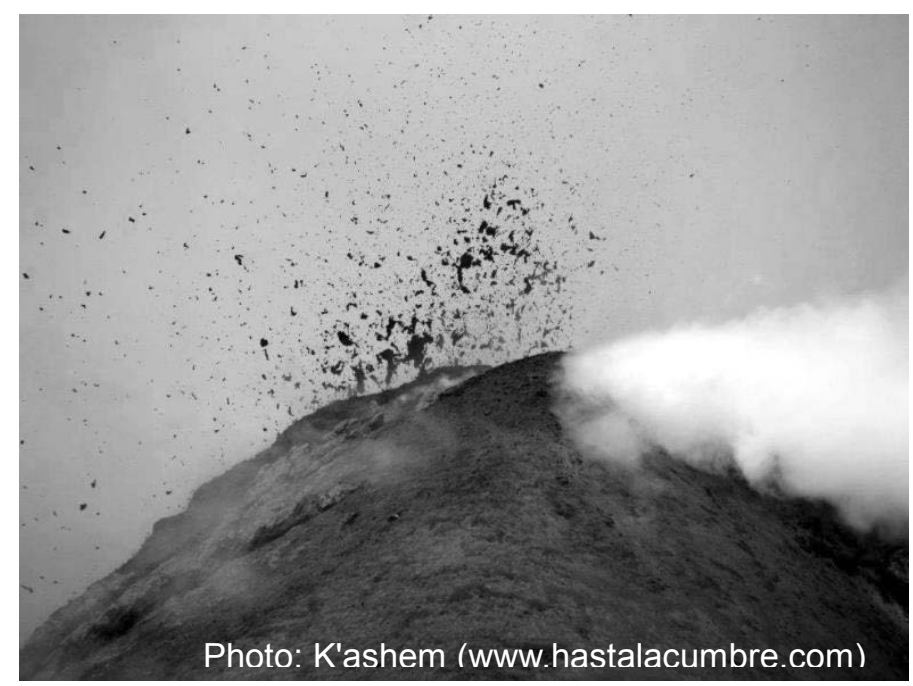

Figure 2.7. Typical Strombolian "bubble burst" at Fuego volcano on June 2012.

Between the two end members of activity there is possibly a continuum of styles, stretching from less impulsive, ash poor, Strombolian-like eruptions to more impulsive, ash rich, Vulcanian-like explosions. The variation on how impulsive and how ash rich the eruptions are can however be independent, i. e. the correlation between "impulsiveness" and "ashiness" is not always very strong, complicating the idea of a two end member classification. Some eruptions ejecta is dominated by ash as would be expected from Vulcanian-type eruptions, but they produce no strong audible noise and produce only weak, emergent rather than impulsive seismic and acoustic signals, as shown by Waite et al. (2013). Ash emissions by such eruptions are less 
impulsive than the strong initial jets seen during the initial few seconds of the more impulsive Vulcanian-type eruptions. The steady, although pulsating character of the emissions can be characterized as lower intensity jetting. The pulsating nature of the ash jetting can be seen as a succession of individual ash rich ejections closely spaced in time. These eruptions eject almost no larger bombs. See Waite et al., 2013 (and their supporting material) for video examples of such eruptions.

The INSIVUMEH observatory in the village of Panimache I (OVFUEGO I) routinely records the background explosive activity. For the 2006 and 2007 period the mean daily number of eruptions was 23.8, although the variation is large going from 0 to more than 100 . The 2006 and 2007 period was a rather high activity period in terms of the frequency of occurrence of background explosive eruptions and therefore places an upper limit to the daily mean number of eruptions over the long term. Over the entire 1999 to 2013 period the daily average is probably smaller, but still on the order of 10 events per day. Deposits produced by individual background explosive eruptions are too small to be mapped, but given the frequency and persistency of such eruptions throughout the current eruptive episode, their cumulative effect may not be negligible. Recent geophysical and geochemical studies can help to constrain the magnitude (volume) of individual background eruptions, as a starting point to make a rough (order of magnitude) estimate of the long term contribution of these eruptions (see the appendix 2.3 for details on these estimates), from such calculations a typical volume on the order of $10^{3} \mathrm{~m}^{3}$ is obtained for the material erupted during background explosive eruptions.

Taking the data on the number of daily explosions and the volumes estimated for typical explosive background eruptions we can estimate the order of magnitude of the cumulative volume of erupted material on the long term. Multiplying the mean $\left(10^{3} \mathrm{~m}^{3}\right)$ expected volume for individual eruptions by the daily mean number of eruptions reported for the 2006 to 2007 period we obtain a mean daily eruption volume of $2.2 \times 10^{4} \mathrm{~m}^{3}$, which translates into a yearly volume of $8.0 \times 10^{6} \mathrm{~m}^{3}$, and over the 14 years of activity since 1999 , the cumulative volume would to $1.1 \times 10^{8} \mathrm{~m}^{3}$. Such an estimate may be exaggerated, as the activity during the 2006 to 2007 period was very high compared to other times within the 1999 to 2013 episode, with a longer term estimate perhaps only being half of this volume $\left(\sim 5 \times 10^{7} \mathrm{~m}^{3}\right)$, assuming $\sim 10$ eruptions a day as a better estimate of the long term average daily number or eruptions, giving a daily eruption rate of $10^{4} \mathrm{~m}^{3}$, which is equivalent to $0.1 \mathrm{~m}^{3} / \mathrm{s}$, and very close to our estimate of the eruption rate during effusive activity. In any case, this is a significant volume of material that had not been accounted for previously. The cumulative volumes over the 2006 through 2007 are plotted in figure 2.8. The best fit regression line and slope value is also shown. 


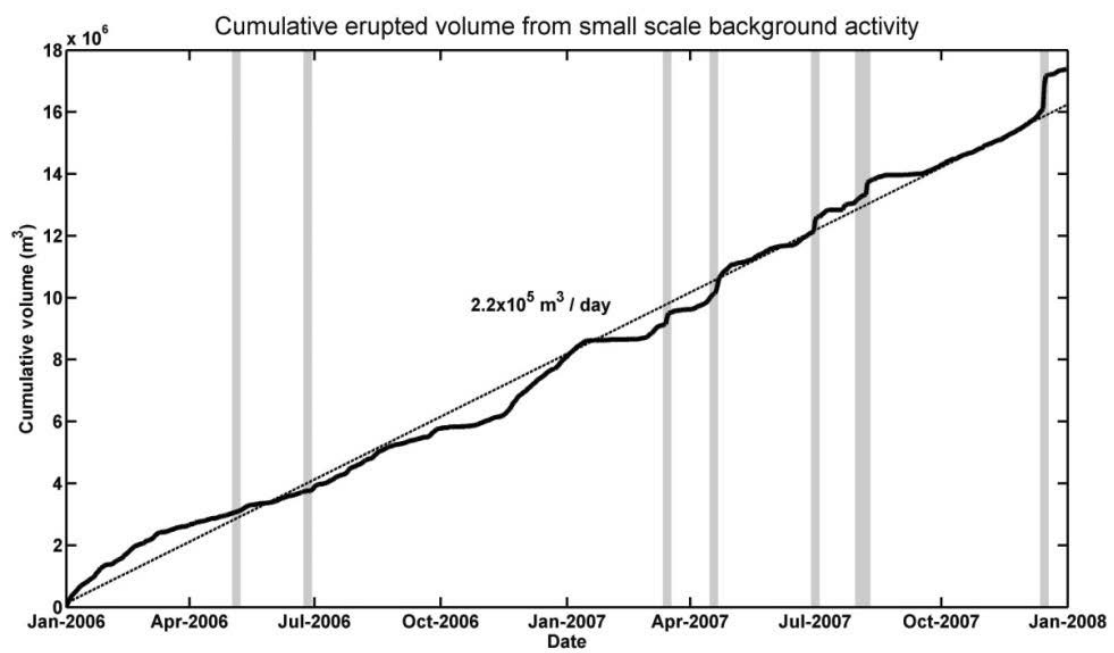

Figure 2.8. Cumulative volume of material erupted during small background explosive eruptions at Fuego volcano (tick black curve), during 2006 and 2007 . A mean erupted volume of $10^{3} \mathrm{~m}^{3}$ is used together with the daily number of eruptions reported by INSIVUMEH. Linear best fit line (dotted black line) is also shown with the slope value labeled as well. Gray vertical lines represent the times of larger "above the background" eruptions.

Given the mobility of the finer pyroclasts (in the ash size fraction) and which may remain suspended in the atmosphere for a longer time (Rose and Durant, 2011) it seems likely that a large fraction of the volume erupted during the background explosive eruptions becomes dispersed beyond the limits of the volcanic edifice.

Regarding a classification scheme for the background explosive eruptions, a variety of characteristics have to be taken into account. Marchetti et al. (2009) discuss energy partition characteristics between infrasonic energy (a measure of the impulsiveness) and thermal energy (which is related to the amount of erupted ash) for different styles of eruptions, and argue that it is the buoyant energy (i. e. the difference between thermal and infrasound energies) what separates eruptions of different styles (Strombolian vs. Vulcanian) in two clearly separate fields. Their analysis was done on a sample of eruptions from different volcanoes (including ash rich Vulcanian eruptions from Fuego, from January 2003), but the same analysis would apply to a single volcano for which the activity style changes over time. Lyons et al. (2009) described two kinds of background explosive eruptions happening between August 2005 and June 2007. During periods of lava flow effusion the explosive activity was described as "minor Strombolian explosions", which could be closer to the Strombolian style end of the activity spectrum. But Lyons et al. (2009) also described what they called "degassing explosions", and which would be closer to the Vulcanian type (larger, more impulsive and ash rich), happening in the absence of lava effusion; most significantly, the main characteristics (ash content and loud sound) of both 
types of eruptions largely overlap. Analyzing a sample of eruptions from January 2008 and January 2009, Waite et al. (2013) defined three types of background activity eruptions, based on the VLP signal they produced. This classification also corresponds with differences in the impulsiveness and ash content, and in the case of ash rich eruptions, included both impulsive (Vulcanian like) and non-impulsive (jet producing) eruptions.

Using a two dimensional Cartesian diagram that shows the impulsiveness and the ash content (fragmentation) on its coordinate axis, we can located the different eruption styles observed at Fuego (see figure 2.9). The variables in the figure are loosely defined on purpose, as this diagram intends to be only a conceptual description of such a possible classification system, but a more rigorous system could be derived from it, by for instance replacing the loosely defined variables with well-defined quantities. Following Walker (1973), fragmentation could be defined as the percentage of erupted material finer than ash. And following Marchetti et al. (2008), the impulsiveness could be defined as the percentage of acoustic, seismic and kinetic energy from ballistic ejecta, with respect to the total energy, which would include all of the above mentioned energy types, plus the thermal energy contained in the erupted pyroclasts, and which ultimately gives rise to the eruptive plume.

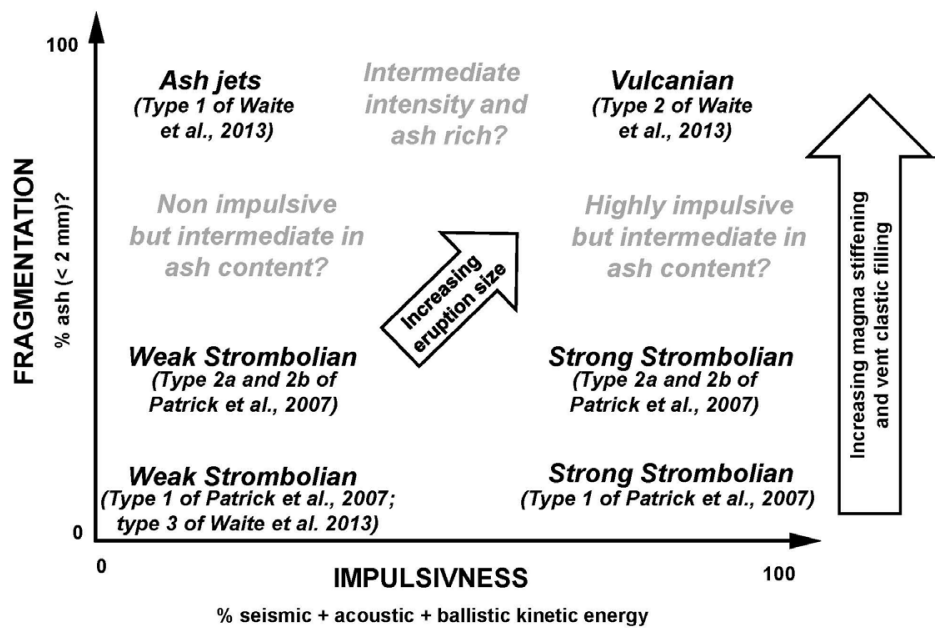

Figure 2.9. Proposed classification diagram for Fuego's background explosive activity. Classifications types defined by other authors are also shown within the diagram. The range of eruptive styles observed for background explosive activity at Fuego virtually covers all the extremes shown in the figure, from highly impulsive ash rich (Vulcanian) to either impulsive but ash poor, or ash rich but non impulsive. It is however more difficult to assess the degree to which intermediate cases occur, i. e. is a full continuum spectrum between the extreme cases possible (gray font cases in figure 2.9)? Visual observations seem to indicate that different degrees of the intermediate cases do indeed occur, but only quantitative measures of the involved variables could prove this idea. 
The position an eruption occupies in the diagram is influenced by factors like the size of the eruption, the vent configuration, and the magma rheology (see text arrows in figure 2.9). Large eruptions will tend to produce more ash, and the large ones $\left(>1000 \mathrm{~m}^{3}\right)$ are invariably closer to the Vulcanian type, whereas truly ash free Strombolian activity only happens at much smaller scales $\left(\leq 100 \mathrm{~m}^{3}\right)$. The presence of clastic material filling the vent and upper conduit region will also have a large impact on the amount of ash produced (in this case the fraction of non-juvenile ash. Finally, the magma rheology may have the most important effect over the activity style, and therefore the location of an eruption in the classification diagram. Higher viscosity and yield strength magmas will tend to produce larger amounts of ash, in the extreme case producing either impulsive and ash rich Vulcanian eruptions, or non-impulsive but still ash rich jets. Future studies focusing on the ash and other pyroclastic products from Fuego's activity may help to elucidate some of these aspects. Given the relatively straightforward and simple way of visually determining if the eruptions are or not ash rich, this could be easily incorporated in the OVFUEGO monitoring routine.

\subsection{Rockfall during background activity and deposits in the "proximal active areas"}

Rockfalls on the upper slopes of Fuego are caused by both effusive and explosive background activity. The lava flow front collapse results in the semi continuous generation of rockfalls during periods of effusive activity, whereas the impacts on the slopes by ballistic projectiles ejected by the explosive eruptions, as well as ground vibration caused by the background explosive activity, cause also abundant rockfalls and loose material avalanching.

Rockfall paths are constrained by the upper cone morphology. The geomorphology of Fuego's upper cone is characterized by broad ( $>200 \mathrm{~m}$ wide), low relief ( $<50 \mathrm{~m}$ deep) channels, radiating away from the summit, and by planezees that laterally constrain the channels (see figure 2.10). This morphology pattern is interrupted by the North-south trending ridge of La Meseta, to the north of the summit. The broad channels become more confined downslope and transition to narrow ( $<200 \mathrm{~m}$ wide), higher relief $(>50 \mathrm{~m}$ ) channels, known as "barrancas". 


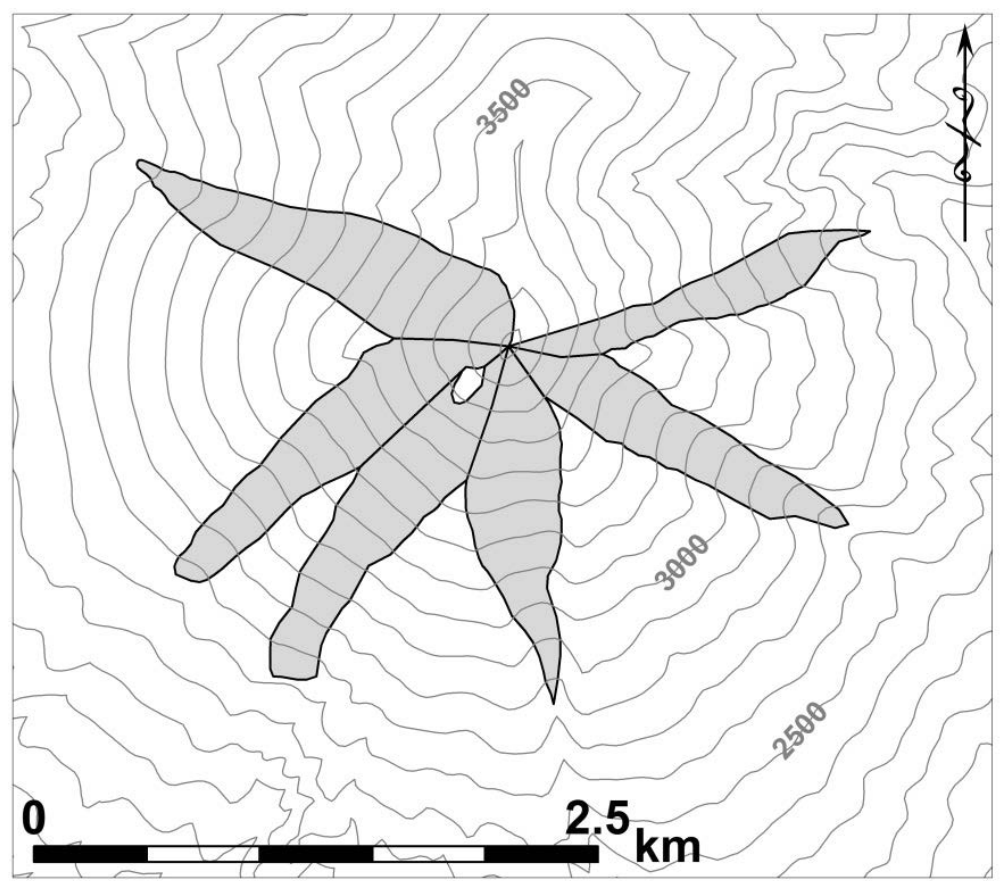

Figure 2.10. Proximal active areas (gray areas) of the upper Fuego cone. Elevation contours in meters above sea level, contour interval of $100 \mathrm{~m}$.

Rockfalls generated from lava flow front collapses, as the lava flows from which they are generated, tend to be constrained by the topography, propagating into channels (gray areas in figure 2.10). Rockfalls caused by explosive eruption may be generated outside such channels, as falling ballistics impact directly on the interchannel planezees, but due to the divergent gradient of these planezes (and the convergent gradients of the channels) the propagating rockfalls tend to be funneled into the channels as the material moves downslope. Rockfalls usually reach distances between 1.5 and $2 \mathrm{~km}$ from the summit vent, from terrains with slope as high as $40^{\circ}$ near the summit, down to slopes of $30^{\circ}$ at the lower end of the broad channels, near the transition to the narrower barrancas. Rockfalls presumably stop as the slope falls below the natural angle of repose of the material $\left(\sim 30-35^{\circ}\right)$, and channel becomes narrower, although individual blocks with enough momentum can sometimes travel further, bouncing outside the channel and into vegetated areas, even causing the vegetation in those areas to ignite. The channel areas where most of the rockfalls propagate and ultimately deposit are also the areas where most of the lava flows and pyroclastic flow material transit over during the larger than background eruptions. The interchannel planezes on the other hand are much less affected, and therefore less modified by such eruptive processes. For these reasons the upper cone channel areas will be referred to as "proximal active areas". 
The volume of material involved in each rockfall is relatively small limited by the dimensions of the lava flow front and the volume of material ejected by individual explosions (probably $<100 \mathrm{~m}^{3}$ for individual lava flow front collapse events, and $<1000 \mathrm{~m}^{3}$ for individual explosive eruptions), but the cumulative effect over time can be significant.
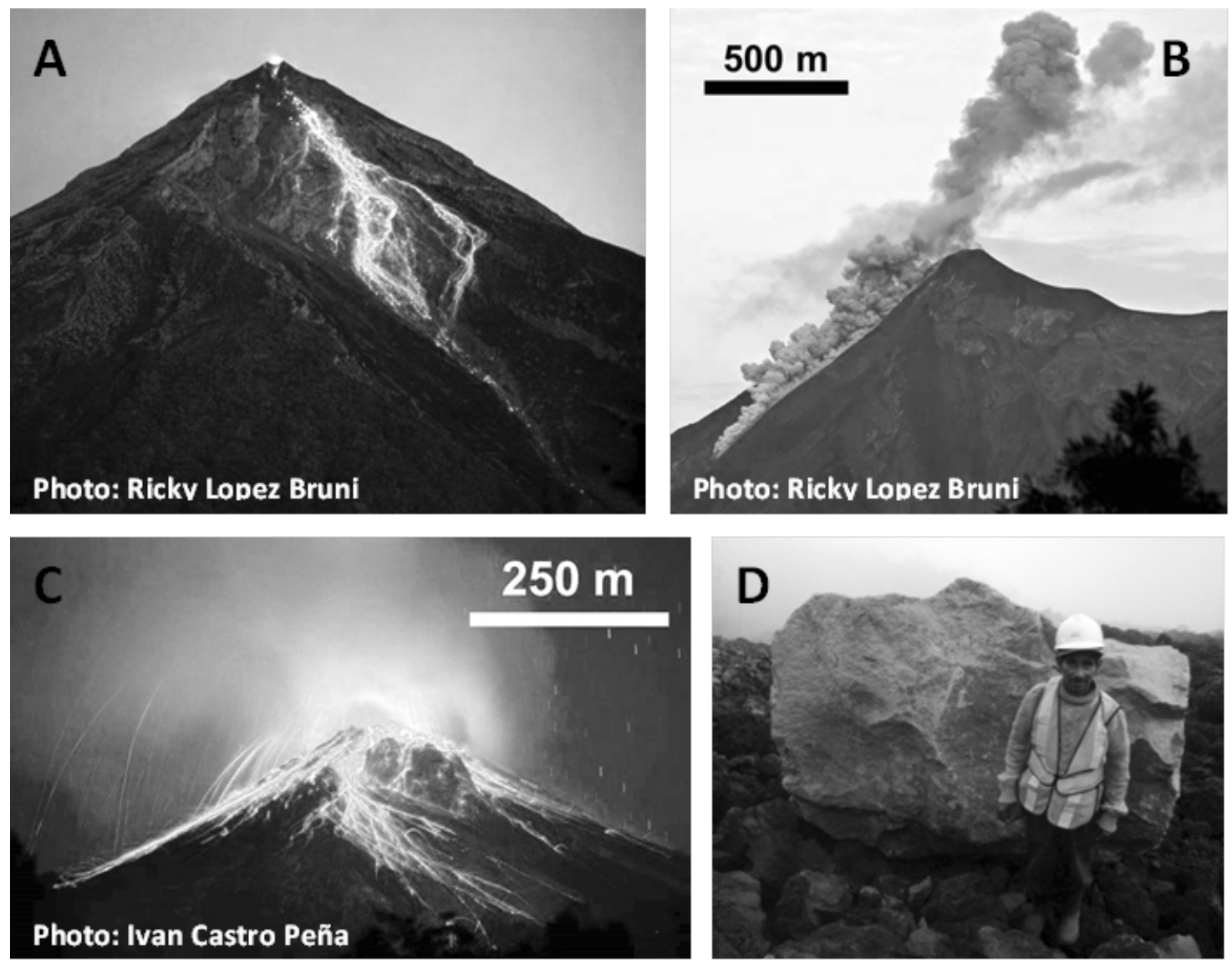

Figure 2.11. A Incandescent rockfall moving down the east upper flank of Fuego volcano, caused by lava flow front collapse. B. transitional rockfall - small pyroclastic flow moving down the east upper flank of Fuego, triggered by a small explosive eruption. C. Incandescent rockfall moving down the west and southwest upper flanks of Fuego volcano, caused by small explosive eruptions. D. Large block transported by rockfall to the transitional region between the proximal active area and the upper Barranca Ceniza channel (ca. 2700 masl), the rockfall was caused by background explosive activity in January of 2009.

The regime of mass transport during rockfall events will change with size and type of material composing the collapsing mass, from individual blocks rolling and bouncing downslope on one extreme, to more or less coherent masses of rocks and minor amounts of fine material, moving simultaneously downslope and which may be considered transitional into pyroclastic flow type of behavior, on the other extreme (figure 2.11). Calder et al. (2002) discussed the case of similar 
collapse phenomena at Soufriere Hills, describing the continuum spectrum between small rockfalls and larger pyroclastic flows, concluding that it is difficult to defined an objectively rigorous distinction between both type of phenomena at the smaller end of the sizes scale. Rockfall generated from the front collapse of lava flows at Fuego are probably similar to those described as "actively generated" at Soufriere Hills, whereas rockfalls caused by background explosive eruptions at Fuego are probably closer to passively generated rockfalls at Soufriere Hills.

The smaller rockfalls consist of individual blocks moving independently, which can be tracked by the trail of dust clouds they leave behind as they bound down the slope during the day, or by the incandescent paths see at night, especially in long exposure photography (see figures 2.11). Similar to the case of Soufriere Hills, as rockfalls increase in size, they tend to carry more finer material, behave more as a coherent and mechanically coupled mass of larger blocks and a finer matrix of ash, within which the interaction between the particles, and the particles and interstitial gas, become more important. Such larger mass movements are probably stratified in the classical sense of an underlying denser granular avalanche "flowing" downhill, and an upper cloud of ash and gas that quickly becomes decoupled. For the rockfalls considered here, the decoupled ash cloud does usually not sweep the ground, as the ash cloud surges commonly generate with larger pyroclastic flows that also happen at Fuego, but rather ascend convectively and quickly disperse.

Rockfalls propagate only over high-angle slopes suggesting that the transport mechanism is limited by frictional interaction of the collapsing material and the terrain surface. The fact that the rockfall avalanches quickly stop over terrain with slope values bellow the typical repose angle of natural gravel and sand, suggests that once initiated, movement is mainly maintained by gravitational rolling, tumbling and sliding on the steep slope, but relatively little momentum is transferred beyond the point where available gravitational energy becomes less than resistive frictional forces. This is very different from the behavior of larger pyroclastic flows generated during the above background explosive eruptions, as will be discussed later.

Two extreme end-types of depositional environments are found in the proximal active areas: close to the summit vent deposition is controlled by effusive lava flow emplacement, ballistic projectile impacts, and ultraproximal tephra deposits. But further away from the vent, downslope the proximal active areas, deposition is gradually controlled by rockfall and pyroclastic flow deposits, although lava flow emplacements still occur during above the background eruptions. The stratigraphy is summarized in figure 2.12. 


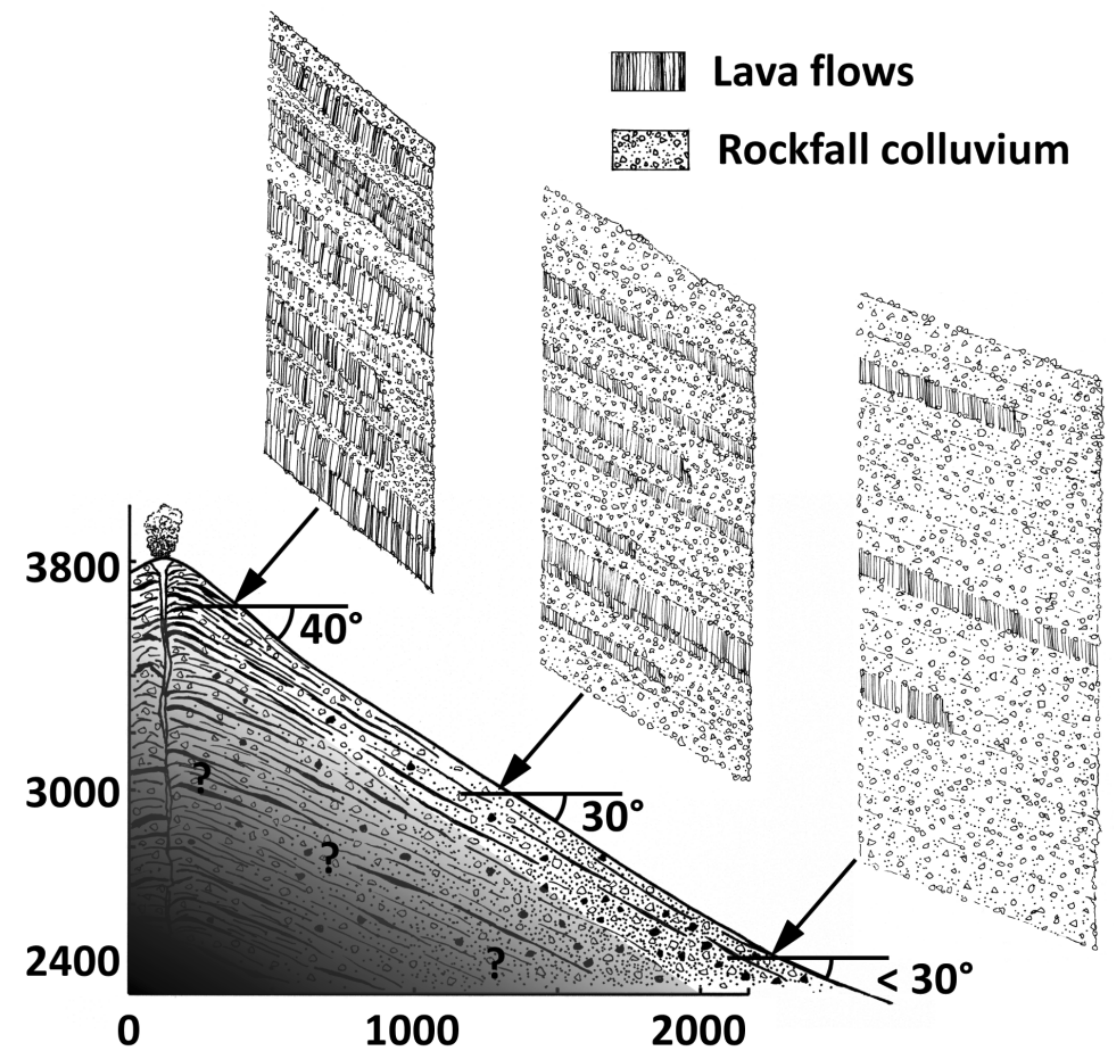

Figure 2.12. Summary of stratigraphy for the proximal active areas. The stratigraphy changes from lava flow dominated near the vent, to rockfall colluvium dominated near the lower extreme.

Grain size sorting due to grainflow and avalanching processes similar to those associated to scoria cone growth probably also happens on these deposits. The filling with clastic debris produced by the rockfall of the mid to lower parts of the proximal active areas has created a characteristic smooth looking surface on aerial photographs; the deposits origin and structure, the surface texture, and the slope values near the angle of repose of natural gravel and sand, are all similar to features commonly found at scoria cones (e. g. Riedel et al. 2003, and references therein), and in such sense the mid to lower proximal active areas similar to scoria cones in the construction process and internal structure. Older sequences exposed on the walls of the upper channels, and which stratigraphically correspond to the structure of the planezes, show a similar stratigraphy of intercalated lava flows and colluvial, matrix poor (sometimes grain supported) breccias.

Deposit thickness estimations are possible by considering elevation differences between digital elevation models (DEMs) from different dates within the 1999 to 2013 eruptive episode. Two 
DEMs were considered in this study, the SRTM DEM (Farr et al. 2007) generated from global radar data acquired in February of 2000, and a DEM derived from elevation contours published by the Instituto Geografico Nacional (IGN) of Guatemala, and which were generated by digital stereophotogrametric methods from high resolution ( $0.4 \mathrm{~m}$ pixel size) aerial photography acquired in February of 2006 (Finnmap and PASCO, 2006; MAGA / CTE, 2006). The quality and resolution of the data, especially the 3 arc seconds pixel resolution SRTM DEM, constrain the sensitivity of the elevation variations that can be detected with this method. In the case of the proximal active areas on the upper cone of Fuego, the DEM differences between February of 2006 and 2000 were usually within 10 and $30 \mathrm{~m}$, which is probably close to the minimum elevation differences that are possible to resolve with the data, especially in the case of the SRTM DEM (e. g. Smith and Sandwell, 2003; Falorni et al. 2005; Rodriguez et al. 2006; Slater et al. 2006). Taking the 20 $\mathrm{m}$ average elevation change and multiplying it by the area of the proximal active areas a volume of $3 \times 10^{7} \mathrm{~m}^{3}$, which is equivalent to a rate of $5 \times 10^{6} \mathrm{~m}^{3} /$ year $\left(0.16 \mathrm{~m}^{3} / \mathrm{s}\right)$. Interestingly, the long term eruption rates for both effusive and explosive background are within that order of magnitude.

\subsection{Effusive activity during large (above background) eruptions}

Lava flows erupted during larger eruptions typically extend beyond $1 \mathrm{~km}$, penetrating in some cases into the narrower Barranca channels to distances $>5 \mathrm{~km}$, and typically display an aa' to blocy texture. The much longer distance reached by these flows in comparison with the flows erupted during background effusive activity is probably related to the much higher lava effusion rates during such eruptions ( $>10^{2} \mathrm{~m}^{3} / \mathrm{s}$ for the larger flows), as such high effusion rates would prevent the early rheological transition from ductile to fragile that may be responsible for flow front collapse on the steep slopes, in a similar way to how effusion rate controls the length of lava flows on flatter slopes according to the classical cooling limited model. As the flow advances down the upper volcano's flanks the slope decreases, further inhibiting the likelihood of flow front collapse, and once the flow fronts have reached slopes $<30^{\circ}$ they will behave much like other aa' or blocky flows reported in the literature for lower slopes.

Lava flow dimensions and surface morphology seems to be also controlled by the local topography. On the upper less confined slopes of Fuego (i. e. the proximal active areas) the flows tend to develop the typical morphology of aa' and blocky lava flows, including lateral levees, a central channel covered by a clincker to blocky layer, and sometimes pressure ridges perpendicular to the direction of movement. As the flows enter the Barrancas on the lower volcano slopes, the Barranca channels confine the flows, leading to thicker and narrower flow 
cross section, compared with what the cross section would probably be on an unconfined terrain with a similar slope (see figure 2.13). The autobrecciation levees formed on the unconfined slope are substitute here by the confining topography, and a different kind of levees is formed due to the variation of flow height in the channel: during the peak of the discharge the lava flow coats the sides of the Barranca up to a maximum level, but later receding to lower levels, as the fluid magma drains downstream, leaving relatively high and vertical levees sticking to the channel walls (see figure $2.13 \mathrm{~B}$ ). This is analogous to collapsing or draining flows observed at other volcanoes, due to the remobilization of a fluid lava flow interior after the emplacement of lateral channel levees. The average flow thickness is estimated to vary between $5 \mathrm{~m}$ on steep slopes (> $\left.20^{\circ}\right)$ to $10 \mathrm{~m}$ on lower $\left(<20^{\circ}\right)$ slopes.
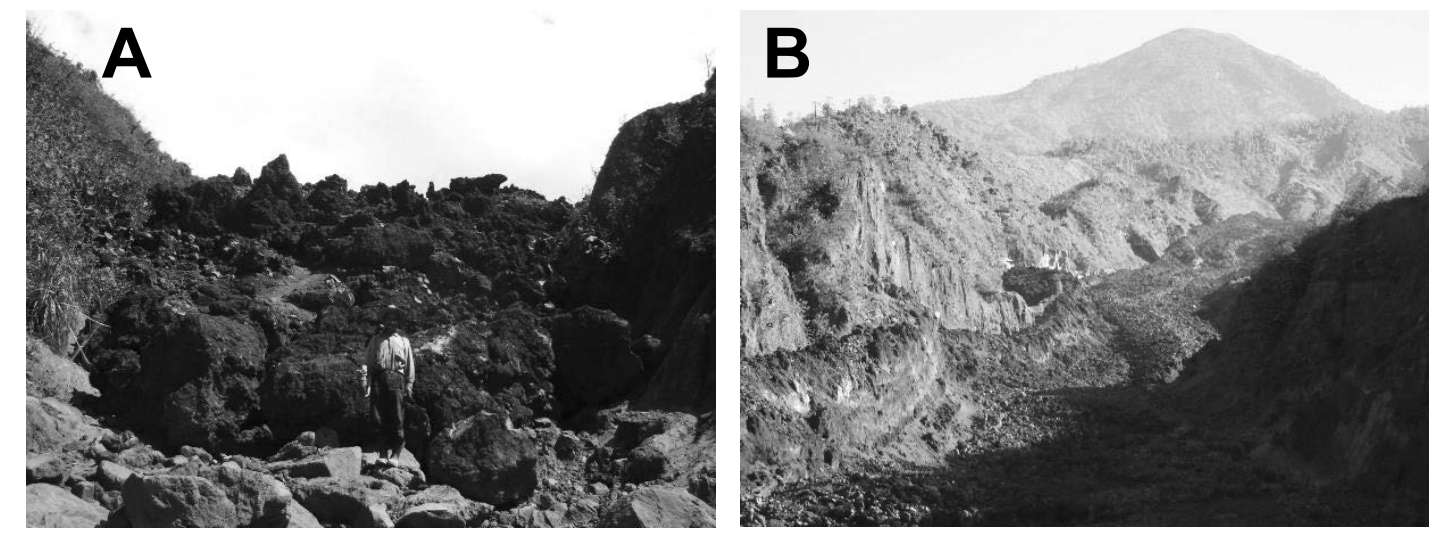

Figure 2.13. A Lava flow front on Barranca Santa Teresa ( $3 \mathrm{~m}$ thick and $\sim 7 \mathrm{~m}$ wide). B Lava flow along Barranca Seca ( $50 \mathrm{~m}$ wide). Notice the confining Barranca topography and the high levees ( $15 \mathrm{~m}$ high).

Lava flows erupted during larger eruptions display a simple morphology and are the result of a single pulse emplacement. The flows tend to be as ephemeral as the eruptions that generate them (with usually a duration $<48$ hours), and due to topographic confinement, flows produced by consecutive eruptions tend to stack one on top of another unless other deposits (e. $\mathrm{g}$. pyroclastic flows) are interleaved between them.

Texturally, the surface of the flows tends to be covered by a wide range spiny aa' lava fragments, from centimeter size lapilli to meter size lava blocks and aa' slabs. Although the individual lava fragments retain a ragged and uneven surface, their interiors are relatively dense, and they 
fracture forming prismatic blocks. The lava texture as seen in hand samples is porphyritic, with abundant plagioclase phenocrists, and minor amounts of pyroxene, olivine and other phases. The eruption mechanism for lava flows generated during larger explosive eruptions differs from the eruption mechanism that produces the lava flows erupted during background effusive activity. Lava fountaining directly feeding lava flows has been observed in some cases at Fuego (e. g. during the January 9 - 10, 2004 eruption), but to what extent these flows are fed by clastogenic lava fountaining and to what extent they are directly fed by lava overflow at the vent is difficult to tell.

The total volume of lava erupted during such events ranges between $\sim 10^{5}$ to $3.5 \times 10^{6} \mathrm{~m}^{3}$, which are erupted over typical periods of 6 to 48 hours, giving mean eruption rates between $5 \times 10^{0}$ to $1.6 \times 10^{2} \mathrm{~m}^{3} / \mathrm{s}$. Eruption rates are therefore 2 to 3 orders of magnitude larger than during background activity.

\subsection{Tephra dispersion during larger eruptions}

Tephra dispersal during larger than explosive background eruptions can be significant. Tephra clouds reported by the Washington VAAC can reach elevations of $\sim 8,000$ masl, and the ash clouds can be tracked for hundreds of kilometers (figure 2.6). Such long range, long-lived clouds at relatively low atmospheric levels imply the presence of a substantial amount of fine ash. The trajectories and ash cloud elevations given by the VAAC are consistent with trajectories and elevations estimated from MODIS images, and trajectories modeling using the atmospheric particle track algorithm HYSPLIT (Draxler et al. 2013) (see figure 2.14, and appendix 2.4 for further examples). 

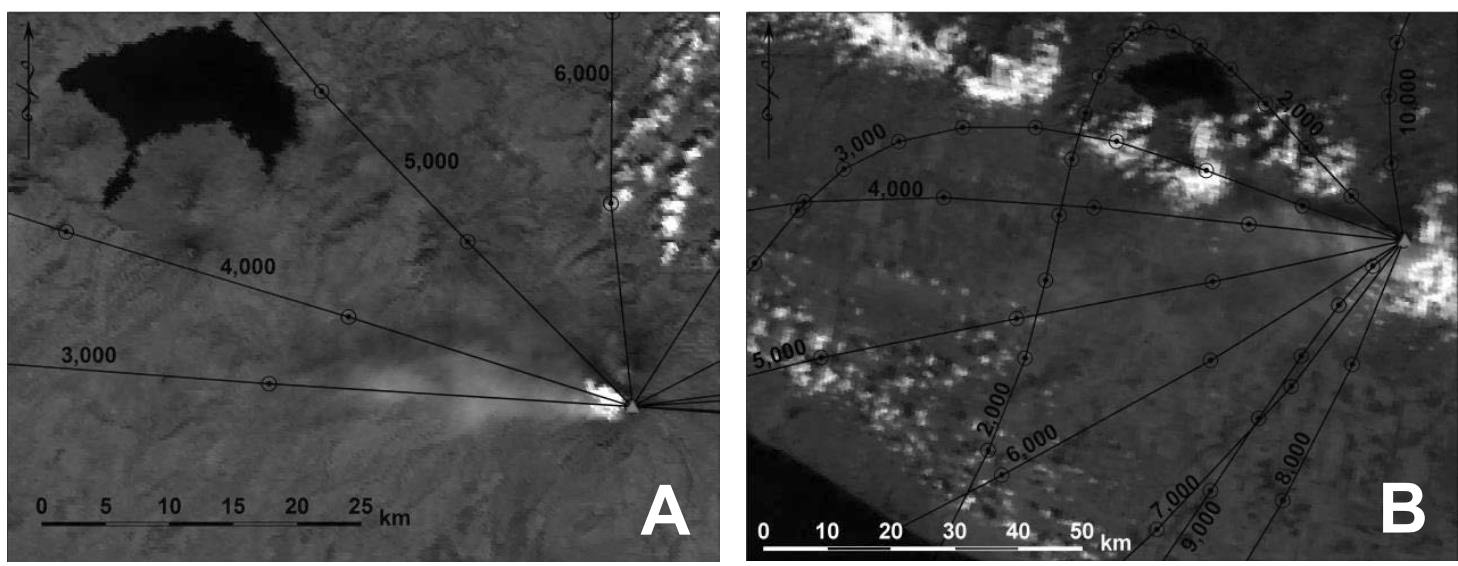

Figure 2.14. MODIS satellite images of ash clouds produced by larger eruptions at Fuego volcano, with HYSPLIT trajectories shown as black lines. Dot and circle marks correspond to one hour intervals in the HYSPLIT trajectory model. Each curve represents an individual run at different elevation levels, as labeled. A. Eruption on January 8, 2003. Notice the low level ( 3000 -4000 masl) of the ash cloud, which may be related to co-pyroclastic flow ash fed by pyroclastic flows that happened during that eruption on Barranca Seca and Taniluya. B. Erution on December 15, 2007. The ash cloud matches a range of HYSPLIT trajectories corresponding to elevations between 300 and 8000 masl. See appendix 2.4 for further examples and a color version of these and other images. Modified from MODIS images courtesy of NASA: (http://ladsweb.nascom.nasa.gov/data/search.html)

Tephra deposits on the ground are usually only a few $1 \mathrm{~mm}$ at distances $>7 \mathrm{~km}$ (e. g. at the villages surrounding Fuego), and no mapping of the tephra deposits has been done so far. Eruption rates can be estimated (to the order of magnitude) from the theoretical and empirical models that relate eruptive column height to eruption rate (see appendix 2.3), and total erupted volumes can be computed by multiplying the eruption rates by the eruption durations. For column heights reaching between 6000 and 8000 masl we obtain eruption rates between $10^{\circ}$ and $10^{1}$ $\mathrm{m}^{3} / \mathrm{s}$, which coupled with eruption durations between 6 and 48 hours give total erupted volumes between $10^{4}$ and $10^{6} \mathrm{~m}^{3}$. Eruption rates estimated in this way fall on the lower end of the eruption rate range inferred for lava flows, suggesting that the eruption rate of magma transformed into tephra is an order of magnitude less than the rate of magma transformed into lava flows, for at least some eruptions. This should perhaps not be too surprising, as the higher eruption rates may favor the formation of clastogenic lava flows instead of airborne tephra formation. A similar relationship with pyroclastic flows will also be explored in the next section.

The specific mechanism for the formation of airborne tephra, especially the finer fraction inferred from the wide ash cloud dispersion, is not clear. Close range observations and video footage of the activity shows a wide range of eruptive styles, from lava fountaining dominated activity that 
produces large lava flows, to large pyroclastic flow generating eruptions, apparently through a Merapi type collapse or "boiling over" mechanism. Examples of the different types of eruptions can be seen in videos available in the internet: the August 8, 2007 eruption (which also generate large pyroclastic flows) clearly shows a lava fountain and a significant ash cloud in this video: http://www.youtube.com/watch?v=zPtGzbMW-Cs, while the December 15, 2007 eruption (which generated the largest lava flow during the 1999 - 2013 eruptive episode) can be seen in this video: http://www.youtube.com/watch?v=XzvbQr7sV0M , and the September 13, 2012 eruption, which generated large pyroclastic flows can also be seen in this video:

http://www.youtube.com/watch?v=vDMD2LBjBOg . As with the background explosive activity, the diversity of apparent eruption styles and products of the above background explosive activity suggests that changes in the eruptive conditions (e. g. magma rheology, gas content, etc.) may be playing an important role in causing such a diversity of eruptive styles.

Similar explosive activity generating substantial amounts of ash and lava flows at Paricutin volcano, and labeled "violent Strombolian" has been associated to a gas rich magma with a relatively high viscosity (Pioli et al., 2008; Erlund et al. 2010). Ash rich activity at Etna in 2001, and 2002 to 2003 has also been interpreted as being caused by the fragmentation of microliterich tachylite melt (Taddeucci et al., 2004; Andronico et al., 2008; Andronico et al., 2009). A similar mechanism, involving a microlite-rich and relatively evolved melt could also play a key role in the generation of ash and the general explosive nature of the activity. Moreover, Whittington et al. (2013) found that samples from lava flows and bombs collected from pyroclastic flow deposits produced by eruptions between 2003 and 2009 had very evolved matrix glass compositions (most in the range of $62-67 \mathrm{wt} . \% \mathrm{SiO}_{2}$, with one case having a matrix glass composition of $\sim 74$ wt. $\% \mathrm{SiO}_{2}$ ), and very high apparent viscosities (tested at $1020^{\circ} \mathrm{C}$ ) between $10^{10}$ and $10^{12} \mathrm{PaS}$. Although the samples could come from magma that further crystalized and evolved after leaving the vent (e. g. as the lava flows moved down the flank and the pyroclastic flows were emplaced and cooled), the evolved melts and high apparent viscosities could be consistent with a melt that behaves rheologically as a brittle material at the vent, and therefore could generate significant amounts of ash.

Tephra, and especially the finer fraction (i. e. ash) is also produced in large quantities during pyroclastic flow generation, i. e. co-pyroclastic flow tephra. This tephra will be particularly fine grained (e. g. Evans et al. 2009) and could account in part for the wide dispersal of ash observed in these eruptions. This is also consistent with the relatively low level of the ash clouds (e. g. figure 2.14 A). The eruptions cloud produced by the September 13, 2012 eruption is a good example of a co-pyroclastic flow dominated ash cloud, and is apparently the ash cloud with the furthest dispersion during the current (1999 to 2013) eruptive episode. The ash cloud was directly 
produced by the convective rise from a set of large pyroclastic flows produced over a short ( $~ 30$ min) period of time, while ash production from the central vent was only minor in comparison.

\subsection{Pyroclastic flows and surges generated during larger eruptions}

Large pyroclastic flows and ash cloud surges are commonly produced by the "above background" explosive eruptions. At Fuego a fairly clear distinction can usually be made between the relatively dense, granular avalanches, and the much more diluted, gas-particle interaction dominated surges and the deposits they leave. The propagation of the first is strongly controlled by the topography, leaving thick and poorly sorted deposits, including very coarse (blocks $>2 \mathrm{~m}$ ) fragments, and will be referred here as pyroclastic flows. The propagation of the second is not controlled as much by the topography, leaving very thin deposits of predominantly fine clast (ash), and will be called ash cloud surges.

Larger pyroclastic flows can reach distances $>7.5 \mathrm{~km}$ from the vent, and potentially reach inhabited and cultivated areas. Pyroclastic flows are generated simultaneously with lava fountaining, and tephra production and dispersion from vertical eruptive columns, erupted from the central vent, but they are also produced in the absence of large summit vent activity as has been discussed in the previous section. Pyroclastic flows and lava flows are commonly generated during the same eruption, but larger eruptions are usually dominated either by lava effusion (e. g. the December 15 - 16, 2007 and January 9 - 10, 2004 eruptions), or by pyroclastic flow generation (e. g. the June 29, 2003, July 16 - 17, 2005, and September 13, 2012 eruptions). Visually, the pyroclastic flows are characterized by billowing ash clouds that elutriate and rise above the dense avalanche part of the flow (see for instance:

http://www.youtube.com/watch?v=vDMD2LBjBOg).

The deposits of these pyroclastic flows consist of diamictons of blocks (or bombs), often with a maximum diameter $>2 \mathrm{~m}$, set in a matrix of ash/lapilli (see figure 2.15). The deposits are predominantly monolithologic, chaotic and massive (non sorted nor stratified), and non indurated. They show typically a light to dark gray color, although in some cases a slight pink hue can be seen, particularly in the upper part of some deposits. Although massive in general appearance, some basic structures can be seen in some outcrops, including coarse tail grading and horizontal trains or concentrations of larger clasts (blocks) separating more homogenous and massive portions of the deposit. These coarser clast trains or concentrations may represent the boundaries between individual pyroclastic flow pulses emplaced on a rapid succession during a single eruption. Despite not being indurated, these deposits can be fairly stable and form almost vertical clifs over periods of several years. Flow units associated to individual pulses form 
deposits with typical thicknesses between 2 and $5 \mathrm{~m}$, but in the channel filling facies, can be up to $10 \mathrm{~m}$ thick.

Accidental lithics, including highly oxidized clasts probably incorporated during transport are sometimes also present. Carbonized wood (from large logs to small branches) is commonly found in over bank deposits, but is rather rare in channel filling facies, in agreement with the expected presence of abundant vegetation in the interfluvial terrains, but a lack thereof in active channel environments. Similarly, degassing or elutriation pipes are rather uncommon in the channel filling facies, but occur more frequently in overbank facies. Fresh deposits (24 -48 hours after emplacement) are covered by loose ash, partially a product of the co-pyroclastic flow elutriated ash, and may be cold enough to walk on them, especially when rainfall contributes to their cooling, but can be hot enough to kill small wildlife trying to cross them. Although some deposits tend to form a slightly more indurated crust at the top, in general they remain highly susceptible to erosion, by surface runoff but mainly by stream flow incision, as will be discussed in the next section concerning the generation of lahars.

The appearance of the deposit at the outcrop scale is identical to the classical "block and ash flow" deposits produced by dome and lava flow front collapse (Merapi type) pyroclastic flows, with the only difference that many blocks don't have the characteristic "breadcrust" texture, but instead have the slightly different "cauliflower" texture. Although some examples have been documented, block and ash flow deposits of basaltic to basaltic andesitic composition have not been reported widely in the volcanological literature. 

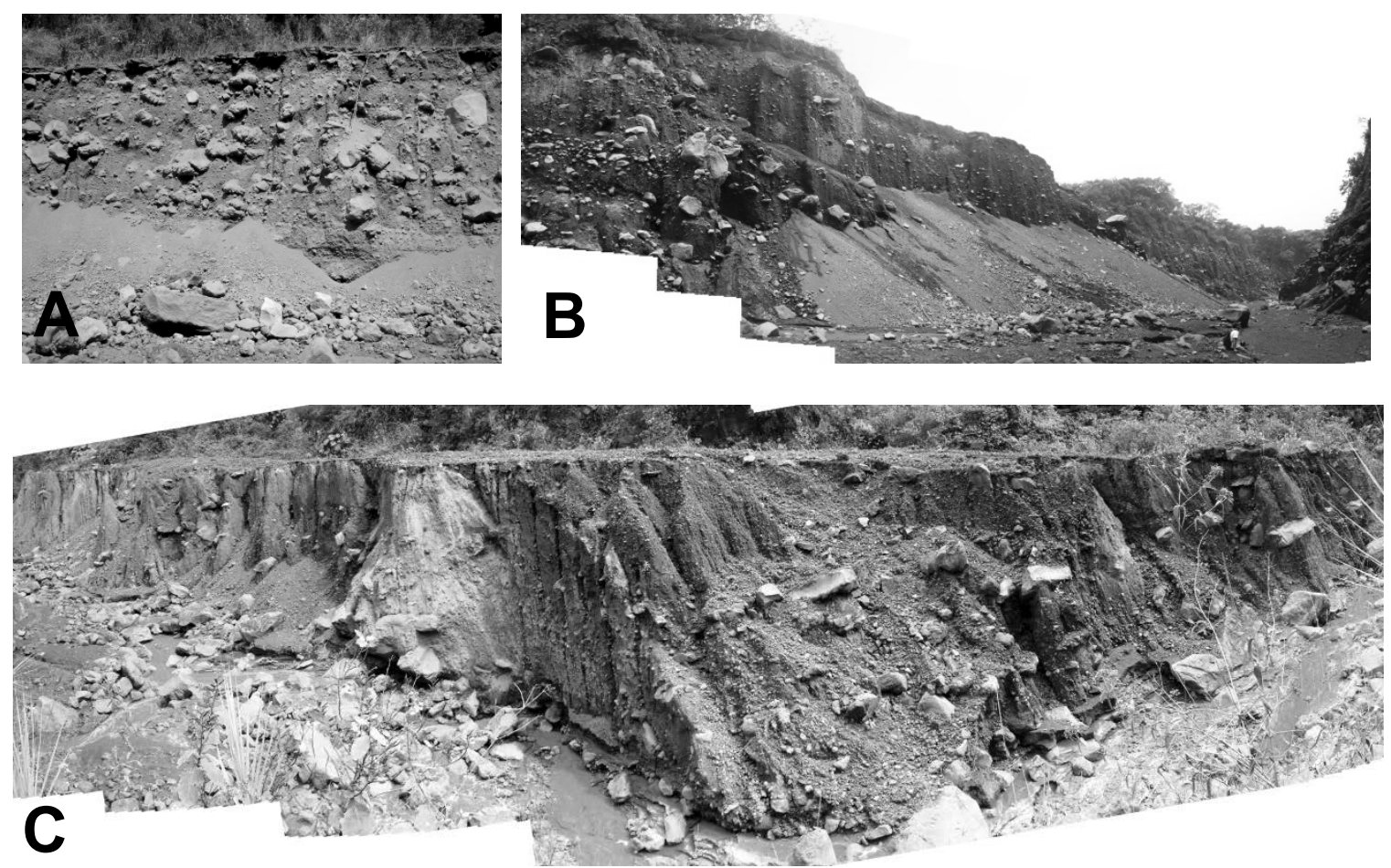

Figure 2.15. Examples of outcrops showing pyroclastic flow deposits generated during eruptions from the current (1999 - 2013) eruptive episode. A Distal (near flow front) deposits of the June 29, 2003 pyroclastic flow deposit, at $\sim 8.2 \mathrm{~km}$ from the summit source. The deposit thicknesses shown in the picture is $\sim 5 \mathrm{~m}$. Notice the abundant cauliflower crust bombs in the deposit. B Distal pyroclastic flow deposit emplaced during the May 21, 1999 eruption on Barranca Las Lajas, at $\sim 8 \mathrm{~km}$ from the summit source. The deposit thicknesses shown in the picture is $\sim 15 \mathrm{~m}$. C Pyroclastic flow deposit from the July 17, 2005 eruption on Barranca Taniluya, at $\sim 5 \mathrm{~km}$ from the summit source. The deposit thickness is $\sim 12 \mathrm{~m}$ in the center of the picture.

The blocks commonly have a "cauliflower" texture, similar to what some authors call cauliflower crust bombs (Alvarado and Soto, 2002), although in our case their origin is not likely to be that of bombs in the classical sense, i. e. ejected as ballistic projectiles and forming a cooled crust in midair trajectory. Blocks with a smooth surface may have lost the "cauliflower" texture by abrasion and friction within the pyroclastic flow, but many seem to have acquired the smooth texture at the origin of the flow, as they are found next to cauliflower blocks with an intact crust. Block interiors are dense and have a texture similar to the lava flows, i. e. porphyritic, with abundant plagioclase phenocrists, and minor amounts of pyroxene, olivine and other phases. 

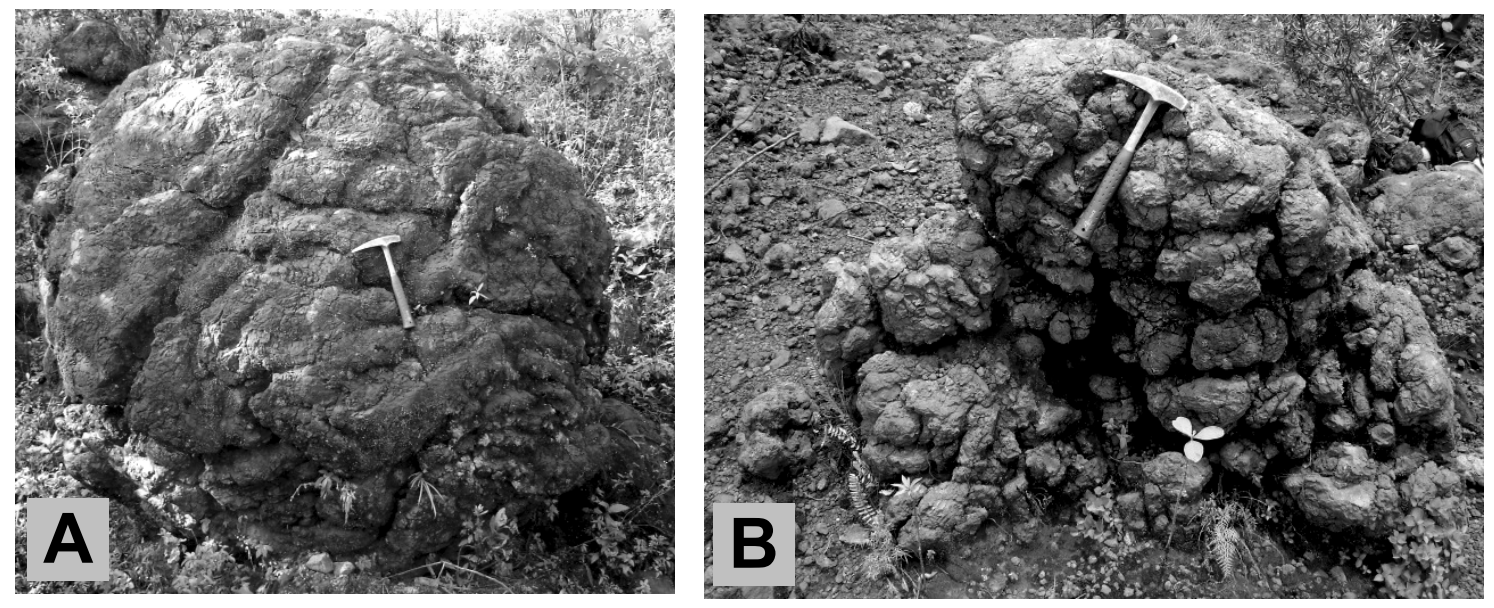

Figure 2.16. Examples of cauliflower crust blocks from the June 29, 2003 pyroclastic flow on Barranca Seca. A Round shaped cauliflower crust block near the terminus of an overflow facies lobe adjacent to Barranca Seca ( $7.5 \mathrm{~km}$ from the summit source). The block was originally buried in the deposit, but was subsequently exposed (January 2006) by $\sim 2 \mathrm{~m}$ of vertical erosion. Rock hammer is $\sim 30 \mathrm{~cm}$ long. B "Folded" cauliflower crust block sticking above the surface of the channel filling facies within the old (prior to June 29, 2003) barranca channel.

Occasional vesicle concentrations and strings are visible in some blocks, with sheared vesicles being a common occurrence in cauliflower crust blocks. No clear or sharp transition between the crust and the block interior is evident in most blocks, but in some case a slight increase of vesicles from the crust to the interior is noticed in some cases. No other structure or textural variation is noticeable in block interiors, but blocks consistently break in concentric curved fracture surfaces, to form shell shaped fragments, when hit with the hammer. Cauliflower blocks seemed to show post emplacement deformation, sometimes displaying elongated and convoluted forms, as opposite to the more equant shapes of typical blocks found in pyroclastic flows formed by dome or flow front collapse, at more silicic volcanoes. 

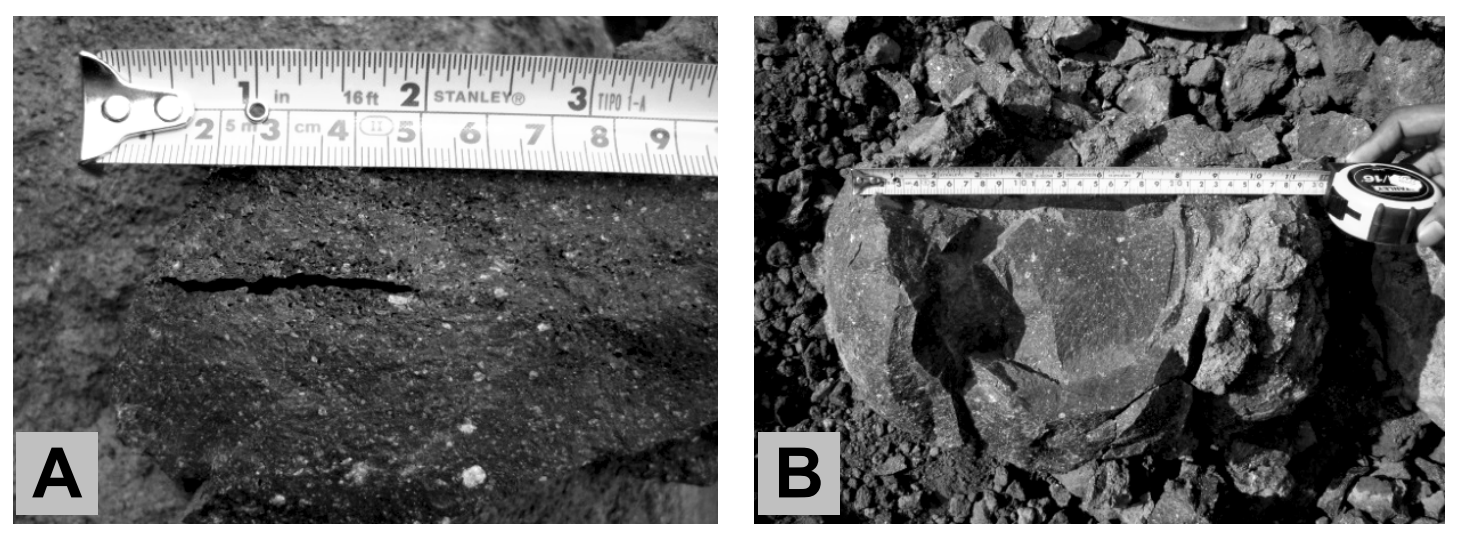

Figure 2.17. Internal features found in cauliflower crust blocks. A Shearing elongated bubbles in a predominantly dense block texture. B Concentric-curved fracture surface pattern commonly found in cauliflower crust blocks when hit with a hammer.

The formation of the cauliflower crust texture has been attributed to different processes at other volcanoes, involving in most cases the rapid cooling (chilling) of the surface of hot magma fragments, either by contact of the magma with water or ice, or the quick exposure of the magma to cold ambient air. At Fuego volcano the contact with ice can be ruled out, and the presence of water in large enough quantities to cause the ubiquitous texture found in many of the flows also seems very unlikely, as most of the cauliflower-crust-bomb bearing deposits were emplaced on dry channels. Alternatively, the cauliflower texture has been attributed to the rapid emptying of a "lava pool" (Alvarado and Soto, 2002), but such an explanation also seems unlikely for Fuego, especially considering the large volume (up to $10^{7} \mathrm{~m}^{3}$ ) of some deposits. Whatever the process that causes the cauliflower texture is, it will be closely linked to the general pyroclastic flow formation mechanisms, as will be discussed later.

The pyroclastic flow deposits exhibit a range of facies similar to those described for block and ash flows (Schwarzkopf et al 2005), but most pyroclastic flows are strongly constrained by the confining topography of the barrancas in which they flow, forming channel filling facies deposits. In some cases, the pyroclastic flow exceed the capacity of the channel cross section to contain the flow, spilling outside the channel, and forming overbank or overflow facies deposits. Whether a pyroclastic flow remains contained within a channel or overflows its margins will depend both on the capacity of the channel to contain flow (i. e. the cross sectional area), the characteristics of the flow, mainly the volumetric flux rate, and other effects linked to the flow dynamics. Most notably among the flow dynamics effects are the inertial effects caused by abrupt changes in the flowing direction imposed by changes in the channel shape or by obstacles in its course, similar to the superelevation of flowing water caused by changes in the direction of the channel axis. 
The deeply entrenched Barrancas topography on the medial to distal slopes of Fuego volcano, hosts channels with a large cross sectional area, often exceeding $10^{4} \mathrm{~m}^{3}$ (see figure 18), capable of containing the relatively large peak volumetric flux rates of individual pyroclastic flow pulses, e. g. for a pyroclastic flow pulse moving at $20-40 \mathrm{~m} / \mathrm{s}$, a cross sectional area of $10^{4} \mathrm{~m}^{3}$ could contain volumetric flux rates as high as $2-4 \times 10^{5} \mathrm{~m}^{3} / \mathrm{s}$, whereas the flows that happened during the current eruptive episode had discharge rates that probably were $<10^{5} \mathrm{~m}^{3} / \mathrm{s}$. In some cases however, the cross sectional area of the Barranca is abruptly reduced to much lower values, especially in segments where the depth of the Barranca is reduced (see figure 18). In such cases the conditions are much more favorable for pyroclastic flows to overflow the channel margins, and this seems to have been the case for the June 29, 2003 pyroclastic flows propagating down Barranca Seca, on the western flanks of Fuego. 

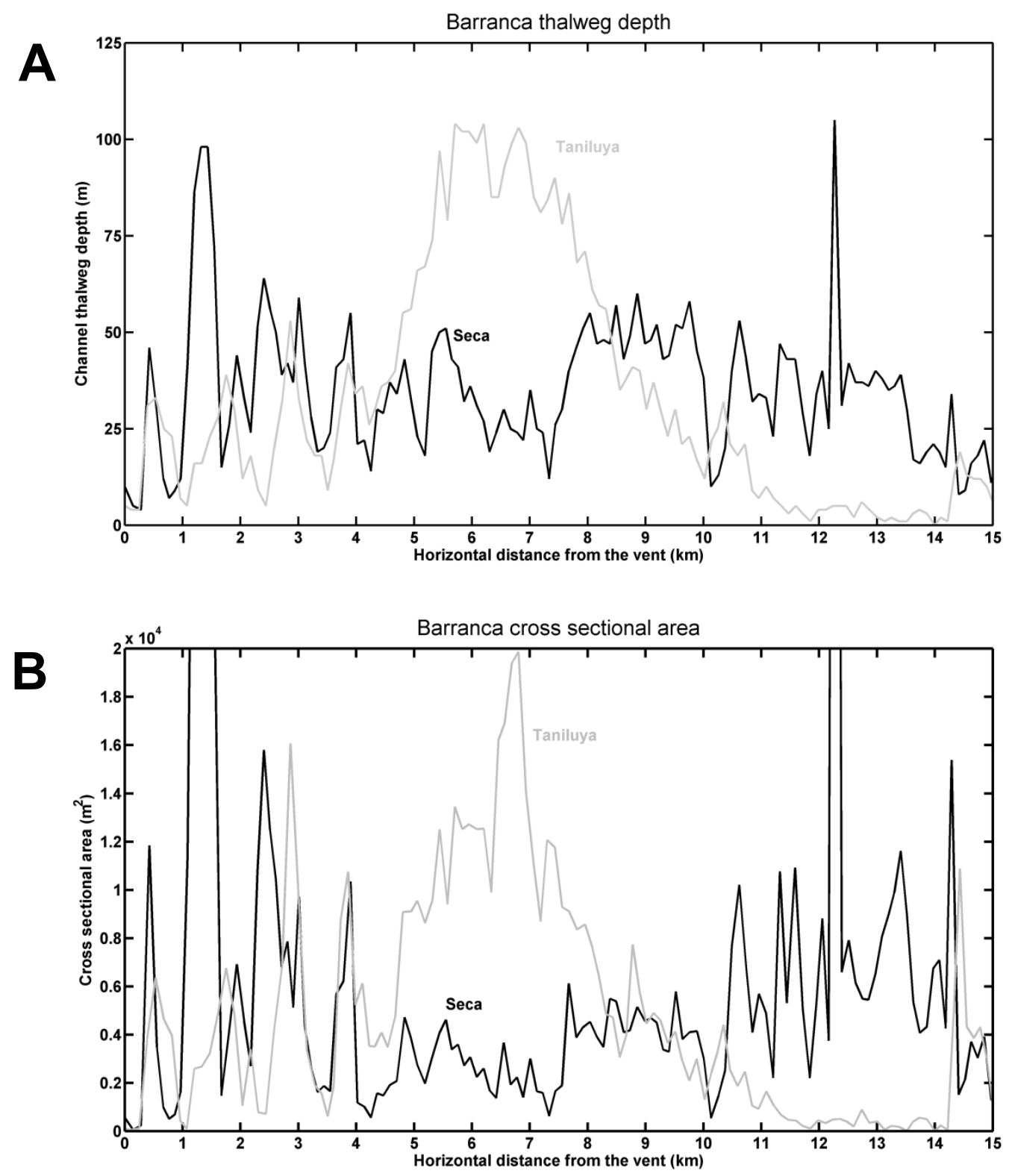

Figure 2.18. A Barranca thalweg depth and B Barranca cross sectional area, vs. distance from the vent as measured from a 2006 DEM. Notice that for Barranca Seca both depth and area dip down to a minimum between 6.5 and $7.5 \mathrm{~km}$ from the vent, corresponding to the location of the pyroclastic flow overflowing the Barranca channel. Barranca Taniluya, shown here for comparison, has a much larger cross sectional area and channel thalweg depth to as far as 10 $\mathrm{km}$, but then steadily decreases as the channel merges into the alluvial plain.

The reduction of the cross sectional area of the Barranca can also happen during a single eruption, as the sequential emplacement of individual pyroclastic flow pulses progressively reduces the available channel cross section, possibly causing subsequent flow pulses to exceed the channel capacity, overflowing the margins and propagating over the interfluvial terrain. This 
seems to have been at least partially the case of the June 29, 2003 pyroclastic flows as well. Sharp bends in the Barranca Seca channel could also have slowed down the flow at those locations, promoting deposition and channel cross section reduction. Figure xx shows the hypothesized sequence of events that may have led to the overflow of the Barranca Seca by the June 29, 2003 pyroclastic flows.
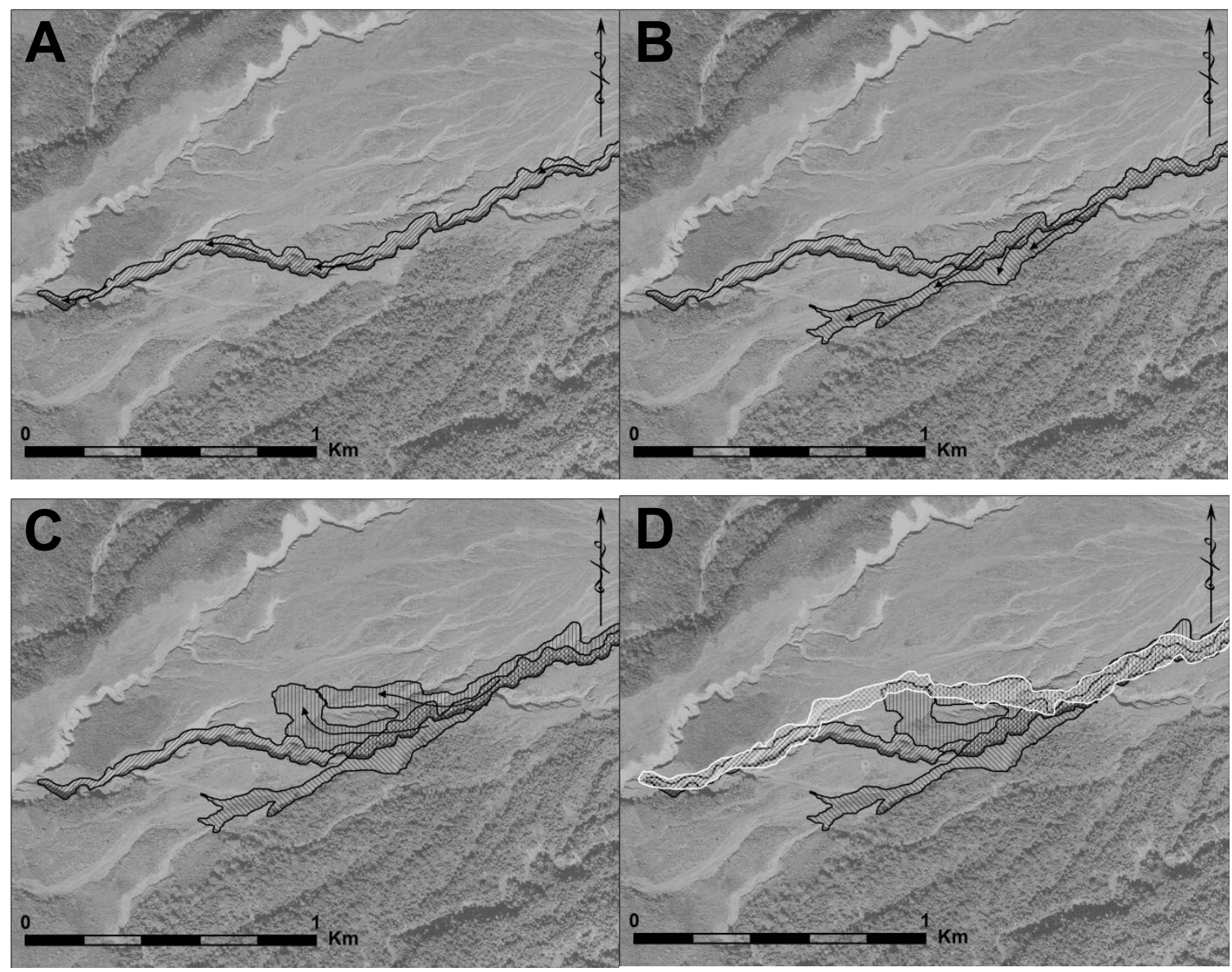

Figure 2.19. Sequence of events leading to the avulsion of a small segment of Barranca Seca by pyroclastic flows on June 29, 2003. A Initially the pyroclastic flow pulses (represented by the black polygon) follow the highly confining and sinuous channel of Barranca Seca, downstream to the confluence with Barranca Santa Teresa. The sharp turns and the decreasing slope as the flows move downstream along the barranca may have promoted deposition of pyroclastic material, reducing the available channel cross sectional area. $\mathbf{B}$ and $\mathbf{C}$, At some point during the eruption, the pyroclastic flow pulses could not be contained, (possibly due to the reduced channel section) and start overflowing the channel margins, innundating the adjacent interfluvial terrain. D After months of intense erosion related to rainfall generated lahars, a new channel (white polygon) is has been established paralel to the older (pre-June 29, 2003) channel. E The old and new channels are compared. Background aerial photography for A through $D$ is from 1980, and for $E$ is from 2006. 


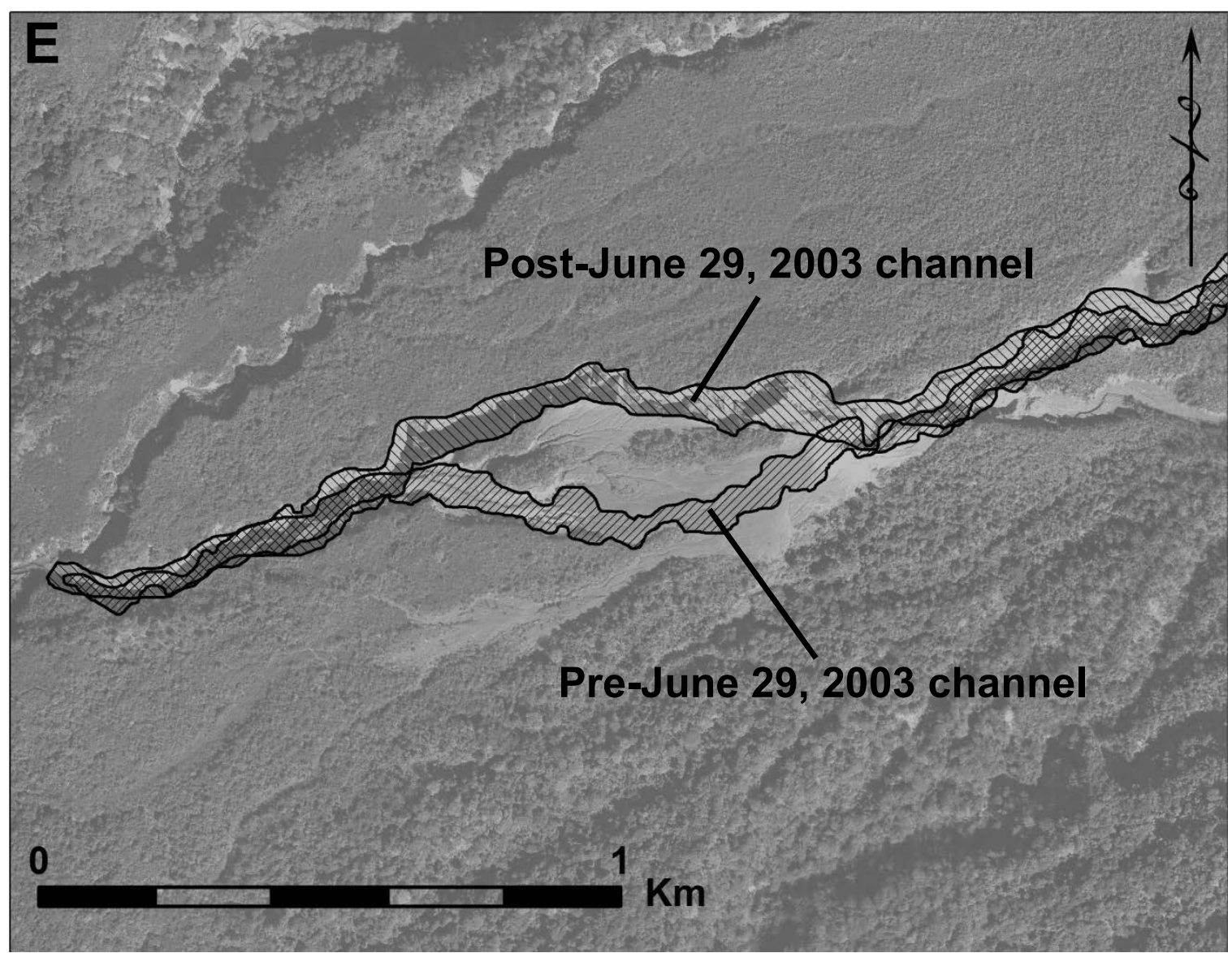

Figure 2.19. Continuation....

Individual pyroclastic flow pulses leave sometimes clear lobbate deposits and at Fuego this seems to be the case when the deposits are emplaced on relatively unconfined terrain (e. g. the overbank facies). Within the confined environment of the Barranca's channel the lobate morphology is less obvious, but the terminus of individual pyroclastic flow pulse deposits can sometimes be recognized, forming relatively steep lobbate fronts (see figure $2.20 \mathrm{~A}$ ). The deposits have usually a flat top (figure $2.20 \mathrm{C}$ ), especially when confined to narrow channels, i. e. the channel filling facies. The deposit relief of individual pyroclastic flow pulses is relatively small ( $<5 \mathrm{~m}$ ) on overbank facies, making their topographic or geomorphologic texture rather cryptic, especially once erosion changes the original deposit surface, and vegetation starts to reclaim the terrain. The valley and low terrain filling tendency of these deposit tends to smooth the topography in the rugger medial cone reaches of Fuego, which can sometimes be observed when erosion cuts through deposit sequences, when the lower contact of the deposits show the rugged, incised channels and slope topography of the pre-deposit, but the upper surface show the characteristic flat top morphology of these deposits (see figure $2.20 \mathrm{C}$ ). Further details on the surface morphology of the pyroclastic flows deposit formed during the June 29, 2003 can be seen 
in the videos and related description on appendix 2.5 , taken from helicopter flights within a month of the eruption, including the lobbate morphology of the flow deposits surface, super-elevation effects on the outer edge of sharp bends.
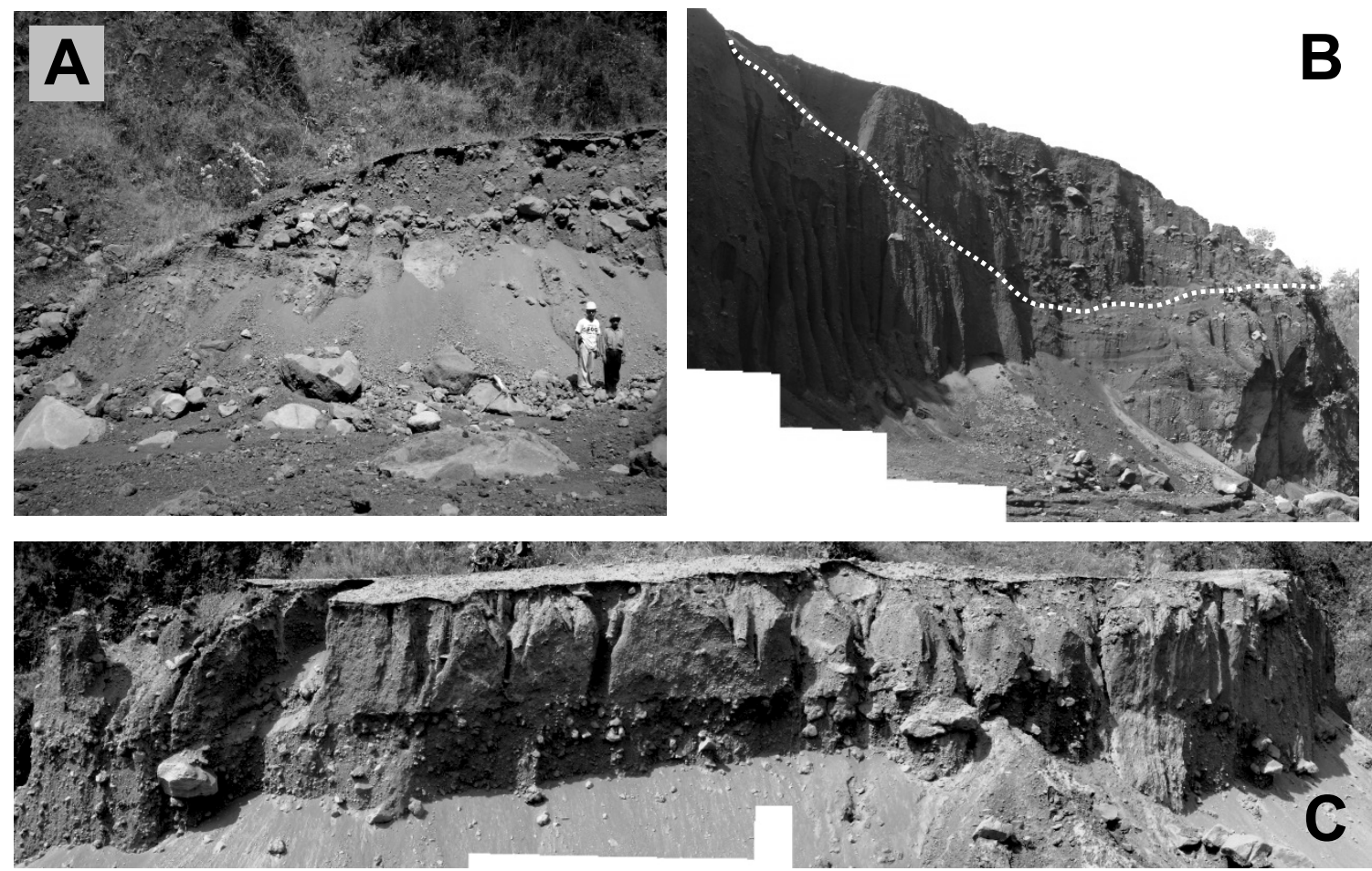

Figure 2.20. Examples of pyroclastic flow deposit characteristics discussed in the text, from the June 29, 2003 pyroclastic flow. A Flow front deposit at the terminus of the deposit on Barranca Seca. The deposit is $\sim 5$ at this point ( $8.5 \mathrm{~km}$ from the summit source), and the snout of the flow front forms $a \sim 26^{\circ}$ slope, the slope was likely steeper immediately after emplacement, as post emplacement modification probably reduced the slope. B Overbank facies deposit showing the rugged and sloped contact surface with the pre-deposit topography (white dashed line) and the flat deposit top. C Flat top deposit showing a thin, moderately indurated layer at the top. Notice the differences between the two flow units produced by the same eruption. 
In the non-confined overbank facies, and in areas where no ash cloud surges occurred, the margins of the pyroclastic flow deposits show a sharp transition to the region of undamaged vegetation, the transition is only a few meters wide. In some channel filling facies areas the
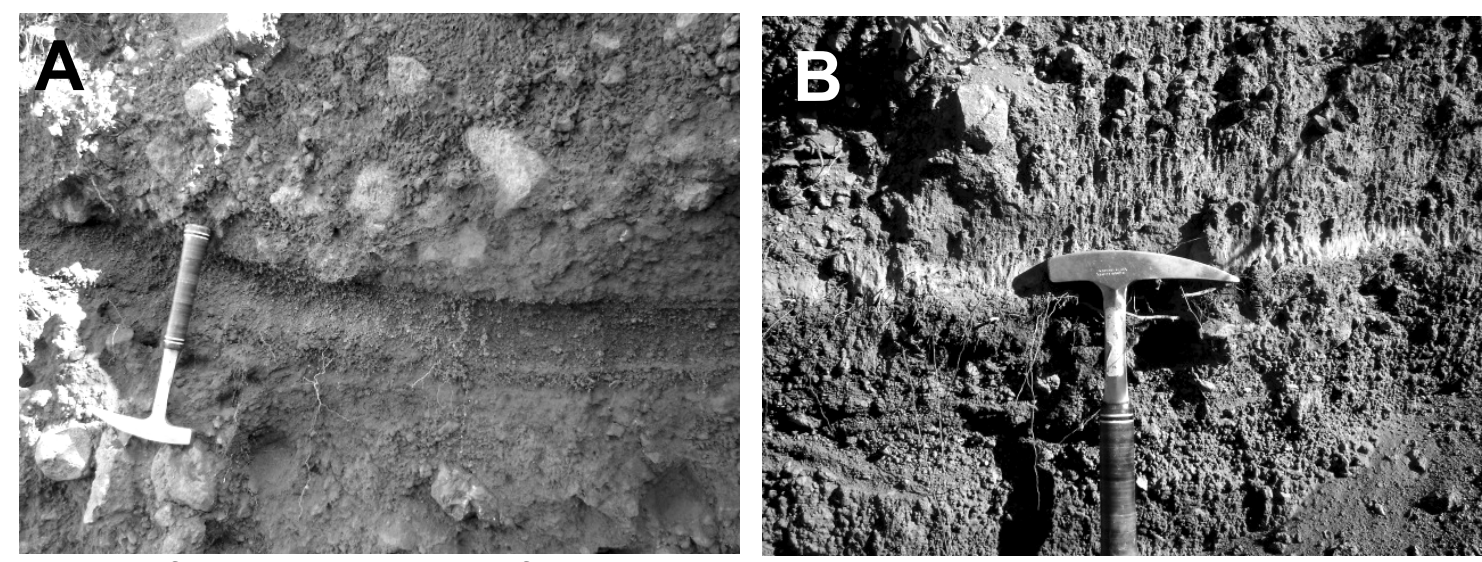

pyroclastic flow deposit sits atop of a thin $(0.5$ to $2 \mathrm{~cm})$ ash layer, interpreted to be the ash cloud surge immediately preceding the denser granular part of the flow. In some cases the pyroclastic flow deposit overlays a small lapilli layer interpreted to be air-fall tephra produced either from a central vent eruptive column or from a co-pyroclastic flow tephra cloud (see figure 2.21).

Figure 2.21. Ash and tephra layers underlying the June 29, 2003 pyroclastic flow deposit. A Tephra layer immediately below the pyroclastic flow deposit ( $12 \mathrm{~cm}$ thick), on the upper Barranca Seca ( $4 \mathrm{~km} \mathrm{~W}$ from the vent), interpreted to be airfall tephra from a central vent eruptive column, or from a co-pyroclastic flow cloud. B Fine ash layer ( $2 \mathrm{~cm}$ thick) immediately underneath the distal ( $7.5 \mathrm{~km}$ from the vent) pyroclastic flow deposit (overbank facies). This layer is interpreted as an ash cloud surge deposit.

Grainsize analyses from the matrix component of the pyroclastic flows shows results that are similar to grainsize distribution from other pyroclastic flow deposits, especially block and ash flows from other volcanoes, e. g. at Soufriere Hills (Cole et al. 1998; Calder et al. 2002a, 2002b), Colima (Saucedo et al. 2002, 2004), and Merapi (Schwarzkopf et a. 2005; Charbonnier and Gertisser, 2008), and as it will be discussed in the next chapter, also similar to older deposits at Fuego. Overall the distributions look similar and there is no obvious systematic relationship with the facies environment from which the different samples come from, nor the eruption (e. g. A, B, $C$, and $D$ from 2003 vs $E$ and $F$ from 2005 in figure 2.22). The relative lack of particles close to the $-2 \varphi$ can be seen in all the samples and a peak between 1 and 2. $\Phi$ is also evident. Perhaps more interesting is the consistent and sometimes very pronounced peak at the coarse size particle extreme of the distribution, between -4 to $-3 \varphi$, for all the analyzed samples. This implies that the matrix is rich in gravel size clasts, and perhaps the arbitrary limit of $-4 \varphi$ to define the matrix grain size is not adequate. A grain size analysis including coarser sizes, potentially also 
extending to the boulder size, would help to clarify this issue. In all the samples, the fraction of clasts finer than $4 \varphi$ is less than $8 \%$, and can be as small as $2 \%$. Such a fine depleted matrix perhaps reflects the effect of fine ash elutriation as the flow is propagating downslopes, which also would help to explain the abundance of fine ash in the eruptive clouds produced by some of these eruptions (i. e. the co-pyroclastic flow ash cloud).

A

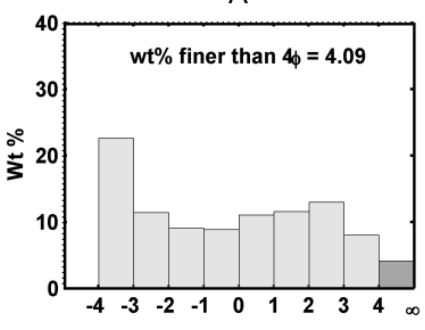

$\mathrm{D}$

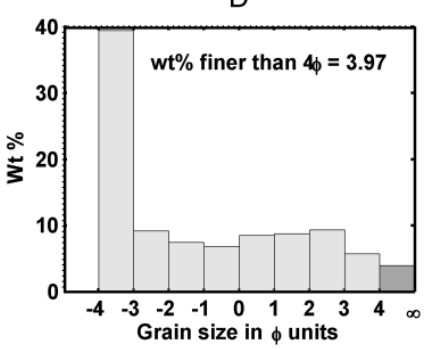

B

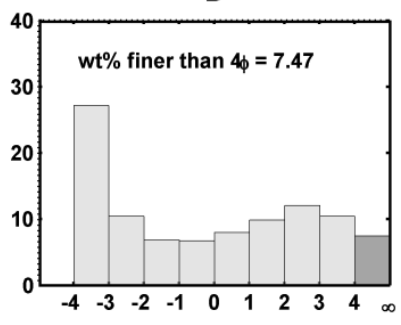

$\mathrm{E}$

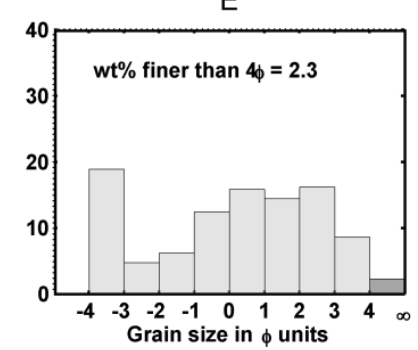

C

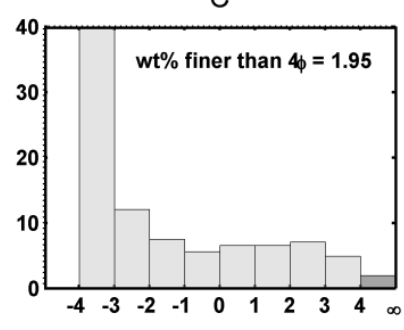

$\mathrm{F}$

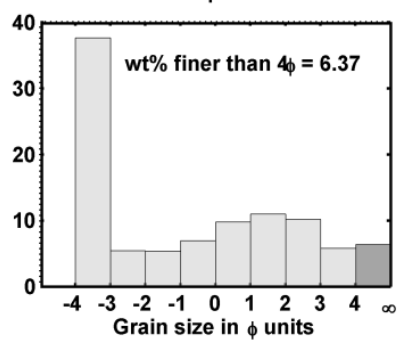

Figure 2.22. Grain size distributions of pyroclastic flow matrix material. A Sample of the flow front deposit of the June 29, 2003 pyroclastic flow, in Barranca Seca. B and C, Channel fill facies of June 29, 2003 pyroclastic flow, in Barranca Seca. D Overbank facies of the June 29, 2003 pyroclastic flow, immediately adjacent to Barranca Seca. E and F, Channel fill facies of the July 17, 2005 pyroclastic flow deposit in Barranca Taniluya.

Ash cloud surges have also happened during large (above background) explosive eruptions during the current eruptive episode. Ash cloud surges have been restricted to the upper $\sim 6 \mathrm{~km}$ of the pyroclastic flow paths, remaining relatively close $(<500 \mathrm{~m}$ ) to the path (usually defined by a Barranca channel) on which the corresponding pyroclastic flows have propagated (see figure 2.23). In some cases the abrupt change in the direction of the pyroclastic flow path seems to have caused the generation and detachment of the ash cloud surge (see videos on appendix $2.5)$, but in other cases the ash cloud surges seem to just follow a parallel path to the pyroclastic flow; e. g. while the pyroclastic flow propagates contained inside the Barranca channel, the ash cloud surge sweeps the interfluvial terrain adjacent to the barranca, with a surge direction subparallel (with a small perpendicular component, away from the channel) to the pyroclastic flow direction inside the barranca (see figure 2.23). 


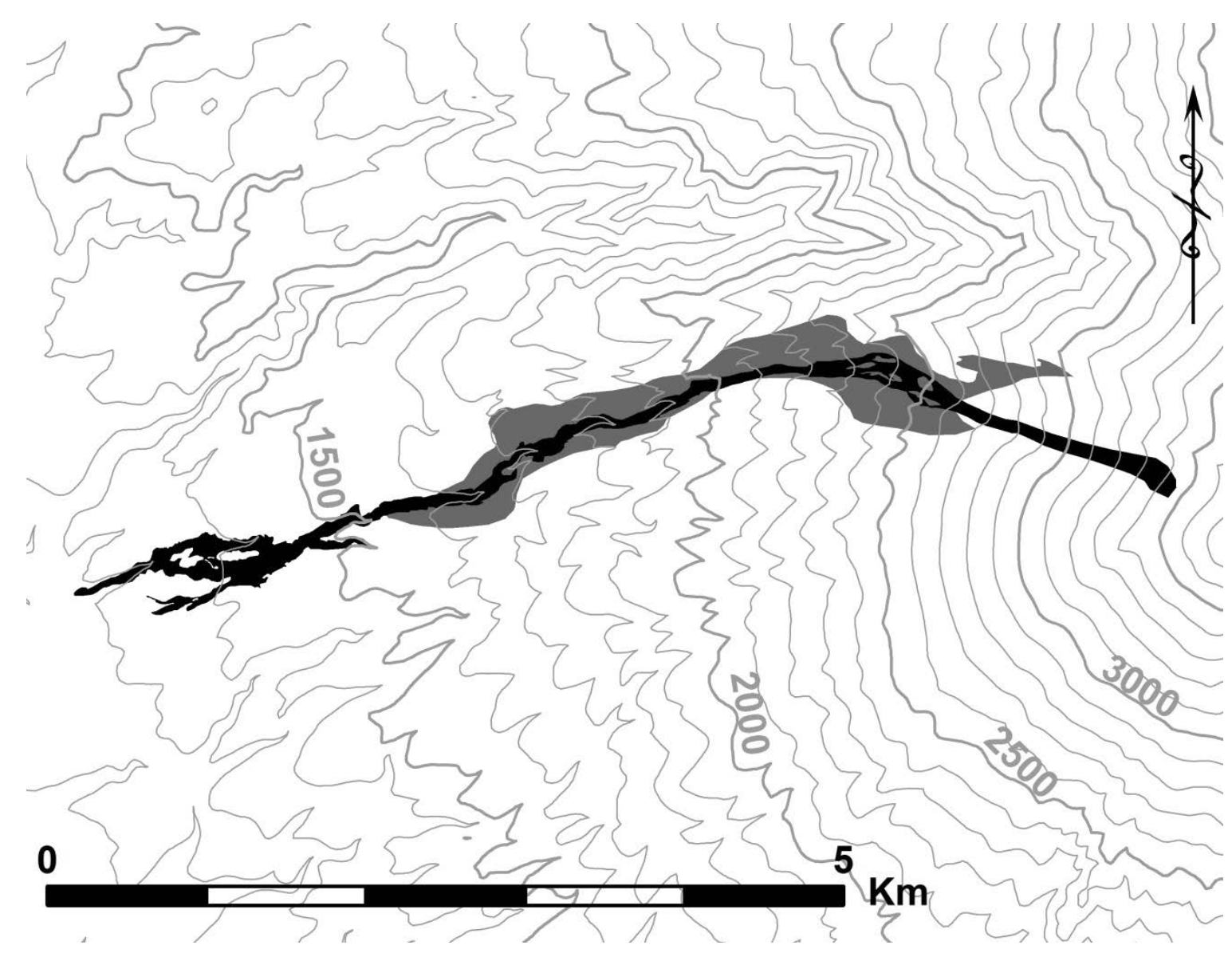

Figure 2.23. Map showing the areas covered by pyroclastic flow (in black) and ash cloud surge (in gray) deposits from the June 29, 2003 eruption. Elevation contour interval $100 \mathrm{~m}$, elevation values in masl.

Ash cloud surge deposits consist of a medium to fine ash matrix, with a minor component of embedded lapilli size pyroclasts, having thicknesses that vary from $<1 \mathrm{~cm}$ to $\sim 25 \mathrm{~cm}$ (see figure 2.24). Deposits can be directly below the deposit of an associated pyroclastic flow, as previously discussed in this chapter, but are found without an overlying co-genetic pyroclastic flow deposit in areas where only the ash cloud surges escape the Barranca channels, while the dense pyroclastic flow didn't, in such cases the ash cloud surge deposit may still be covered by cogenetic airfall tephra. Deposits appear massive and unstratified close to the co-genetic pyroclastic flow deposit (or the Barranca channel in which they are contained), but show some faint stratification further away.

Ash cloud surges can have varying degrees of impact on the forest, from complete destruction of all vegetation by uprooting trees and bushes, and breaking tree trunks $(60-70 \mathrm{~cm}$ in diameter) close to the ground level $(<2 \mathrm{~m})$, to lower level damage, including partial stripping of foliage and 
bark from trees. As the level of destruction decreases the chance for recovery of the affected vegetation increases, depending on how resistant and resilient the particular plants are. Intermediate to severe levels of damage include entire forest sections where large threes were left standing, but the leaves and the bark on the side facing the ash cloud surge had been completely stripped (see figure $2.24 \mathrm{C}$ ). Rock fragments embedded in trunks and branches were common in these areas (see figure 2.24 B).

In contrast to areas invaded by pyroclastic flows deposits, which mostly remain unvegetated to the present (2013), the areas affected only by ash cloud surges start to be reclaimed by vegetation within a year of the occurrence of the eruption; presumably the comparatively thin deposit (underneath which the pre-eruption soil is mostly preserved), and the potential for survival of some plants, allows vegetation to come back quickly. The implication for mapping the extent of ash cloud surges is that the footprints of such phenomena are rather ephemeral, and in the case of remote sensing imagery, require images that are less than a few months old, to actually be able to map the affected areas.
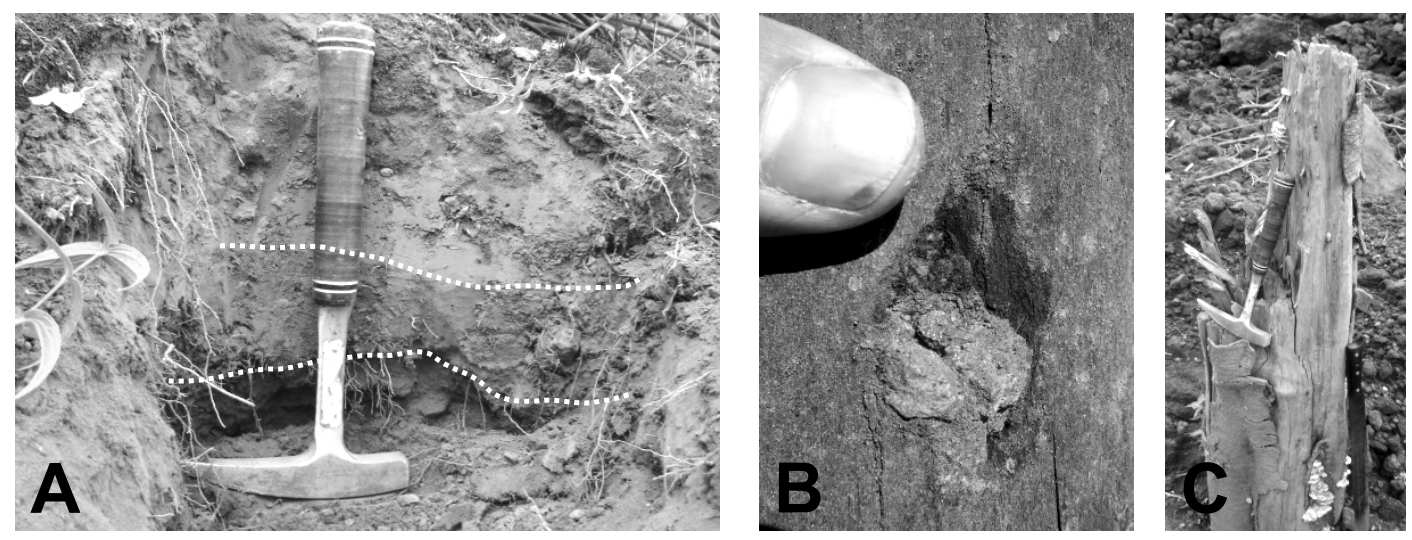

Figure 2.24. A Ash cloud surge deposit from the June 29, 2003 eruption on the interfluvial terrain next $(\sim 259 \mathrm{~m})$ to Barranca Seca. White dashed lines separate two ash cloud surge deposits, the lower is slightly coarser grained than the upper one. Both deposit were formed in rapid succession during the same eruption. B Small rock embedded in a tree trunk on the interfluvial terrain adjacent to Barranca Seca, caused by the ash cloud surge from June 29, 2003. Notice that the bark has been stripped away. C Tree broken by an ash cloud surge on Barranca Ceniza. Notice the bark stripped only on the right side of the trunk (the side facing the ash cloud surge).

The mechanisms behind the generation of pyroclastics flows and the related ash cloud surges seem to include a variety of possible processes. Small ( $<4 \mathrm{~km}$ run-out) pyroclastic flows are sometimes generated by the collapse of lava flow fronts. This mechanism has been proposed for pyroclastic flows at Fuego since the 1950's (Hantke, 1962, McDonald, 1972), and it has been directly observed in some cases during the current $(1999-2013)$ eruptive episode, e. g. Lyons et 
al. (2009) recognized this mechanism for pyroclastic flows generated during eruptions in 2005 to 2007.

A different mechanism however must be involved in the generation of the larger pyroclastic flows (e. g. June 29, 2003, July 17, 2005, September 13, 2012), because the volume of the larger pyroclastic flow deposits (up to $10^{7} \mathrm{~m}^{3}$ ) is more than an order of magnitude larger than the entire volume of the lava flows that could collapse from the summit region (from typical lava flow dimensions), and certainly much larger than the lava flow front region. Other sources of hot and potentially unstable material (spatter, scoria and bombs) near the summit vent, accumulating as a result of the eruptive activity could also be considered as potential sources (see figure 2.25), suggesting that a much more extensive volume may become unstable and collapse during the occurrence of the larger pyroclastic flows. The strong changes in the summit morphology observed to happen during the large eruptions, and most significantly the apparent missing of large portions of the summit structure, support the idea of large volumetric summit collapses involved in the generation of pyroclastic flows. This ides is also consistent with the general structure and texture of the pyroclastic flow deposits, i. e. the striking block and ash flow aspect resembling those produced by the collapse of silicic domes, including the abundance of dense blocks.
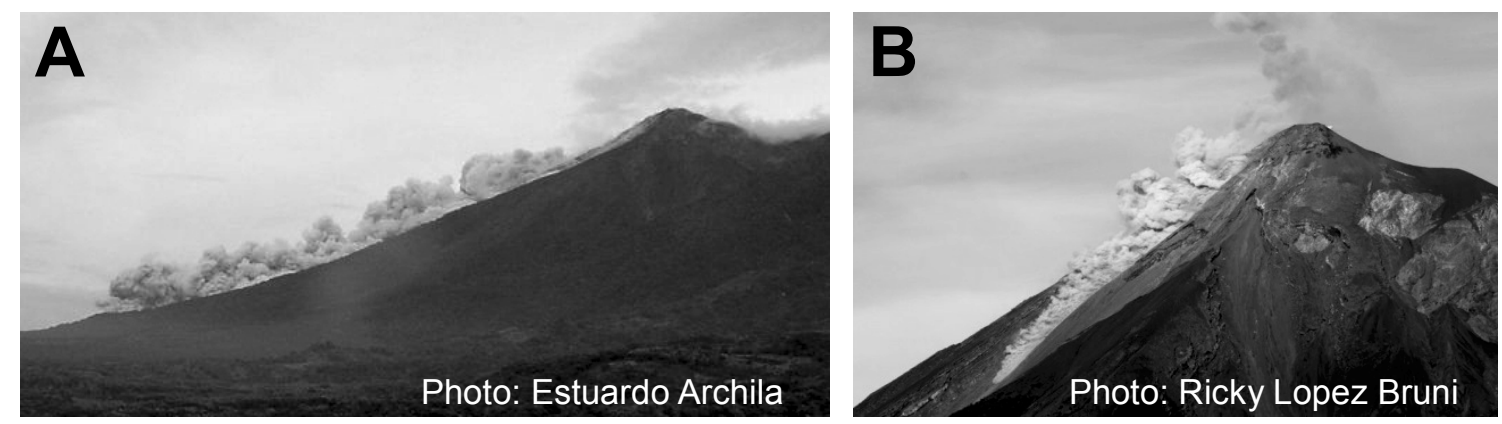

Figure 2.25. Small pyroclastic flows generated by the collapse of lava (possibly including flow front collapse) and hot debris from the summit area. A This picture from July 31, 2002 shows pyroclastic flows ( $4 \mathrm{~km}$ run-out) coinciding with a period of intense effusive activity that started in February of that year on the Las Lajas and El Jute Barrancas, which suggests that the material feeding the pyroclastic flows may have accumulated during the effusive activity, until it became unstable and collapsed forming the observed flows. Notice the lack of activity at the summit vent. B Small pyroclastic flows ( $1 \mathrm{~km}$ run-out) on the upper east flanks of Fuego volcano, taken on August 10, 2011. The flows are also coincident with intense lava effusion and explosive background activity at that time, and for several months prior to it.

The idea of larger summit region collapses generating the pyroclastic flows has been applied to other similar eruptions. Block and ash flow deposit generated by dome or lava flow collapse are typical at many silicic (andesitic to dacitic) domes, e. g. Soufriere Hills (Cole et al. 1998; Calder et 
al. 2002a, 2002b), Colima (Saucedo et al. 2002, 2004), Merapi (Schwarzkopf et a. 2005; Charbonnier and Gertisser, 2008), to the point that they are sometimes called "Merapi type", after the characteristic pyroclastic flows generated by lava and dome collapse at Merapi volcano. Block and ash flow deposits at basaltic to basaltic-andesitic volcanoes have not been described often in the vulcanological literature, and the apparent paucity of such kind of deposits from such magmas could be related to the lower viscosity and dominantly ductile rheological behavior that they tend to exhibit in comparison with more silicic, dome forming magmas. However a few case studies on basaltic to basaltic-andesitic volcanoes include similar deposits, and several alternative generation mechanisms have been proposed.

Behncke et al. (2003) describe "dome collapse pyroclastic flows" of basaltic origin, which apart from the composition of the magma, would be identical to silicic dome collapse flows. Alvarado and Soto (2002) proposed that andesitic pyroclastic flows at Arena were generated by the failure of the crater wall, leading to the collapse of a "lava pool" contained inside the crater, arguing that the rapid cooling of the magma led to the formation of the cauliflower crust texture in blocks (or bombs). This is a slightly different "lava collapse" mechanism, but could still be considered as similar to the typical dome collapse mechanism. Nairn and Self (1978) describe a series of eruptions at Ngauruhoe on February 19, 1975 (the eruptions that happened between 13:00 and 14:00 hours, local time) that produced pyroclastic flows by "slumping of rapidly accumulated large pyroclasts continually falling from the eruption column onto the summit". This mechanisms is also very similar to a gravitational lava mass collapse, and although the residence time of the hot material (bombs, spatter, etc.) on the steep slope may be very short, the description by Nairn and Self (1978) seems to imply that the material feeding the pyroclastic flows had mainly come to rest on the slope before becoming unstable and collapsing into the flows. Arguably, if the material accumulating is hot and ductile enough, the accumulation rate is sufficiently high, and the slope is steep enough, the falling material could deform in a ductile manner (e. g. like spatter or plastic interior bombs), weld or homogenize, and possibly form a clastogenic lava flow instead of a pyroclastic flow, if the strain rate is high, but the ductile-fragile transition is not crossed.

A different pyroclastic flow generation process that has been associated to basaltic and basalticandesitic magmas involves the continuous or almost continuous feeding of pyroclastic flows by hot (incandescent or close to magmatic temperature) material, falling from an eruptive column, probably fed by a lava fountaining. In such cases the collapsing material doesn't start moving from a repose condition on the volcano's slope, but rather inherits the momentum from falling out of the eruptive column. The degree of coupling (mechanically and thermally) of the pyroclasts (solid phase) with the gas as it exist the vent and before it hits the slope could be low, in cases 
where clast size is large and initial momentum is high, leading to the separation of the pyroclasts in a one (solid) phase mass flux, ultimately causing the gravitational collapse of the predominantly solid phase on the slopes of the cone. As the degree of coupling between pyroclasts and the gas phase increases, the mass flow becomes increasingly dominated by both phases (solid pyroclasts and gas), becoming closer to the flow behavior assumed in many volcanic eruption column and column collapse models, e. g. Sparks et al. (1978), Wilson et al. (1980), Valentine and Wohletz (1989), and Clarke et al. (2002). It is in such context, i. e. coupled two phase (gas and pyroclasts) flow that we will consider the column collapse mechanism. Such models consider an initial momentum dominated movement, which depending on whether the density of the eruptive column remains above or below the density of the ambient air surrounding it, may be followed by buoyant rise of a plume up to an elevation at which neutral buoyancy is attained (e. $\mathrm{g}$. in Plinian eruption columns, this elevation may be tens of kms above sea level), or may collapse to form pyroclastic flow. The ability of the eruptive column to reach a density less than the surrounding air depends on the rate at which air is entrained through turbulent exchange into the column, and heated by thermal exchange from the suspended pyroclasts, expanding and loosing density. This requires a large enough concentration of small (large specific area) and hot pyroclasts. The failure to attain buoyancy leads to the column collapse.

For collapsing columns (e. g. those failing to attain buoyancy), the elevation that the coupled gasparticles mixture may reach depends strongly on the initial velocity (and therefore momentum) of the mixture as it exits the vent. Even if the mixture collapses after losing momentum, given a high enough initial velocity, the mixture (and even more the largest particles within it) can reach elevations of several hundred meters above the vent. Therefore, collapsing columns can range from relatively high (several hundreds of meters above the vent) fountains of pyroclasts and gas mixtures, to very low overflows of pyroclasts and gas mixtures, barely flowing over the vent rim. The later style of eruptive collapse is sometimes referred to as the "boiling over" pyroclastic flow generation mechanism.

Behncke (2009) reviewed the occurrence of basaltic pyroclastic flows at Etna, and describes a "fountain collapse onto steep slope" mechanism (see his figure 6a), which is different from the "collapse of dome-like structure" pyroclastic flow formation mechanism discussed previously for the 1999 Etna eruption (Behncke et al. 2003). Yamamoto et al. (2005) also propose a similar model for the basaltic pyroclastic flows that they describe at Fuji volcano (see especially their figure 11). The description of the pyroclastic flows generation mechanism for 2006 Tungurahua eruption, given by Kelfoun et al. (2009) seems to also fit this model. The "fountain collapse" mechanism and the cases that have been associated to it, seem to be closer to the decoupled 
solid-gas phases end of the spectrum rather than the column collapse case, as previously discussed. And as discussed in the lava collapse section, the rheology, accumulation rate, and slope will determine whether a clastogenic lava flow or a pyroclastic flow will form from the hot material accumulating on the slopes around the vent.

Other case studies describe mechanisms that seem to be closer to the column collapse (i. e. coupled solid and gas phase flow) process, forming deposits similar to those generated by pyroclastic flows at Fuego. Wolf (1878) was among the first to describe, based on witness accounts relayed to him, the generation of pyroclastic flows by what seems to have been a "boiling over" mechanism. Wolf, based on the descriptions given by eye witnesses, uses several words to describe the pyroclastic mixture as it left the crater and flowed down the flanks, the words he uses could be translated from his original paper in German as "bubbling or boiling over" (übersprudeln), "outburst, effervescence, etc." (Aufwallung), etc., and in one case he mentions the Spanish word that witnesses would use (ebullicion), which could also be translated as "boiling"; in any case, he stresses the point that the mixture didn't reach much elevation before collapsing, suggesting that the mechanism was a characteristic "boiling over" case. Although Wolf calls the deposits from such flows "lava", it becomes clear from his description that such deposits are pyroclastic flow deposits, very similar to those described here from Fuego volcano.

The previously mentioned study by Nairn and Self (1978), describing the collapse of accumulated material from the summit region, during the February 19, 1975 Ngauruhoe eruption, also describes what seems to be column collapse fed pyroclastic flows (happening the same day at $18: 10$, local time), stating that "the interior of the cloud began to collapse to form a pyroclastic avalanche...". Miyabuchi et al. (2006) proposed a similar model for the formation of basaltic pyroclastic flows at Aso volcano, in which a partially solidified lava lake (analogous to the lava pool in Alvardo and Soto, 2002) is ejected explosively, and the ejection of magma coated blocks results in the cauliflower texture (see especially their figure 8). Although Miyabuchi et al. (2006) consider that this eruption had a phreatomagmatic component, the description of the pyroclastic flow formation mechanism is very similar to the "boiling over" case. Moore and Melson (1969) describe a formation mechanism (including color photographs) for the pyroclastic flows occurring at Mayon volcano during the 1968 eruption, which may be in between the "fountain collapse onto steep slope", predominantly one phase (pyroclasts) material hitting the steep slopes, and the "boiling over", two phase (pyroclasts and gas mixture) collapse mechanisms, which they call the St. Vincent type, as it is also known in other classification systems. 
All these studies consider pyroclastic flows that generated similar block and ash flow deposits, from basaltic, basaltic-andesitic, and in some cases andesitic volcanoes, and typically include cauliflower crust bombs; this make them similar to the Fuego case, and could potentially share common processes in the generation of pyroclastic flows. Although the occurrence of pyroclastic flows generated by lava and other hot material collapse seems quite evident (see figure 2.25 and associated discussion in the text), it is less clear to what extent the other mechanisms, including column and fountain collapse, could also play a role in the generation of pyroclastic flows at Fuego. This is especially difficult to assess for eruptions that simultaneously display en eruptive column and the generation of pyroclastic flows. In some cases the eruptive activity at the summit vent is relatively weak, when compared to the magnitude of the pyroclastic flows, and this could either mean that such flows are being generated by static lava/hot material collapse from the upper cone (Merapi style), or by boiling over of a dense pyroclastic-gas mixture, and perhaps one of the best examples of such kind of observations, would be the video of the pyroclastic flows generated during the September 13, 2012 eruption, available at:

http://www.youtube.com/watch?v=ntfkQ38Wxoc

(see also figure 2.26). The video shows impressive and vigorous pyroclastic flow generation and propagation down Fuego's flanks, but simultaneously only minor activity at the summit vent; such behavior suggests a Merapi type generation mechanism, but a strongly directed (towards Barranca Trinidad) "boiling over" mechanism can't completely be ruled out either.

Pyroclastic flows seem to behave as dense granular flows, their movement being driven by gravity and therefore strongly controlled by the topography. The role of fluidization in the flow transport mechanism must be important, considering that the flow reaches long distances (> 8 $\mathrm{km}$ ) moving within, at times, highly sinuous and confined channels, even backing up at the confluence with other channels (see figure 2.26 and videos on appendix 2.5), and leaving flat top deposits. Such fluidization is probably related, at least in part, to the pore pressure experienced during the flow due to the gaseous phase.

Also noteworthy from the perspective of the possible transport mechanisms is the presence in pyroclastic flow deposits of cauliflower crust blocks, which are very fragile and highly susceptible to lose their crust by impact (as seen in the field by hitting them with a hammer), but yet are abundant in the distal (> $8 \mathrm{~km}$ from the source) parts of the deposits, showing intact cauliflower crusts. This implies that either the cauliflower crust was not that fragile at the time of emplacement of the flow deposits, or that the flow process was gentle enough to preserve the majority of such textures. The first explanation is probably more likely, suggesting a high emplacement temperature (i. e. the blocks were still hot and ductile when deposited, and 
acquired the characteristic cauliflower texture post-emplacement), which is also consistent with other field observations, including the abundance of completely charred vegetation in such deposits.

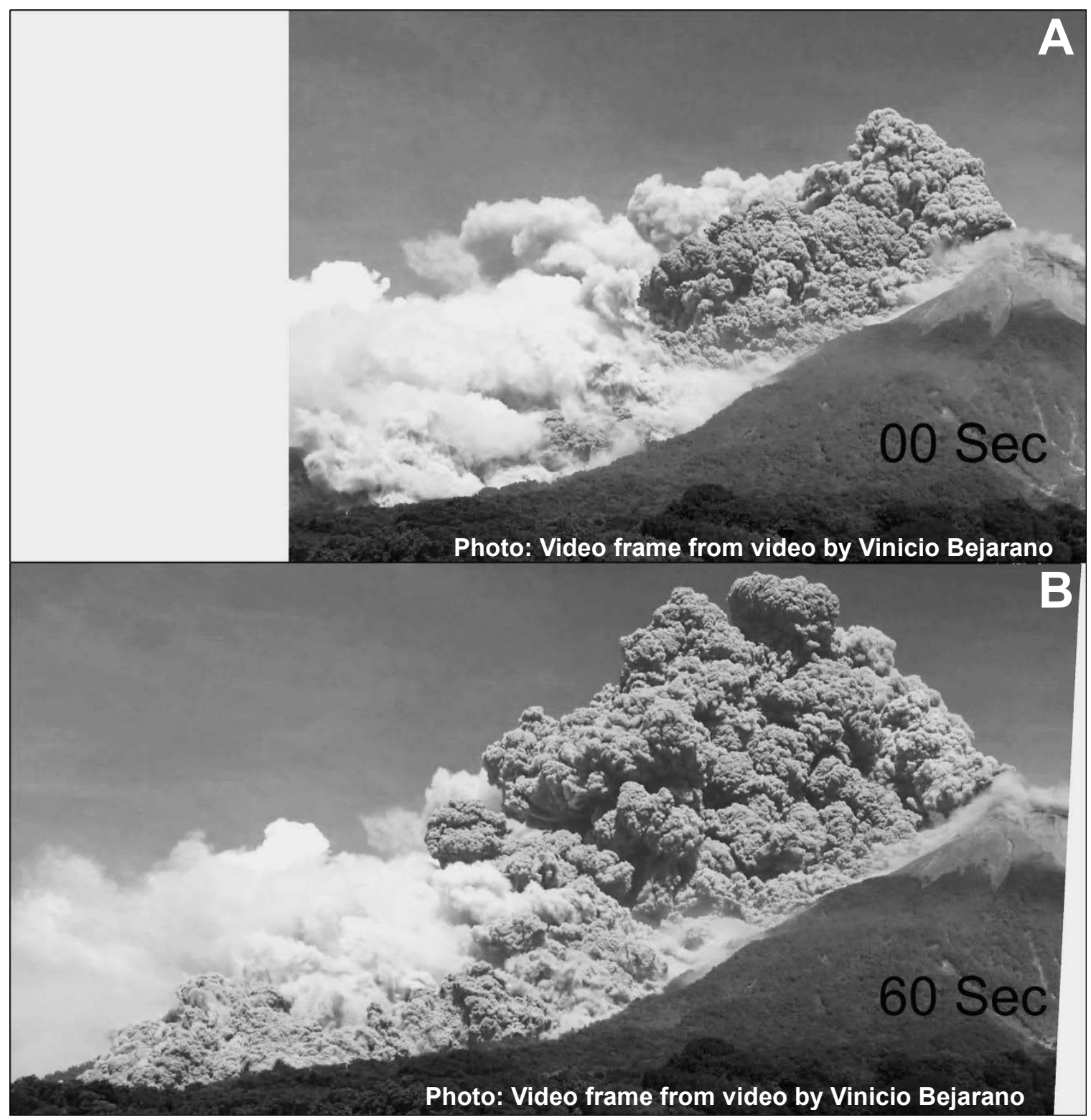

Figure 2.26. Video frames ( $\mathbf{A}$ and $\mathbf{B}$ ) at 0 and 60 seconds (arbitrary initial time) taken from a location $\sim 8 \mathrm{~km}$ to the east of the volcano, during the September 13, 2012 eruption. Notice that only minor activity is taking place at the summit vent over the full minute that takes for the pyroclastic flow to develop and propagate down the flank of Fuego, along Barranca Trinidad. Such behavior suggests a Merapi type generation mechanism, but a strongly directed (towards Barranca Trinidad) "boiling over" mechanism can't completely be ruled out either. This can be contrasted with eruptions that also produced pyroclastic flows but were at the same time producing an incandescent lava fountain, as can be seen in this video:

http://www.youtube.com/watch?v=zPtGzbMW-Cs , and which suggests that a "fountain collapse 
onto steep slope" mechanism was probably associated to the generation of those flows. Surprisingly however, all the pyroclastic flow deposits have the same appearance in the field and therefore are indistinguishable from another, even if the eruption mechanisms may be slightly different.

The relative role of particle-dispersive and frictional forces is not clear, but is expected to be dominant for such kinds of dense granular flows (e. g. Iverson, 1997). The abundance of a fine grained matrix in the pyroclastic flow deposits (despite some loss of finer ash as part of the copyroclastic flow tephra cloud due to elutriation processes during transport) could be the product of comminution milling by attrition of fragile fragments (e. g. scoria, tephra and even larger blocks and bombs) during the flow movement, and would imply a strong granular-frictional and collisional transport regime.

Flow velocities are difficult to estimate, and were probably highly variable throughout the flow path and at different times. Video and photographic evidence suggests that most of these flows took only a few minutes to move between 4 and $8 \mathrm{~km}$, implying mean velocities of a few tens (10 -40 ) of $\mathrm{m} / \mathrm{s}$. Flow velocities were probably much faster at higher elevations and on steeper slopes, than on the lower and less inclined, distal segments of the flow paths. The decoupling of ash cloud surges at such higher elevations and slopes is consistent with such behavior. At more distal parts, the flow in sinuous channels lead to superelevation phenomena, as can be seen from field documentation (e. g. see videos on appendix 2.5), but such superelevationa are relatively minor $(<10 \mathrm{~m}$ for curvature radii of $<250 \mathrm{~m}$ ) and suggest that flow velocities were also low at those points.

Applying standard methods to estimate velocities from superelevation data and choosing correction factors between 1 and 5 (e. g. Prochaska et al. 2008), we obtain velocities $<20 \mathrm{~m} / \mathrm{s}$. Whether such an approach is strictly valid for the granular flows we are considering in our case or not, will not be discussed in detail here, but this method seems appropriate for highly fluidized and dense granular flows, and therefore puts constraints on the velocities that such flows could have; less fluidized (dry friction and dispersive collisional stress dominated flows) would be expected to move even slower. The lack of ash cloud surges detaching from the distal segments of pyroclastic flows also support the idea that the flow velocities at those locations were relatively low. Eventually, flow velocities dropped below the dynamic threshold at which the flow could keep moving, apparently freezing "en masse" and forming the characteristic lobbate shaped deposits, forming steep flow fronts. At such low velocities, overflowing of the Barranca channel, as in the case of the June 29, 2003 pyroclastic flow, was probably caused by the channel cross sectional area reduction by progressive flow pulse deposition, rather than due to kinetic effects (e. $\mathrm{g}$. 
inertial superelevation) associated to flow dynamics at similar overflow cases in other volcanoes, e. g. at Merapi, as described by Lube et al. 2011, even for perhaps similarly low velocities (18 $21 \mathrm{~m} / \mathrm{s}$ in the case of Merapi, as described and modeled by Lube et al. 2011).

Channel cross section filling, margin overflow and adjacent interfluvial terrain inundation by the pyroclastic flows, followed by shifting of the Barranca channel as the erosion cuts a new channel at a slightly different location, is in many ways similar to the process of channel avulsion in alluvial and fluvial systems (Singerland and Smith, 2004). However, in the case of the pyroclastic flow caused channel avulsion, the processes that cause the disappearance of the old channel (i. e. pyroclastic flow deposits filling) are of a fundamentally different nature than the processes that cut, excavate and establish the new channel (i. e. alluvial and fluvial erosion), in contrast to still different but relatively closer related processes of deposition and erosion causing avulsion of alluvial and fluvial channel systems. This unique type of avulsion may be of fundamental importance in building part of the edifice of stratovolcanoes like Fuego, as will be discussed in the next chapter, and is central in giving the volcanic terrain on the medial cone slopes, it's characteristic geomorphic texture: the alternation deep and highly confined Barrancas, and relatively gentle interfluvial terrains.

Finally, although some simple geometry parameterization has been applied to pyroclastic flow deposits at in other cases, the application of such parameters to the Fuego deposits may be more problematic, given the strong interaction they have with the topography. For example, Calder et al. (1999), following the ideas that Iverson et al. (1998) applied to lahars, and Dade and Huppert (1998) applied to rock avalanches, applied a mobility parameter that incorporates the deposit's volume and area $\left(A / V^{2 / 3}\right.$, where $A$ is the planimetric area occupied by the deposit, and $V$ is the deposit volume) to characterize the mobility of pyroclastic flows, and this parameter has been subsequently used by other authors for that same purpose (e. g. Vallance et al. 2010). The highly confined nature of Fuego's drainage will result in much thicker deposits emplaced over much smaller planimetric areas, resulting in small $(<40)$ values of $A / V^{2 / 3}$, which otherwise would be interpreted as a low mobility for such kinds of flows. However such an assessment doesn't takes into consideration the lateral friction between the flow and the channel walls, and the corresponding energy consumption. The vertical stacking of multiples individual pulses on top of another within a Barranca channel also complicates the application of the parameter, as the stack of deposits corresponding to different pulses should ideally be treated separately, even if they originated from the same eruption. 


\subsection{Lahar activity following larger eruptions}

Lahars are common during normal rainfall after the occurrence of large eruptions, especially those producing pyroclastic flows. During the rainy season lahars can recur daily, and transport very large amounts of volcanic material from the steeper upper and medial sections of the cone, to the lower and flatter distal cone reaches and beyond.

Given the high recurrence, and relatively predictable behavior of most "normal rain" triggered lahars, it is possible to observe and film them directly over periods of heightened lahar activity. The video of a lahar on October of 2003 provided on appendix 2.5, with a detailed description and interpretation of the observed lahar characteristics, represents a good example of such type of lahars. The lahar flow usually develops a strong initial surge wave that carries logs and sometimes boulders at its flow front. The flow can be highly variable, and the discharge tends to vary significantly over the duration of the lahar, producing a series of pulses or waves, with periods of a few minutes. The lahar consistency also varies widely, even between different parts of a single lahar, ranging in appearance from murky water, which not able to carry large loads of sand and rock, and looks more fluid, to a thick and much more viscous appearance, resembling that of wet concrete. Lahars with the less dense and viscous consistency are probably carrying a low sediment load, both in suspension and as bed load, and the maximum observed size of clast being transported in those cases is (depending on the terrain slope) usually $<<1 \mathrm{~m}$ in maximum diameter, mainly by rolling and dragging of the rocks on the channel bed. On the other extreme, lahars with a much denser and more viscous looking consistency probably have a much higher sediment load, especially in suspension, and the maximum observed size of clasts that they can transport is often $>2 \mathrm{~m}$, in what sometimes appears to be a "floating" and bouncing regime.

These higher density and sediment content lahars can also carry sand and smaller rocks (usually falling on the lahar from the lateral banks) on their surface fore several tens of meters before they sink or get mixed in the flow, suggesting that their density or yield strength (or a combination of both) is very high. The higher sediment content and larger boulder carrying parts of lahars tend also to coincide with peaks in the lahar discharge. Often the lahars are hot, as the erosive and bulking action of the lahar cuts into still hot pyroclastic flow deposits, producing steam reach flows, even several $(8-10)$ months after the emplacement of the pyroclastic flow deposits. Many of these characteristics can be seen in the lahar video provided in appendix 2.5 .

Lahar dimensions and velocities also vary widely, and depend heavily on where within the lahar path they are observed. From relatively small $(<2 \mathrm{~m}$ wide and $<1 \mathrm{~m}$ deep) and slow $(<2 \mathrm{~m} / \mathrm{s})$ flows, to very large ( $>40 \mathrm{~m}$ wide and $>4 \mathrm{~m}$ deep) and fast $(>8 \mathrm{~m} / \mathrm{s}$ ) peak flows. The 
corresponding peak discharges would range between $<10 \mathrm{~m}^{3} / \mathrm{s}$ in small flows, to $>1000 \mathrm{~m}^{3} / \mathrm{s}$ for the larger flows. The duration of individual lahar events is constrained by the duration of the rain that causes them, and usually ranges from 10 minutes in the case of small flows, to several hours in the case of the largest events. The total volume transported by the lahars is difficult to assess, as will be discussed when considering the INSIVUMEH data, later in this section, but rough estimates indicate that volumes with orders of magnitude between $10^{3}$ and $10^{5} \mathrm{~m}^{3}$ can be carried by lahars triggered by "normal rain". As the rain amount (intensity and duration) increases, so does the scale of the lahars, transitioning at some point to the case of the extreme rainfall events that will be discussed in the next section.

Deposits from normal rain induced lahars tend to be small, as the lahars quickly transition from the intermittent (mostly dry) stream channels into the permanent drainage network around the volcano. As the lahars flow into larger and permanent streams hosting rivers flowing at high discharge rates, which is in general the case during the rainy season and in particularly during the rain events that caused the lahar, the lahar dilutes and may produce in the end deposits that are very different from what would have been the deposit if the lahar would have continued flowing and depositing on a (pre-lahar) dry channel. Lahar dilution leads to a transition from sediment dominated debris flow regime, through hyperconcentrated flow regime, to a common high sediment content water flow regime (Vallance, 2000). The deposits will likewise change for all such cases, but more importantly, deposition doesn't occur until the flow velocity decreases sufficiently, which is largely dependent on the local slope and flow rate at each particular point, but in most cases (for the active Barrancas) the confluence with diluting streams happens before the lahar starts to produce a significant deposit. Therefore most of the lahar flows tend to leave only small primary deposits. Deposits are usually contained within the channel and therefore are subject to further erosion and modification by normal stream flow or subsequent lahars.

Lahar deposits include a variety of types, but in general form sand to gravel matrix diamictons, with variable amounts of larger clasts imbedded in the matrix, including boulders that may exceed $2 \mathrm{~m}$ in maximum diameter. The deposits can be very similar in general appearance to the pyroclastic flow deposits from which the lahar flows form, but are less monolithologic, often including accidental lithics of oxidized lava, unburned wood, indurated soil fragments, and other non-related fragments. Although some of the deposits have little structure or stratification, some exhibit coarse tail grading (normal or reversed), and the deposits from intermediate to more diluted (hyperconcentrated) flows, which are the most common ones, often show weak stratification (see figure 2.27). Induration is slight in some deposit but not pervasive for all. All young deposits are clay poor and are very susceptible to water erosion, in a similar way as 
pyroclastic flow deposits. Deposits tend to be light to dark gray, but may include visible amounts of variously colored clasts, most notably red oxidized basaltic scoria and lava clasts. Horizons of better sorted clasts sometimes mark the transition between different depositional events. The amount of non-charred wood can be high (> $5 \%$ ) in some deposits, but is usually much lower than that for "normal rain" triggered lahars. Microstructures, like bubbles and dissecation structures are rare. As the lahar regime flow transitions into lower sediment load regimes, the texture and morphology of the corresponding deposits also shows analogous changes, resulting in typical alluvial and fluvial deposits that display well-formed stratification structures and gradation. Individual lahar units are also commonly separated, sometimes through erosive contacts, by more diluted stream flow deposits. Units from individual flow events are usually $<2$ $\mathrm{m}$ and many times $<1 \mathrm{~m}$ thick, resulting in lahar deposit sequences of many stacked and thin flows (see figure 2.27).

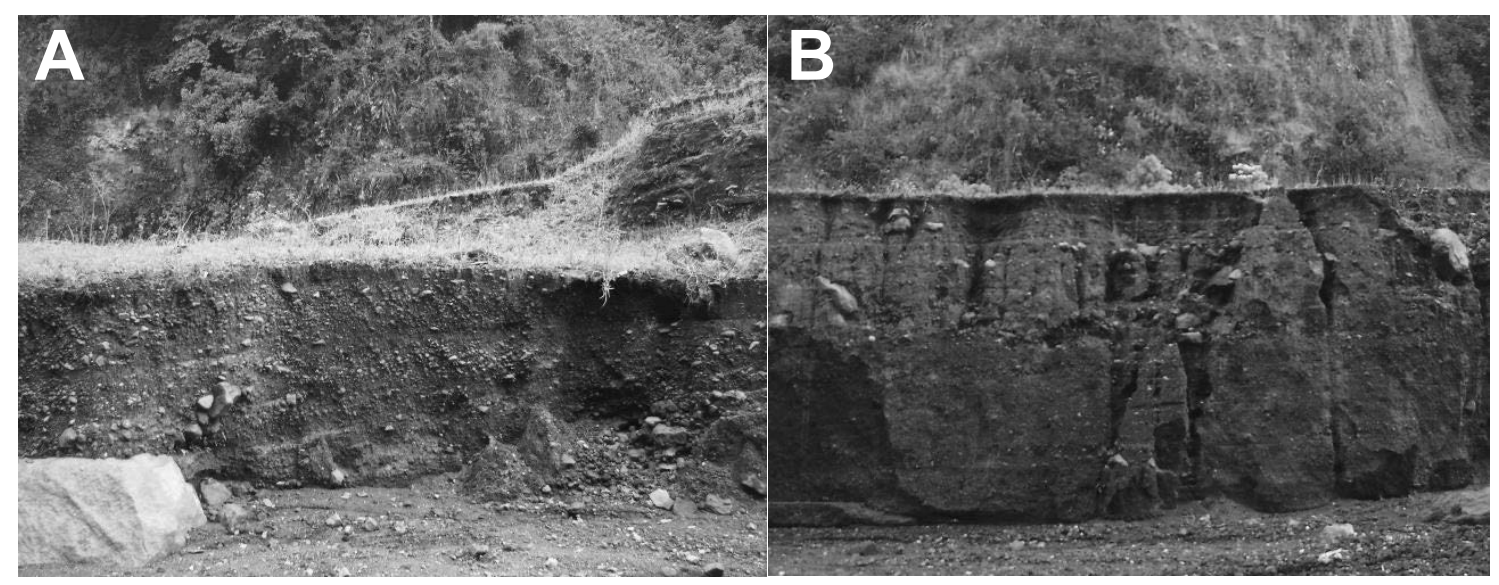

Figure 2.27. Sequences of lahar deposits on Barranca Seca formed after the large 2003 pyroclastic flow generating eruptions, and during that year's rainy season. A Sequence of lahar deposits located in the lower reaches of Barranca Seca, immediately upstream from the confluence of with the La Playa river. The height of the terrace is $\sim 2 \mathrm{~m}$. Weak stratification and coarse tail reversal sorting of some units can be seen. Maximum clast size of particles embedded in the deposit is $\sim 40 \mathrm{~cm}$, and the local slope is $\sim 15^{\circ}$. B Sequence of lahar deposits on Barranca Seca located on the intermediate reaches of Barranca Seca (the local slope is $20^{\circ}$ ). The terrace height is $\sim 5 \mathrm{~m}$ and the largest clasts embedded in the deposit have a maximum diameter of $\sim 0.8$ $\mathrm{m}$. Notice the clearly stratified aspect of the sequence and the presence of finer (fluvial?) sorting layers in between the individual lahar deposit units.

Clast rounding (i. e. increase in roundness) with distance from the lahar source is apparent in the field for gravel to boulder size clasts, throughout the length of laharic transportation ( 1 to $5 \mathrm{~km}$ ), but more significantly, no cauliflower crust textures are preserved in laharic deposits beyond $250 \mathrm{~m}$ from the pyroclastic flow deposit terminus, despite the abundance of such textures in the original pyroclastic flow deposits from which the lahars are formed. This implies that the fragile cauliflower crust texture doesn't survive the vigorous collisional and frictional transportation in the 
lahar flow regime, further supporting the idea that this texture is acquired by blocks and fixed to the fragile state in the pyroclastic flow deposit, after the flow stops and the deposit has been emplaced, otherwise the cauliflower crust wouldn't survive the transport in the pyroclastic flow itself. Variations in sphericity are harder to judge in the field.

The drainage system at Fuego can be characterized according to channel-reach morphology classification systems (e. g. Montgomery and Buffington, 1997) to better understand how lahar flow regimes relate to local morphology, erosive and sedimentary processes, and ultimately observed deposits. The laharic activity during normal rain conditions is almost exclusively restricted to drainages that have received pyroclastic flow deposits, which usually includes seven Barrancas (Seca, Taniluya, Ceniza, Trinidad, El Jute, Las Lajas, and Honda), and the following description applies to those barrancas.

As the drainage high in the upper cone transitions from the proximal active areas into the Barranca channels, the morphology changes from a less confined and broader cross section morphology to a more confined and narrower channel. On those high elevation locations the channel-reach morphology would correspond to colluvial channels (in pyroclastic flow deposit dominated areas), or bedrock channels (in lava flow dominated areas) (see figure 2.28), following the Montgomery and Buffington (1997) nomenclature. The channel slope on these reaches is > $14^{\circ}$ with a mean close to $20^{\circ}$, the active channel widths are usually between 10 and $50 \mathrm{~m}$, and the depths are between $\sim 5$ and $40 \mathrm{~m}$, corresponding to cross sectional areas between 50 and $2000 \mathrm{~m}^{2}$. The active channels are within larger Barranca channels, which are central in routing the pyroclastic flows on that part of the volcanic slope. No perennial water streams are present on these channel reaches, and only during rainfall due they carry water. Sediment supply is provided by the volcanic activity, and most significantly by pyroclastic flows. These channel reaches have usually a lower elevation boundary between 1200 and 1900 masl, whereas the upper boundaries (the transition between proximal active areas and Barranca channels) are found between 2500 and 2700 masl. At their lower boundaries these channel reaches drain areas of 2 to $3.5 \mathrm{~km}^{2}$.

In the case of colluvial channels formed in pyroclastic flow deposits, the channel morphology is controlled by very steep to subvertical lateral walls $\left(>70^{\circ}\right)$ flanked by talus cones, forming a deeply entrenched and confining channel (see figure 2.28 C and figure 2.29). The channel continuity is often interrupted by lateral colluvial slumping from the walls, leading to the formation of small pools in between talus cones (figure 2.29). Observed over a period of 5 months (July to November of 2003), the development of the new Barranca Seca channel was followed as it was cut into pyroclastic flow deposits over a length of $\sim 1.7 \mathrm{~km}$, after the avulsion caused by the 
overflowing of the pyroclastic flows on June 29, 2003. After the emplacement of the flow on June 29,2003 , the drainage was disturbed to the point where no stable channel existed anymore. Initial observations on the days and weeks following the eruption showed the re-establishment of water flow over the new pyroclastic flow deposit surface, first as overland (surface runoff) flow, but after less than two weeks it started to form an incipient drainage channel (see videos on appendix 2.5 and their respective description). This disruption stopped the generation and transport of lahars following the June 29 eruption for about 46 days (until August 14), despite a cumulative local rainfall of $\sim 600 \mathrm{~mm}$ over that time period. This drainage disruption also caused the damming of tributaries to the Barranca Seca and the formation of a small ephemeral lake (see videos on appendix 2.5). 

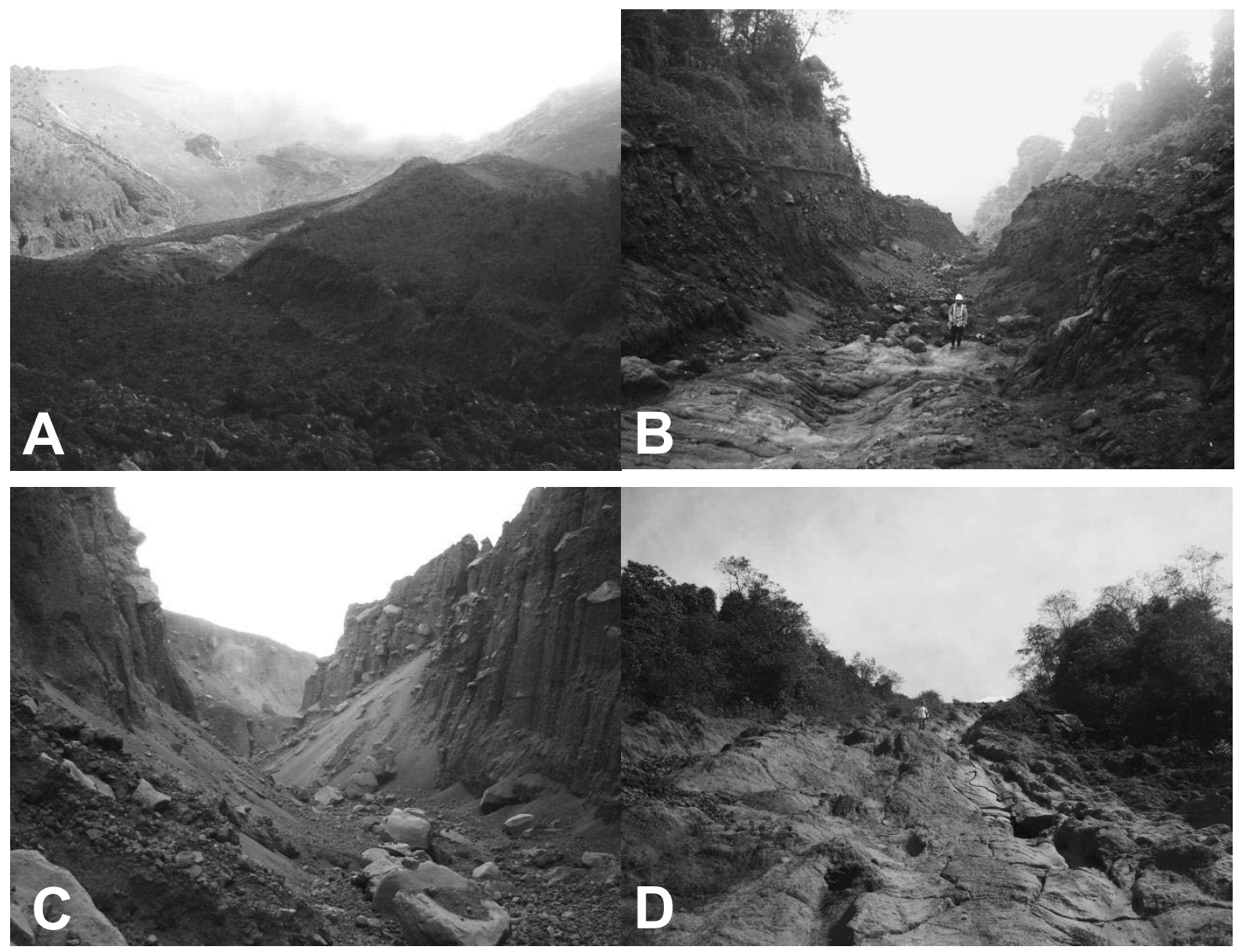

Figure 2.28. Colluvial and bedrock channel reaches on the upper Fuego flanks. A Bedrock channel at the transition between the proximal active area and the Barranca Seca per se, on the upper west slopes of Fuego. The channel is covered by a thick recent (December 15, 2007) lava flow, with a very rugged surface (see the corresponding section for a description of this lava flows), rich in bounder sized aa' lava fragments. The channel is relatively wide $(\sim 40 \mathrm{~m})$ and shallow $(<5 \mathrm{~m})$ on this location. Shrouded in clouds is the summit of Fuego, on the upper right corner of the picture. B Mixed bedrock (lava flow - bottom) and colluvial (pyroclastic flow margins) channel morphology on the upper Barranca Ceniza. The channel is $\sim 15 \mathrm{~m}$ wide and $\sim 8$ $\mathrm{m}$ deep. The bottom is a smooth lava surface covered in some place by a thin veneer of sand and gravel. A person is shown for scale. C Colluvial (pyroclastic flow deposit) channel morphology on the medial section of Barranca Seca, cut through the June 29, 2003 pyroclastic flow. The depth of the channel is $\sim 25 \mathrm{~m}$ and the width is $\sim 20 \mathrm{~m}$. Notice the nearly vertical walls and the talus cones buttressing the channel walls. D Bedrock channel morphology, showing the very smooth surface of an old lava flow that has been "polished" by fluvial erosion, and has virtually no clastic cover. The channel sides are very low $(<5 \mathrm{~m})$ and the channel width is $\sim 15 \mathrm{~m}$. 


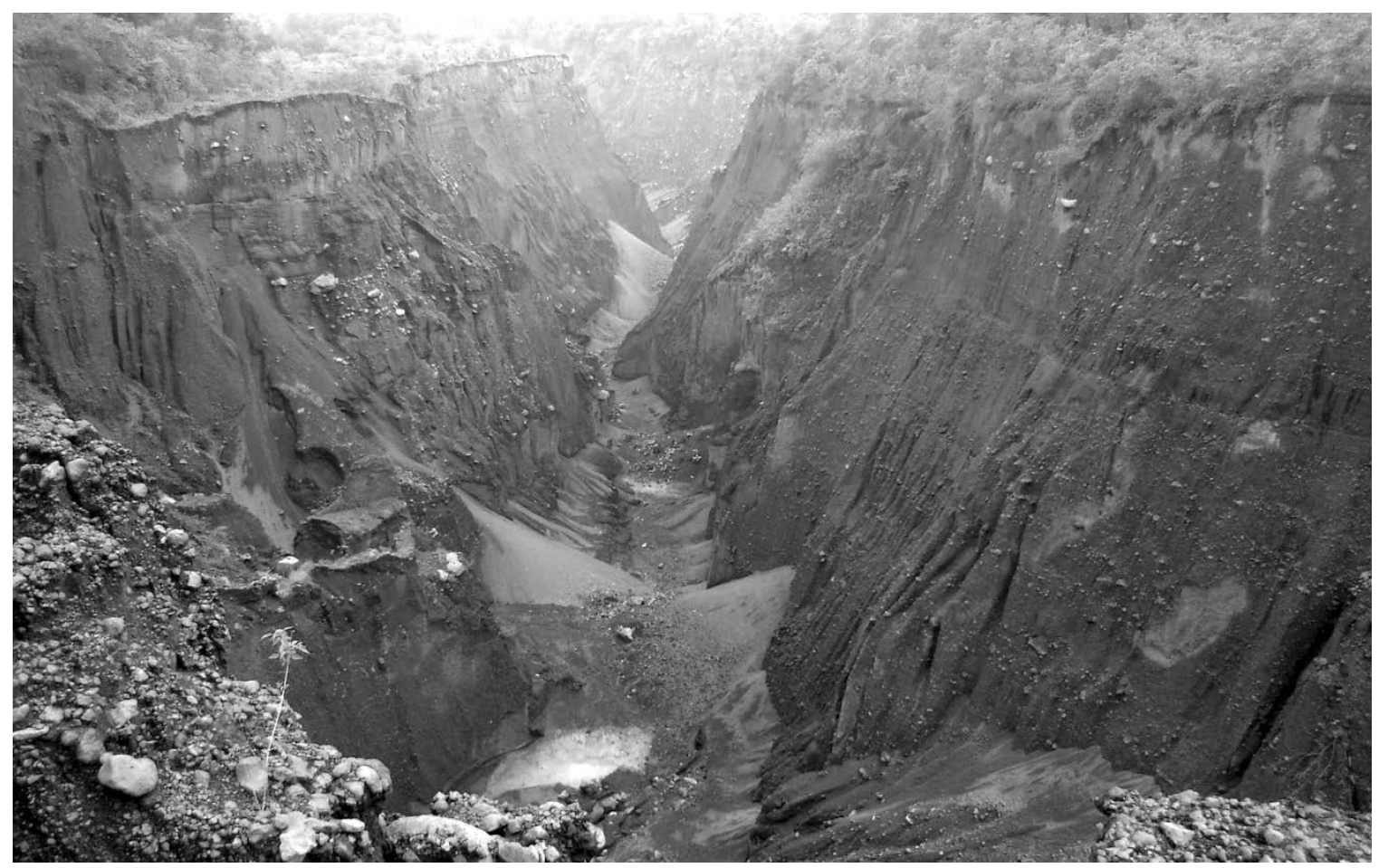

Figure 2.29. Barranca Seca new (post June 29, 2003 eruption) channel. An initially much narrower and as deep channel was formed during the 2003 wet season (mid-August through November) through dominantly vertical erosion, but that channel has since then widened through horizontal (mainly lateral bank undercutting) erosion (photo from January 2011). The depth of the channel is 40 to $50 \mathrm{~m}$, and the width is $50 \mathrm{~m}$. Notice the alternation of talus cones and small ponded water pools.

Once an incipient channel had formed, retrogressive erosion started to cut along the steepest segment of the new channel. By the end of July, roughly one month after the pyroclastic flow deposit had been emplaced, a small channel had been formed and from that moment on the process of channel formation started to accelerate. And by mid-August, as the rainfall increased, the first lahars started to be reported by OVFUEGO II, as they descended the Barranca Seca drainage. The channel erosion was initially predominantly vertical, deepening the channel and forming virtually vertical walls in the process, cutting 40 to $50 \mathrm{~m}$ into the deposit in a matter of two months, and providing the bulk of the material transported in the lahars that descended through Barranca Seca. As the slope of the channel thalweg decreased due to the erosive stream incision, the vertical downward speed of incision decreased, and during the following years only minor downward cutting continued; and so the erosion switched from predominantly vertical to horizontal, as lateral bank undercutting became more important, and the channel width steadily increased over the next few years (see figure 2.29). 
Downstream from the colluvial and bedrock channel reaches, the channel morphology is dominated by the typical cascade channel-reach morphology, that further downstream transitions into step-pool channel morphology (see figure 2.30), representing also the change from colluvial (or pyroclastic flow dominated) to alluvial to fluvial (lahar and river dominated) systems. Barranca channels start to carry water forming perennial streams, starting usually at elevations between 850 and 1200 masl. The barranca morphology changes to larger cross sections, increasing the depth (up to $100 \mathrm{~m}$ ) and width (up to $150 \mathrm{~m}$ ) of the channels, as the cross sectional area reaches a maximum (>10 $\mathrm{m}^{2}$ in some cases). Channel slopes decrease below $15^{\circ}$ but remain above $2^{\circ}$. The main sources of material for generating lahars, i. e. pyroclastic flow deposits, become less abundant and only during large events (e. g. June 29, 2003, September 13, 2012, etc.) will the pyroclastic flows resupply these areas with sediments. Erosion in those cases is very intense, as it is the generation of lahars. Laharic deposition in these reaches is minimal, being erosion the predominant effect of lahars. The areas drained by these channel morphologies can be $>10 \mathrm{~km}^{2}$. The channels never transition into other morphologies from the idealized sequence proposed by Montgomery and Buffington (1997), e. g. plane-bed, poole-riffle, or dune-ripple, because before that happens the Barranca streams flow into larger fluvial streams.

The association of lahars with local rainfall is evident, but the details of that relationship are complex and subtle. Daily rainfall records kept by the INSIVUMEH observatories go back to 2001, and allow us to explore some basic relationships between these two phenomena. The INSIVUMEH observatories also keep a record of lahars that includes a qualitative description of their size and intensity, as "pequeño" (small), "moderado" (moderate) and "fuerte" (strong). Based on such reports and assuming a reasonable range of volumes as typical for each class size given in the INSIVUMEH category, we can estimate the cumulative volume transported by lahars at particular drainages.

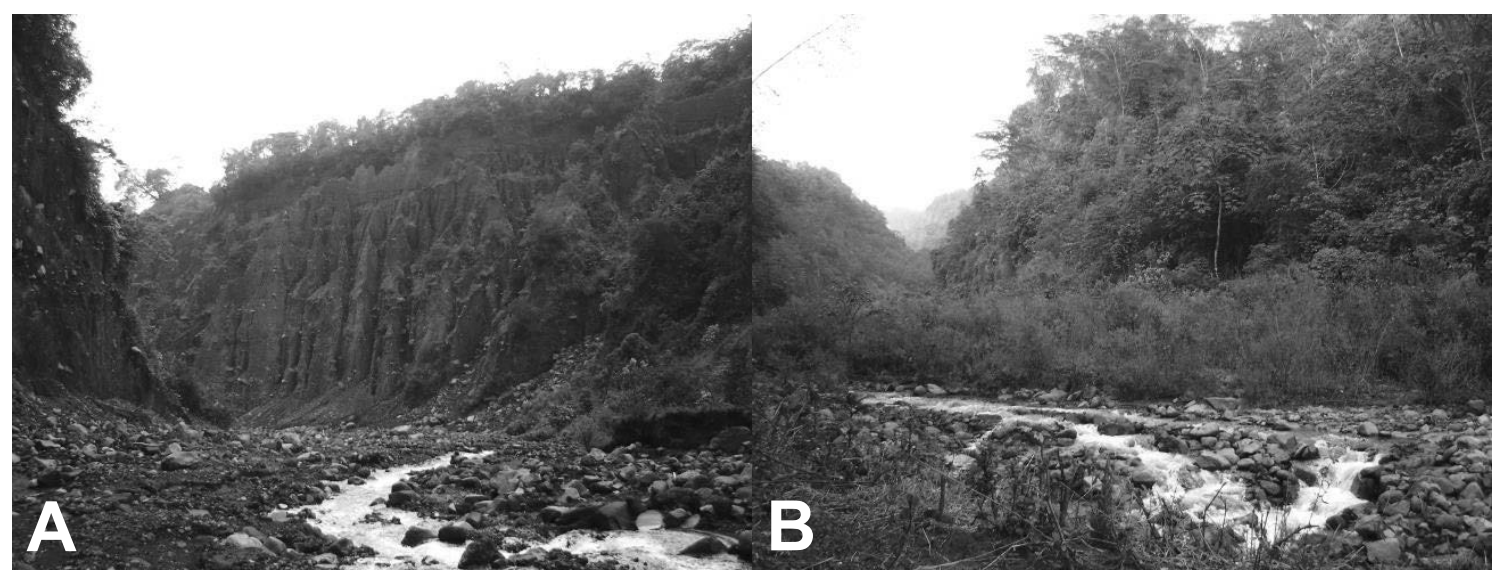

Figure 2.30. A Cascade channel-reach morphology, and B, step-pool channel morphology at the medial segments of Barranca Taniluya. 
Figure 2.31, shows a graph of such estimation, together with the local rain data for the Barranca Seca (rain data are from the OVFUEGO I observatory). The gray area represents the cumulative volume of lahars, and is shown with a large range of uncertainty, given the rather loose association between the INSIVUMEH lahar classes and the possible volumes that can be assigned to them. It can be seen from the figure that lahars activity increases clearly after eruptions, but of course only if there is also enough rainfall to generate the lahars. If the volume estimations are correct, the 2003 laharic season may have removed as much as 2 to $3 \times 10^{6} \mathrm{~m}^{3}$ of mainly pyroclastic material from the upper slopes of the Fuego cone. As will be seen at the end of this chapter, that volume is a significant fraction of the pyroclastic material deposited by pyroclastic flows on Fuego's slope during that year. In reality however, the material removed by lahars is not the same as the material deposited by the pyroclastic flows, as will be discussed later in this section.

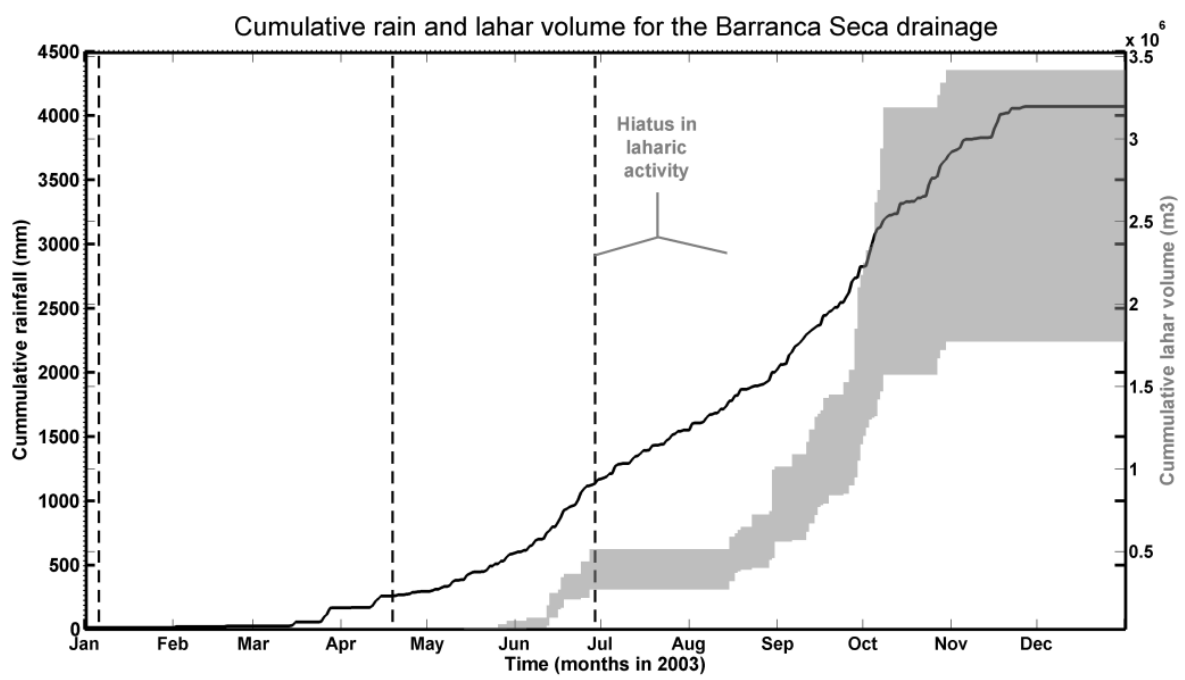

Figure 2.31. Cumulative rainfall and lahar flow volume transit through Barranca Seca, as observed at OVFUEGO II observatory in Aldea Sangre de Cristo ( $9 \mathrm{~km}$ to the west of the vent). Rainfall data are from OVFUEGO I observatory in Aldea Panimache I $(\sim 7.5 \mathrm{~km}$ from the vent and $\sim 4.5$ from OVFUEGO II). Notice the hiatus in laharic activity immediately after the June 29 pyroclastic flow emplacement, until August 14, despite $\sim 600 \mathrm{~mm}$ of rainfall recorded at OVFUEGO I.

The initiation process of lahars has been extensively described in the literature. Rain triggered lahars can be generated by slope failure mechanisms (e. g. Iverson et al. 1997, Iverson 2000), by erosion of tephra through surface runoff, possibly enhanced by reduced infiltration due to the tephra (e. g. Collins and Dunne, 1986; Manville et al. 2000; Major and Yamakoshi, 2005; Nemeth and Cronin, 2007), or by direct erosion of pyroclastic flow deposits (e. g. Lavigne and Thouret, 
2002; van Westen and Daag, 2005). In the Fuego case the main source of material for the generation of lahars are also pyroclastic flows, but rather than being eroded by distributed surface runoff, the main erosive factor in the Fuego case is the stream flow on channels established in such deposits. The case of the Barranca Seca lahars and channel erosion previously discussed illustrates this mechanism. The reason for this erosive power is the combination of a relatively large upstream drainage area, between 2.5 and $6 \mathrm{~km}^{2}$ for the Barranca Seca channel over the main pyroclastic flow deposit from June 29,2003 , and a relatively high channel slope $\left(\sim 10^{\circ}\right.$ on average, and $>20^{\circ}$ in the steeper segments of the channel).

At Barranca Seca, before the emplacement of the June 29, 2003 pyroclastic flow the mean channel slope for the segment between the confluence with the Barranca Santa Teresa (point A in figure 2.32) and the upper avulsion bifurcation point (point $C$ in figure 2.32) was $\sim 9^{\circ}$. After the pyroclastic flow had been emplaced the mean channel slope between the confluence with Barranca Santa Teresa and the lower avulsion bifurcation point (point B in figure 2.32) was $12^{\circ}$, while the slope between the upper and lower avulsion bifurcation points became $7^{\circ}$. This seems like a rather moderate slope increase, but at the flow front and at many locations along the new deposit the slopes were much higher $\left(>20^{\circ}\right)$.

The available material, non-indurated pyroclastic flow deposits, is easily erodible and constitutes a virtually endless source of material, as the supply is not limited to a specific pyroclastic flow deposits, but extends to deposit sequences of tens of older pyroclastic flows. In the case of Barranca Seca in 2003 the pyroclastic flow deposition caused a channel avulsion and the subsequent shifting of the (new) channel location, the new channel cut by erosion was incised into pyroclastic deposit that were in part deposited by the 2003 eruptions, in those areas where the new channel coincides with the pre-2003 eruptions channel, but the channel was incised into older pyroclastic flow material (mainly from eruptions that occurred in the 1970's). 


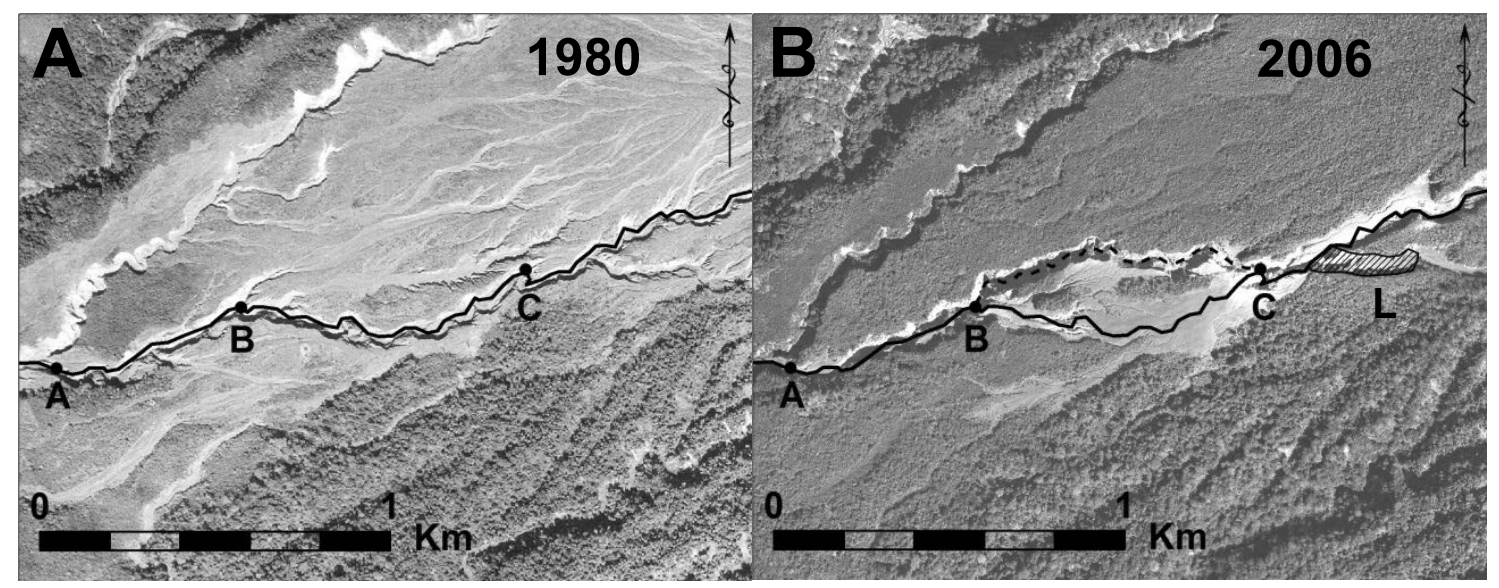

Figure 2.32. Map of the avulsed channel and corresponding changes. A The 1980 aerial photograph shows the conditions of the channel as it was before the deposition of the June 29, 2003 pyroclastic flow. Points A, B, and C correspond to the confluence of Barranca Seca with Rio de la Playa, the lower (avulsion) bifurcation and the upper bifurcation points, respectively. The continuous black line shows the pre-2003 Barranca Thalweg. B Same as in A but on the 2006 aerial orthophoto, and including the post-2003 Barranca Thalweg as a dashed black line.

During fieldwork on the pyroclastic flow deposits it was common to observe the erosion of the pyroclastic material happening in real time by rainwater. On steep slopes (e. g. talus cones) rainwater would collect in channels and once the water film exceeded a few centimeters, the sand and finer sized material in the pyroclastic flow deposit is easily incorporated in the flow. If the sediment load increased above a certain value the mixture seemed to behave like a granular flow, forming channel and levee structures, and leaving deposits with lobate morphology. Figure 2.33, shows small scale examples of such flows which happen during a short but intense rain event. 

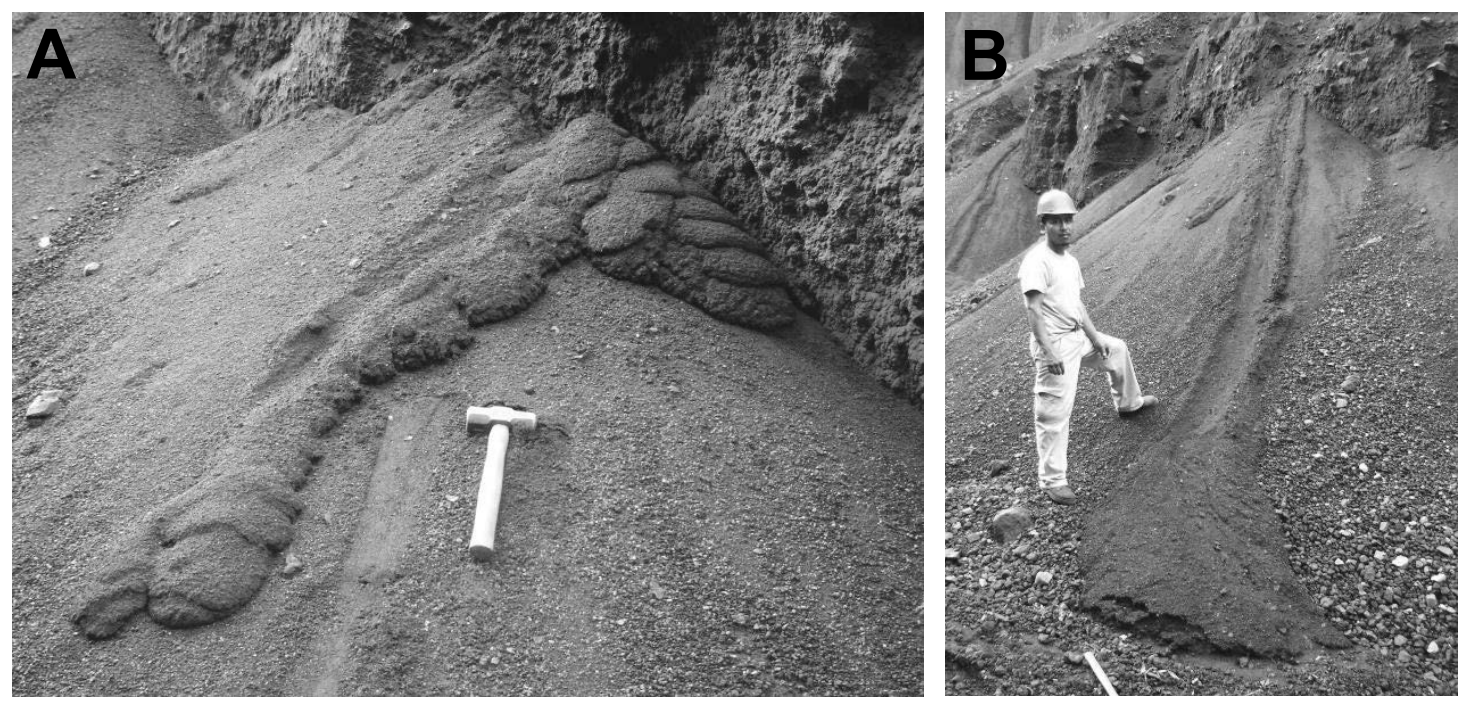

Figure 2.33. Small scale examples of rainwater erosion and the formation of small lahar-like flows on the upper reaches of the Barranca Seca channel. A Series of lobate deposits formed by high sediment load flows on the steep slope of a talus cone. B Small channel with levees formed by a similar flow on a talus cone.

Based on the concept of stream power (Bagnold, 1960, 1966, and 1977) and adapting it to our DEM to obtain a stream power index by multiplying the tributary area by the local channel slope, both derived from the DEM (Wilson and Gallant, 2000), we can explore how water discharge (through tributary area as a proxy) and local slope may influence the erosion of the pyroclastic flow deposit, leading to the formation of lahars. Figure 2.34 shows the stream power index values along the channel of Barranca Seca. Unfortunately the calculation of local channel slope from the DEM seems to be affected by artifacts, probably inherited from the process of interpolating the DEM from an elevation contour dataset. Despite this problem it seems that the stream power reaches a maximum value between 3.5 and $6 \mathrm{~km}$ from the vent, corresponding to the area where the pyroclastic flow was emplaced, and supporting the idea that stream flow is the critical erosion factor involved in the formation of lahars. 

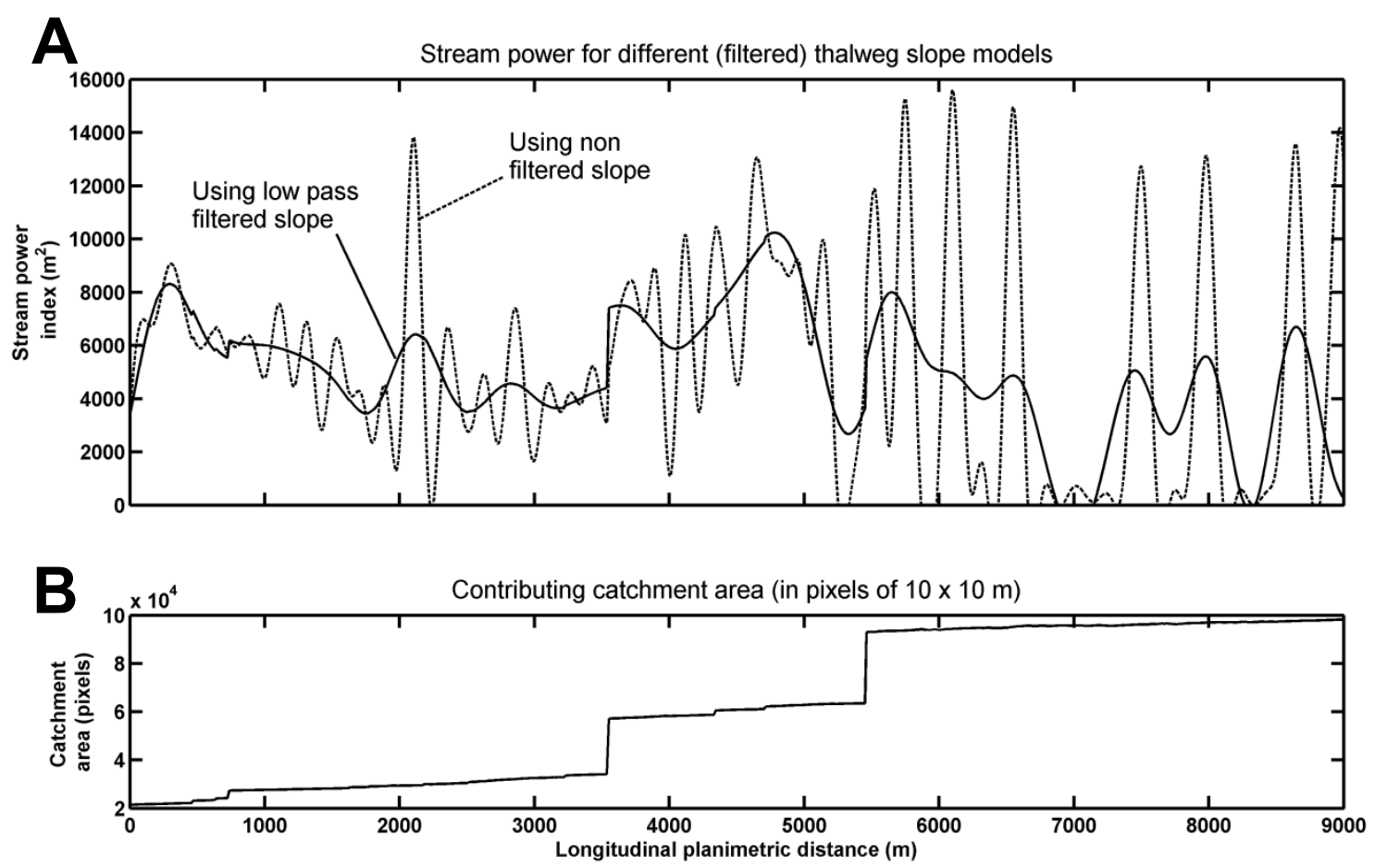

Figure 2.34. A Stream power index calculated from a10 m pixel DEM for the Barranca Seca channel. Large oscillations of the calculated slope channel hinder a good estimation of the stream power index, but using a low pass filtered version we obtain values that suggest a maximum erosive power at the location of the June 29, 2003 pyroclastic flow deposit. See the text for more details. B. Contributing catchment area. This factor of the stream power index is highly discontinuous at points where affluent join the stream, but the impact in the stream power index is small compared with the variation introduced by the slope.

\subsection{Lahar activity following extreme rainfall events}

Rainfall in the Fuego volcano area follows a seasonal pattern, with a dry season lasting from November through May and a rainy season extending from June to October. The total yearly rainfall recorded at the OVFUEGO I (in Aldea Panimache I) observatory is usually between 4000 and $6000 \mathrm{~mm}$. Guatemala is also frequently affected by tropical storms and hurricanes, which deliver a significant part of the total yearly rainfall. Although the less intense effects of such storms are common during the rainy season and most of the times have only small, localized and ephemeral impacts, some storms can cause extremely intense and extended rainfall. Such extreme rainfall events can cause widespread landslides, mudflows and flooding, affecting large parts of the country. In volcanic areas these events also produce landslides and lahars, overlapping with lahars that are generated during "normal rainfall". 
Two rainfall events between 1999 and 2013 produced enough rain to be considered extreme, causing extensive damage in Guatemala and neighboring countries. Between October 1 and 5 , 2005, hurricane Stan produced extreme rainfall in Guatemala, southern Mexico and El Salvador. The rain record at OVFUEGO I (Aldea Panimache I) shows a maximum of $223 \mathrm{~mm}$ on October $5^{\text {th }}$, followed on the $6^{\text {th }}$ by $187 \mathrm{~mm}$, while the OVFUEGO II record shows a maximum daily rainfall of $408 \mathrm{~mm}$ on October $6^{\text {th }}$ and a daily amount of $276 \mathrm{~mm}$ for the $5^{\text {th }}$. This discrepancy, considering the close proximity of the stations $(<5 \mathrm{~km})$ is significant and raises the possibility that the rain data could be wrong, but in any case the values are very high compared with an average daily rainfall value between 10 and $15 \mathrm{~mm}$, and reflects the extreme nature of the event. Similarly, between May $29^{\text {th }}$ and June $5^{\text {th }}$ of 2010 , tropical storm Agatha produced extensive and intense rainfall in Guatemala, including the Fuego volcano region. A maximum daily rainfall of $179 \mathrm{~mm}$ was recorded by the OVFUEGO I (Aldea Panimache I) observatory on May $30^{\text {th }}$. Figure 2.35 shows the cumulative rainfall for both Stan and Agatha as recorded by the Fuego observatories.

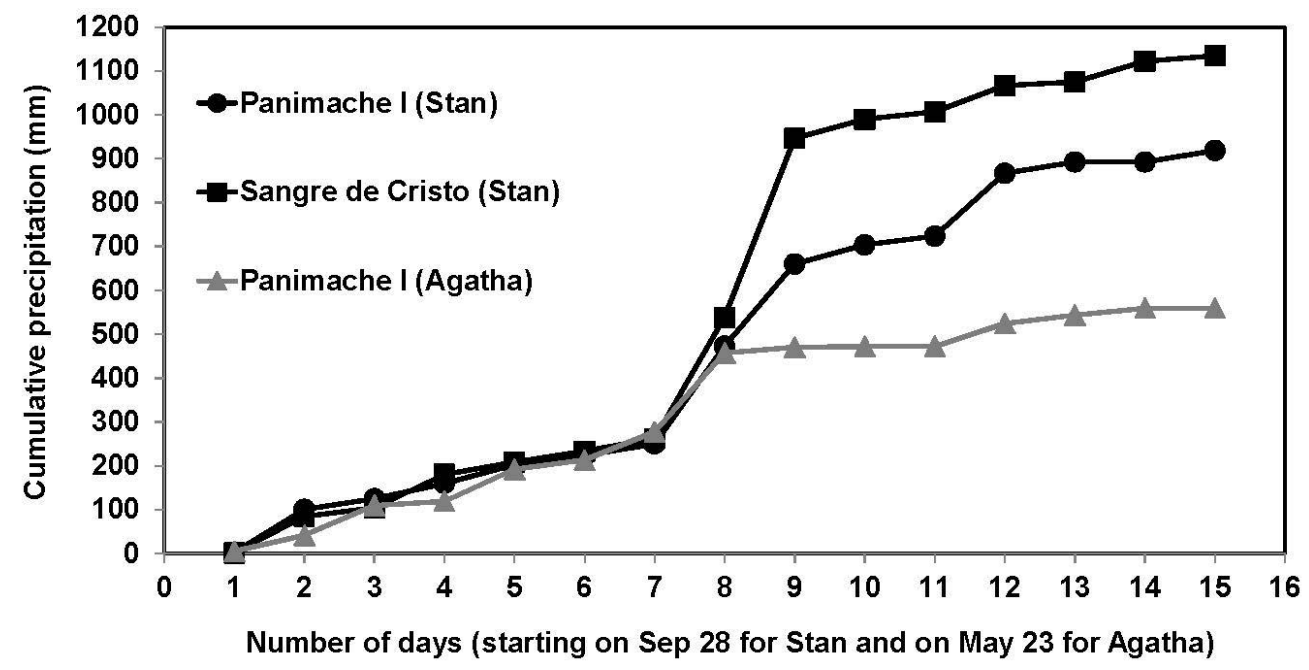

Figure 2.35. Cumulative rainfall during storms Stan and Agatha, as recorded by the INSIVUMEH Fuego observatories.

Extreme rainfall event lahars are usually much more water rich than normal rain lahars, and although individual waves can be recognized, the laharic flow during the most intense phase of the storm becomes a quasi-continuum flow, over periods of many hours; this process results in a highly erosive flow in the upper parts of the drainage system. Dilution of the lahars by mixing with water rich streams is also much stronger as all the flows reach large streams very quickly.

The extreme rain events produced a large number of lahar, not only in the usually active Barrancas, but also in Barrancas that otherwise have no activity. The intense rainfall and laharic 
activity was associated with both erosion and deposition of large volumes of volcanic material. Extreme rainfall event lahars are usually much more water rich than normal rain lahars, and although individual waves can be recognized, the laharic flow during the most intense phase of the storm becomes a quasi-continuum flow, over periods of many hours; this process results in a highly erosive flow in the upper parts of the drainage system. Dilution of the lahars by mixing with water downstream is also much stronger, as all the flows quickly reach streams with high water flow. Erosion was predominant on higher ( $>500$ masl) and steeper $\left(>10^{\circ}\right)$ slopes, whereas deposition happened on the lower slopes. Erosion of this kind can deeply cut the channel at the crossing of dirt roads, blocking access to some of the communities around the volcano.

Terraces related to extreme events are typical in the upper reaches of the Barranca channels. Cut terraces, reaching up to $\sim 8 \mathrm{~m}$ in height, are abundant in channels with a clastic bed, and expose the pre-event channel fill. Fill terraces are less common or at least less evident, as the deposition in the lower reaches leads to extensive alluviation but poor vertical exposure of the deposits. Even for cut terraces, there is sometimes a thin veneer of fresh deposit on top of the terrace (see figure $2.37 \mathrm{~A}$ ), probably reflecting the early, non-erosive stages of the lahar flow, but as the flow continues fueled by the extreme rainfall, the process on those sites becomes predominantly erosive. Multiple extreme rainfall events happening without long reposes produce sets of nested terraces, which depending on the continuation of erosive or aggrading activity may or not be expanded, deepened or filled. Figure 2.36, shows a series of terraces formed during storms Stan and Agatha, in Barranca Las Lajas and Barranca El Jute. The nested terraces produced by Stan and Agatha can be seen in upper reaches of the Barrancas around Fuego, and imply minimum erosion incision depths of $\sim 8 \mathrm{~m}$ on Las Lajas and El Jute during Agatha, and $\sim 4 \mathrm{~m}$ at those same locations during Stan. The incision values for Stan are poor underestimates, as the filling by alluvia and laharic deposition in the channel during the following 5 years has decreased the relative height of these terraces. 

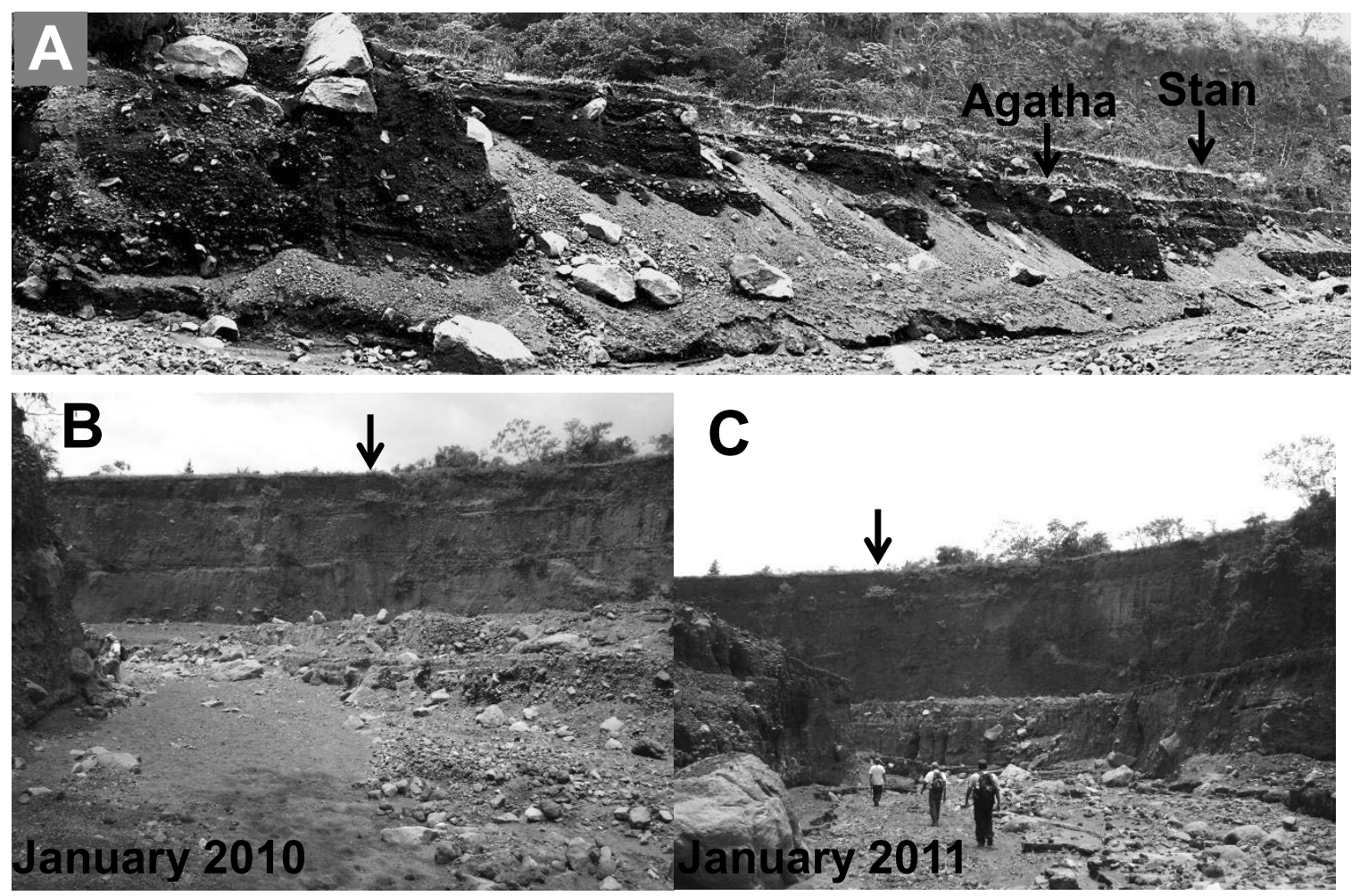

Figure 2.36. A Nested terraces cut by storms Stan (in 2005) and Agatha (in 2010) into the channel bed of the Las Lajas Barranca. The height of the Agatha terrace is $\sim 5 \mathrm{~m}$, and the height of the Stan terrace (above the Agatha terrace) is $\sim 2 \mathrm{~m}$, for a combined incision of $\sim 7 \mathrm{~m}$ by both events at the location of the picture. Notice the stratified nature of the exposed channel bed deposit (laharic-alluvial and fluvial). $\mathbf{B}$ and $\mathbf{C}$ show the same location on the Barranca El Jute in January 2010 and January 2011. The vertical downward arrow shows the same point in both pictures. Notice the $\sim 5 \mathrm{~m}$ terrace exposed in January 2011 and which didn't exist in January 2010.

The deposits of the lahars generated by extreme rain events are volumetrically much larger than those associated to normal rainfall, but happen on the lower reaches of the drainage system, coinciding with less confined and lower relief channels. Texturally some deposits, especially the most proximal, are similar to those of lahars generated by "normal rain", and therefore can also be similar to pyroclastic flow deposits, as discussed previously, however most of the deposits, which correspond probably to more water rich, hyperconcentrated types of flows, have a distinctively different texture and appearance at the outcrop scale. Many deposits exhibit a matrix of sand in which larger blocks are embedded, but in general the abundance of large blocks is less than in some of the "normal rain" lahars. Some deposits also exhibit a grain-supported structure of cobble to pebble size clasts (see figure $2.37 \mathrm{~B}$ ). Some deposits are highly heterolithologic, especially downstream from the confluence with streams draining other older volcanic, or even non-volcanic areas. Such deposits have a much more clay rich appearance, and often include fragments of clay-rich soils that are usually not seen within the Fuego stratigraphy. 


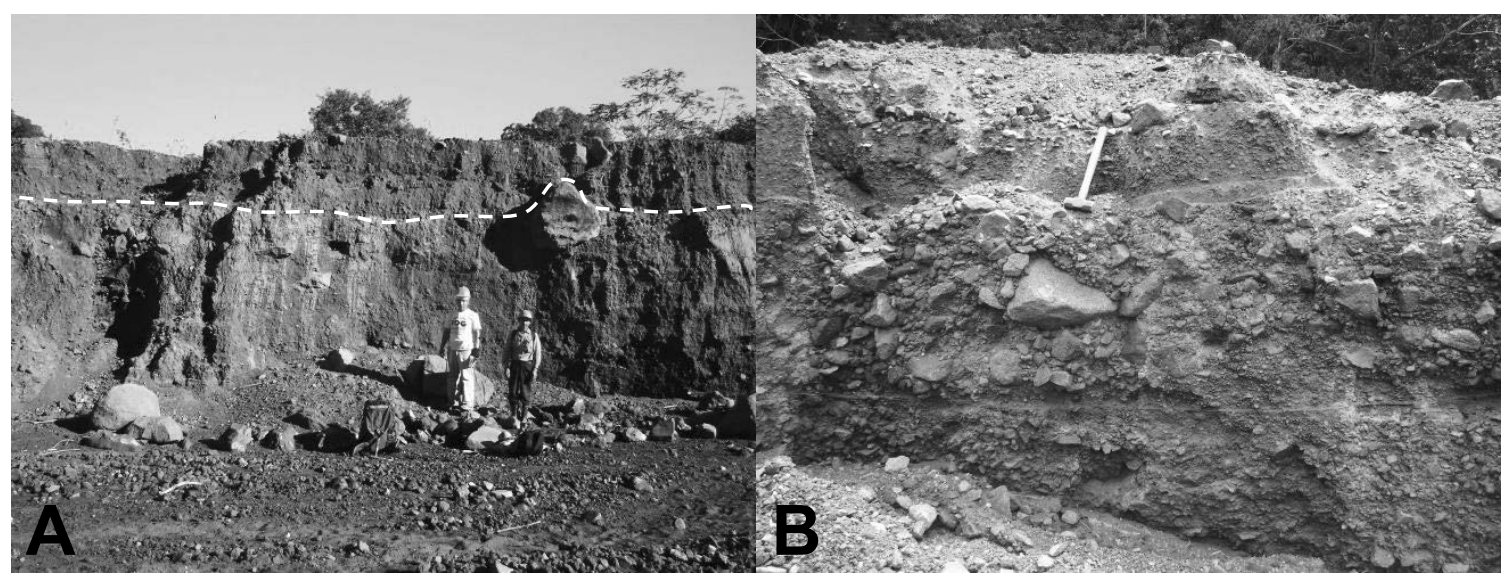

Figure 2.37. Extreme rain event lahar deposits on Barranca Seca (A) and Barranca El jute (B). The deposit on Barranca Seca is a relatively thin $(\sim 80 \mathrm{~cm})$ veneer atop of the terrace (separated by the white dashed line in $\mathbf{A}$ ) and is very similar to the (laharic?) underlying deposits exposed in the terrace wall by the erosive power of the lahar. The deposit sequence on El Jute shows a lower matrix poor (clast-supported) deposit dominated by gravel to cobble size clasts, topped by a matrix rich and finer graded lahar deposit.

Using the high resolution imagery it is possible to map the areas of erosion and deposition associated to the extreme rainfall events. Figure $x x$ shows the comparison of pre and post event distribution of lahar deposit on alluvial plain of the Achiguate river (between 16 to $23 \mathrm{~km}$ from the vent), which is fed by the Las Lajas and El Jute Barrancas. From a single branch (west) stream in 2004 (pre-Stan), the Achiguate alluvial plain was invaded by a new (east) branch during Stan, remaining a two branch drainage during 2006. During Agatha the areal changes were much larger, as both branches expanded laterally, covering with sediments the adjacent terrain. This examples illustrates how the lower reaches of the drainage system, are very sensitive to laharic sedimentation. These changes, although significant in the context of the storms considered, are much smaller than the changes seen during the 1970's associated to larger eruptions and also extreme rainfall events. 

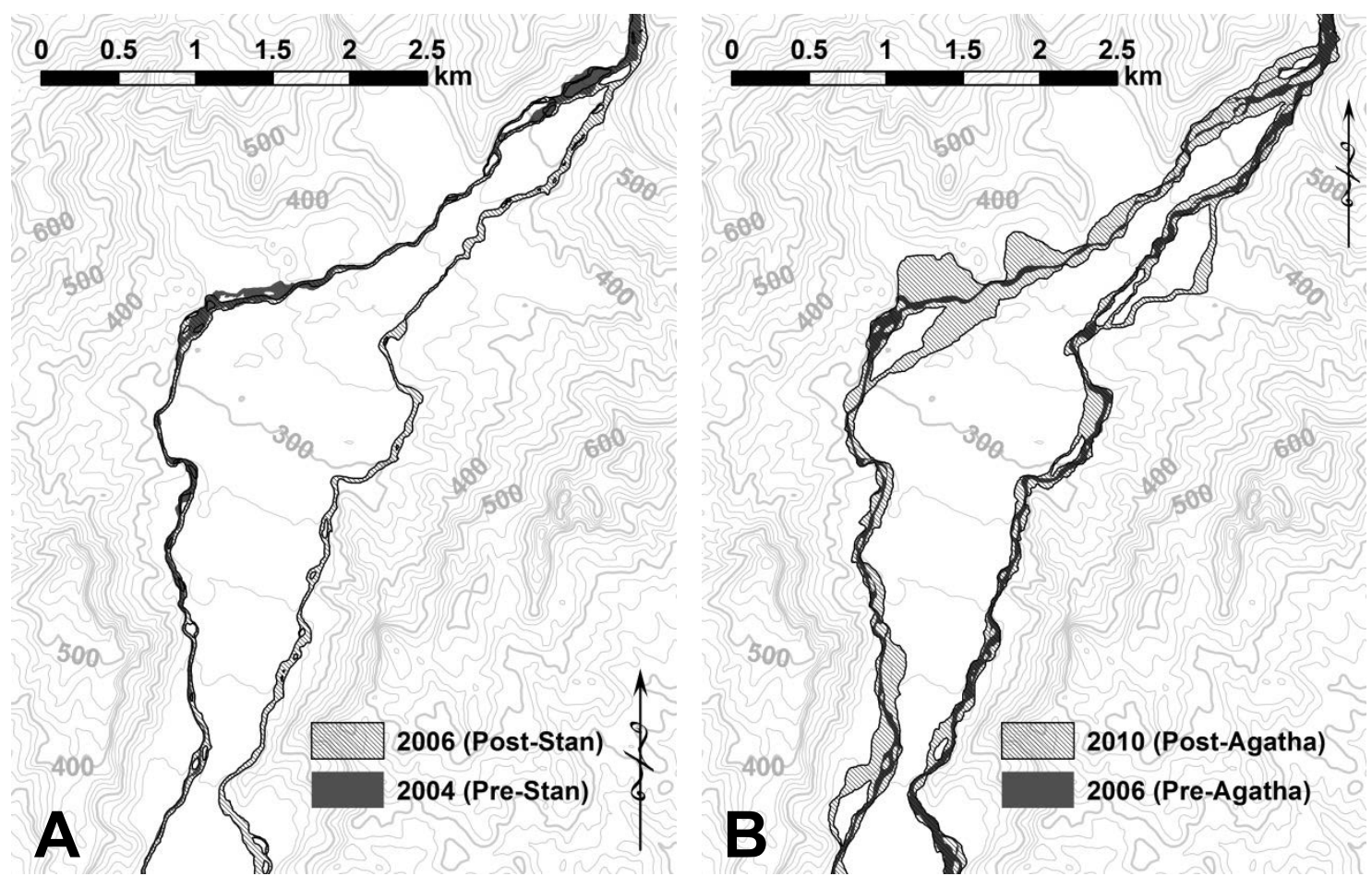

Figure 2.38. Maps of areas affected by laharic deposition in the Achiguate alluvial plain. Comparisons between pre and post Stan (A) and pre and post Agatha (B) are show.

\subsection{Summary of volcanic activity from 1999 to 2013: inventory of events and deposits}

Based on the various source of documentation, fieldwork and remote sensing dataset described in appendix 2.1, mapping of all recognizable deposits emplaced from May 1999 to June of 2013 was done, resulting in 117 different units. The deposits were mapped in ArcGis and store in ESRI shapefile format. These files are included in appendix 2.6. The mapped deposits from 1999 to 2013 are shown summarily in figure 2.39. Perhaps the most obvious feature in the map on figure 2.39 is that all the deposition was either close to the vent $(<2 \mathrm{~km})$ or on one of the major Barranca drainages.

This feature may just be due to the scale of the activity that happened during the observed period of time, as larger flows (e. g. pyroclastic flows and lahars) could extend far beyond the existing channels; similarly the relatively thin $(<1 \mathrm{~cm})$ airfall tephra deposits are not included in the map, but larger eruptions, producing thick $(>10 \mathrm{~cm}$ ) tephra layers would cover much more extensive areas. A further discussion about the scale issue will be included in the next chapter. 


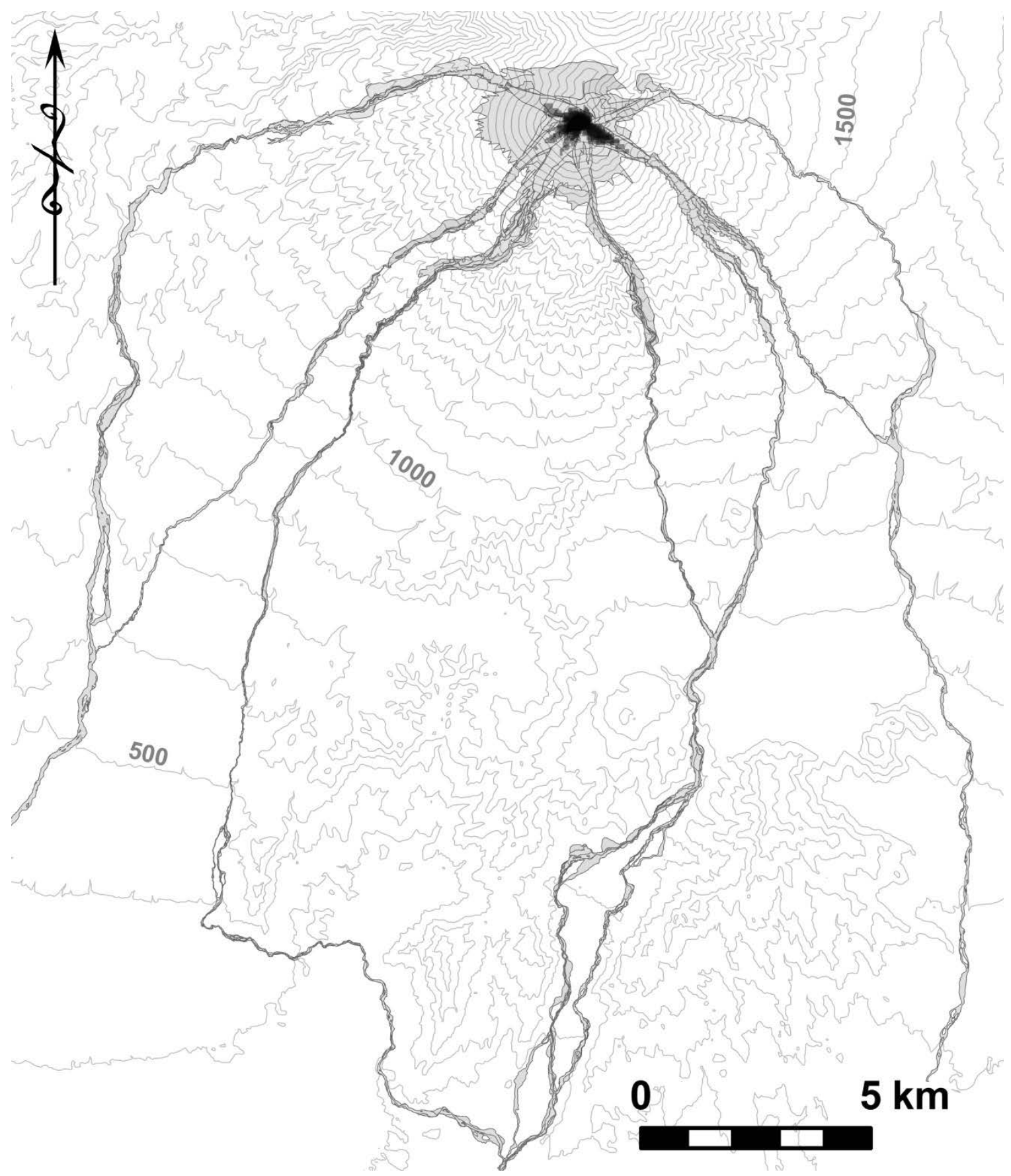

Figure 2.39. The figure shows all the mapped deposits related to volcanic and laharic activity for the 1999 to 2013 period. Notice the strong channel control on (mainly flow) deposits. The dark area near the summit results from the high number of lava flows mapped near the vent.

The geometric characteristics of the deposits can be estimated based on such mapping. Table 2.1 lists the dimensions of the deposits from the largest eruptions in the eruptive episode. 
Table 2.1. Dimensions of deposits erupted during the May 1999 to June 2013 eruptive episode.

\begin{tabular}{|c|c|c|c|c|c|c|c|c|c|c|}
\hline \multirow[t]{2}{*}{ Date } & \multirow{2}{*}{$\begin{array}{l}\text { *Deposit } \\
\text { type }\end{array}$} & \multirow{2}{*}{$\begin{array}{c}\text { Area } \\
\left(\times 10^{6} \mathrm{~m}^{2}\right) \\
\end{array}$} & \multicolumn{3}{|c|}{ Mean thickness (m) } & \multicolumn{3}{|c|}{ Volume $\left(\times 10^{6} \mathrm{~m}^{3}\right)$} & \multirow{2}{*}{$\begin{array}{c}\text { Length } \\
(\mathbf{k m}) \\
\end{array}$} & \multirow[t]{2}{*}{${ }^{* *} A / V^{2 / 3}$} \\
\hline & & & Min & Best & $\operatorname{Max}$ & Min & Best & Max & & \\
\hline $5 / 21 / 1999$ & P. flow & 1.69 & 2.0 & 15.0 & 25.0 & 3.4 & 25.4 & 42.3 & 10.2 & 20 \\
\hline $5 / 21 / 1999$ & P. surge & 0.65 & 0.1 & 0.2 & 0.5 & 0.0 & 0.1 & 0.3 & 5.9 & 253 \\
\hline $1 / 8 / 2003$ & P. flow & 0.53 & 2.0 & 10.0 & 20.0 & 1.1 & 5.3 & 10.6 & 5.6 & 17 \\
\hline $6 / 29 / 2003$ & P. flow & 0.81 & 2.0 & 15.0 & 25.0 & 1.6 & 12.2 & 20.3 & 8.0 & 15 \\
\hline $6 / 29 / 2003$ & P. surge & 1.0 & 0.1 & 0.2 & 0.5 & 0.1 & 0.2 & 0.5 & 5.8 & 292 \\
\hline $1 / 9 / 2004$ & Lava flow & 0.24 & 1.0 & 5.0 & 15.0 & 0.2 & 1.2 & 3.6 & 3.9 & 21 \\
\hline $7 / 17 / 2005$ & P. flow & 0.36 & 2.0 & 10.0 & 20.0 & 0.7 & 3.6 & 7.2 & 5.2 & 15 \\
\hline $\begin{array}{l}7 / 17 / 2005 \\
5 / 5 / 2006\end{array}$ & $\begin{array}{l}\text { P. surge } \\
\text { P. flow }\end{array}$ & $\begin{array}{l}0.29 \\
0.18\end{array}$ & $\begin{array}{l}0.1 \\
2.0\end{array}$ & $\begin{array}{c}0.2 \\
10.0\end{array}$ & $\begin{array}{c}0.5 \\
20.0\end{array}$ & $\begin{array}{l}0.0 \\
0.4\end{array}$ & $\begin{array}{l}0.1 \\
1.8\end{array}$ & $\begin{array}{l}0.1 \\
3.6\end{array}$ & $\begin{array}{l}5.4 \\
3.2\end{array}$ & $\begin{array}{c}194 \\
12\end{array}$ \\
\hline 8/8/2007 & P. flow & 0.31 & 2.0 & 10.0 & 20.0 & 0.6 & 3.1 & 6.2 & 4.3 & 15 \\
\hline $12 / 15 / 2007$ & Lava flow & 0.47 & 2.0 & 10.0 & 20.0 & 0.9 & 4.7 & 9.4 & 5.3 & 17 \\
\hline $9 / 13 / 2012$ & P. flow & 1.75 & 2.0 & 15.0 & 25.0 & 3.5 & 26.3 & 43.8 & 8.2 & 20 \\
\hline $9 / 13 / 2012$ & P. surge & 1.74 & 0.1 & 0.2 & 0.5 & 0.1 & 0.3 & 0.9 & 6.6 & 352 \\
\hline
\end{tabular}

${ }^{*} \mathrm{P}$. flow $=$ pyroclastic flow, $\mathrm{P}$. surge $=$ Ash cloud surge.

${ }^{* *}$ The parameter $\mathrm{A} / \mathrm{V}^{2 / 3}$ describes the mobility of the flow (see text for more details)

The areas covered by the volcanic deposits are close to $2 \mathrm{~km}^{2}$, but the maximum distance reached by the deposits can exceed $10 \mathrm{~km}$, reflecting the very elongated shape of the deposits in plan view. Although the areas are reasonably well constrained, the deposit thicknesses are poorly know in most cases, especially for pyroclastic flow deposits that tend to have a highly variable thickness due to the rugged pre-emplacement topography. Only after erosion exposes the full vertical extent of the deposits at many places can a decent estimation of the thickness be made, but excessive erosion can also be problematic. Perhaps the best constrained thickness estimate was done for the June 29, 2003 pyroclastic flow deposit, for which 20 thickness measurements (using a laser range finder) were done over a length of $4.5 \mathrm{~km}$ over the main (thickest) part of deposit, where erosion has cut through the deposit, giving a mean thickness of $17 \mathrm{~m}$. Such thickness is still a minimum estimate because in many places the erosion had not completely cut through the deposit, allowing only a minimum thickness to be estimated. After considering the length of each segment, a weighted average of $15 \mathrm{~m}$ is obtained. The measured thickness of the June 29, 2003 deposit varies between $2 \mathrm{~m}$ on the distal overbank facies, to $35 \mathrm{~m}$ in the channel filling facies. Based on such field observations minimum, maximum, and best estimates values for the average thickness can be guessed, and used to estimate the volumes of the deposits. 
The most voluminous deposits produced during the eruptive episode correspond to pyroclastic flow deposits, reaching values on the order of $10^{7} \mathrm{~m}^{3}$. As expected the lowest values of volume correspond to the thin ash cloud surge deposits. The two lava flow deposits included in the list, which are probably the largest lava flows produced during the 1999 to 2013 episode, are of similar size than pyroclastic flow deposit volumes. The eruptions that produced these deposits typically lasted between 24 and 48 hours, and in most cases the bulk of the deposits were emplaced over a much shorter period of time, implying minimum eruption rates, averaged over the entire duration of the eruption, on the order of 10 to $300 \mathrm{~m}^{3} / \mathrm{s}$, and instantaneous eruption rates that could be as large as $10^{4} \mathrm{~m}^{3} / \mathrm{s}$ during the most intense phases of the eruptions, e. $\mathrm{g}$. considering that the $2.7 \times 10^{7} \mathrm{~m}^{3}$ of pyroclastic flow material erupted over less than 1 hour during the September 13, 2013 eruption gives a minimum eruption rate of $7.5 \times 10^{3} \mathrm{~m}^{3} / \mathrm{s}$.

The values of mobility parameter $A / V^{2 / 3}$ (Calder et al. 1999) for the pyroclastic flows are very low $(12-20)$, and fall below what would be typically expected for column collapse $(\sim 150)$ or even dome collapse ( 37) pyroclastic flows (Vallance et al. 2010). As discussed in section 2.8, this is probably due to the highly confining nature of the drainages on which the flows propagate, and neglects the energy that potentially is dissipated through lateral channel wall friction, i. e. the planimetric area is not representative of the total area over which the flow loses energy by interacting, mainly through friction, with the boundaries. But perhaps more important is the fact that the total volume estimates for the mapped deposits is not emplaces in a single flow pulse, but rather over several flow pulses, and as such, it would be more appropriate to apply the $A / \mathrm{V}^{2 / 3}$ parameter to the individual pulses. Assuming that between 5 and 20 pulses could be involved in the emplacement of the total pyroclastic flow deposit during one eruption (up to 6 individual pulses have been observed in the stratigraphy of the June 29, 2003 pyroclastic flow deposit), then the volume would be decreased by a similar factor while the area (at least for the furthers reaching pulses) would not, implying that the values for the $A / V^{2 / 3}$ parameter could be between 50 and 400 , which is closer to the values observed at other eruptions (e. g. Vallance et al. 2010)

Lahar volumes are not included in Table 2.1, as mapping and isolating the volume of their deposit is much harder in the Fuego case that for the other volcanic products. The areas of deposition could be compared in such cases, but this will be left for the next chapter, as it is more significant to compare those areas with areas inundated by lahar deposits during previous (pre-1999) eruptions and extreme rainfall events. The list of deposits in table 2.1 corresponds to only a small fraction of the deposits produced by "above the background" eruptions, being the only ones that could be mapped in the field and using remote sensing data. Other large eruptions also generated significant deposits, however they most likely fall in the lower end of the volume values 
listed in table 2.1, otherwise they would have been much more conspicuous and wouldn't have escaped the mapping efforts. We could assume a conservative value of $10^{6} \mathrm{~m}^{3}$ for deposits related to these eruption (not considering far-flung airborne tephra), and this figure will be used in estimating cumulative volumes through time, later in this section.

From the available documentation provided by INSIVUMEH and CONRED, and combining it with remote sensing data, as described in appendix 2.1, a list of the "above background" explosive eruptions has been compiled. Defining a threshold of cut-off criterion to separate background activity from "above background" eruptions is subjective, nevertheless, a list of eruptions is presented (table 2.2), that includes all the events that produce abnormally high or intense activity, and resulted in the generation of large volcanic deposits, like those discussed in this chapter. Many of those eruptions also triggered a crisis responses from INSIVUMEH and CONRED, leading in some cases to evacuations of the nearby communities.

The table 2.2 lists 26 eruptions over a 14 year period, since May of 1999, i. e. an average of and eruption every 0.54 years. The occurrence of eruptions is actually non-periodic in time, with repose periods going from only a few days in August of 2007, to more than four years between December of 2007 and May of 2012. Although virtually all the eruptions produce tephra, there seems to be a tendency for the other products to be dominated either by pyroclastic flows or by lava flows, and most significantly, the dominance of either one of those products alternates between eruptions. This alternation could be seen as a switching between predominantly effusive and explosive activity styles, but in practice both lava flow and pyroclastic flow eruptions are often accompanied by very similar eruptive activity from the central vent, e. g. lava fountaining and the formation of $a \sim 3-4 \mathrm{~km}$ high (above the vent) eruptive column, implying that in both cases the activity at the vent is predominantly explosive, but the end products can be very different, depending on other factors. Magma rheology and gas content may play a fundamental role in determining the generation of these different types of products, or perhaps the factors controlling the production of pyroclastic flows vs lava are more related to how the magmatic products are deposited near the vent, and how they further behave in a brittle vs. ductile manner. 
Table 2.2. Catalog of "above background" eruptions from 1999 to 2013.

\begin{tabular}{|c|c|c|c|c|c|c|c|}
\hline No. & Start date & End date & 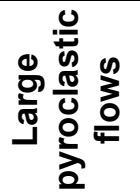 & 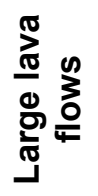 & 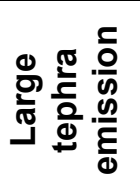 & 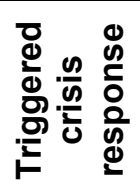 & 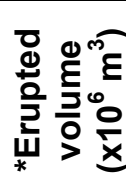 \\
\hline 1 & $5 / 21 / 1999$ & $5 / 21 / 1999$ & $\bar{x}$ & & $x$ & $x$ & 25.5 \\
\hline 2 & $9 / 21 / 2000$ & $9 / 21 / 2000$ & & & $x$ & $x$ & $1 ?$ \\
\hline 3 & 2/9/2002 & $2 / 12 / 2002$ & & $x$ & 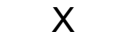 & $x$ & $1 ?$ \\
\hline 4 & $7 / 28 / 2002$ & $7 / 31 / 2002$ & $x$ & & & & $1 ?$ \\
\hline 5 & $1 / 6 / 2003$ & $1 / 9 / 2003$ & $x$ & & $x$ & $x$ & 5.3 \\
\hline 6 & $4 / 19 / 2003$ & $4 / 22 / 2003$ & $x$ & & $x$ & $x$ & $1 ?$ \\
\hline 7 & $6 / 29 / 2003$ & $6 / 30 / 2003$ & $x$ & & $x$ & $x$ & 12.4 \\
\hline 8 & $1 / 9 / 2004$ & $1 / 10 / 2004$ & & $x$ & $x$ & $x$ & 1.2 \\
\hline 9 & $12 / 22 / 2004$ & $12 / 25 / 2004$ & & $x$ & $x$ & $x$ & $1 ?$ \\
\hline 10 & $7 / 16 / 2005$ & $7 / 18 / 2005$ & $x$ & & $x$ & $x$ & 3.7 \\
\hline 11 & $12 / 27 / 2005$ & $12 / 28 / 2005$ & $x$ & $x$ & $x$ & $x$ & $1 ?$ \\
\hline 12 & $5 / 5 / 2006$ & $5 / 8 / 2006$ & $x$ & & $x$ & $x$ & 1.8 \\
\hline 13 & $6 / 26 / 2006$ & $6 / 27 / 2006$ & $x$ & & $x$ & $x$ & $1 ?$ \\
\hline 14 & $3 / 15 / 2007$ & $3 / 17 / 2007$ & & $x$ & $x$ & $x$ & $1 ?$ \\
\hline 15 & $4 / 18 / 2007$ & $4 / 22 / 2007$ & $x$ & & $x$ & $x$ & $1 ?$ \\
\hline 16 & $7 / 1 / 2007$ & $7 / 2 / 2007$ & & $x$ & $x$ & $x$ & $1 ?$ \\
\hline 17 & $8 / 2 / 2007$ & $8 / 2 / 2007$ & $x$ & & $x$ & $x$ & $1 ?$ \\
\hline 18 & 8/7/2007 & 8/9/2007 & $x$ & & $x$ & $x$ & 3.1 \\
\hline 19 & $12 / 15 / 2007$ & $12 / 15 / 2007$ & & $x$ & $x$ & $x$ & 4.7 \\
\hline 20 & $5 / 19 / 2012$ & $5 / 20 / 2012$ & $x$ & $x$ & $x$ & $X$ & $1 ?$ \\
\hline 21 & $6 / 10 / 2012$ & $6 / 11 / 2012$ & & $x$ & $x$ & $x$ & $1 ?$ \\
\hline 22 & $9 / 3 / 2012$ & 9/4/2012 & $x$ & & $x$ & $x$ & $1 ?$ \\
\hline 23 & $9 / 13 / 2012$ & $9 / 13 / 2012$ & $x$ & & $x$ & $x$ & 26.9 \\
\hline 24 & $2 / 17 / 2013$ & $2 / 18 / 2013$ & & $x$ & $X$ & $x$ & $1 ?$ \\
\hline 25 & $3 / 3 / 2013$ & $3 / 4 / 2013$ & & $x$ & $x$ & $x$ & $1 ?$ \\
\hline 26 & $3 / 19 / 2013$ & $3 / 20 / 2013$ & & $x$ & $X$ & $X$ & $1 ?$ \\
\hline
\end{tabular}

*Volumes calculated from deposits (see Table 2.1) when available, otherwise assigned a default value of $1\left(\times 10^{6} \mathrm{~m}^{3}\right)$ followed by a question mark.

Virtually all the eruptions have triggered some sort of crises response by the authorities and the people in the communities around the volcano, including massive evacuations. It is not a surprise that after such a heightened level of activity over 14 years, the population living near to the volcano and the authorities have become aware of the potential for disaster, as will be discussed in a later chapter.

Using the same source of information that were used to compile the tables 2.1 and 2.2 (see appendix 2.1) we can also classify the type of background activity as discussed in this chapter. 
Combining the information on the type of background activity (effusive vs. explosive) at different times, and the timing of "above background" explosive eruptions, we can summarize the activity of Fuego volcano in a single chart (see figure 2.40). Figure 2.40 shows the previously discussed pattern of irregular and non-periodic eruptions through time (black vertical lines), including eruption clustering in time and longer periods without large eruptions. The style of background activity is also highly variable, switching between the two styles (effusive and explosive) over a large range of time scales, from a few days to more than 2 years. Longer, and presumably more stable periods of either explosive or effusive background activity coincide with very few larger than background eruptions, with the exception of the $2012-2013$ period. Larger than background eruptions happen more often during effusive background activity, but several of the largest eruptions happened during periods of explosive background activity, failing to follow the pattern described by Lyons et al. (2009) for the 2005 - 2007 period.

\section{Fuego's eruptive activity (1999 - 2013)}

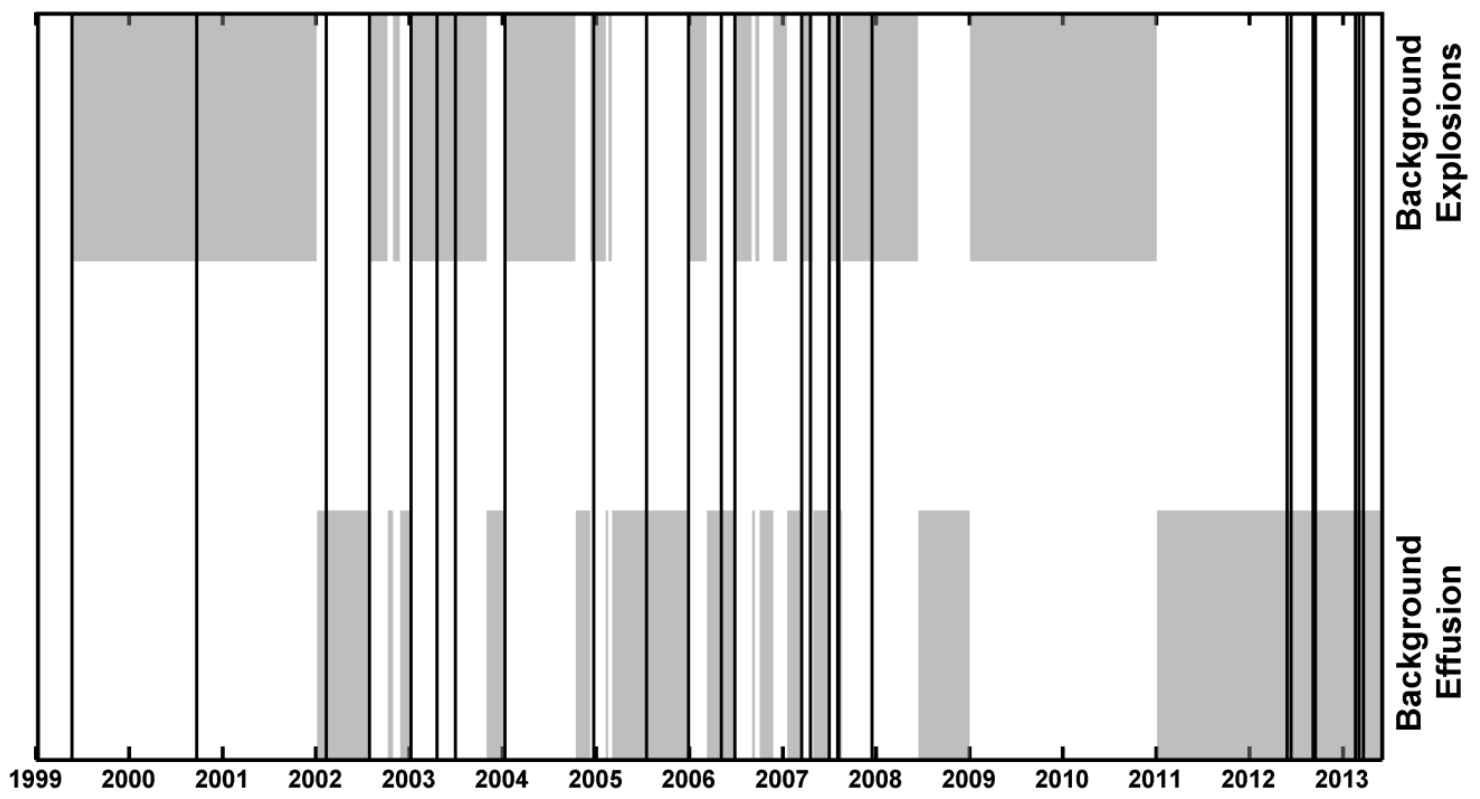

Figure 2.40. Summary of the activity at Fuego volcano from 1999 through 2013. The black vertical lines represent the times of occurrence of "above background" explosive eruptions. Periods of background explosive activity are represented by the gray shaded boxes in the upper part of the plot, whereas the periods of background effusive activity are shown by the gray shaded boxes in the lower part of the plot.

The persistency of the background activity throughout the duration of the current eruptive episode (1999 - 2013) is striking and deserves some more attention. Intermediate resolution satellite imagery shows this pattern clearly (see videos in appendix 2.2), with the exception of a brief period at the beginning of 2001, a hot spot remains active throughout the entire eruptive episode. 
Using the thermal IR band on the Landsat sensor we can track the radiant flux and mean temperature of the vent area through time. Figure 2.41 shows the thermal anomaly intensity at Fuego's vent: choosing a $6 \times 6 \mathrm{~km}$ square centered on the Fuego vent the areas with radiance values 2, 3 and 4 standard deviations the mean were chosen from each image between 1999 and 2013, the resulting maps were stacked and then normalized by the total number of analyzed images, shown in parts $A, B$ and $C$ of figure 2.41 , to give the probability that a given pixel will be 2, 3 and 4 standard deviations above the mean radiance value within the $6 \times 6 \mathrm{~km}$ window. At the 2 standard deviation threshold the non-vegetated upper Fuego flanks are clearly visible, as they consistently appear hotter than the vegetation covered background. However, as we choose higher thresholds ( 3 and 4 standard deviations above the mean radiance) the hotspot on the summit vent becomes clearly isolated from the rest of the image. Part $D$ shows the normalized stacked radiance for all the images from 1999 through 2013, also displaying the thermal anomaly at the vent. 

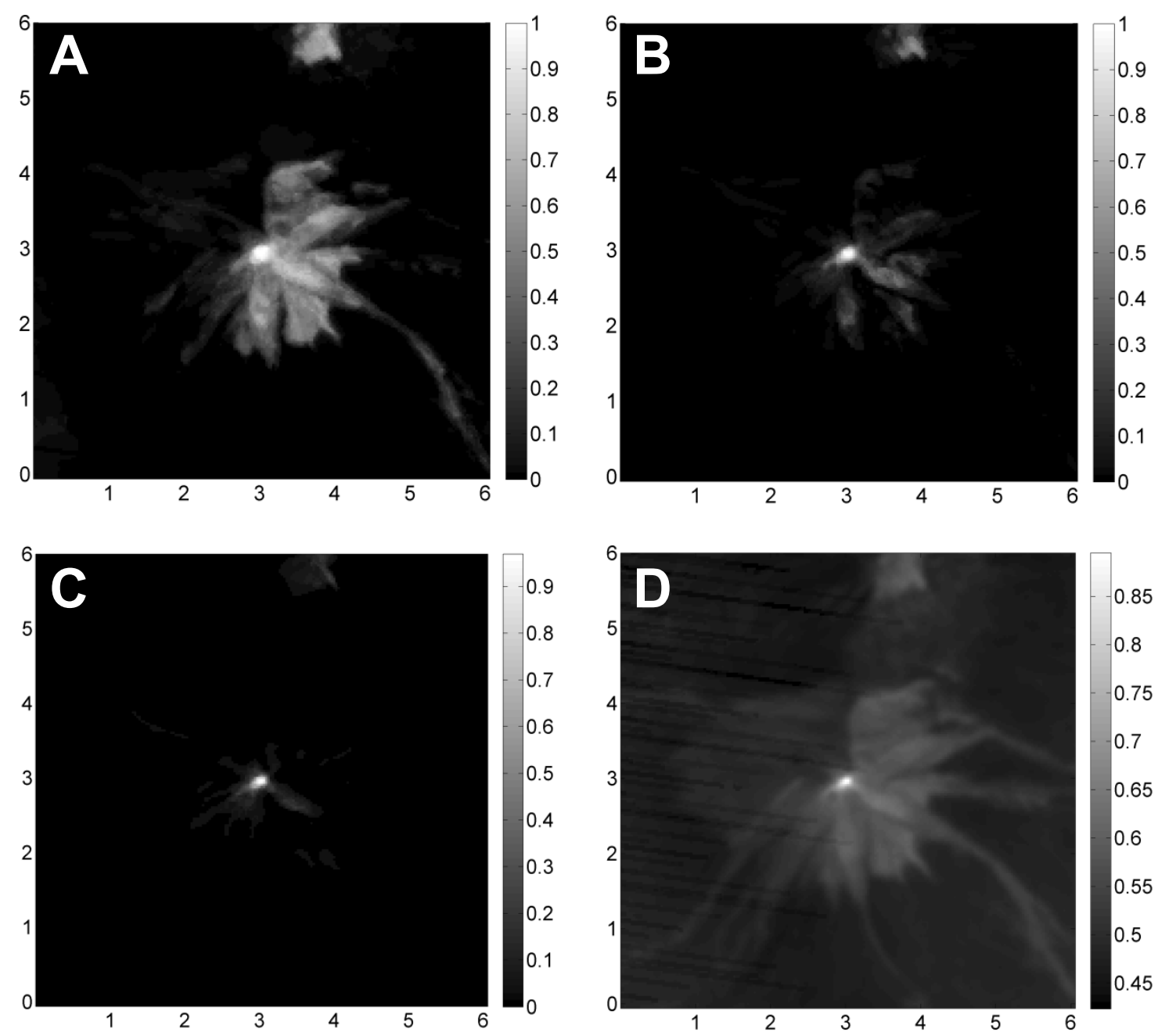

Figure 2.41. Thermal anomalies at the Fuego summit vent. A, B and $\mathbf{C}$ show respectively, the probabilities of observing a pixel with a radiance value 2,3 , and 4 above the mean radiance value for the $6 \times 6 \mathrm{~km}$ window show in the images, derived from the Landsat thermal IR (band 6) images from 1999 to 2013. As the threshold to define the radiance anomaly increases the hotspot becomes more evident. D Shows the normalized stack of all the (cloud free) Landsat thermal IR images (band 6) of the summit region from 1999 to 2013.

Some other features also remain visible in the images on figure 2.41 as the threshold for the radiance value is increased from 2 to 4 standard deviation above the mean. Most notably, elongated areas directed to the barrancas headwater regions are visible in the imagery, possibly corresponding to lava flows that remained active over several Landsat images. 

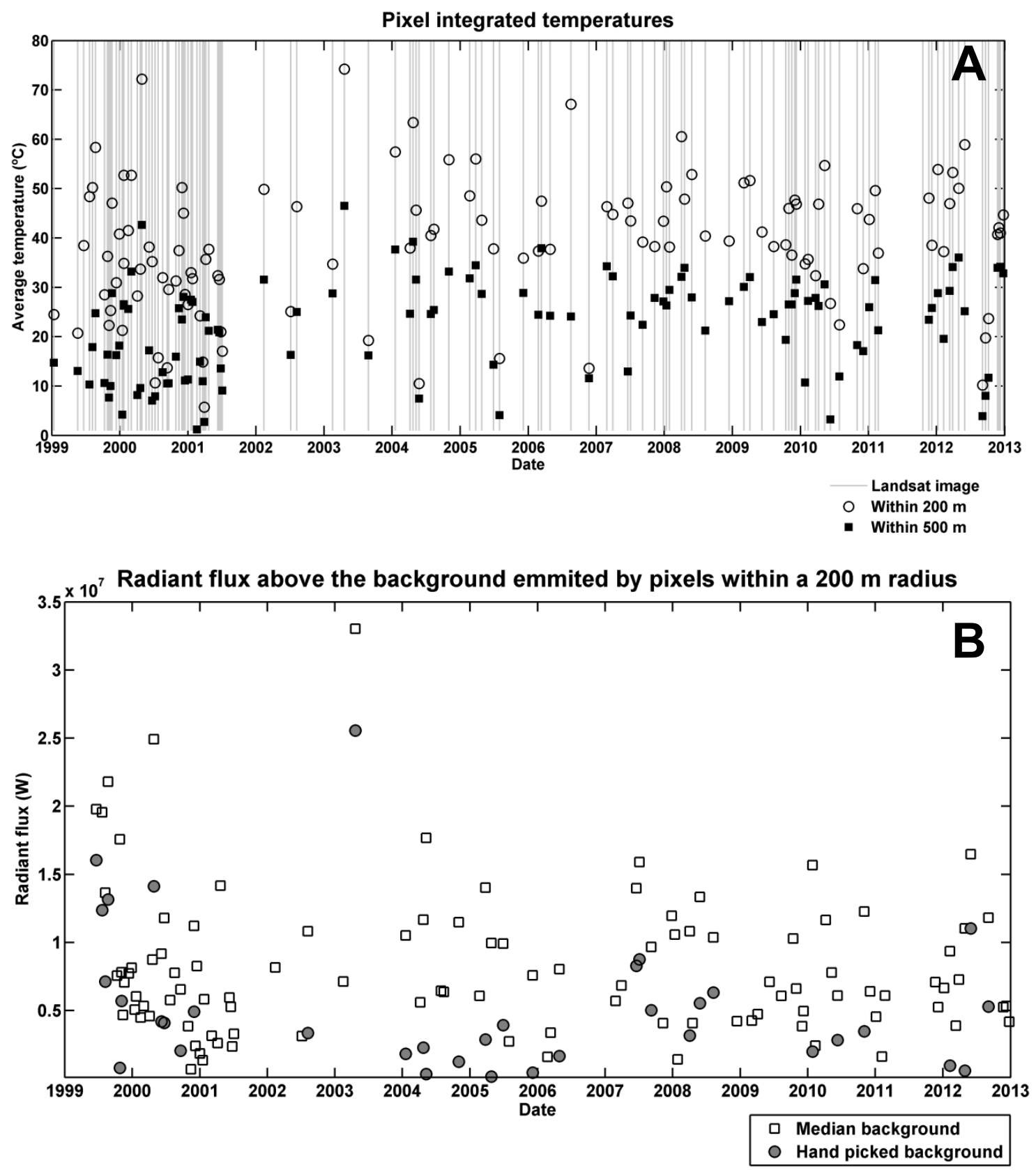

Figure 2.42. A Pixel integrated (at sensor brightness) temperatures for areas within 200 and 500 $\mathrm{m}$ of the summit vent, calculated from the Landsat ETM+ thermal IR sensor (band 6). B Radiant flux values above the background calculated from the same sensor as in $A$. The background values were calculated both as the median radiance value for the $6 \times 6 \mathrm{~km}$ window, and manually selected from the break in the radiance vs distance from the vent, curve.

At sensor brightness temperature (without atmospheric correction) and radiant flux were calculated for all available Landsat images, for the thermal IR channel (band 6). Figure 2.42 
shows the evolution over time of the average temperature and radiant flux from the summit vent region. Other than the slightly lower average temperature values before 2002 , the average pixel integrated temperatures within 200 and 500 from the summit remain surprisingly stable through most of the eruptive episode, and seem to be fairly insensitive to changes in the style of background activity (effusive vs. explosive).

Despite the constancy in thermal output, the vent region has experienced large changes throughout the 2011 - 2013 eruptive episode. Figure 2.43 show the early evolution of the vent area, as it transitioned from the pre-1999 configuration, through the May 21, 1999 explosive eruption, and the subsequent background explosive (1999 - 2001) and later effusive (2002 2003) activity. Sometimes the activity happens simultaneously from several different vents (e. g. see video on appendix 2.2, especially the satellite images corresponding to the year 2013), but their separation is usually $<200 \mathrm{~m}$, and therefore they can be considered as part of the same vent or "vent system". Lyons et al. (2009) also documented two simultaneously active vents during some of the eruptions in 2005 to 2007. 

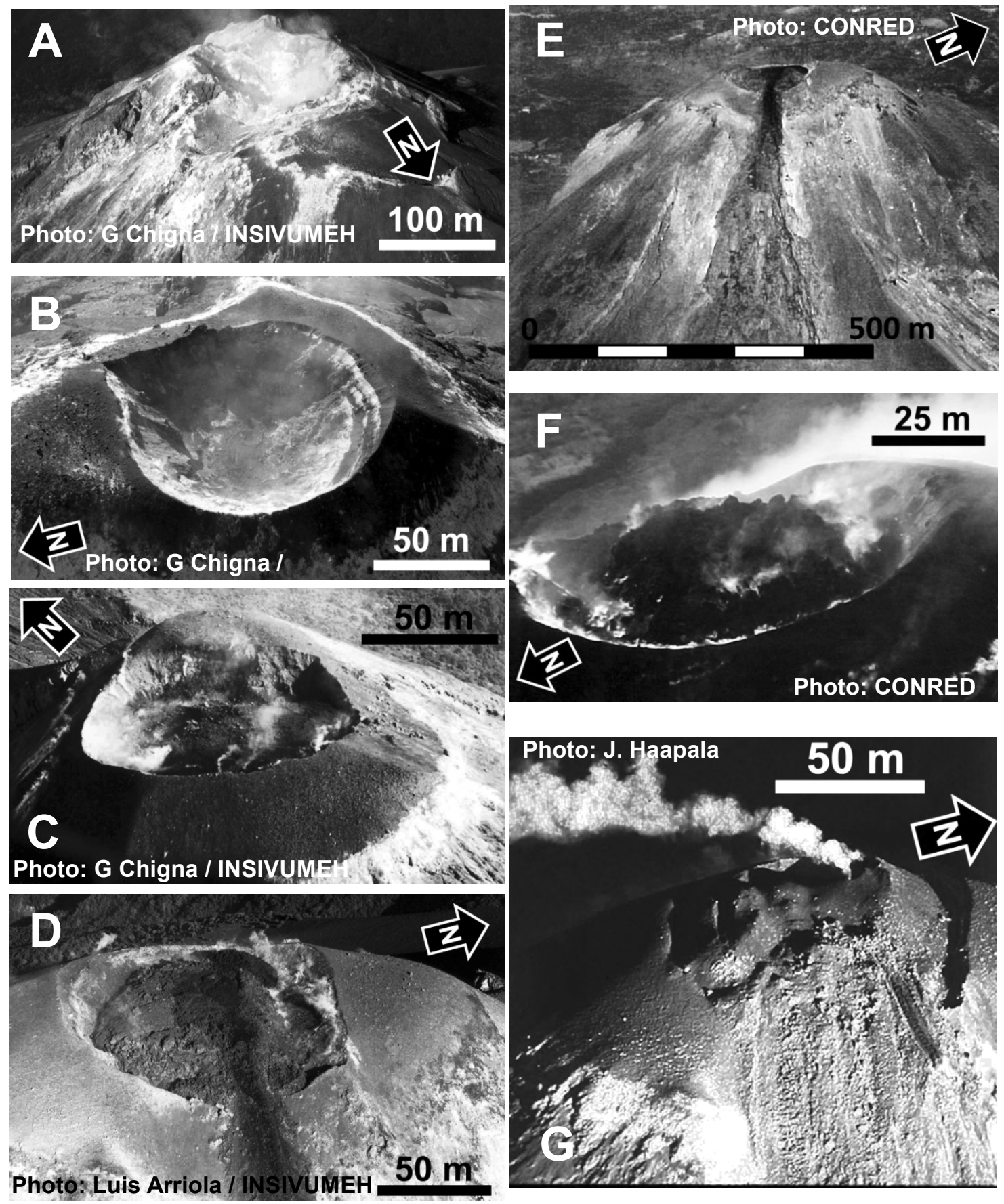

Figure 2.43. Evolution of the vent region through the May 21, 1999 eruption and the January March 2002 effusive activity. A. September 1996. There had been no eruptive activity since 1986. B. November 15, 2001. The vent shows the changes caused by the large May 21, 1999 eruption and the following small (background) explosive activity. Light and dark strata alternating on the south wall of the crater correspond to deposits from the May 21, 1999 eruption and later activity. Notice the flat bottom of the crater and the overall "bowl" morphology of the large crater, as well as the smaller nested craters inside the larger crater. Blocks $>2 \mathrm{~m}$ across are visible on the small plateau immediately north of the crater. 

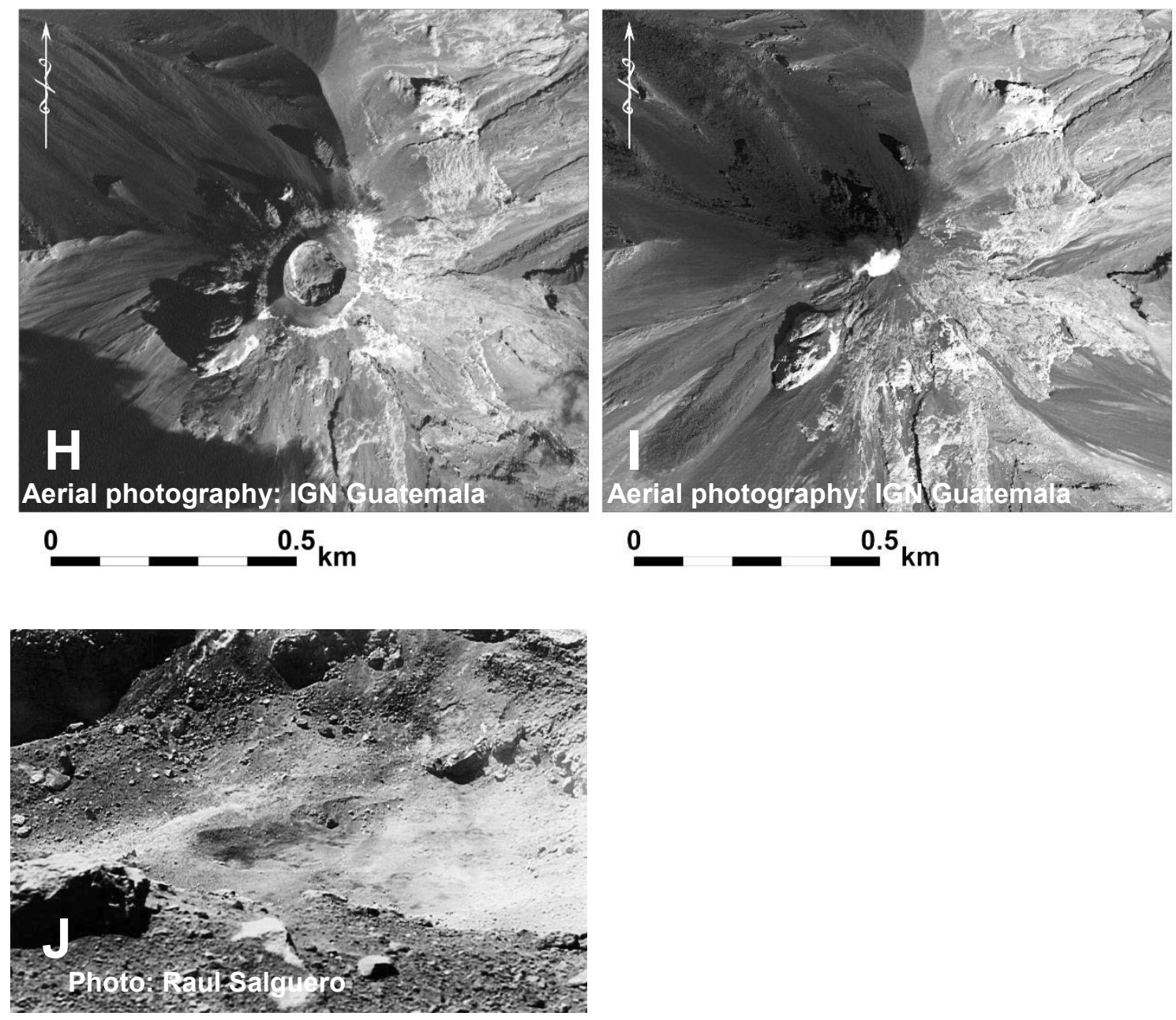

Figure 2.43, continuation... C. January 14, 2002. Lava effusion since January 3, 2002 produced a low profile "dome" inside the large crater. Notice how the "dome" is about to reach the lower SE crater rim. Activity had been dominantly effusive since the beginning of lava accumulation in the crater. D. February 2, 2002. A lava flow emanating from the "dome" has breached the lower SE crater rim. Notice the rough texture and complex structure of the dome. E. February 2, 2002. View of the lava flow flowing out of the crater on the SE flank of Fuego, towards the headwaters of Barranca Las Lajas and Barranca El Jute. F. February 2, 2002. View of the "dome" from the NW, showing the relief of the structure above the crater floor. G. March 9, 2002. The summit region shows changes after the February $11-13$ eruption and the following effusive activity. Notice the nested crater inside the larger crater, and that occupies the central portion of what previously was part of the "dome". H. March 10, 2001. Aerial photograph showing the crater left by the large May 21, 1999 eruption and the subsequent activity (compare with B) before the onset of the effusive activity in 2002. I. February 2006. Aerial photograph showing the summit region completely covered with recent products of the eruptive activity. None of the features of the large $1999-2002$ crater are visible anymore. J. July 1, 2001. Crater interior as viewed from the crater rim. Notice the debris covered flat bottom, and the central nested crater (subtle depression) with a glowing incandescent (dull-red) center.

Throughout this chapter we have reviewed the different types of activity, the related volcanic processes and the resulting deposits occurring during the ongoing 1999 to 2013 eruptive episode. 
The diversity of the activity styles can be summarized in a simple diagram (see figure 2.44) that includes the processes and expected deposits types.

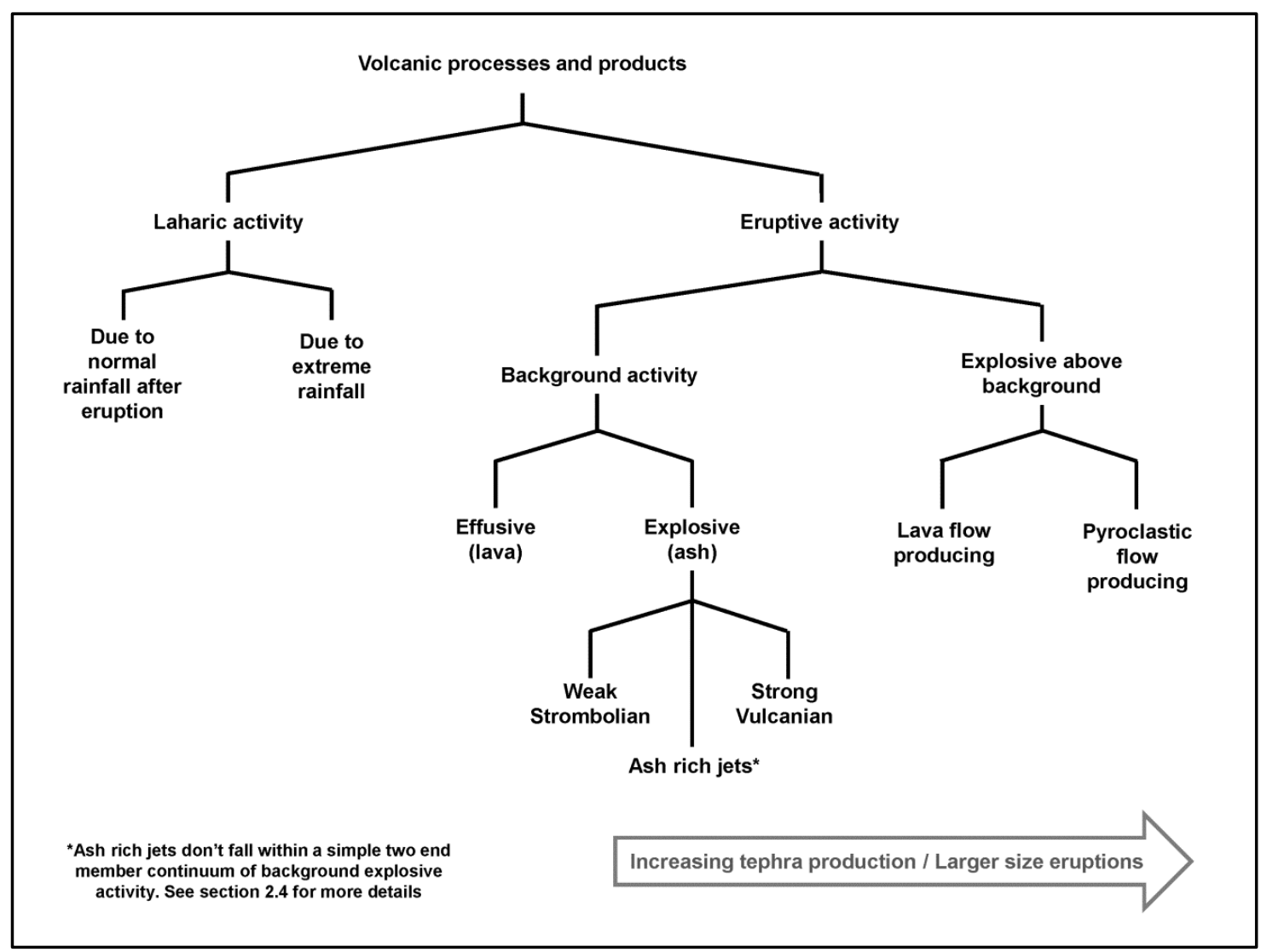

Figure 2.44 Diagram of volcanic processes and products at Fuego volcano.

Taking the information of volume from the "above background" eruptions together with the estimated eruption rates during the different types of background activity, a rough estimate of the erupted volume throughout the entire eruptive episode can be produced. Figure 2.45 shows the cumulative volume through time estimated assuming a background eruption rates of $0.1 \mathrm{~m}^{3} / \mathrm{s}$ and the volumes of individual eruptions given in table 2.2. A significant fraction of the volume of erupted material is contributed by only a few large eruptions (e. g. May 21, 1999; June 29, 2003; September 13, 2013). The background also contributes with an important volume of material on the long run, erupting as much a $\sim 1 / 3$ of the total volume output. A cumulative volume of $\sim 146$ million $\mathrm{m}^{3}$ erupted by June 2013 would be equivalent to an average volumetric eruption rate of $10^{7} \mathrm{~m}^{3} /$ year, or $\sim 0.3 \mathrm{~m}^{3} / \mathrm{s}$, such that the activity during the current eruptive episode can contribute with significant amounts to the long term eruptive budget of the volcano, this idea will be explored in more detail in the next chapter. 


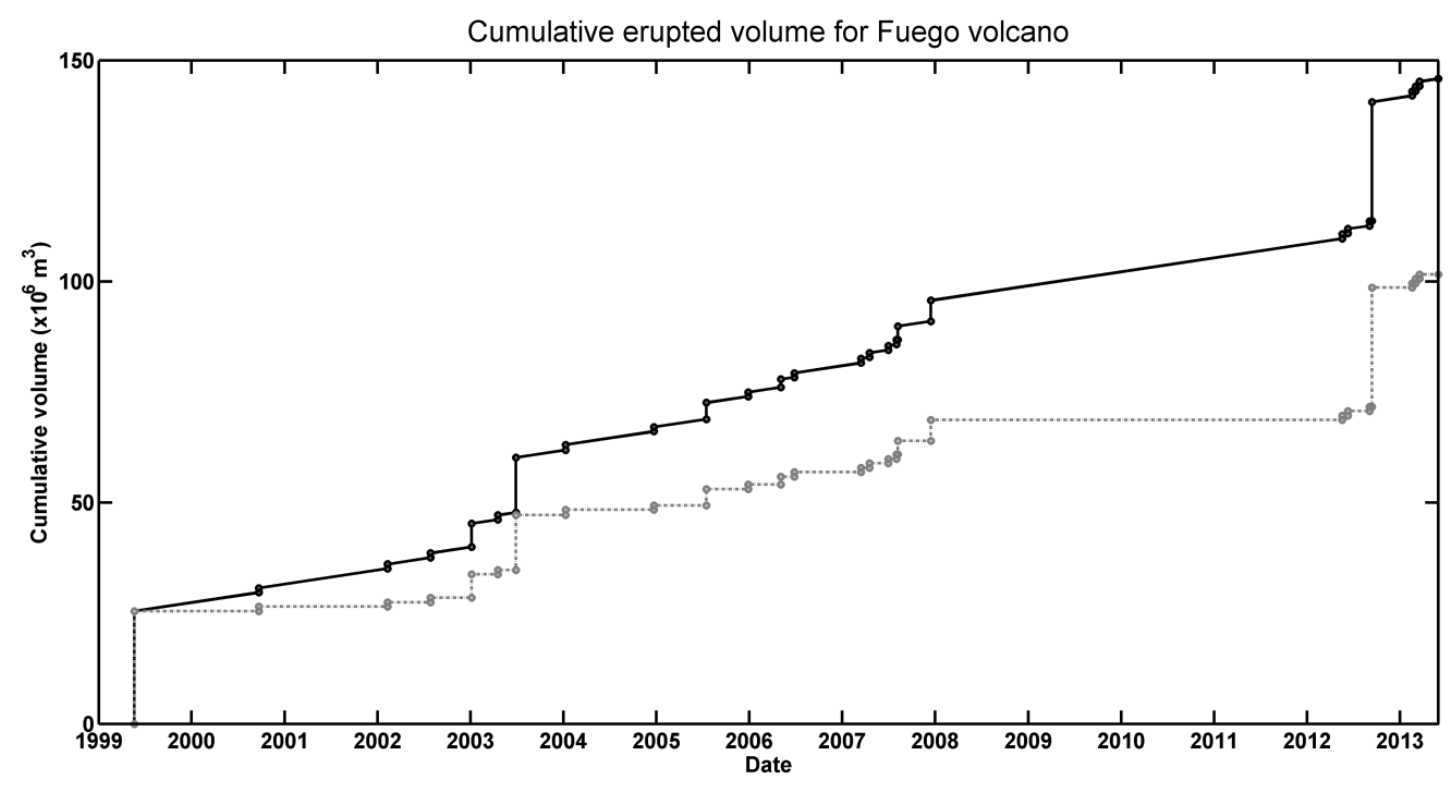

Figure 2.45. Cumulative erupted volume for Fuego volcano. Individual eruption volumes are taken from table 2.2. The black solid line estimates the volume assuming a background eruptive rate of $0.1 \mathrm{~m}^{3} / \mathrm{s}$. The dotted gray line doesn't consider the volume contribution of the background activity.

The pattern of eruptions through time seems to be clustered (e. g. see figures 2.40 and 2.45). To better assess the pattern of eruptive activity during the $1999-2013$ period, the time series is treated as a renewal process and both Log-logistic and Weibull distributions are fitter to dataset of inter-eruption intervals, following Connor et al. (2003) and Watt et al. (2007). Figure 2.46 shows the quality of the data fitting. The data are fit better by a Log-logistic distribution than by a Weibull distribution, similar to the case of Soufriere Hills volcano (Connor et al. 2003), but this fit is controlled by only one extremely long inter-eruption interval (the one happening from December 2007 to May 2012). Without that point, the Weibull distribution actually fits the data better. This illustrates the problem described by Watt et al. (2007) with some eruption time series, and raises the question of whether the 1999 - 2013 period should be considered a single eruptive period following a Log-logistic distribution of inter-eruption times, or if the activity could be better characterized as two episodes (1999 - 2007, and 2012 - 2013) separated by a longer activity gap (2007 - 2012). The continuity of background activity throughout this period suggests that characterizing the whole period as a single episode would make more sense from a volcanological perspective. The description of the dataset by a Weibull distribution suggests that the process driving the occurrence of eruptions is perhaps dominated by a simple failure mechanism. If magma is stored at an intermediate reservoir, perhaps left over from the eruptions in the 1970's as suggested by Berlo et al. (2012), a constant flus delivered to a shallower level 
could trigger the recurrent eruptions, and would be controlled by the failure of the shallow storage and conduit system.
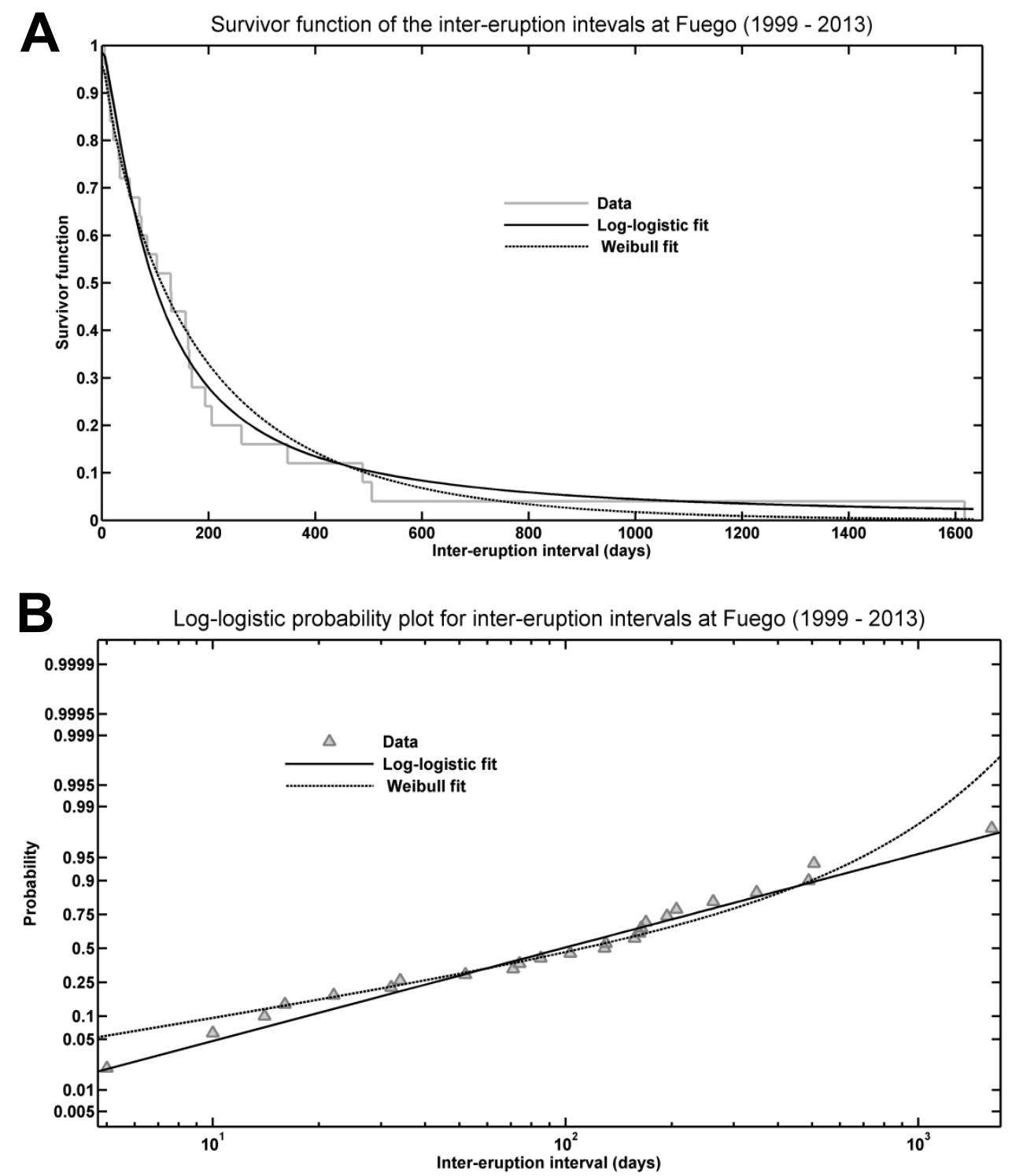

Figure 2.46. Probability function fitting to the inter-eruption intervals for Fuego from 1999 to 2013. A Survivor function fit to Log-logistic and Weibull distributions. B Log-logistic probability plot for the fitter Log-logistic and Weibull distributions Notice the good fit to the Log-logistic distribution, conditioned by the extreme values in the dataset.

The activity of Fuego discussed in this chapter shares similarities to the activity at other volcanoes. The similarities in the background and "paroxysmal" activity at Etna, especially in the generation of pyroclastic flows (Behncke et al., 2003) and tephra (Andronico et al. 2008) suggest that similar processes may be happening at both basaltic volcanoes. Similar analogies can be 
drawn with Fuji (Yamamoto et al. 2005) and Aso (Miyabuchi et al. 2006) with respect to pyroclastic flows. Slightly more silicic volcanoes, including Arenal (Alvarado and Soto 2002), Tungurahua (Kelfoun et al. 2009) and Mayon (Moore and Melson 1969) also produce very similar deposits, and may therefore be analogous cases.

\subsection{Conclusions}

Between 1999 and 2013 Fuego volcano displayed a wide range of activity styles, including 26 relatively large (some up to $10^{7} \mathrm{~m}^{3}$ ) explosive eruptions, and generated pyroclastic flows, lava flows and moderate tephra dispersion around the volcano. But even between these larger events Fuego maintained a virtually continuous background level of activity, alternating between periods of explosive activity, e. g. small Vulcanian $\left(\sim 10^{3} \mathrm{~m}^{3}\right)$ to Strombolian eruptions, happening on average 10 to 20 times per day, and periods of dominantly low rate $\left(\sim 0.1 \mathrm{~m}^{3} / \mathrm{s}\right)$ effusive activity. Larger eruptions produced significant (up to $2.6 \times 10^{7} \mathrm{~m}^{3}$ ) pyroclastic and lava flows deposit, and large un-quantified amounts of airborne tephra.

Flow (lava and pyroclastic) deposits were mostly restricted to the channels that drain the volcanic edifice (the Barrancas), but in one case (the June 29, 2003 eruption) a pyroclastic flow deposit overflowed the channel margins, inundating the adjacent interfluvial terrain, and causing the channel's avulsion. A total volume of erupted volcanic products of $\sim 146$ million $\mathrm{m}^{3}$ has been conservatively estimated for the eruptive episode, implying a long term averaged eruption rate of $\sim 0.3 \mathrm{~m}^{3} / \mathrm{s}$. Of the total erupted volume $\sim 2 / 3$ correspond to larger (above background) eruptions, and $\sim 1 / 3$ of the volume was erupted by the background activity, highlighting the importance of taking such activity into account when estimating the volcanic eruption rate.

Pyroclastic flow deposits can be classified as block and ash flow deposits, resembling deposits produced by lava and dome collapse at silicic domes, despite the relatively low silica content (basaltic to basaltic andesitic) of the erupted magma at Fuego. The mechanisms involved in the generation of the pyroclastic flows include the collapse of lava flow fronts, and other hot material located on unstable slopes at the summit region. Other generation mechanisms, including fountain and eruptive column collapse could be possible, especially for the largest eruptions during the eruptive episode, but require more research to be confirmed with more certainty. Ash cloud surges associated to pyroclastic flows are also a common occurrence during large eruptions.

Lahars happen frequently and include two main types, those generated by normal rainfall, happening after larger eruptions, especially if pyroclastic flow deposits were emplaced on the 
upper reaches of the Barrancas, and those generated by extreme rainfall events (e. g. tropical storms and hurricanes), which can be independent of the preceding volcanic activity. Lahars generated by normal rainfall originate mainly from direct stream erosion acting on the deposits of pyroclastic flows emplaced in the Barranca channels, the streams are usually ephemeral and caused by the intense rainfall that normally happens in the region. The erosion rapidly cuts through the pyroclastic deposits and re-establishes more stable conditions (e. g. lower gradient channel) in the stream, self-limiting the potential for further erosion and lahar generation, ultimately causing the decline in the number and magnitude of lahars, until new pyroclastic flow deposits are emplaced in the drainage system. Extreme rainfall generated lahars have a different mechanism, i. e. the collapse of unstable slopes and the transformation of the landslide into a mudflow. This process is not unique to volcanic terrains and happens simultaneously at other mountain slopes in the region affected by the extreme rainfall. Laharic processes are highly erosive on the upper reaches of the drainage system, commonly forming cut terraces, and become depositional only at the lower reaches, where the flow extends laterally and out of the channel, to inundate the adjacent terrain.

Lava flows at Fuego are common during the background activity, but these flows are short and commonly collapse after flowing a few hundred meters, to feed the downslope debris fields. Longer and more voluminous (up to $4.7 \times 10^{6} \mathrm{~m}^{3}$ ) lava flows are also common during the larger eruptions, but do not approach the volume of the largest pyroclastic flow deposits. Lava flow morphology is typically aa' to blocky, but due to the high confining morphology of the Barrancas in which they flow, they develop an unusual morphology, including very tall levees, associated to the peak of the volumetric flux. The background explosive activity also displays a variety of eruptive styles, that range from typical Strombolian bust, to more violent Vulcanian type explosions, but also include non-impulsive, ash rich jets.

The complexity and variety of processes and resulting products at Fuego can be overlooked without careful observations of the activity and the associated deposits. Monitoring and documenting such activity has been possible due to the efforts of agencies like INSIVUMEH and CONRED, and can be complemented by the vast and readily accessible satellite remote sensing datasets. Combining these sources of information with additional fieldwork it was possible to give a detailed description of the activity and products generated by Fuego throughout the 1999 to 2013 eruptive episode.

The importance of the study of Fuego's low level activity stems from the following three main considerations: 1 . The observations of low level activity processes may be generalized or 
extended to larger magnitude eruption, due to the common mechanisms behind such processes, independently from the scale of the activity. 2 . The long term impact of the low level activity can be significant, especially in contributing to the volume of the upper volcanic edifice. 3 . Some of the eruptions observed during the relatively low level activity period may be large enough to represent a hazard for communities located close to the volcano. 


\section{Comparison of the current (1999 - 2013) eruptive episode with previous eruptions at Fuego volcano, and revision of the volcanic facies model.}

\subsection{Fuego's extended history}

Fuego's past (pre-1999) eruptive activity is separated in three periods, according to how well the eruptive activity has been documented and how much additional information it would be possible to acquire. The first period corresponds to volcanic activity during the decade of 1970, in which a series of large eruptions and their products were studied by several authors, in a series of scientific papers and academic theses. The second period corresponds to other historic eruptions before 1970, and extending back to the XVI century, but mostly documented during the XX century. These eruptions were documented in less detail than those happening in the 1970's, mostly on a descriptive level by sometimes casual observers. The third period corresponds to prehistoric eruptions, for which there is obviously no witness accounts, but which can be studied through their deposits. The distinction between prehistoric and historic eruptions, especially regarding the identification of their deposits and for earlier events in the historic record (e. g. XVI through XVIII centuries), can be problematic as will be discussed in chapter 5 , but in this chapter most of the historic, per-1970 eruptions discussed happened in the XX century.

\subsection{Documentation of the previous (up to the 1970s) eruptive activity}

Historical documents going back to the beginning of the colonial period in the XVI century mention, and in some cases describe in much detail, some of the eruptions and extended eruptive activity, as will be discussed in detail in chapter 4 . The colonial historians and chroniclers of the time compiled the first catalogs of eruptions. Until the first half of the IXX century such descriptions, although very valuable in allowing us to build a general picture of the size of the eruption and some of the phenomena that they generated (e. g. extensive tephra fall), predated the development of modern volcanology, were made by witnesses from diverse backgrounds (although usually belonging to the most educated levels of society at the time) and are focused on the aspects that were more salient for the particular observer witnessing the eruption. Not to mention that many such descriptions have survived only through indirect sources, and may have been altered in the process of communication.

The situation changed during the second half of the IXX century, with when several geologists explored Fuego; in 1865 Karl von Seebach climbed the volcano (von Seebach, 1892) and so did Dollfus and Montserrat the following year (Dollfus and Montserrat, 1868). From these early expeditions we have the first truly detailed geological accounts of the volcano, including the first maps of the vent area. These authors, together with many other late IXX century and early XX 
century researchers (Fuchs, 1865 and 1882; Rockstroh, 1883; Montessus de Ballore, 1884; Santis, 1891; Sapper, 1913 and 1925) extended the tradition of the colonial historians and chroniclers in compiling eruption catalogs. However it was not until 1932 that a major eruption of Fuego was documented in detail by an earth scientist, when Deger published his report about the eruption and the chemistry of its products (Deger, 1932). Relatively little was documented about the eruptive activity during the following decades, the reports being usually restricted to short notes (Dozy, 1949; Hantke, 1951; 1953; 1955: 1959: 1962; Volcanological Society of Japan IAVCEI 1963; 1964; 1967; 1969; Meyer - Abich, 1956; Mooser et al. 1958), despite the evidence for relatively large eruptions from the late 1940's through the 1960's.

Renewed attention was given to the Fuego activity following the large eruptions that took place during the 1970's, especially the 1971 to 1974 eruption cluster. Bonis and Salazar (1973) described the large eruptions on September 1971 and February to March 1973. Rose et al. (1973) describe the September 1971 eruption, focusing on the air-fall tephra deposit. Rose et al. (1978 and 2007) describe in detail the October 1974 sequence of sub-Plinian eruptions, focusing as well on the air-fall tephra deposit. Roggensack (2001) studied melt inclusions from the 1974 eruptions series, and further developed a model of the magmatic plumbing system feed the eruption. Davies et al. (1978) on the other hand studied the pyroclastic flow deposits from the October 1974 eruptions. Additionally a series of master's thesis and doctoral dissertations focused on studying the deposits of pyroclastic flows, lahars, and downstream alluvial and fluvial deposits generated during these years (e. g. Quearry, 1975; Hebberger, 1977; Vessell, 1979), from which a series of papers were also derive, including the paper by Davies et al. (1978) on the fluvial transport and sediment characteristics of the drainages impacted by the eruptions from the 1971 to 1974 cluster. Vessel and Davies (1981), building on the earlier work by Vessell (1979) integrated the information from studies on pyroclastic flows, lahars, and alluvial and fluvial sedimentation into a facies model for the volcano. The deposits from these eruptions, mapped by Skilton, Schweig and Vessell in 1976, and published by the Instituto Geografico Militar (1983). Smaller scale activity and sporadic eruptions continued throughout 1978, and were documented by the Global Volcanism Program of the Smithsonian Institute. During the 1980's and 1990's Fuego remained quiescent, with only one exception in 1987.

\subsection{Volcanic activity during the decade of 1970}

Eruptive activity throughout the 1970's included low level background activity punctuated by much larger explosive eruptions, a dual style of activity that bears some similarity with the activity during the 1999 - 2013 eruptive episode. The largest eruptions happened on September $14-15,1971$; 
February 22 - March 2, and March 22 - 23, 1973 (Bonis and Salazar, 1973; Rose et al., 1973); and October 14 - 23, 1974 (Rose et al., 1978; Davies et al., 1978, Rose et al., 2007).

\subsubsection{Airfall tephra}

The September 14 - 15, 1971 eruption produced an extensive and tephra blanket, highly elongated to the WNE (see figure 3.1 A), whereas the October 1974 eruptions produced a cumulative les elongated blanket directed to the SW (see figure 3.1 B). These are the only two sets of eruptions for which the tephra fall deposits have well constrained isopach maps and detailed descriptions of the characteristics of the airfall tephra deposits are given by Rose et al., 1973; Rose et al., 1978; and Rose et al., 2007. However, calculating the volume of the tephra fall deposit may be challenging even in cases where there are relatively good isopach maps (e. g. Pyle, 1989; Fierstein and Nathenson, 1992; Bonadonna and Houghton, 1995); this is reflected in the variability of results on table 3.1 , which gives the volumes of the airfall tephra deposits from the 1971 and 1974 eruptions, calculated from the isopach data given by Rose et al., 1973 and Rose et al., 1978, but using several different methods. The September 1971 eruption produced an airfall tephra volume $\sim 10^{8} \mathrm{~m}^{3}$, while the aggregate airfall tephra volume for the series of eruptions in October of 1974 is of the order of 1.5 to $4 \times 10^{8} \mathrm{~m}^{3}$. It seems in any case that the volumes have orders of magnitude in the range of $10^{7}$ and $10^{8} \mathrm{~m}^{3}$, putting these eruptions in the VEI 3 - 4 category.
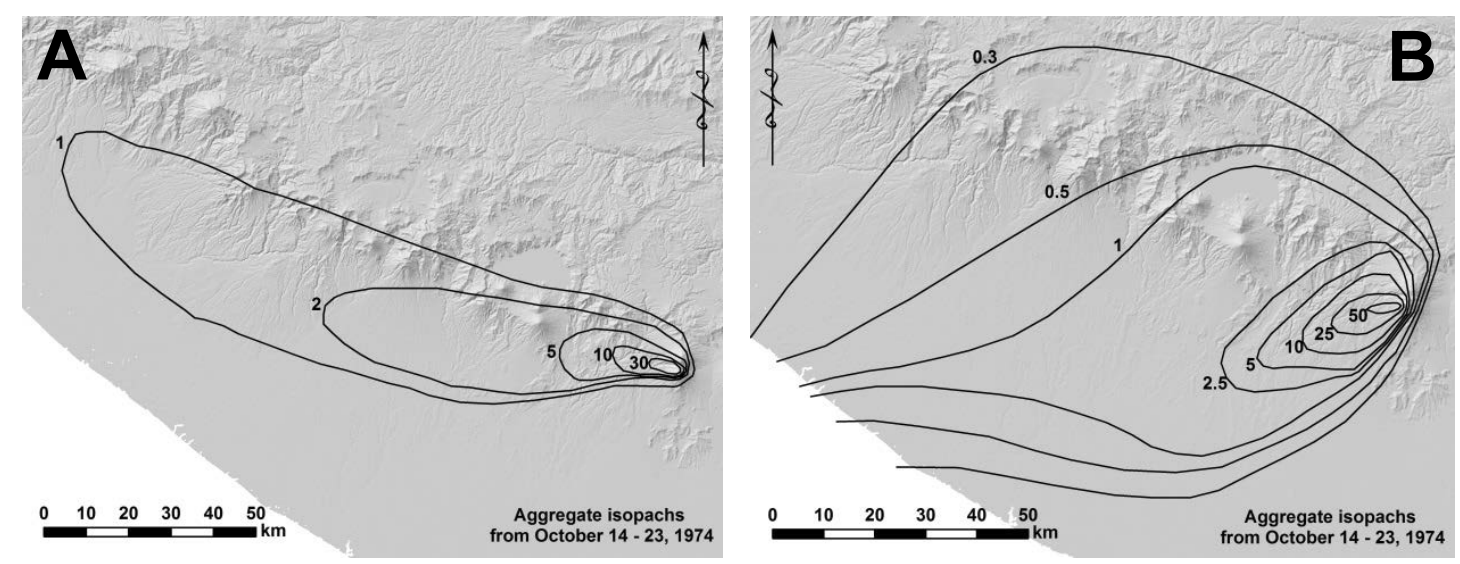

Figure 3.1. Isopach maps from (A) the September $14-15,1971$ (modified from Rose et al.,1973), and (B) the aggregate tephra fall from the series of eruptions happening between October 14 and 23, 1974 (modified from Rose et al., 1978). 
Table 3.1 Airfall tephra deposit volumes for eruptions in 1971 and 1974.

\begin{tabular}{|c|c|c|c|}
\hline Date & Volume $\left(\mathrm{m}^{3}\right)$ & Method & Reference \\
\hline \multirow[t]{6}{*}{ 9/14/1971 } & $6.00 E+07$ & Log-log thickness vs. area & Rose et al., 1973 \\
\hline & $1.42 \mathrm{E}+08$ & $\begin{array}{l}\text { Exponential (Pyle, 1989) } \\
\text { integrated to infinity }\end{array}$ & $\begin{array}{l}\text { Fierstein and } \\
\text { Nathenson, } 1992\end{array}$ \\
\hline & $5.20 \mathrm{E}+07$ & $\begin{array}{l}\text { Exponential (Pyle, 1989) } \\
\text { integrated to } 1 \mathrm{~cm}\end{array}$ & $\begin{array}{l}\text { Fierstein and } \\
\text { Nathenson, } 1992\end{array}$ \\
\hline & $7.50 \mathrm{E}+07$ & $\begin{array}{l}\text { Power law (Bonnadona and } \\
\text { Houghton, 2005) Option } 1^{*}\end{array}$ & This study \\
\hline & $3.01 \mathrm{E}+08$ & $\begin{array}{l}\text { Power law (Bonnadona and } \\
\text { Houghton, 2005) Option } 2^{*}\end{array}$ & This study \\
\hline & $5.33 E+07$ & Incremental & This study \\
\hline \multirow[t]{3}{*}{$10 / 14 / 1974$} & $3.60 \mathrm{E}+07$ & incremental & Rose et al. 2007 \\
\hline & $3.70 \mathrm{E}+07$ & Exponential (Pyle, 1989) & Rose et al. 2007 \\
\hline & $4.60 \mathrm{E}+07$ & $\begin{array}{l}\text { Power law (Bonadonna and } \\
\text { Houghton, 2005) }\end{array}$ & Rose et al. 2007 \\
\hline \multirow{4}{*}{$\begin{array}{l}10 / 14- \\
10 / 23 / 1974\end{array}$} & $1.57 \mathrm{E}+08$ & Exponential (Pyle, 1989) & this study \\
\hline & $1.98 \mathrm{E}+08$ & $\begin{array}{l}\text { Power law (Bonnadona and } \\
\text { Houghton, 2005) Option } 1^{*}\end{array}$ & this study \\
\hline & $2.99 \mathrm{E}+08$ & $\begin{array}{l}\text { Power law (Bonnadona and } \\
\text { Houghton, 2005) Option } 2^{*}\end{array}$ & this study \\
\hline & 2 to $4.00 E+08$ & Log-log thickness vs. area & Rose et al., 1978 \\
\hline
\end{tabular}

Of the total volume of material erupted and transported as airfall tephra, only a small amount falls near the vent, with the majority being dispersed over tends and even hundreds of kms. Using the isopach data (see the methods in appendix 3.1) we can assess what percentage of the total volume of material erupted as airfall tephra falls at a given distance from the vent (see figure 3.2), and for the September 1971 and October 1974 eruptions, this is only a small fraction. If we consider the volcanic edifice extending to less than $10 \mathrm{~km}$ from the vent, as will be discussed at the end of this chapter, the percentage of airfall tephra deposited on the edifice is only between $20 \%$ and $30 \%$ for those eruptions. This has important implications for the growth and age models that have been proposed for the volcano, and will be discussed in more detail at the end of this chapter. 


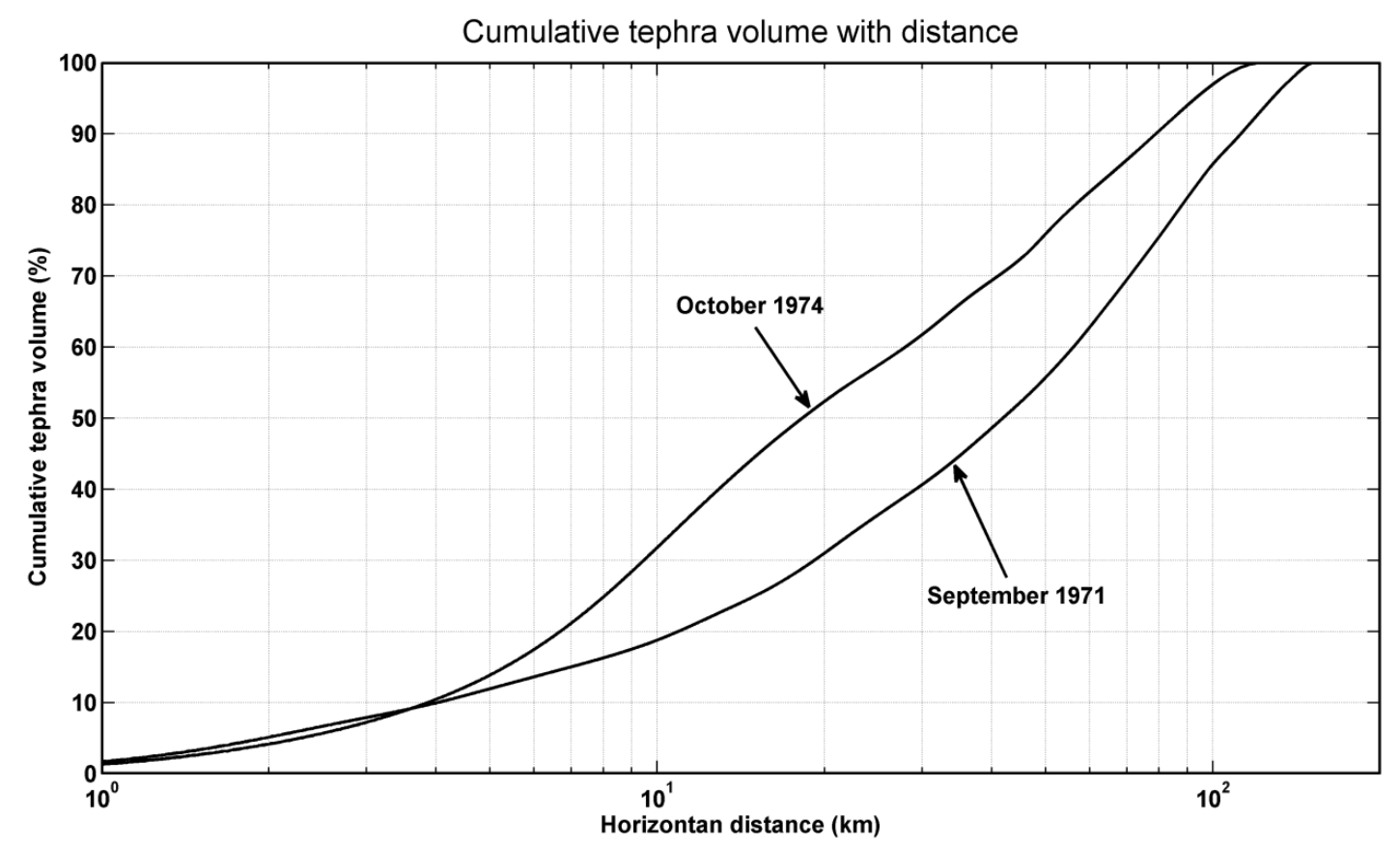

Figure 3.2. Cumulative airfall tephra volume with distance for Fuego eruptions in 1971 and 1974. Calculated from isopach data from from Rose et al., 1973 and 1978 (see text for details).

All other airfall tephra deposits erupted during the 1970's were probably much smaller (Rose et al., 1978), but since there are no isopach maps it is difficult to assess their volume. Of the list of eruptions compiled by Rose et al. (1978, table 1), none approached the 1971 and 1974 events magnitude, but the February - March, 1973 eruptions are listed next in order of importance. Bonis and Salazar (1973) mention that the $10 \mathrm{~cm}$ isopach extended only $10 \mathrm{~km}$ from the vent, and so the deposits from these events are probably at least an order of magnitude less voluminous than the 1971 and 1974 airfall tephra deposits.

Airfall tephra dispersion produced by eruptions during the 1999 to 2013 episode never reached the magnitude of the 1971 and 1974 events. Although there are no volume estimates for the tephra deposits generated during 1999 to 2013 , the thicknesses of the largest tephra producing events (e. g. May 21, 1999, June 29, 2003 and September 13, 2012) never exceeded $1 \mathrm{~cm}$ at 10 $\mathrm{km}$ from the vent, and tephra fall $>1 \mathrm{~mm}$ was never reported further than $\sim 25 \mathrm{~km}$ from the vent. Therefore the deposit from the largest airfall tephra producing eruptions during the 1999 to 2013 period may have been at most as large as the February - March 1973 airfall tephra deposits, and are probably at most on the order of $10^{6}-10^{7} \mathrm{~m}^{3}$. Airfall tephra production by smaller eruptions between 1975 and 1978 (Rose et al. 1978) was probably of similar magnitude to that associated to the "above background" explosive eruptions from 1999 to 2013 (see table 2.2). 
Background activity during the 1970's is less well known, although some detailed accounts area available (Martin and Rose, 1981). Studies of small ash rich explosive eruptions during that period (Rose et al., 1980; Wilson and Self, 1980) describe activity that seems similar, in magnitude and style, to the ash rich background explosive eruptions during the $1999-2013$ period.

\subsubsection{Pyroclastic flows and surges}

Pyroclastic flows activity and deposits during the 1970's have been documented by several authors (Bonis and Salazar, 1973; Quearry, 1975; Hebberger, 1977, Davies et al., 1978; Vessell, 1979). The eruptions that produced large volumes of airfall tephra in 1971 and 1974 also generated extensive pyroclastic flow deposits, however, other eruptions which did not produce large airfall tephra deposits, like the February - March 1973 eruptions, may have produced pyroclastic flows at least as large as those produced in 1971 and 1974 (Bonis and Salazar, 1973).

In addition to the documentation available through the scientific literature, excellent vertical exposure of deposits' stratigraphy and detailed imagery and mapping from the 1970's allows to recognize and compare the deposits of pyroclastic flows from the 1970 decade with recently (1999 - 2013) emplaced pyroclastic flow deposits (see appendix 3.1 for details about the methods). The pyroclastic flow deposits from the 1970's are virtually indistinguishable from pyroclastic flow deposits generated during the 1999 - 2013 period, displaying in both cases a characteristic block and ash flow texture, as described in chapter 2 . The scale of the deposit is however much larger: the deposit sequences from single eruptions can be up to $\sim 80 \mathrm{~m}$ thick (see figure 3.3 A) in channel filling facies. Stacked sequences of overbank facies deposits can have an accumulated thickness of up to $25 \mathrm{~m}$ thick (see figure $3.3 \mathrm{~B}$ ). 

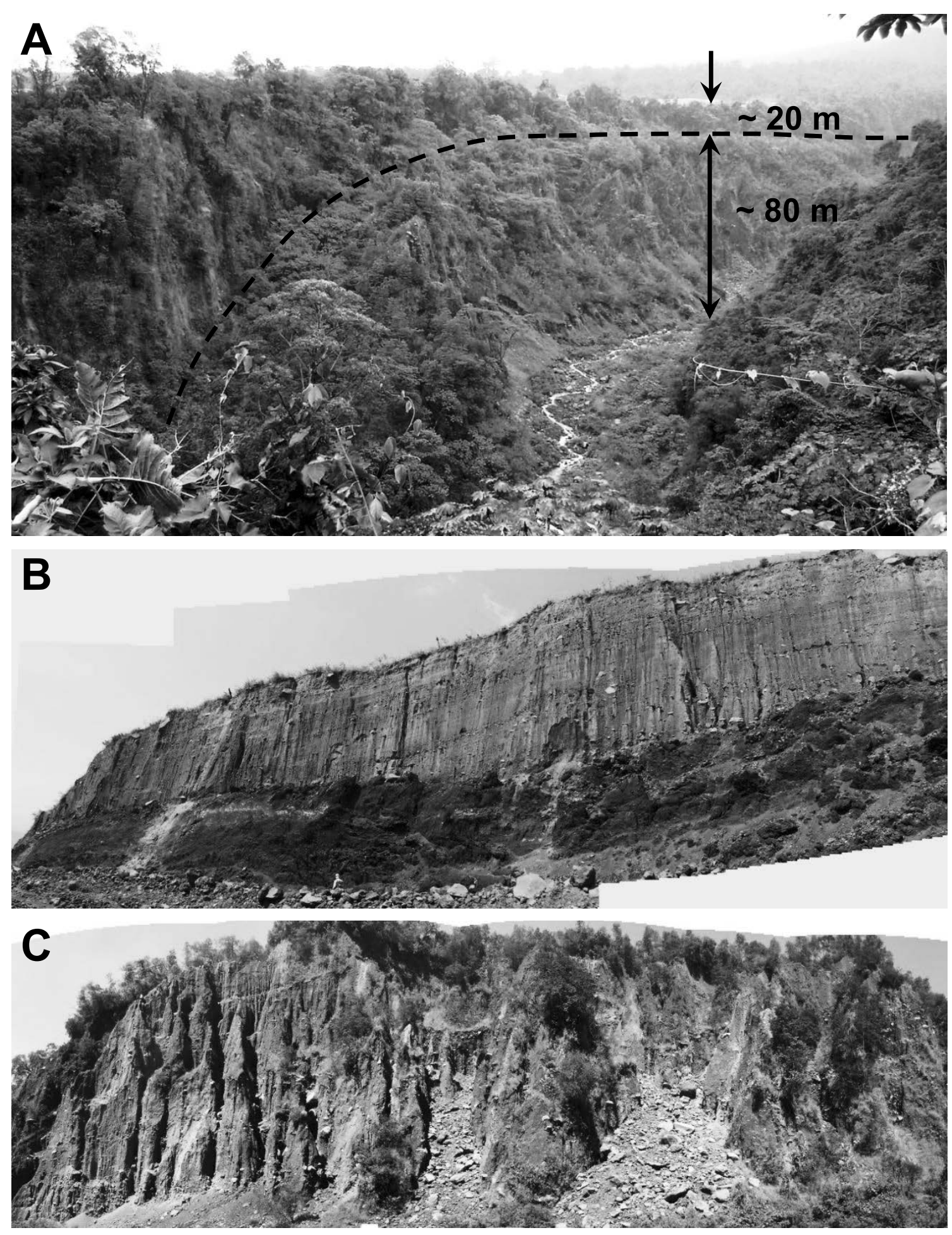

Figure 3.3. A Sequence of pyroclastic flow deposits from the 1970's, exposed on the channel walls at Barranca Taniluya and thinning out towards the terminus of the sequence. The sequence 
belongs to the typical channel fill facies, and seems to be uninterrupted (no interbedded paleosols, nor large erosive or depositional breaks) over the whole exposed thickness $(\sim 80 \mathrm{~m})$. Notice that the deposit sequence nearly reached the rim of the Barranca channel; the Panimache I village is located on the iterfluvial terrain, at $\sim 500 \mathrm{~m}$ from the channel at this location. B Sequence of pyroclastic flow deposits from the 1970's exposed on the wall of Barranca Seca. These deposits correspond to overbank facies, with individual units having typically thicknesses between 1 and 4 meters. The total exposed thickness of the sequence at this point is $\sim 25 \mathrm{~m}$, and as in the Taniluya case, it does not show evidence of large time breaks or other significant events (e. g. erosion, soil formation) happening between the emplacement of individual units. C Typical erosive pattern on the nearly vertically exposed pyroclastic flow deposits from the 1970's. This pattern reflects strong erosive action by tributary ephemeral streams, activated during high intensity rainfall and draining only small catchment areas. Such a pattern is very similar to the erosion pattern of pyroclastic flow deposits from recent (e. g. June 29, 2003) eruptions, and reflects the still highly unstable nature of many 1970's pyroclastic flow deposits. All pictures by the author.

Pyroclastic flow deposits are massive, poorly sorted diamictons, with an ash and lapilli matrix and variable amounts of embedded blocks. Blocks are dense, with surface texture varying from smooth to cauliflower crust. Ash cloud surge deposits from the 1970's are sometimes also observed in between pyroclastic flow deposits, but such deposits are far less likely to be preserved and therefore are more a rarity. The grain sizes distributions of the matrix from pyroclastic flow deposits emplaced in the 1970's are very similar to those of deposits emplaced during 1999 to 2013 (see figure 3.4). 

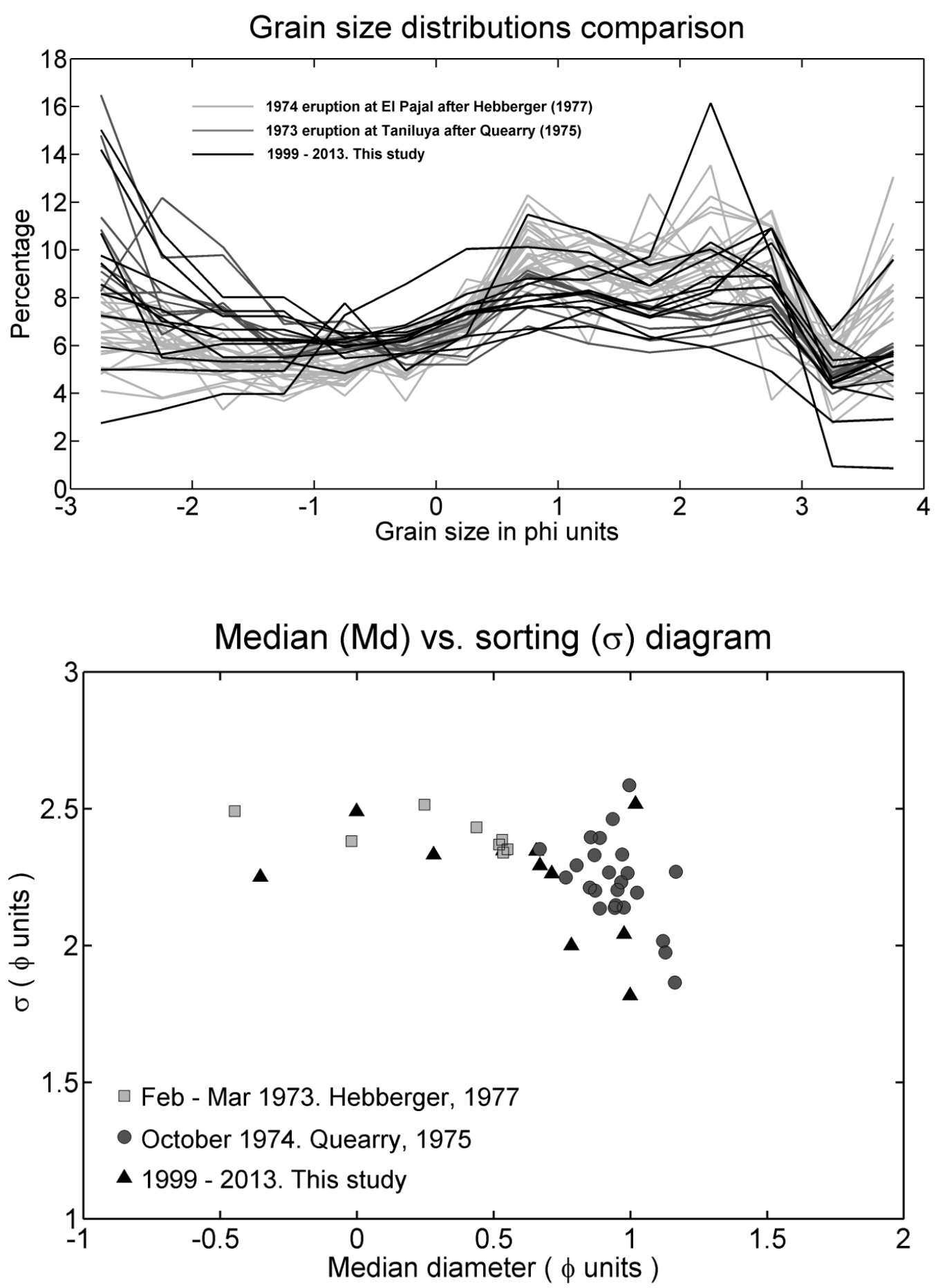

Figure 3.4. A Grain size distributions for samples from deposits emplaced during the 1973 and 1974 eruptions, and eruptions from the 1999 to 2013 period. B Median vs. Inman sorting 
coefficients for the same deposits. Notice the overlap of the $1999-2013$ sample parameters with those of both the 1973 and 1974 samples.

Channel filling facies are dominant due to the highly confining Barrancas morphology, but overbank deposits are also extensive on the east (Alotenango plain), and especially west (Barranca Seca - Santa Teresa plain) flanks, where channels have a small cross section and overflowing happens easily. Mapping of deposits during the 1970's was done by several authors, and compiled in the compiled into the 1:50,000 scale geologic quadrangle map published by the IGN (IGN, 1983). The map aggregates all the pyroclastic flow deposits into a single 1971 to 1974 unit, without making distinctions between different eruptions. Similarly Vessel (1979, figure 15) presents a map in which all the 1971 to 1974 deposits are grouped in a single unit. Using Landsat MSS images and aerial photographs from the 1970's (see appendix 3.1) it is possible to distinguish between pyroclastic flow deposits produced during the 1971, 1973 and 1974 eruptions. Figure 3.5 shows some of the deposits seen in the images and how this helps constrain the emplacement times of such events. 

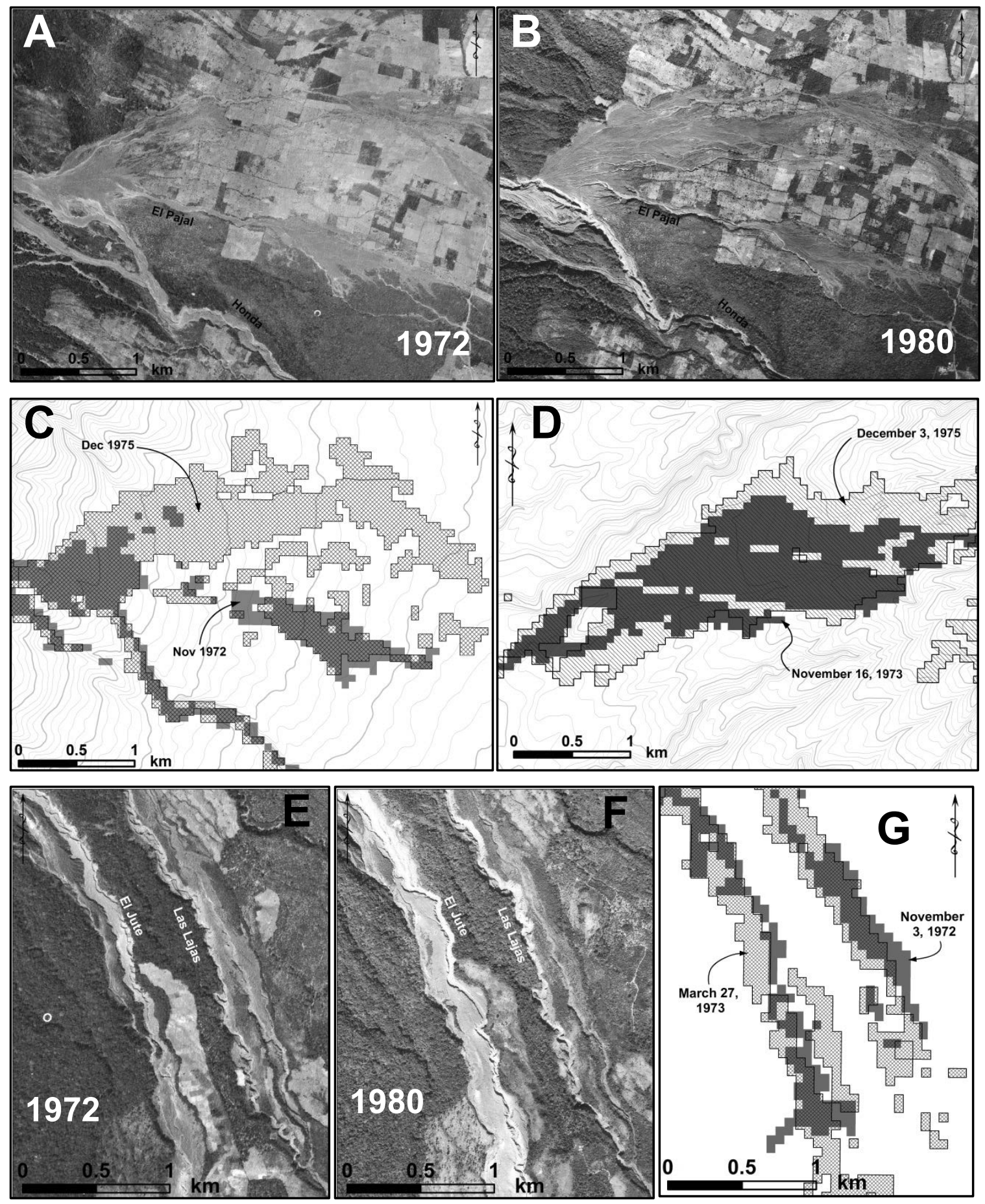

Figure 3.5. Deposit seen in aerial photography and Landsat MSS images. A and $\mathbf{B}$ show the difference in the deposits visible in aerial photographs from 1972 to 1980 on the Alotenango plain. Pyroclastic flows are already visible in Barranca Honda and Quebrada El Pajar in 1972, and are interpreted to be from the September 1971 eruption. The 1972 aerial photo also shows limited (< $1 \mathrm{~km}$ ) pyroclastic flows avulsion and overflowing on the Alotenango plain, which by 1980 is much more widespread $(>2 \mathrm{~km}$ ). While in 1972 the Barranca Seca channel had a flat bottom due to pyroclastic flow filling, presumably from the September 1971 eruption (but see the discussion in 
section 3.6 about the possibility that this deposit came from the 1957 eruption instead), a deep channel is visible in the 1980 aerial photograph. C Shows the mapped deposits on Alotenango plain derived from Landsat MSS images. The gray solid area represents the deposits as seen in November 1972, while the cross-hatched areas show the deposits extension by December of 1975 , and they generally agree with the much higher resolution aerial photography. $\mathbf{D}$ shows the pyroclastic flow deposits on the Barranca Seca - Santa Teresa fan, mapped from Landsat MSS images. Gray areas correspond to the mapped deposit November 1973, and cross-hatched areas correspond to the deposit distribution by December 1975. E and F show the deposition areas for the Las Lajas and El Jute Barrancas, which correspond to channel filling facies, but are still clearly recognizable in both aerial photography and Landsat MSS imagery. G shows the differences in deposition between November 1972, and March 27, 1973, shortly after a large pyroclastic flow producing eruption. It becomes clear from combining the information in $\mathbf{E}, \mathbf{F}$, and G, that the large pyroclastic flow deposits see on El Jute, were emplaced during the 1973 eruption. Aerial photography modified from IGN (see appendix for permisions).

The extension of pyroclastic flow deposit emplaced during the 1970's is much larger than those emplaced during the 1999 - 2013 eruptive period. Deposits confined to deep Barranca channels (i. e. channel filling facies) may display a similar planimetric area, but the distance reached by the pyroclastic flows in the 1970's is usually longer, and thickness of the 1970's deposits is also much larger. Pyroclastic flow deposit belonging to the overbank facies show a much stronger contrast in extension, as the deposits from the 1970's activity covered a wider area. Figure 3.6 is a comparison between the areas covered by pyroclastic flow deposits during the 1970's and during the 1999 - 2013 period, showing the much more extensive distribution of deposits emplaced during the 1970's. Further comparison of volumes will be left for the end of this chapter. 


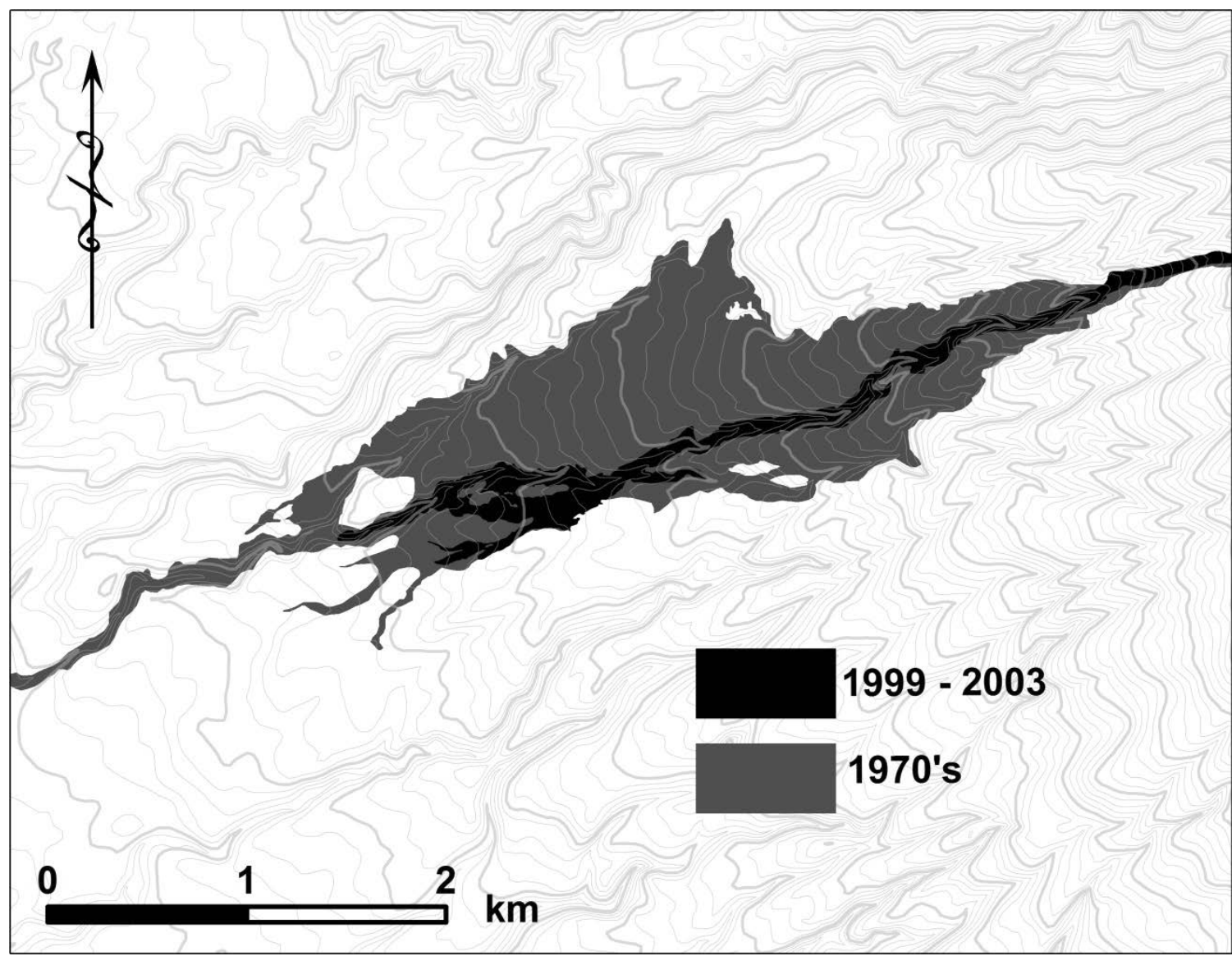

Figure 3.6. Comparison of areas covered by pyroclastic flow deposits erupted in the 1970's and during the 1999 - 2013 eruptive period, on the Barranca Seca - Barranca Santa Teresa pyroclastic fan region. Mapping based on aerial photography by IGN and field-mapping by the author.

The pyroclastic flow generation mechanism during the 1970's eruptions is not clear. The descriptions given by Quearry (1975) and Davies et al. (1978) suggest that during the larger eruptions (e. g. October 1974) the pyroclastic flows are formed by the column collapse or "boiling over" mechanisms discussed in chapter 2. Stoiber (1974) presented a series of photographs taken from a location on the ENE flank of the volcano (Finca Capetillo), at a distance of $\sim 8 \mathrm{~km}$ from the vent, partially documenting the generation and propagation of the pyroclastic flows generated by the October $14^{\text {th }} 1974$ eruption; unfortunately the view of the crater itself is covered by clouds and the very initiation moment of the flows cannot be seen. The presence of a large vertical eruptive column, up to $\sim 15 \mathrm{~km}$ for the October 14, 1974 eruption (Rose et al. 2007) and probably higher for more intense eruptions (e. g. the September 1971 and October 17 - 18, 1974), makes the column collapse hypothesis plausible. However, other eruptions, and mainly the February - March 1973 sequence, did not produce very large vertical columns nor extensive tephra fall deposits (Bonis and Salazar, 1973), which could be more consistent with the "boiling 
over" mechanism. The nature of the deposits, dominated by dense clasts, is however more commonly associated to pyroclastic flows generated by lava or dome collapse events at other volcanoes, rather than by column collapse (Calder et al., 1999; 2002 Kelfoun et al., 2009).

It is therefore not possible to clearly infer the details about the pyroclastic flow generation mechanism, with the available information; furthermore different mechanisms may be acting during different eruptions and more than one mechanism may be necessary to explain all the observations. Further observations and analysis of both the process as it happens (e. g. perhaps through thermal and radar imaging) and of the products (e. g. studies of the physical and chemical characteristics of the pyroclasts, and models of their fragmentation and transport) are needed to better understand how the pyroclastic flows are generated. The limitations of our understanding of how these flows are generated extend to the recent $(1999-2013)$ eruptions, despite relatively abundant and good visual observations.

The transportation regime for the flows can only be inferred to be similar to that discussed for the pyroclastic flows generated during the 1999 - 2013 eruptions (see chapter 2), as many of the features in the deposits are very similar for both kinds of flows, e. g. the highly mobility of the flows inside sinuous channels, but usually without overflowing the channel margins even when the deposit almost reaches the channel rim (e. g. figure 3.3 A), suggest that the flows had the characteristics of dense granular flows, as discussed for pyroclastic flows happening during the 1999 - 2013 episode (see chapter 2). The overbank deposits described by Quearry (1975) and Davies et al. (1978) for the pyroclastic flows that they studied near Barranca Honda and Quebrada EI Pajal, also resemble strongly the overbank deposits from the June 29, 2003 eruption in Barranca Seca.

\subsubsection{Lahars}

Laharic activity during the 1970's and the resulting deposits were also investigated by several authors. Hebberger (1977), Davies et al. (1979) and Vessell (1979) summarize the general erosion and sediment transportation process from the volcano down to the sea, focusing on the sedimentological characteristics of the materials (e. g. grainsize distribution, clasts shapes), componentry (e. g. types and provenance of particles, like crystals, etc.) and the fluvial hydraulics of the channels, especially downstream from where they transition from intermittent to permanent.

Lahars caused by normal rainfall happening after the large eruptions in the 1970's were similar in many aspects to lahars also caused by normal rainfall during the $1999-2013$ eruptive episode. 
Their deposits are indistinguishable from deposits of recent (1999 - 2013) lahars, but their extension is much bigger, as will be shown later in this section. As with the lahars happening during the 1999 - 2013 period, lahars in the 1970's seem to have been sourced mainly from the pyroclastic flow deposits emplaced in the Barrancas during large eruptions, resulting from the very intense stream erosion that acted directly on the pyroclastic flow deposits (see Davies et al. 1979, especially their figure 3 and caption).

Lahars associated to extreme rainfall are not certain, but may also have happened at least one time during the 1970's. During September 20 - 26, 1971 hurricane Irene-Olivia produced intense rainfall in the Fuego volcano region, reaching a maximum of $50 \mathrm{~mm}$ on September 24 for that region (Ponce, 1972). Although the intensity was much less than during extreme events Stan and Agatha in 2005 and 2010 (see chapter 2), the resulting flooding destroyed the Pantaleon Bridge to the SW of the volcano. Ponce (1972) argues that for the observed rainfall amount the resulting flood is rather unexpected, and concludes that it was the effect of the volcanic material accumulated on the slopes of Fuego from the very recent September $14-15$ eruption, that mainly caused the lahar.

Deposits of the 1970's lahars have been exposed in many channels, especially when channel avulsion due to laharic sedimentation caused the new channel to cut through overbank deposits, and in many case through the pre-1970's substrate (see figure 3.7). Individual laharic deposits units tend to be $<2 \mathrm{~m}$ thick, and are often $<1 \mathrm{~m}$ thick, similar to lahar deposit units discussed in chapter 2. Figure 3.7 shows a sequence of laharic deposits from the 1970's, overlying much thicker, massive non-stratified pyroclastic flow deposits, exposed due to channel avulsion on Barranca Taniluya, triggered by the laharic activity in the 1970's. 


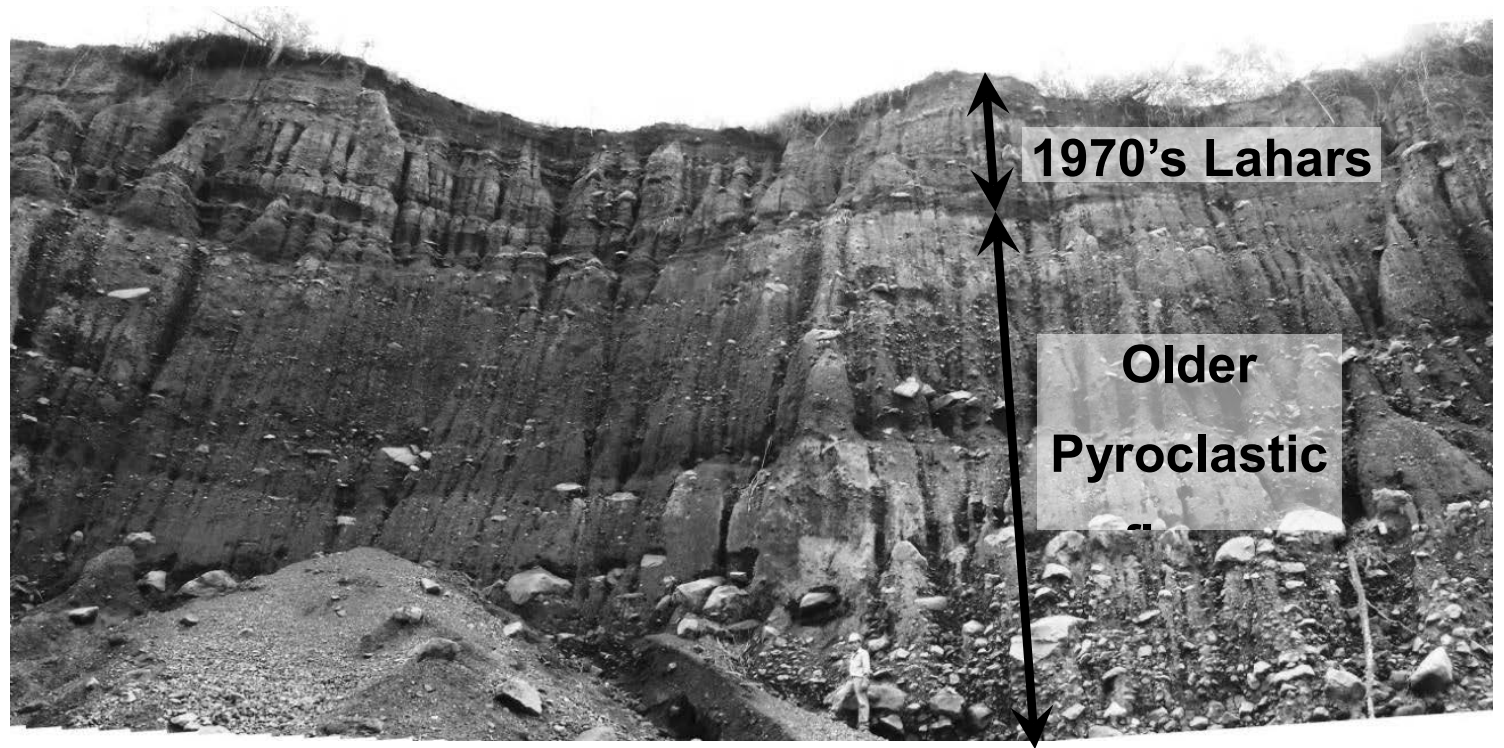

Figure 3.7. Lahar deposits from the 1970's overlying older pyroclastic flow deposits on Barranca Taniluya. Lahar and pyroclastic flow deposits are labeled and their thicknesses indicated by the black arrows. Notice the relatively fin bedding of the lahar deposits on the upper section compared with the massive appearance of the pyroclastic flow deposits. The thickness of the whole section is $\sim 12 \mathrm{~m}(\sim 4$ of lahar deposits in the upper section $+\sim 8 \mathrm{~m}$ of pyroclastic flow deposits in the lower section).

Mapping off the laharic deposits from the 1970's was done using the aerial photographs and Landsat MSS images. The emplacement of deposits happened several years beyond the occurrence of large eruptions, as expansion of the area affected by laharic sedimentation goes at least until 1979 (see figure 3.8). 

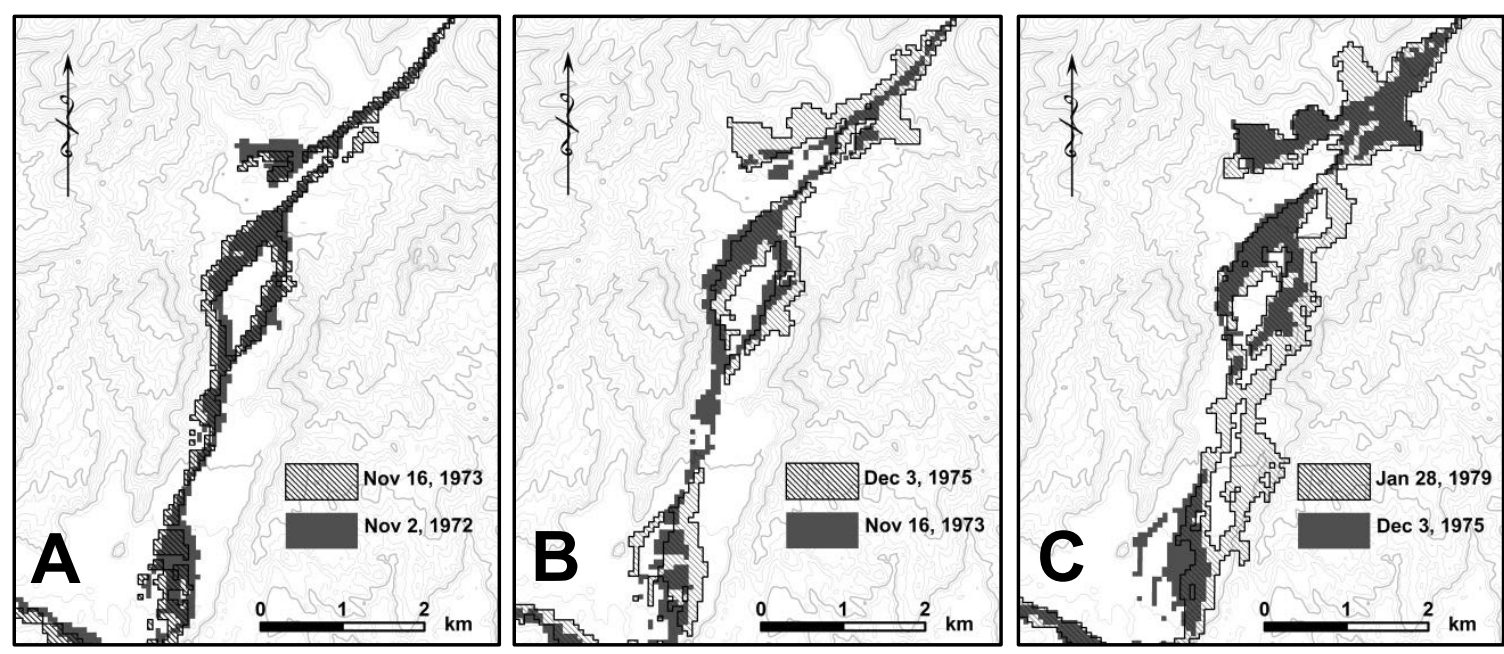

Figure 3.8. Laharic deposits in the upper Achiguate River region (15-20 km from the vent), mapped using Landsat MSS images from 1972 to 1979. A No significant change can be seen in deposition between November 1972 and 1973, suggesting that there was no significant laharic sedimentation during the rainy season following the larger pyroclastic flow eruptions in February and March 1973. B An increase in the area covered by sediments happened between November 1973 and December 1975, possibly related to the emplacement and subsequent erosion of pyroclastic flow deposits from the October 1974 eruption. C A large increase of the area covered by laharic sediments happened between December 1975 and January 1979, despite the relatively minor volcanic activity that took place over those years. Mapping by the author.

The mapping of lahar deposits through time allows reconstructing some of the avulsion and channeling shifting events that happened in response to the excessive sedimentation associated to the laharic activity. Figure 3.9 shows the avulsion of the Taniluya channel, the abandonment of the Obispo channel, and the associated changes in the drainage system happening during the 1970 's on the SW flank of Fuego, in response to laharic sedimentation. Such changes were much larger and significant than any changes in the drainage system seen during the $1999-2013$ period. 


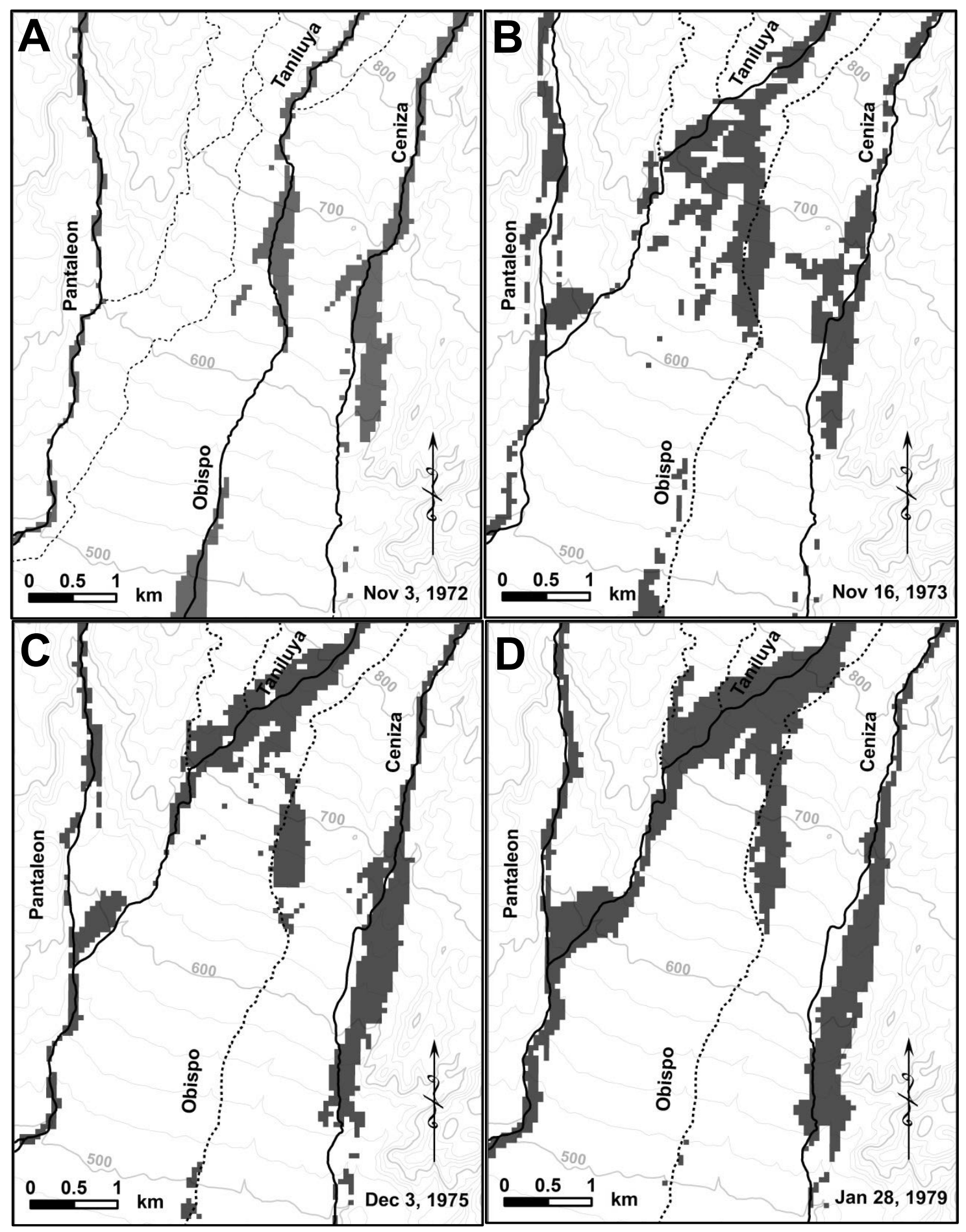

Figure 3.9. Avulsion and channel abandonment in the Taniluya - Obispo drainage system through the 1970's, mapped using Landsat MSS images. A In November 1972 the Taniluya river flows still into the Obispo river. Laharic deposits are detected in both the Taniluya - Obispo and Ceniza drainages. B By November 1973, extensive laharic deposition between Taniluya and 
Pantaleon rivers, and the avulsion of the Taniluya channel has occurred, leaving the Obispo River abandoned. C By December 1975 the laharic deposition had expanded along the new Taniluya and old Ceniza channels. At the same time the sediments in the Obispo channel start to be less visible, possibly due to vegetation reclaiming the deposits after the channel abandonment. D Further laharic deposition by January 1979 increases the areas covered by sediments along the Taniluya and Ceniza channels, while the Obispo channel is virtually indistinguishable in the Landsat imagery. Mapping by the author.

The extension of deposition of laharic material in the lower reaches of the Fuego drainage during the 1970's is much larger than the area affected by laharic deposition during the $1999-2013$ period. Figure 3.10 shows a comparison of the areas affected by laharic deposition on the upper Achiguate River. The area covered by laharic deposits during Hurricane Stan was small compared with area covered by the laharic activity in the 1970's, and the area covered by laharic deposits during Storm Agatha, although considerably larger than the area covered during Hurricane Stan, is still much smaller than the area affected by laharic deposition during the 1970's.

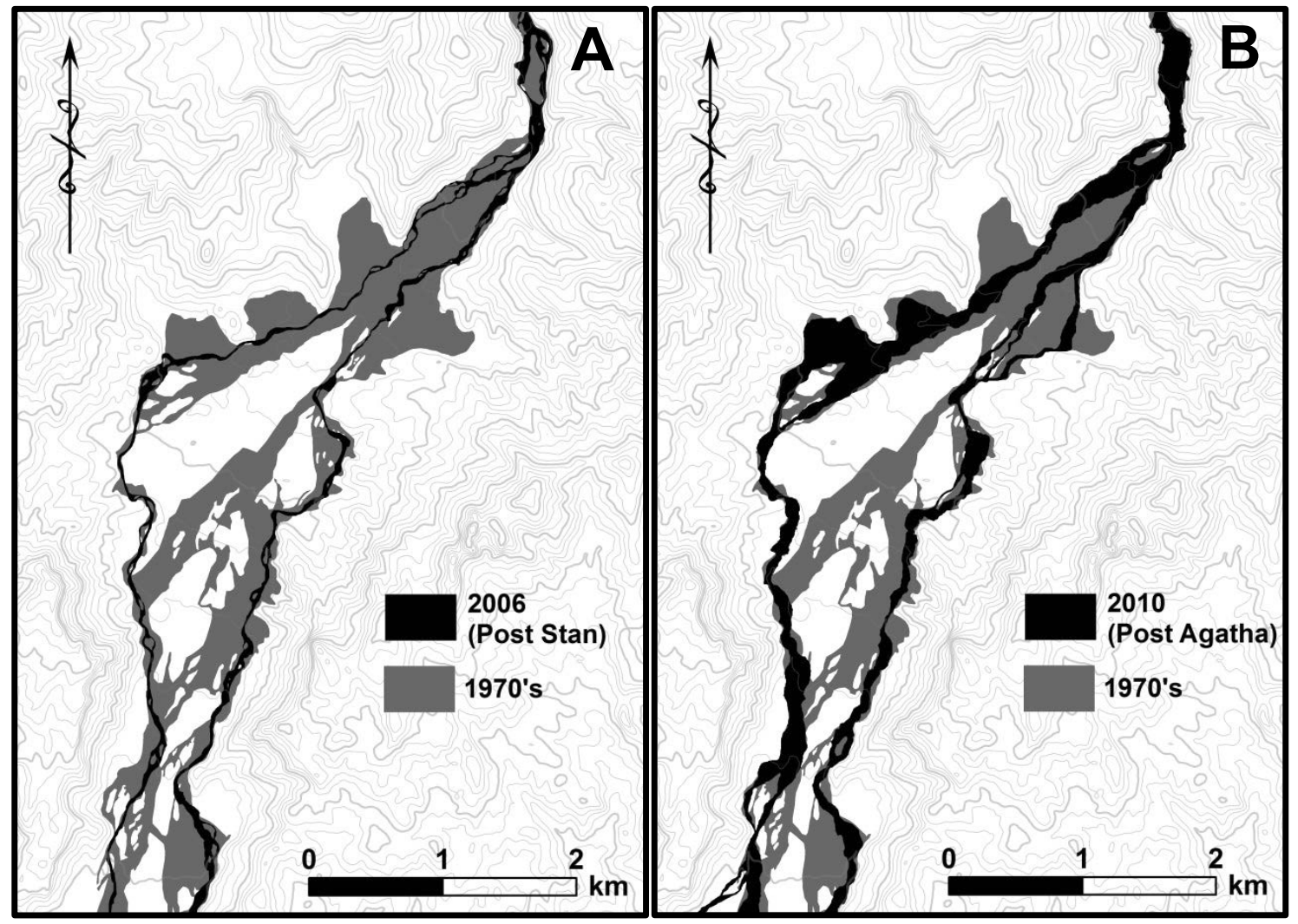

Figure 3.10. A Comparison between areas covered by laharic deposits in the 1970's and during Hurricane Stan (2005). B Comparison of the same laharic areas in the 1970's and the deposition areas covered during Storm Agatha (2010). Mapping by the author. 


\subsection{Volcanic activity prior to 1970 and its products}

\subsubsection{Activity and deposits during the $X X$ century, prior to 1970}

The information available for eruptions prior to 1971 is very scarce. A few authors have published accounts on the activity during the historic period, and mostly during the later IXX and XX centuries, being rather descriptive and short. The January 21, 1932 eruptions had a magnitude similar to the 1971 and 1974 eruptions, causing extensive tephra fall to the east of the volcano, reaching Honduras and EI Salvador. Deger (1932) gives a detailed description of the eruption, including chemical analysis of the products and photographs of the following activity. Hantke (1951, 1955, 1959, and 1962) describes the eruptions from the 1940's through the 1950's, in a summarized way and includes references to "strong ash showers", "darkened in the surroundings" (due to tephra clouds), etc. Hantke (1962) mentions that during the February 19 21, 1957 eruption "ash fell $100 \mathrm{~km}$ from the volcano", reaching El Salvador. Eruptions during the 1960's were also large, e. g. the November 9, 1962 eruption producing ash fall as far as Huehuetenango, > $100 \mathrm{~km}$ from the volcano (Volcanological Society of Japan - IAVCEI, 1963). The September 28 - October 1, 1963 eruption produced tephra accumulation on roofs in Antigua and Alotenango ( 8 and $18 \mathrm{~km}$ from the vent) that required immediate cleaning to avoid collapse (perhaps several cms of tephra?) (Volcanological Society of Japan - IAVCEI, 1963).

Furthermore, the local oral tradition includes accounts of several large eruptions from the 1950's through the 1970's, many times including vivid details about the tephra fall, the darkness and the material that came down rushing through the Barrancas (pyroclastic flows?) and the subsequent lahars, unfortunately these accounts are less precise on the dates of such eruptions. One such account describes a large eruption, comparable in size to the 1971 eruption, happening on May 3, 1967 and causing extensive damage to the Fincas (farms) Los Tarros and La Union, at 15 and $30 \mathrm{~km}$ from the vent, respectively (Otoniel Matias, personal communication 2009).

Photographic evidence further shows some details of large eruptions during the 1940's through 1960 's. Figure 3.11 shows a series of photographs of an eruption in 1947 taken by airline pilot Ned Wilson, for which the exact date is unknown. The eruptive column in those pictures rises some $8-10 \mathrm{~km}$ above the vent (12-14 km above sea level), and pyroclastic flows are also evident, flowing down on both the $E$ and $W$ flanks of the volcano. Other similar examples include August 12, 1966 eruption (see http://www.geo.mtu.edu/volcanoes/fuego/pic/f30.gif). 


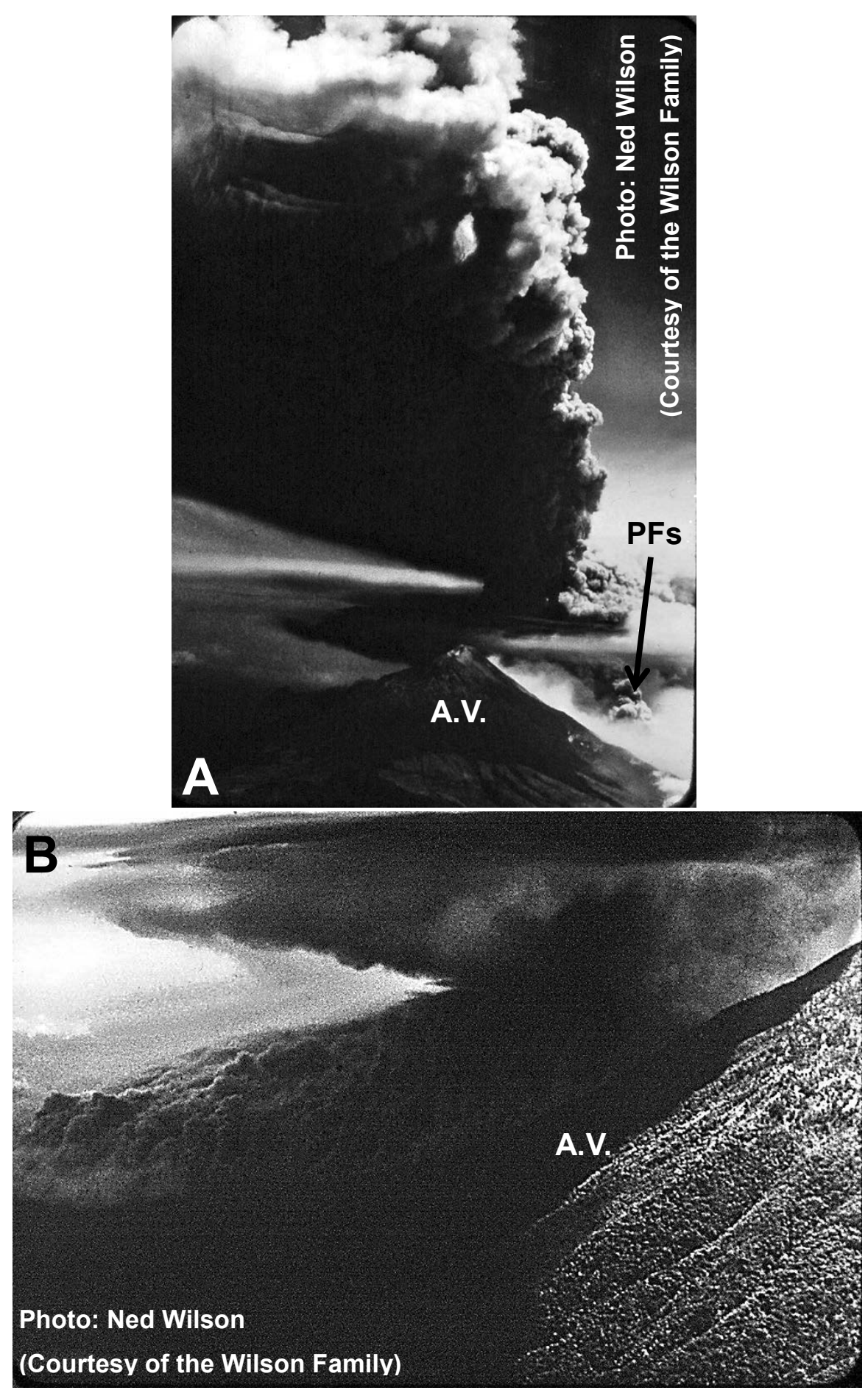

Figure 3.11. Aerial photographs from a Fuego eruption in 1947. A The eruption shows a large eruptive column, reaching $8-10 \mathrm{~km}$ above the vent, as well as pyroclastic flows descending the WNW flanks of the volcano (labeled PFs with a black arrow). Acatenango volcano is in the foreground (labeled A.V.). B Closer view showing pyroclastic flows descending the $E$ flank of the volcano. Acatenango is again on the foreground and labeled as A.V. 
From these descriptions and documents it seems that some of the eruptions were considerably large. Rose et al. (1978, table 1) rated several of these eruptions as having a similar magnitude to the September 1971 eruption, although Bonis and Salazar describe the 1971 eruption as "the most spectacular eruption... in memory (at least 70 years)". Further quantifying the sizes of these eruptions is not possible with the available information, but judging from the better documented cases studied in this chapter, the erupted volumes are likely to have orders of magnitude in the range of $10^{6}$ to $10^{8} \mathrm{~m}^{3}$, corresponding to VEI $2-4$.

Apart from the very conspicuous eruptive columns and associated tephra fall, the accounts also include references to other phenomena. Deger (1932) describes the deposits of the 1932 eruption as "mud rivers" erupted by the volcano on the east flank (along the former channel of Barranca Honda?), which most likely were not mudflows but pyroclastic flow deposits. The accounts given by Zies $(1932,1938)$ of the flows and their deposits support this idea, and from the description he gives of their generation, resembles the description of the "boiling over" generation mechanism. Hantke (1962), citing Pough and Mulford, describes pyroclastic flows forming during the February $19-21,1957$ eruption which flowed down the E flank of Fuego, stating that "it reached the foot of the mountain and broadened an additional $3 \mathrm{~km}$ in a fan form, on the slope it had filled a Barranco with a depth of $15 \mathrm{~m}$ and a width of $100 \mathrm{~m}$; ; this description suggests that the pyroclastic flow spilled outside of the channel to inundate the adjacent intefluvial terrain, forming an overbank facies deposit, to a distance of $6-7 \mathrm{~km}$, considering that the "foot" of the mountain on the Alotenango plain is located at some 3 to $4 \mathrm{~km}$ from the vent. Considering this description, it is possible that the pyroclastic flow deposit from this eruption is the one visible in figure 3.5 A along Quebrada El Pajal, an alternative to the previous interpretation that the deposit was emplaced during the 1971 eruption. The mechanism for the formation of the pyroclastic flows was described by as "a very rich lava was being extruded, but not as a flow or dome, rather the lava became pulverized immediately after it left the Bocca and not only did high ash clouds come from here, but also incandescent avalanches moving down fast on the flanks, which were constituted apart from the gases by lava fragments of all sizes from the fine sand up to the blocks of many meters in diameter". This description could fit the classical lava or dome collapse generated pyroclastic flows (i. e. Merapi type), but it could also be describing a "boiling over" mechanism

Several of the references (Hantke, 1955; 1959; Meyer-Abich, 1956; Volcanological Society of Japan - IAVCEI, 1969) also mention lava flows during the April 9 - 13, 1953, the July 1955, and the August $4-7,1962$ eruptions. Meyer-Abich (1956) provided a sketch map based on aerial photography, of the April 1953 lava flow, and in his description he states that the flow "stopped at 
about half the relative height of the volcano" $(\sim 2,500-3,000$ masl). The lava formed a thick flow which filled a deep Barranca on the upper slopes of the volcano (see figure 3.12). The July 1955 eruption may have produced a more viscous lava, since it was described as "a small lava dome", and a lava diente, literally a "tooth" in Spanish, by Hantke (1959), further stating that according to Bullard "it's surface has a rounded aspect". The largest lava flows reported during this period were probably erupted during the August $4-7,1962$ eruption, consisting of two flows that were channelized inside Barranca Honda, "filled its upper portion" (Volcanological Society of Japan IAVCEI, 1969) and continued flowing to reach a point $\sim 3 \mathrm{~km} \mathrm{~W}$ of the road that goes from Alotenango to Escuintla.

Using these descriptions and the aerial photographs from the 1970's it is possible to map some of these lava flows (see figure 3.12). Although the 1:50,000 scale geologic quadrangle map published by the IGN (IGN, 1983) includes some recent lava flow units on the $E$ flank of the volcano, the authors of the map interpreted that deposit to be from the 1953 eruption. However, from the sketch map and description given by Meyer-Abich (1956) and from the description of the large lava flow produced during the August $4-7,1962$, a different conclusion can be reached, as presented in figure 3.12. In the alternative interpretation the 1953 lava flow is much shorted and is directed to the NE into the channel of what currently constitutes Barranca Honda. A different lava flow, erupted in August of 1962, flowed down a channel that does not existing anymore, and which was tributary to Barranca Honda; the flow emplaced in this channel during the 1962 eruption was much larger ( $4.6 \mathrm{~km}$ long) and completely filled the upper Barranca channel, inverting the topography to forma ridge. Vertical elevation differences in the terrain (analyzed from DEMs representing the terrain in 1954 and 2006) of $60 \mathrm{~m}$ can be associated to the emplacement of the lava flow on this channel. 


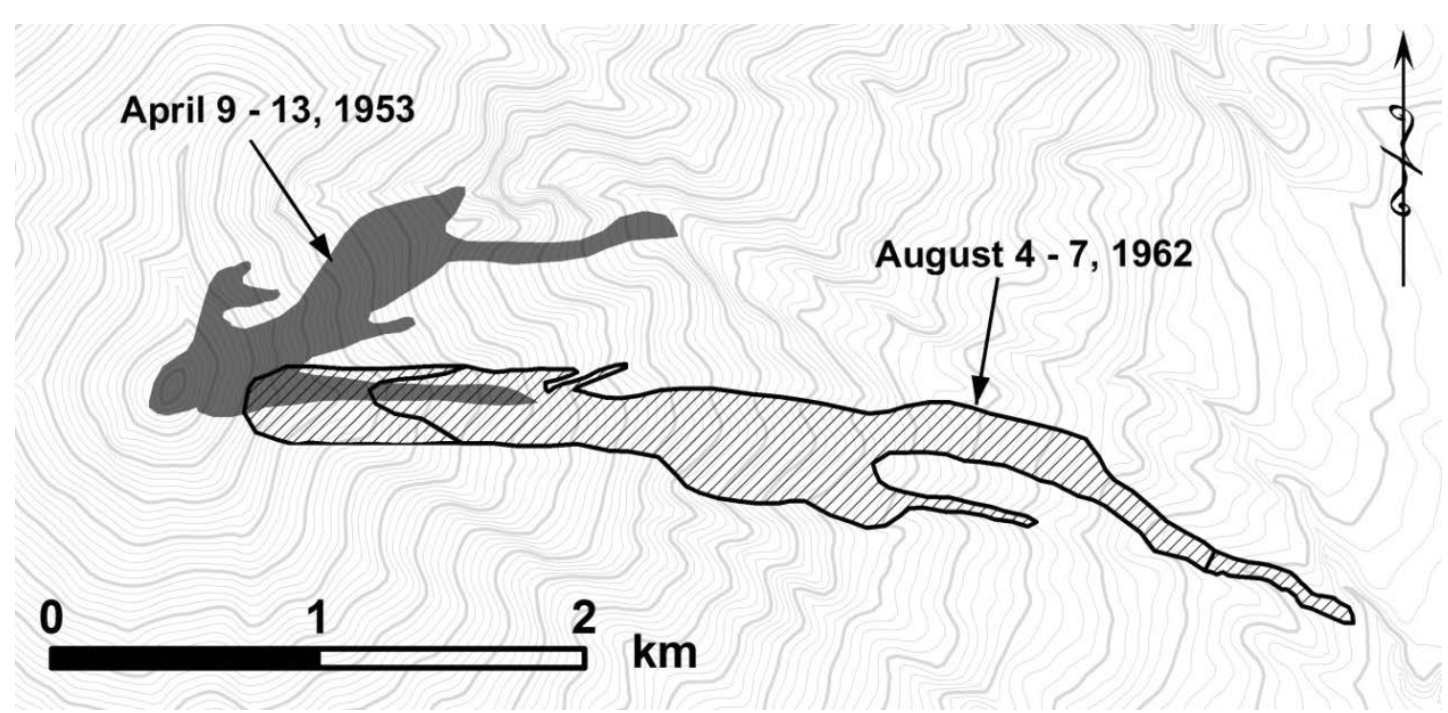

Figure 3.12. Lava flows emplaced on the east flank of Fuego volcano during the 1950's. Mapping by the author.

Some descriptions suggest a relatively high viscosity of the erupted lava (e. g. the July 1955 eruption), a behavior that would be expected at more silicic (e. g. andesitic stratovolcanoes or dacitic domes) volcanoes, but seems unlikely for the predominantly basaltic to basaltic-andesitic (bulk composition) magmas commonly erupted at Fuego. It is possible that some of the apparently more viscous flows had a more silicic composition, as no chemical analysis of these particular lavas have been published, and that the composition of later eruptive products became less silicic again. But it is also possible that other factors contributed to the apparently high viscosity of the magma, e. g. melt undercooling and dehydration, and groundmass crystallization (especially microlites).

Only one explicit reference to lahars was found for the activity between the 1932 and 1971 eruptions, corresponding to lahars that happened during an eruption on October $29-30,1963$, on Barranca Honda (Volcanological Society of Japan - IAVCEI, 1969). The lahars on October 29 spilled outside the Barranca channel, destroying cultivated and forested areas, and getting close to the road between Alotenango and Escuintla. The author mentions that the lahars on October 30 killed seven people, but gives no further details. Documentation of the activity before 1932 is restricted to witness accounts of the eruptions, which will be analyzed in more detail in chapter 5 . 


\subsection{Mapping and dimensions of deposits erupted during the 1970's}

As with the deposits from the $1999-2013$ eruptive episode, mapping of the deposits produced during the 1970's, and in a few cases deposits erupted before 1970, resulted in a dataset of 35 depositional units stored in GIS files (see appendix 3.2), from which the dimensions, including area, volume, and other general geometric characteristics of the deposits can be estimated. As discussed in chapter 2 , the main limitation is estimating realistic deposit thicknesses. Many of the deposits from the 1970's are well exposed, as erosion has cut through them, especially those non-indurated clastic deposits that are less resistant to erosion (e. g. pyroclastic flow and lahar deposits); it is however difficult in many cases to discriminate between deposits belonging to different eruptions, even in cases where exposure in outcrops due to erosion is excellent, because the large number of events and the short time between their occurrence. Nevertheless, based on fieldwork measurements and estimates of the mapped deposits thickness we can estimate reasonable minima and maxima values for the mean thickness, and a best estimated constrained within those extremes (see also the discussion in chapter 2).

For deposits that were not mapped but for which there is available information on the characteristics of the eruptions that generated them, often only at a descriptive level, we can make a rough estimate of the order of magnitude of erupted material; such an estimate is poorly constrained and has a much higher uncertainty than the estimates based on fieldwork and remote sensing mapping. Many of the events listed in table 1 of Rose et al. (1978) are included in this category.

Table 3.1 shows the volume estimates for mapped deposits and erupted volumes for eruptions previous to 1970. Many of these estimates are minima, because mapping of the deposits was limited by the availability of imagery (e. g. cloud cover obscured some of the areas in aerial photography and Landsat imagery). The total cumulative volume for the data in table 3.1 is $9.3 \mathrm{x}$ $10^{8} \mathrm{~m}^{3}$. 
Table 3.1. Dimensions of volcanic deposits erupted between $\sim 1940$ and 1978

\begin{tabular}{|c|c|c|c|c|c|c|c|c|c|c|}
\hline \multirow[t]{2}{*}{ Date } & \multirow{2}{*}{$\frac{\text { Product }}{\text { type }}$} & \multirow{2}{*}{$\frac{\text { Area }}{\left(\times 10^{6} \mathrm{~m}^{2}\right)}$} & \multicolumn{3}{|c|}{$\begin{array}{c}\text { Mean thickness } \\
(\mathrm{m})\end{array}$} & \multicolumn{3}{|c|}{ Volume $\left(\times 10^{6} \mathrm{~m}^{3}\right)$} & \multirow{2}{*}{$\frac{\text { Length }}{(\mathrm{km})}$} & \multirow[t]{2}{*}{${ }^{*} \mathrm{~A} / \mathrm{V}^{2 / 3}$} \\
\hline & & & Min & Best & Max & Min & Best & Max & & \\
\hline 1944 & Air tephra & - & - & - & - & $10^{6}$ & $10^{7}$ & $10^{8}$ & - & - \\
\hline 1947 & Air tephra & - & - & - & - & $10^{6}$ & $10^{7}$ & $10^{8}$ & - & - \\
\hline 1947 & P. flow & - & - & - & - & $10^{6}$ & $10^{7}$ & $10^{8}$ & - & - \\
\hline $\begin{array}{l}\text { Abr } 9-13 \\
1953\end{array}$ & Lava flow & $5.5 \times 10^{5}$ & 2 & 40 & 60 & $1.1 \times 10^{6}$ & $2.2 \times 10^{7}$ & $3.3 \times 10^{7}$ & 2.1 & 7 \\
\hline $\begin{array}{l}\text { Feb } 19 \text { - 21, } \\
1957\end{array}$ & P. flow & $6.2 \times 10^{5}$ & 2 & 15 & 40 & $1.2 \times 10^{6}$ & $9.3 \times 10^{6}$ & $2.5 \times 10^{7}$ & 6.9 & 14 \\
\hline $\begin{array}{l}\text { Feb } 19-21 \\
1957\end{array}$ & Air tephra & - & - & - & - & $10^{6}$ & $10^{7}$ & $10^{8}$ & - & - \\
\hline $\begin{array}{l}\text { Aug } 4-7 \\
1962\end{array}$ & Lava flow & $10^{6}$ & 2 & 10 & 20 & $2.0 \times 10^{6}$ & $10^{7}$ & $2.0 \times 10^{7}$ & 4.4 & 22 \\
\hline $\begin{array}{l}\text { Aug } 4-7 \text {, } \\
1962\end{array}$ & Air tephra & 一 & - & - & - & $10^{6}$ & $10^{7}$ & $10^{8}$ & - & - \\
\hline Oct, 1962 & Air tephra & - & - & - & - & $10^{5}$ & $10^{6}$ & $10^{7}$ & - & - \\
\hline Nov 9, 1962 & Air tephra & - & - & - & - & $10^{6}$ & $10^{7}$ & $10^{8}$ & - & - \\
\hline $\begin{array}{l}\text { Sep } 28 \text { - Oc } \\
1,1963\end{array}$ & Lava flow & - & - & - & - & $10^{6}$ & $10^{7}$ & $10^{8}$ & - & - \\
\hline $\begin{array}{l}\text { Sep } 28 \text { - Oc } \\
1,1963\end{array}$ & Air tephra & - & - & - & - & $10^{6}$ & $10^{7}$ & $10^{8}$ & - & 一 \\
\hline Feb 7, 1966 & Air tephra & 一 & 一 & 一 & 一 & $10^{5}$ & $10^{6}$ & $10^{7}$ & - & 一 \\
\hline $\begin{array}{l}\text { Apr } 20 \text { - May } \\
1,1966\end{array}$ & & - & - & - & - & $10^{6}$ & $10^{7}$ & $10^{8}$ & - & - \\
\hline $\begin{array}{l}\text { Apr } 20 \text { - May } \\
1,1966\end{array}$ & Air tephra & - & - & - & - & $10^{6}$ & $10^{7}$ & $10^{8}$ & - & - \\
\hline $\begin{array}{l}\text { Aug } 12-13 \text {, } \\
1966\end{array}$ & Air tephra & - & - & - & - & $10^{6}$ & $10^{7}$ & $10^{8}$ & - & - \\
\hline $\begin{array}{l}\text { Apr } 22 \text { - 24, } \\
1967\end{array}$ & Air tephra & - & - & - & - & $10^{6}$ & $10^{7}$ & $10^{8}$ & - & 一 \\
\hline May 3, 1967 & Air tephra & 一 & 一 & 一 & 一 & $10^{6}$ & $10^{7}$ & $10^{8}$ & - & 一 \\
\hline $\begin{array}{l}\text { Sep } 14-15, \\
1971\end{array}$ & P. flow & $6.8 \times 10^{6}$ & 2 & 15 & 40 & $1.4 \times 10^{7}$ & $10^{8}$ & $2.7 \times 10^{8}$ & 8.7 & 31 \\
\hline $\begin{array}{l}\text { Sep } 14-15 \text {, } \\
1971\end{array}$ & P. surge & $4.1 \times 10^{5}$ & 0.1 & 0.2 & 0.5 & $4.1 \times 10^{4}$ & $8.1 \times 10^{4}$ & $2.0 \times 10^{5}$ & 2.1 & 217 \\
\hline $\begin{array}{l}\text { Sep } 14-15 \\
1971\end{array}$ & Air tephra & - & - & - & - & $5.2 \times 10^{7}$ & $10^{8}$ & $3.0 \times 10^{8}$ & - & 一 \\
\hline $\begin{array}{l}\text { Feb } 22 \text { - Mar } \\
23,1973\end{array}$ & P. flow & $9.7 \times 10^{6}$ & 2 & 15 & 40 & $1.9 \times 10^{7}$ & $1.5 \times 10^{8}$ & $3.9 \times 10^{8}$ & 9.2 & 35 \\
\hline $\begin{array}{l}\text { Feb } 22-\text { Mar } \\
23,1973\end{array}$ & P. surge & $2.5 \times 10^{6}$ & 0.1 & 0.2 & 0.5 & $2.5 \times 10^{5}$ & $5 \times 10^{5}$ & $1.3 \times 10^{6}$ & 3 & 397 \\
\hline $\begin{array}{l}\text { Feb } 22 \text { - Mar } \\
23,1973\end{array}$ & Air tephra & - & - & - & - & $10^{6}$ & $10^{7}$ & $10^{8}$ & - & - \\
\hline $\begin{array}{l}\text { Oct } 10-23 \text {, } \\
1974\end{array}$ & P. flow & 2.2 & 2 & 15 & 40 & $2.2 \times 10^{7}$ & $1.7 \times 10^{8}$ & $4.4 \times 10^{8}$ & 10.1 & 37 \\
\hline
\end{tabular}


$\begin{array}{llllllll}\text { Oct } 10-23, & & & \\ 1974 & \text { Air tephra } & - & - & -6 \times 10^{8} & 2 \times 10^{8} & 4.0 \times 40^{8} & -\end{array}$

\begin{tabular}{|c|c|c|c|c|c|c|c|c|c|c|}
\hline Date & Product & Area & & $\begin{array}{l}\text { thicl } \\
(\mathrm{m}) \\
\end{array}$ & & \multicolumn{3}{|c|}{ Volume $\left(\times 10^{6} \mathrm{~m}^{3}\right)$} & \multicolumn{2}{|c|}{ Length ${ }^{*} \mathrm{~A} / \mathrm{V}^{2 / 3}$} \\
\hline \multicolumn{2}{|c|}{$\begin{array}{l}\text { May 28, } \\
1975 \quad \text { P. flow }\end{array}$} & - & - & - & - & $10^{5}$ & $10^{6}$ & $10^{7}$ & 一 & - \\
\hline $\begin{array}{l}\text { May 28, } \\
1975\end{array}$ & Air tephra & - & - & - & - & $10^{5}$ & $10^{6}$ & $10^{7}$ & 一 & 一 \\
\hline $\begin{array}{l}\text { Jul } 23 \text { - Aug } \\
4,1975\end{array}$ & P. flow & 一 & - & - & - & $10^{5}$ & $10^{6}$ & $10^{7}$ & 一 & 一 \\
\hline $\begin{array}{l}\text { Sep 18, } \\
1975\end{array}$ & Air tephra & - & - & - & - & $10^{5}$ & $10^{6}$ & $10^{7}$ & 一 & 一 \\
\hline $\begin{array}{l}\text { Oct } 11-21 \\
1975\end{array}$ & Air tephra & - & - & - & - & $10^{5}$ & $10^{6}$ & $10^{7}$ & 一 & - \\
\hline Mar 3, 1977 & Air tephra & - & - & - & - & $10^{5}$ & $10^{6}$ & $10^{7}$ & - & - \\
\hline Apr 19, 1977 & 7Air tephra & 一 & - & - & - & $10^{5}$ & $10^{6}$ & $10^{7}$ & 一 & 一 \\
\hline $\begin{array}{l}\text { Sep } 26-28 \text {, } \\
1977\end{array}$ & P. flow & - & - & - & - & $10^{5}$ & $10^{6}$ & $10^{7}$ & - & 一 \\
\hline $\begin{array}{l}\text { Sep } 26-28, \\
1977\end{array}$ & Air tephra & - & 一 & - & - & $10^{5}$ & $10^{6}$ & $10^{7}$ & - & - \\
\hline Oct 2, 1977 & P. flow & 一 & - & - & - & $10^{5}$ & $10^{6}$ & $10^{7}$ & 一 & - \\
\hline Oct 2, 1977 & Air tephra & - & - & - & - & $10^{5}$ & $10^{6}$ & $10^{7}$ & - & - \\
\hline Oct 19,1977 & 7P. flow & 一 & - & - & - & $10^{5}$ & $10^{6}$ & $10^{7}$ & 一 & - \\
\hline Oct 19,1977 & 7Air tephra & - & - & - & - & $10^{5}$ & $10^{6}$ & $10^{7}$ & - & - \\
\hline $\begin{array}{l}\text { Jan } 19-31 \\
1978\end{array}$ & P. flow & - & 一 & - & - & $10^{6}$ & $10^{7}$ & $10^{8}$ & 一 & 一 \\
\hline $\begin{array}{l}\text { Jan } 19-31 \\
1978\end{array}$ & Air tephra & 一 & 一 & - & - & $10^{6}$ & $10^{7}$ & $10^{8}$ & 一 & - \\
\hline $\begin{array}{l}\text { Nov 21, } \\
1978\end{array}$ & P. flow & - & - & - & - & $10^{5}$ & $10^{6}$ & $10^{7}$ & 一 & - \\
\hline $\begin{array}{l}\text { Nov 21, } \\
1978\end{array}$ & Air tephra & 一 & 一 & - & - & $10^{5}$ & $10^{6}$ & $10^{7}$ & 一 & 一 \\
\hline
\end{tabular}

* The parameter $\mathrm{A} / \mathrm{V}^{2 / 3}$ describes the mobility of the flow (see section 2.8)

Figure 3.13 shows cumulative erupted volume curve for Fuego volcano between 1944 and 2013 (including the data from chapter 2). It becomes apparent that the eruption cluster from 1971 to 1974 contributed with the largest part of the erupted volume. The frequent occurrence of eruptions in the $1999-2013$ period somewhat resemble the period prior to 1970 , leading to the question of whether another cluster of large eruptions may be possible in the foreseeable future, a question that may be crucial from a hazards assessment perspective. 


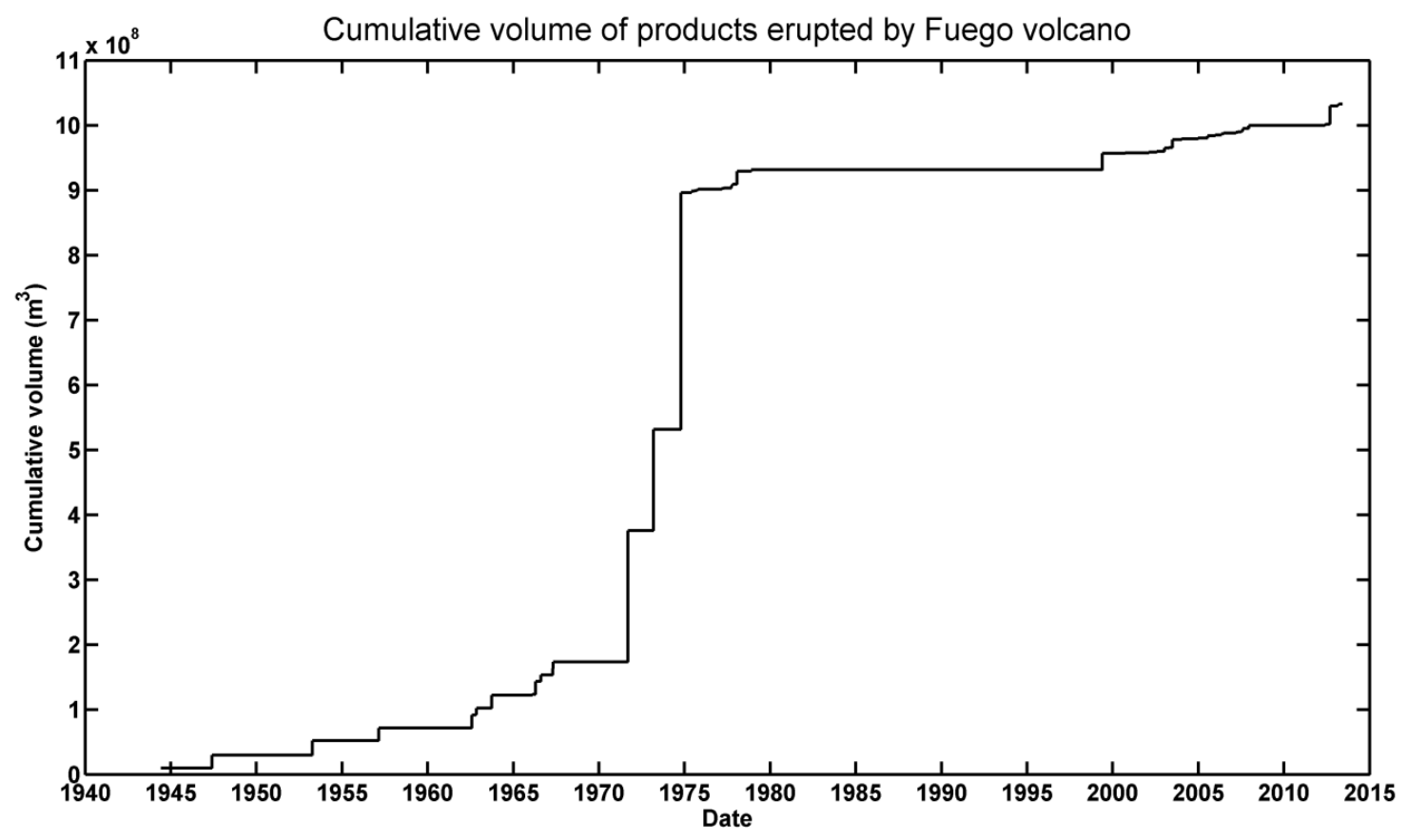

Figure 3.13. Cumulative volume of products erupted by Fuego volcano from 1944 to 2013. Based on mapping by the author.

Vessell (1979, table 1) also presented volume estimates for the pyroclastic flow deposits emplaced during the 1971 - 1974 eruptive cluster, but his value is lower, giving a total of $1.8 \mathrm{x}$ $10^{8}$, while the estimation presented here gives a total of $4.1 \times 10^{8} \mathrm{~m}^{3}$ for the total volume of pyroclastic flows erupted during the $1971-1974$ eruptive cluster. However this difference by more than a factor of 2 is still within the range of minimum $\left(5.5 \times 10^{7} \mathrm{~m}^{3}\right)$ and maximum $\left(1.1 \times 10^{9}\right.$ $\mathrm{m}^{3}$ ) values that we consider reasonable, as presented in table 3.1 , and illustrates the large uncertainties present in the volume estimates, mainly introduced by the uncertainty in the mean thickness of the deposits.

The availability of both airfall tephra and pyroclastic flow deposit volume estimates allows analyzing the partition of volume into both types of deposit. Whereas for the 1971 and 1974 eruptions the pyroclastic flows account for $51 \%$ and $45 \%$ of the total erupted volume, for the 1973 eruptions the pyroclastic flow volume represents $94 \%$ of the total erupted volume, based on a the poorly constrained volume of airfall tephra for that event. This implies that a different eruption mechanism was behind the 1973 eruptions, and further illustrates that large pyroclastic flows, on the order of $1.5 \times 10^{8} \mathrm{~m}^{3}$, can be generated in the absence of a large vertical eruptive column at the vent. 
The estimated volume partition here presented for the 1974 eruption is however very different from that given by Davies et al. (1978), who estimate a value of only $5 \times 10^{6}$ to $10^{7} \mathrm{~m}^{3}$ for the pyroclastic flows deposit, giving much smaller percentages of $2.4 \%-4.8 \%$, (using an airfall tephra volume of $2 \times 10^{8} \mathrm{~m}^{3}$ ); this difference is significant and falls outside the range of values given in table 3.1. The values given by Davies et al. (1978) fall within the volume estimates for some recent eruptions (e. g. May 21, 1999; June 29, 2003, and September 13, 2012), which seems unlikely given the field remote sensing mapping evidence. Moreover, the relatively good agreement with the total volume of pyroclastic flow material given by Vessell (1979) further supports the idea that the actual volume of pyroclastic flow material erupted during the 1974 eruptions must have been much larger, as otherwise the 1974 eruption would have only produced $3 \%-6 \%$ of the pyroclastic flow material erupted during the 1971 to 1974 cluster. In any case, these differences reflect the high uncertainty present in the volume calculations.

Lahar deposit dimensions are not included in table 3.1, and quantifying their volume is very difficult, however we can easily track the area covered by sediments, using the remote sensing data. Figure 3.14 shows the changes in the areas covered by laharic sediments along the drainages that receive sediments from Fuego's activity throughout the 1970's. The area considered is that of the drainage system before it joins the major rivers (e. g. Guacalate, Pantaleon, etc.). As it would be expected, there is a general trend of increasing area with time, presumably related to the increase in the source material for lahars provided by the recurrent eruptions. In the case of the Obispo rive the trend decreases with time, which is consistent with the channel avulsion and channel abandonment previously discussed in this chapter. Most trends tend to stabilize after 1975, growing less, or even declining slightly, presumably due to vegetation reclaiming land that recently was covered by laharic sediments. The Achiguate river is however an exception to this observation, as the area covered by sediments continues increasing at a high rate between 1975 and 1979 , such an increase may be due to delayed sediment transport in the relatively distant $(15-20 \mathrm{~km})$ location of the sediment deposition areas with respect to the volcanic sources. This further suggests that the scale of individual lahar events may not be larger than the lahar events generated after the much smaller eruptions of the current (1999-2013) eruptive episode, but that it is the longer term accumulation of such events, over several rainy seasons, what causes the more extensive distribution of laharic deposits, following the larger eruptions in the 1970's. 


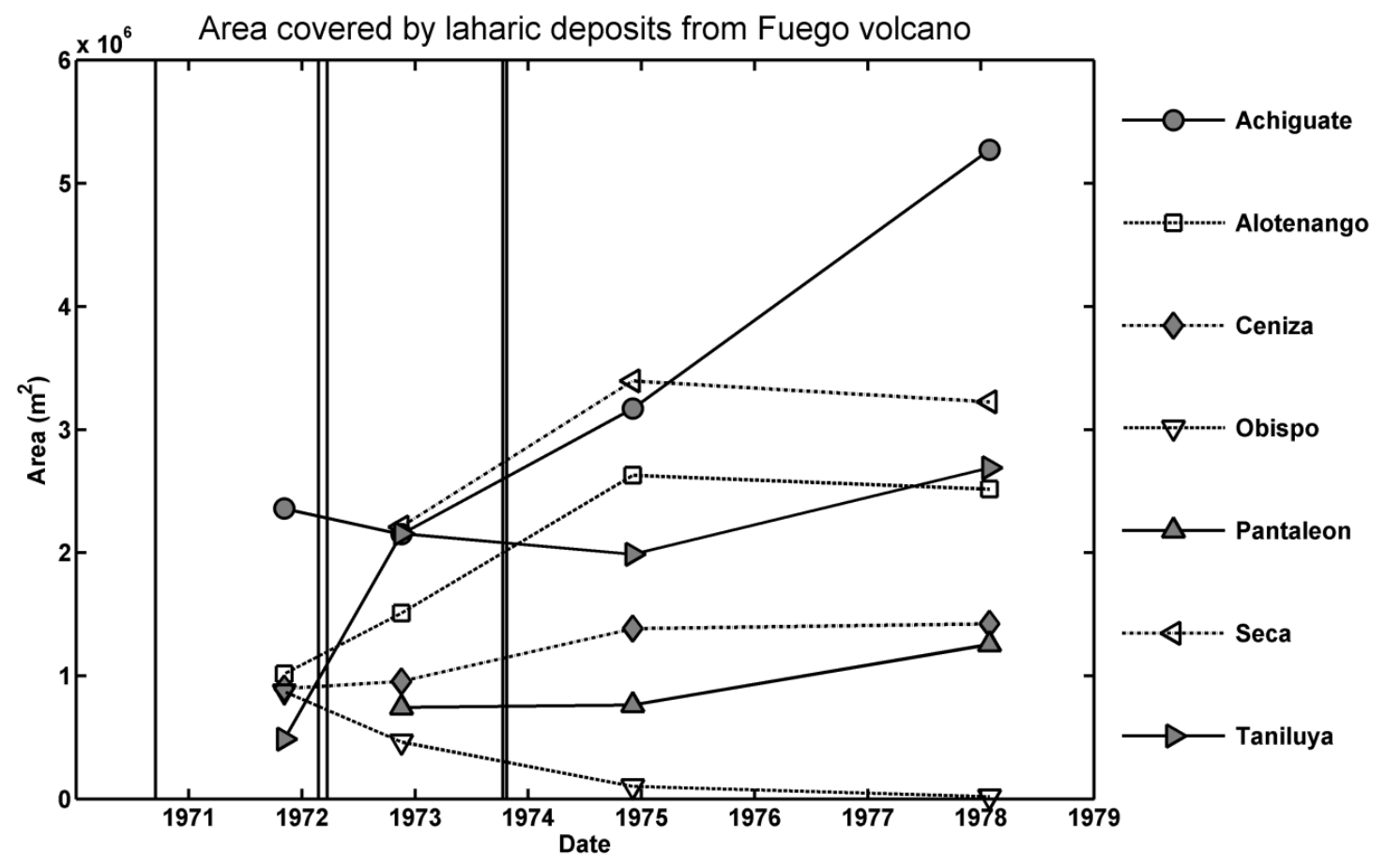

Figure 3.14. Area covered by laharic deposits originating on Fuego volcano, during the 1970s. Vertical lines represent the large eruptions in 1971, 1973 and 1974. Based on mapping by the author.

\subsubsection{Prehistoric deposits}

Prehistoric eruptions can be studied through the deposit left and constitute the majority of the deposits observed during the fieldwork (see appendix 3.1). These deposits share many of the characteristics with the more recent deposits, and only a brief overview of them will be presented here.

Prehistoric tephra fall deposits are abundant around Fuego, and given the presence of multiple possible sources (e. g. Acatenango, Fuego, and even Pacaya), also very complex to analyze. Figure 3.13 shows an example of the local tephra stratigraphy at a location $16 \mathrm{~km}$ to the NE of the vent, spanning $\sim 51 \mathrm{ka}$. This section includes some of the key regional stratigraphic markers (labeled in the figure), corresponding to silicic airfall tephra layers erupted during intermediate and large silicic eruption from other volcanoes (Koch and McLean, 1975; Wunderman and Rose, 1984; Rose et al. 1999). The section also contains more than 120 intermediate to mafic airfall 
tephra layers, showing typical thicknesses between $<5$ and $60 \mathrm{~cm}$, many of them being coarse grained and must therefore have erupted from a nearby source. The location of this stratigraphic section, between Fuego, Acatenango and Agua volcanoes illustrates the complexity of studying these deposits, as the intermediate to mafic tephra layers could have been sources from any of these volcanoes. Although Basset (1996) analyzed the tephra stratigraphy for Acatenango volcano and was able to discriminate the sources of different tephra deposits (e. g. Acatenango, Fuego, and Agua) based on geochemical fingerprinting, no attempts to identify individual tephras was done in this study.

Most significantly, none of the key stratigraphic marker tephras was found in the stratigraphic sections that were the focus of this study (at $<10 \mathrm{~km}$ from the vent, mostly within the Barrancas), suggesting that those sections were mostly younger than the stratigraphic markers. The youngest stratigraphic marker is a fine white ash $15-20 \mathrm{~cm}$ thick, which was tentatively correlated with the airfall tephra from the llopango Tierra Blanca Jove eruption, tentatively dated at 536 AD (Dull et al 2010). This may seem surprisingly young, but is consistent with the majority of the radiocarbon dates (presented later in this chapter) obtained for deposits in this study being younger than that age; only two ages are older, and correspond to deposits for which the upper part of the stratigraphic section was probably not complete.

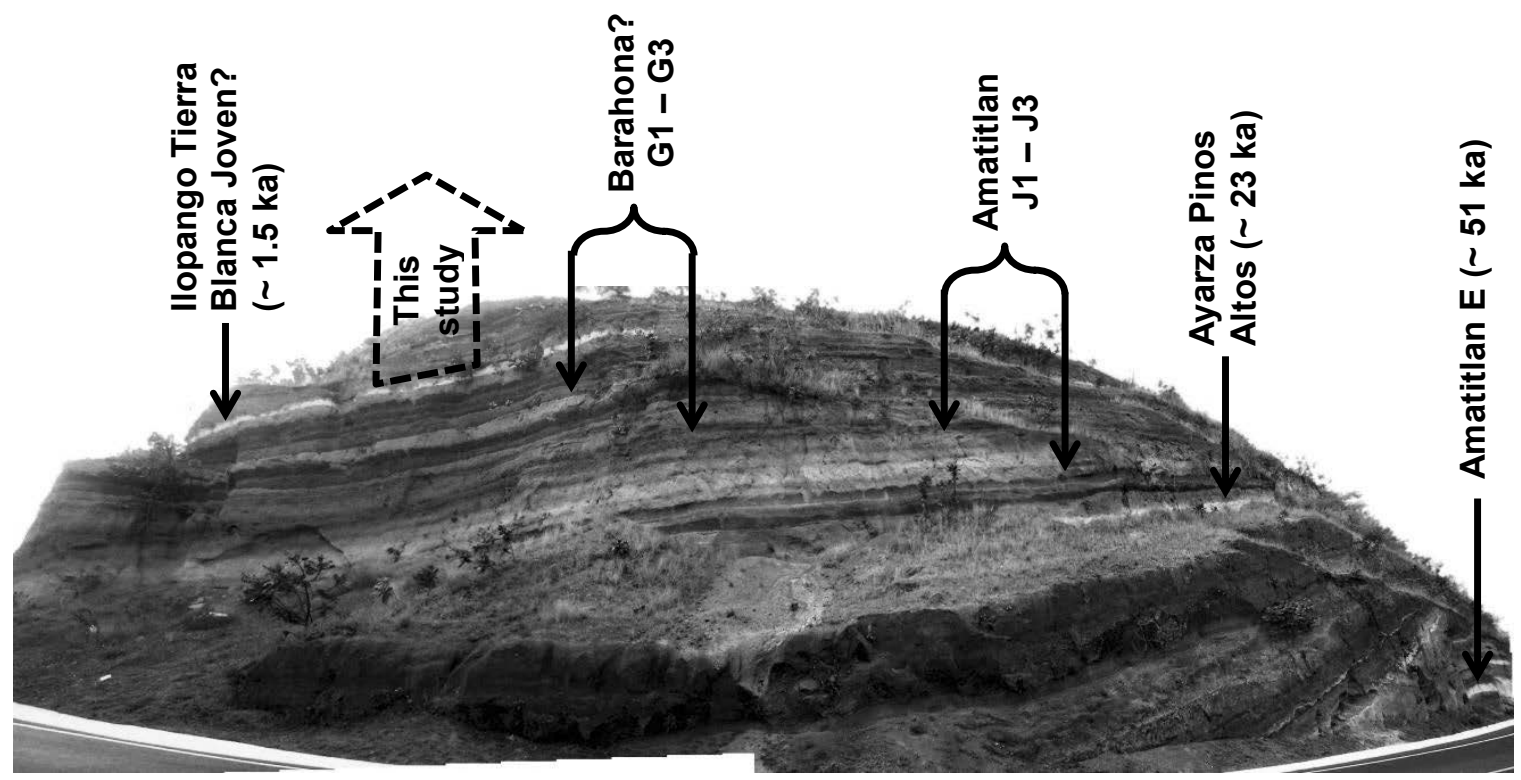

Figure 3.15. Local stratigraphic section (16 km to the NE from the vent). The whole section is $15 \mathrm{~m}$ thick and contains some 120 identifiable tephra layers (although the actual number may be much larger, especially finer tephras that have been altered and absorbed into paleosols). Reworking of the tephras is seen in some cases, but large discontinuities are not evident. Transitional gradation into silty paleosols is common, but deep clay-rich paleosols are not. 
Airfall tephra deposits within $10 \mathrm{~km}$ from the volcano are abundant, ranging in thickness from $<2$ $\mathrm{cm}$ to $>1 \mathrm{~m}$ at locations close to the vent. Clast sizes vary accordingly, from ash and lapilli dominated deposits, transitioning into bomb rich tephra deposits on the upper slopes $(<3 \mathrm{~km})$ of the volcano. Tephra is usually vesicular (scoria), and when not alterated looks similar to the tephra from recent eruptions at the hand specimen scale. Lithics (dense clasts) in tephras are usually not abundant. Individual airfall tephra units can be interleaved with other deposits (see figure 3.14 A), but are most commonly found in groups or packets of tephra layers (see figure 3.14 B and C). Flow deposits interleaved with individual tephra units are usually interpreted to be of channel facies, implying that the tephra layers were deposited inside channels, perhaps in direct relationship with the interleaving flow deposits (i. e. generated by the same eruption). Airfall tephra packets on the other hand are interpreted as deposited outside the channels. This depositional pattern then represents the contrast between the horizontally continuous nature of airfall tephra layers, mantling the topography over channels and interfluvial terrain vs. the horizontally discontinuous nature of flow deposits, which tend to be focused on the channels and topographic lows (figure $3.14 \mathrm{D}$ ). 

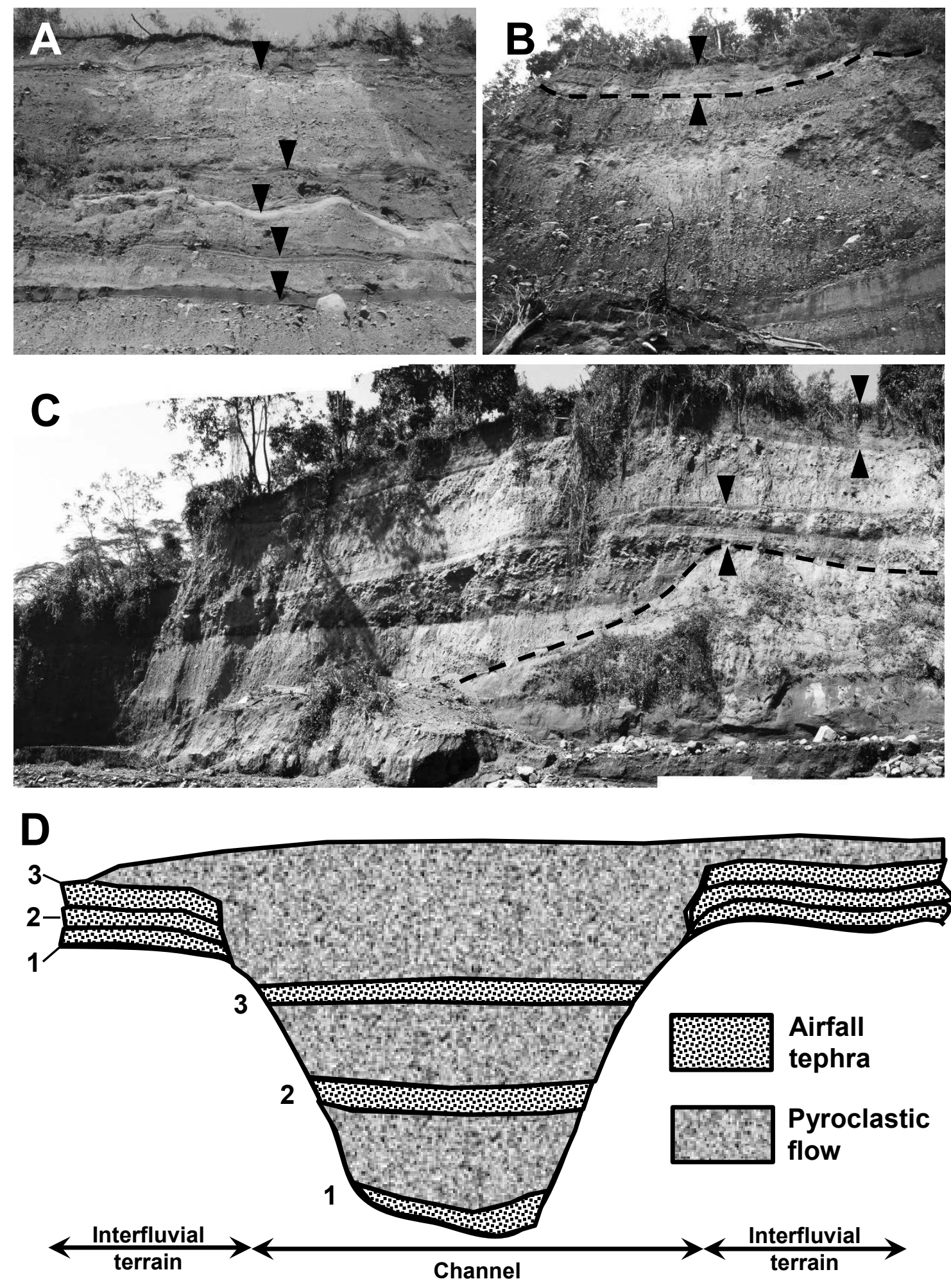
Figure 3.16. A Individual airfall tephra units (each indicated by an inverted black triangle) interleaved with pyroclastic flow deposits on Barranca Seca. B Sequence of 7 tephra fall units (indicated by the two black triangles and the dashed black line) on top of a sequence of pyroclastic flow deposits on Barranca Las Lajas. C Two airfall tephra sequences (bracketed by black triangles) are shown in between pyroclastic flow deposits on Barranca Ceniza. A paleochannel surface is indicated by the dashed black line. D. Illustration of the depositonal environment resulting in individual tephra units within the channel vs. packets of tephra units on the interfluvial terrain. Numbers 1 through 3 correspond to the same tephra units in the channel and the adjacent interfluvial terrain.

Prehistoric pyroclastic flow deposits can be challenging to identify, and especially to discriminate from lahar deposit. While recent (e. g. 1970's and 1999 to 2013) deposits can sometimes be linked to the specific eruptions that generated them and can be mapped in the field with high confidence, prehistoric pyroclastic flow deposits can look very similar to other diamictons, especially proximal lahar facies, which in most cases were probably derived from pyroclastic flow deposits. Based on characteristics observed in recent deposits we can identify many of the prehistoric pyroclastic flow deposits with a reasonable level of certainty. Deposit characteristics, as well as field relations, including features that indicate high temperature (the presence of burned wood, elutriation pipes, "baked" soils underneath, etc.), the presence of blocks with fragile cauliflower crust, the relationship with other possibly co-genetic deposits (e. g. ash cloud surges, airfall tephra), and position of the deposit with respect to the expected facies (see section at the end of this chapter), all were useful criteria to identify the deposit types. These criteria include and complement those outlined also by Vessell (1979), for deposits at Fuego volcano.

At the outcrop scale, prehistoric pyroclastic flow deposits are very similar in appearance to more recent deposits. Pyroclastic flow deposits are massive, poorly sorted, consisting of an ash to lapilli matrix with variable block concentrations. Blocks are dense and often show cauliflower crust textures. Only two deposits out of 86 sites contained abundant vesicular bombs, in one case possibly involving the mingling of two different magmas. When discernible, channel facies were more often observed than overbank facies. Carbonized wood is abundant in some deposits (especially in overbank facies), and "baked" (dark, carbon rich) soils were observed at the base of some deposits. Ash cloud surge deposits, show the typical fine grained, weakly stratified appearance of more recent deposits. Ash cloud surges were found directly underneath pyroclastic flow deposits, suggesting a co-genetic emplacement, but were not recognized as individual units outside channel environments, perhaps because of poor preservation but also due to the difficulty of recognizing such deposits as individual units among fine grained tephra deposits and soils.

Figure 3.15 illustrates some of the described characteristics. 

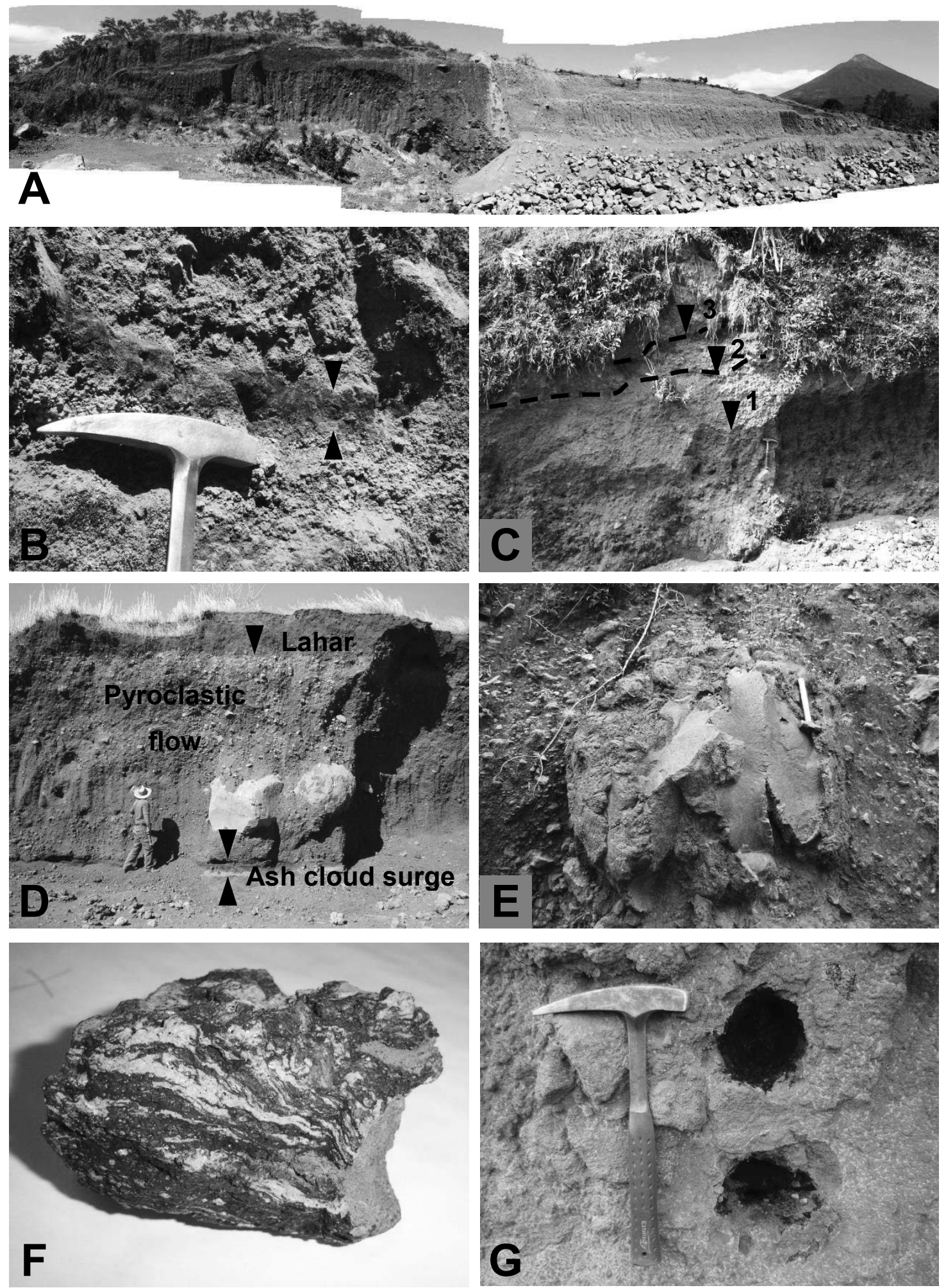
Figure 3.17. Field and hand sample characteristics of the prehistoric pyroclastic flows. A Panoramic view of a set of pyroclastic flow deposits on an open pit rock quarry on the E flank of Fuego. Sites like this one were key for interpreting the facies setting (e. g. channel vs. overflow) and relationship with other deposits. B Dark, organic rich layer (bracketed by the black triangles), including small carbonized twigs, interpreted to be a "baked soil", in contact with an overlying carbon rich pyroclastic flow deposit, in Barranca Santa Teresa. C Pyroclastic flow overbank facies, interleaved with airfall tephra deposits at a Panimache I village roadcut. Numbers 1 , and 3 correspond to pyroclastic flows, whereas number 2 is a tephra fall unit. D. Ash cloud surge deposit in contact with overlying pyroclastic flow and lahar deposits, possibly representing a continuum sequence of events triggered by an eruption, in an open pit rock quarry on the S flank of Fuego. E Cauliflower crust block embedded in a pyroclastic flow deposit on the channel wall of Barranca El Jute. Notice the loss of the fragile cauliflower crust in part of the block due to exposure of erosion. $\mathbf{F}$ Mingled magma vesicular block ( $15 \mathrm{~cm}$ diameter) from and overbank facies pyroclastic flow deposit at the Panimache I village. G Carbonized logs embedded in a pyroclastic flow deposit on Barranca El Jute.

Given the discontinuous nature of pyroclastic flow deposits over the deeply incised topography, no attempts were made to stratigraphically match deposits from different barrancas. Instead, their general stratigraphic patterns were noted and incorporated into a facies model (see section at the end of this chapter).

Prehistoric lava flows are abundant in the upper reaches ( $<4 \mathrm{~km}$ from the vent) of the Barranca channels, but become less abundant and virtually absent on the lower reaches ( $>6 \mathrm{~km}$ from the vent). In the upper reaches the flows are usually confined to the paleochannels, and in many cases form series or packets of flows, without other interleaving deposits. In most cases flow structures are typical of flows aa', with a lower and upper rubble or clinker layer, and a central massive dense lava layer. Flow thicknesses on the upper flanks are commonly between 1 and 4 $\mathrm{m}$, including the upper and lower rubble layers. Due to their more resistant nature, lava flows are many times the material forming the bed of active Barranca channels in high slope channel reaches, as was also discussed in chapter 2. At their termini, the flows often form vertical drops, as erosion is able to cut further down beyond the limit of the lava layer. Figure 3.16 shows lava flow outcrops on the higher Fuego flanks. 

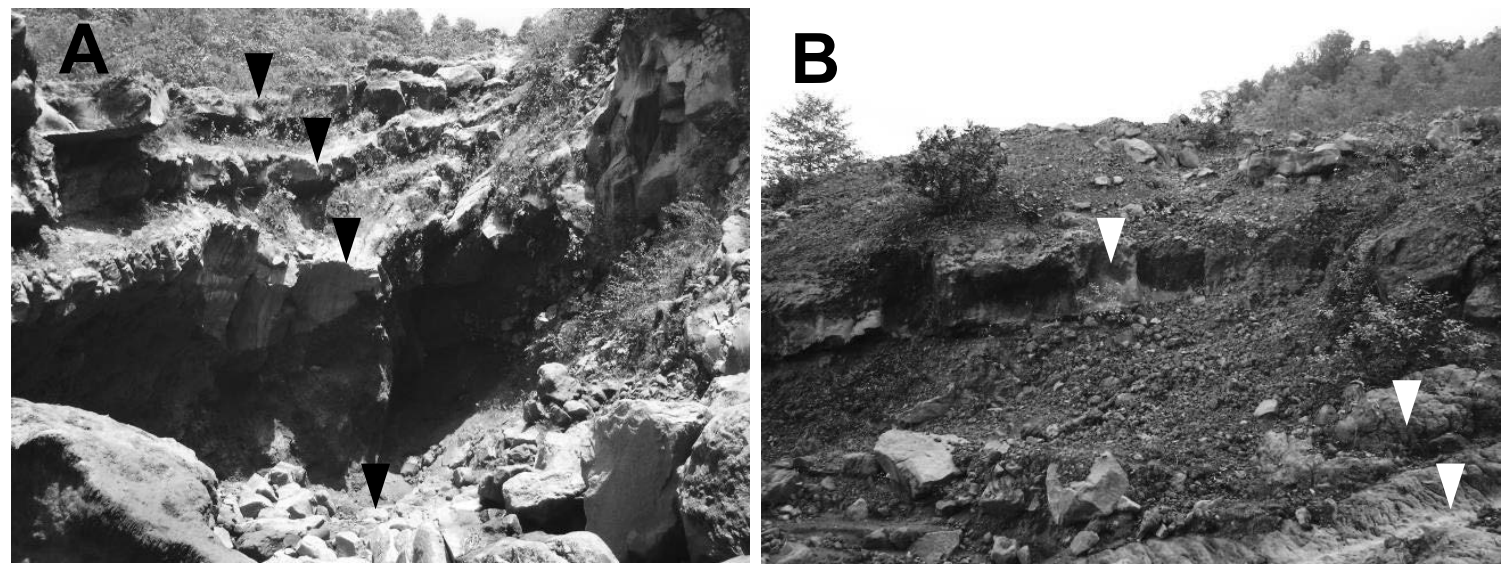

Figure 3.18. Lava flows exposed on Fuego volcano Barrancas. A Sequence of lava flows on the higher reaches of Barranca Taniluya ( $2.5 \mathrm{~km}$ from the vent). Black triangles point to the dens flow interiors, which are separated by layers of rubble, consistent with the classical model of aa' flow structure. Flows are between 1 and $3 \mathrm{~m}$ thick, and at this location the lava flows dominate the stratigraphy. B Lava flows (white triangles pointing to the dense lava cores) intercalated with pyroclastic flow deposits on Barranca Taniluya ( $4 \mathrm{~km}$ from the vent). The flows are 2 to $4 \mathrm{~m}$ thick, and are less abundant than pyroclastic flow deposits.

The description of the prehistoric deposits shows that they are very similar to more recent deposits emplaced during the 1970's and during the $1999-2013$ eruptive episode. From this analogy also follows the inference that eruptive processes in the past must have been very similar to those observed during the recent activity, including larger subplinian eruptions, producing thick airfall tephra blankets, pyroclastic flow deposits filling and sometimes overflowing Barranca channels, ash cloud surges many times associated to pyroclastic flows, lava flows and lahars. The generalized stratigraphic relations between these deposits and the typical locations on which they are expected will be discussed and integrated into an updated and more detailed facies model, in the last part of this chapter.

\subsection{Radiocarbon dating}

Pyroclastic flow deposits at Fuego are often rich in carbonized plants, this allowed us to obtain the ages of nine deposits through radiocarbon dating (see appendix 3.1). Together with 5 radiocarbon ages published by Vallance et al. (2001) for the east flank, and two additional radiocarbon ages obtained through the USGS (Jim Vallance personal communication, 2011), we can build a broad picture of the emplacement history of these pyroclastic flow deposits (see table 3.2 and figure 3.17 ). 
Table 3.2. Radicarbon ages of pyroclastic flow deposits.

\begin{tabular}{llllll}
\hline No. & Sample & Latitude & Longitude & $\begin{array}{l}\text { Radiocarbon } \\
\text { age (YBP) }\end{array}$ & Source \\
\hline 1 & F15-09 & 14.45530 & -90.96619 & $1070+/-40$ & This study \\
2 & F16-09 & 14.44136 & -90.95179 & $1060+/-40$ & This study \\
3 & F35-09-A & 14.44528 & -90.81583 & $230+/-40$ & This study \\
4 & F35-09-C & 14.44528 & -90.81583 & $130+/-40$ & This study \\
5 & F36-09 & 14.38238 & -90.85950 & $2170+/-30$ & This study \\
6 & F37-09 & 14.42248 & -90.82278 & $1980+/-40$ & This study \\
7 & C5-11 & 14.40682 & -90.84193 & $310+/-40$ & This study \\
8 & C2-11-A & 14.46330 & -90.83191 & $5370+/-50$ & This study \\
9 & C1-11-A & 14.44202 & -90.84115 & $<60^{*}$ & This study \\
10 & C14 F10-1 & 14.43206 & -90.93659 & $370+/-50$ & J. Vallance / USGS \\
11 & PF Morelia & 14.42048 & -90.95128 & $420+/-30$ & J. Vallance / USGS \\
12 & V-F13 & 14.45826 & -90.81342 & $970+/-50$ & Vallance et al. 2001 \\
13 & V-F14-A & 14.45544 & -90.81371 & $1375+/-45$ & Vallance et al. 2001 \\
14 & V-F14-B & 14.45544 & -90.81371 & $1050+/-70$ & Vallance et al. 2001 \\
15 & V-F15 & 14.44792 & -90.81099 & $1330+/-60$ & Vallance et al. 2001 \\
16 & V-F16 & 14.43527 & -90.81488 & $3560+/-70$ & Vallance et al. 2001 \\
\hline * & &
\end{tabular}

* The sample is contaminated with modern "bomb carbon" and is therefore assumed to be younger than 60 years.

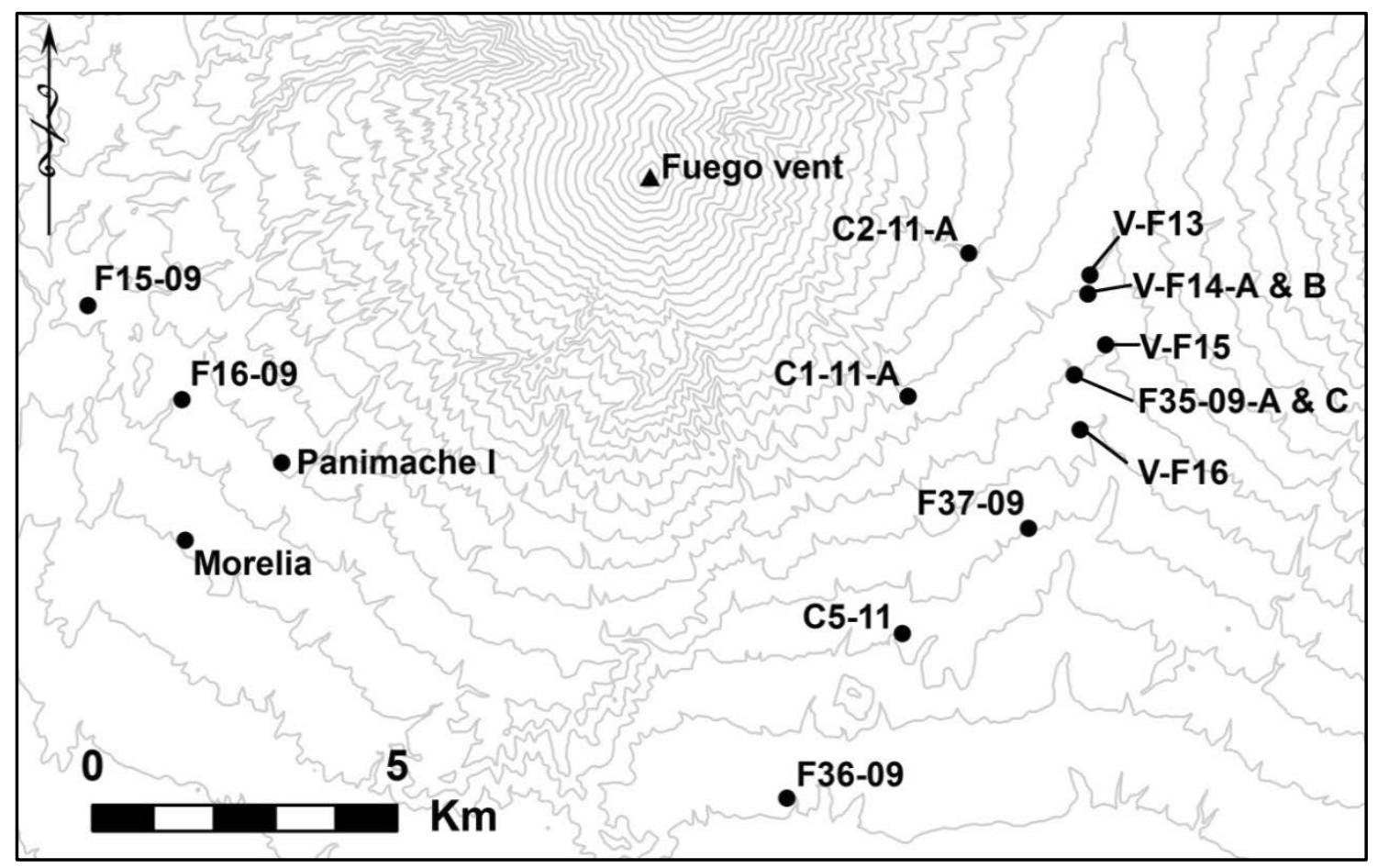

Figure 3.19. Radiocarbon dated deposit locations. See table 3.2 and text for details. 
Calibrated age PDFs for radiocarbon data from pyroclastic flows from Fuego and Acatenango volcanoes

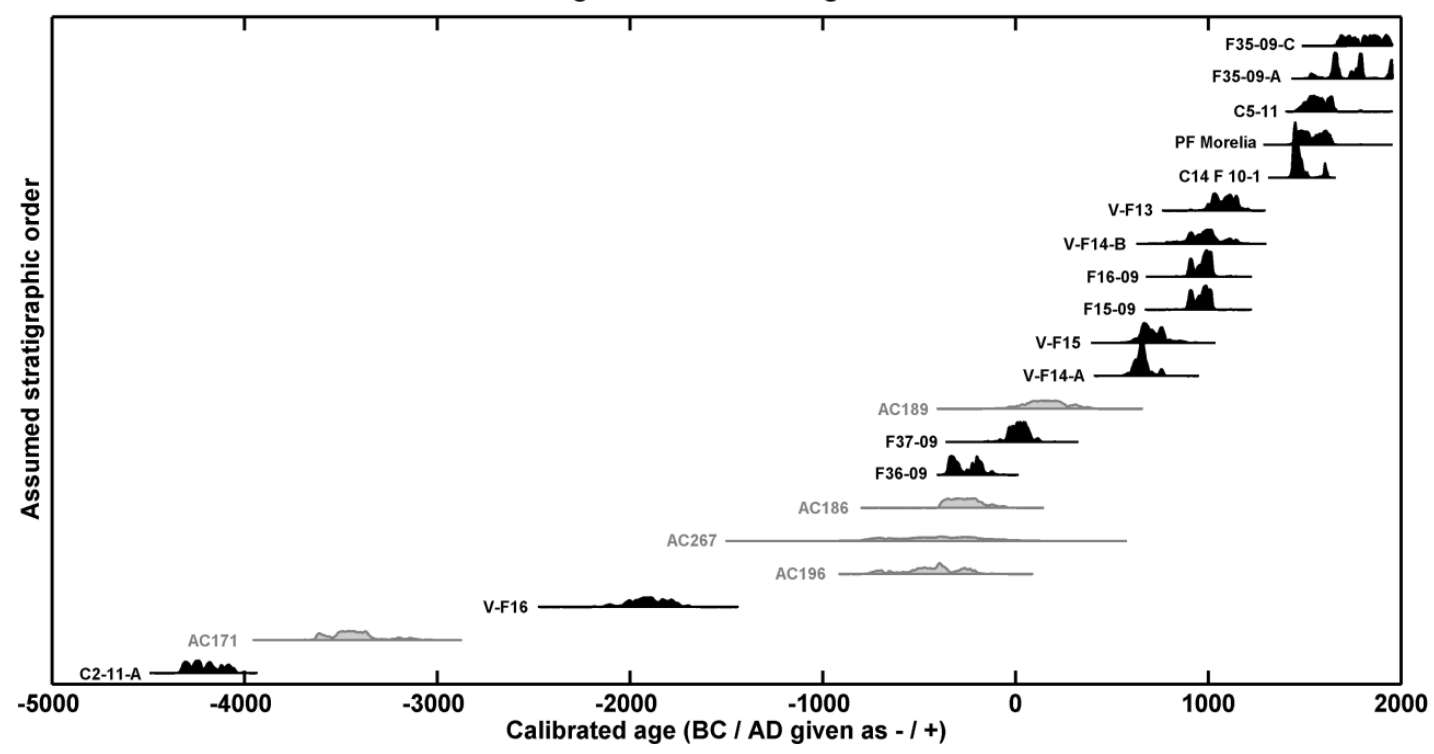

Calibrated age PDFs for radiocarbon data from pyroclastic flows younger than $\sim 2500 \mathrm{YBP}$

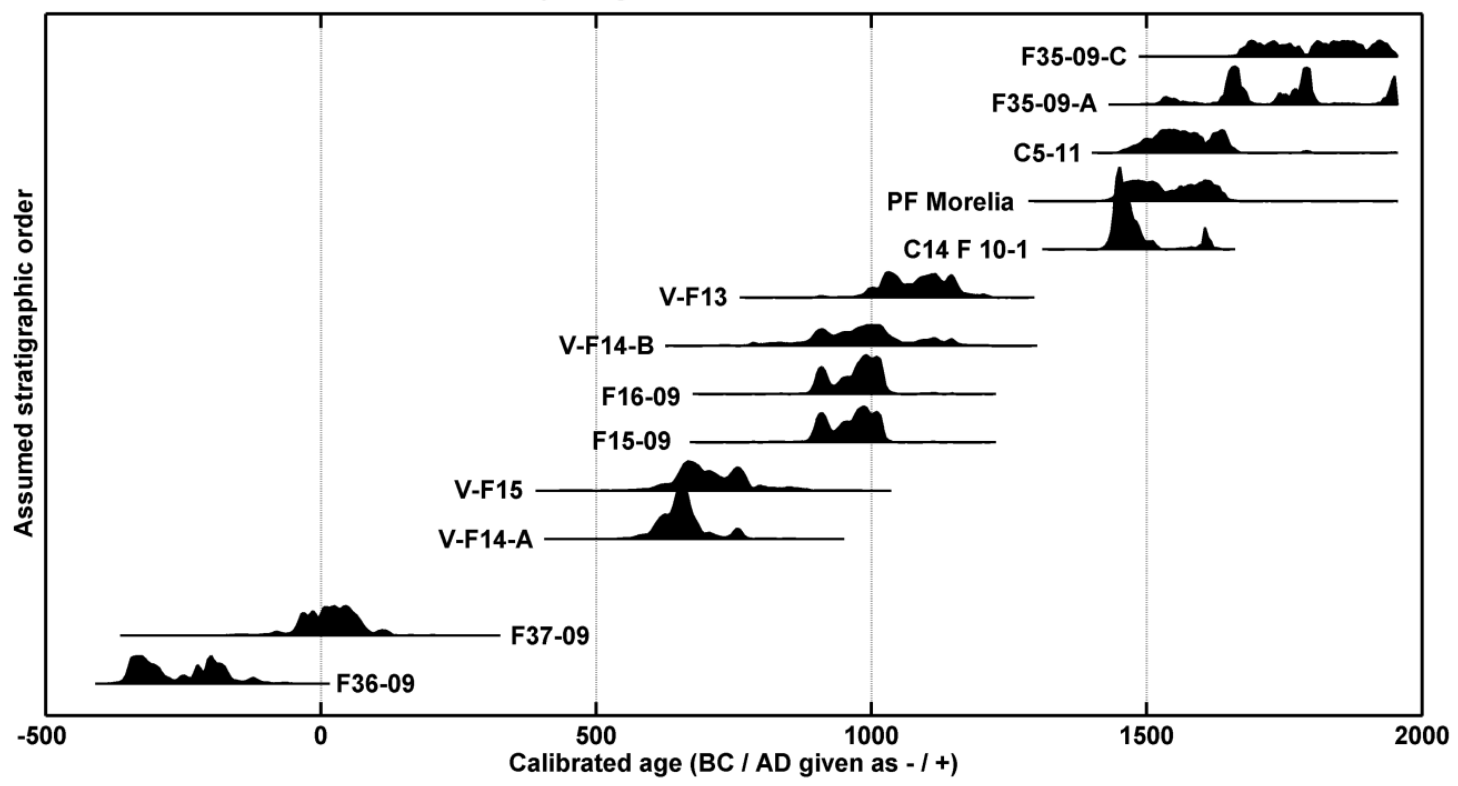

Figure 3.20. Calibrated age probability density functions (PDFs) obtained from the radiocarbon dates given in table 3.2. Calibration was done with OxCal 4.2 software (Bronk Ramsey, 2009), using the IntCal09 calibration curve (Reimer et al. 2009). A Entire age dataset for Fuego volcano (in black), with ages from radiocarbon dates reported by Basset (1996) for Acatenango volcano.(in gray). B Ages for Fuego volcano younger than 500 BC.

Surprisingly the ages obtained are mostly younger than $2.5 \mathrm{ka}$, reflecting the young age and high level of activity that the volcano has maintained over that period of time. Although some of the 
ages overlap with those reported by Basset (1996) for Acatenango volcano (see figure 3.18 A), most of the dates do not, suggesting that activity between both volcanoes may have alternated through time. The new published ages in this study (samples 1 through 11 in table 3.2), include 5 dates which overlap with the historic record (since the XVI century), and therefore would correspond to eruptions that may have been recorded in historical accounts. These new young ages have also important implications for assessing the hazards due to Fuego's activity, as the previously published ages on which Vallance et al. (2001) based their assessment fall outside the historical time range, and the corresponding eruptions were judged to be larger than those see in the historical record, implying that such large eruptions hadn't happened during the last five centuries; the evidence here presented suggests otherwise. The implications for interpreting the historical record and the impact on assessing the hazards will be discussed in more detail in chapter 5 .

\subsection{A revised and expanded facies model for Fuego}

From the preceding sections, and from the description of the activity and deposits in chapter 2, we conclude that prehistoric and recent deposits are very similar, and therefore the processes that generated them were probably also similar. In this section a generalization of the observations reported so far will be made, to derive a facies association model that takes into account the stratigraphic observations, the geomorphology and the possible volcanic processes that originate the different types of products at Fuego.

In a seminal paper, Vessell and Davies (1981, see also Vessell, 1979) outlined a facies association model for the eruptive products of Fuego volcano, and for the derived laharic (alluvial) and fluvial products. Their model was based on observations of the volcanic an laharic activity in the 1970's, and proposed four different facies (association) types: core, proximal, medial and distal, and each facies was linked to a genetic process (sedimentation). They also described the time evolution of the facies model as a series of phases linked to the volcanic activity and the periods of repose. The idea of facies models to characterize and describe central and composite volcanoes was further developed, and later expanded and adapted to other volcanoes, e. g. Ruapehu (Hackett and Houghton, 1989; Palmer, 1991; Palmer et al, 1993). The facies model then becomes fundamental to understand, characterize and describe the formation and evolution of composite volcanoes (Davidson and Silva, 2000). The facies model proposed by Vessell and Davies (1981) can be updated and adapted to the observations reported in this and the previous 
chapter, by considering in more detail the processes and products of the volcanic activity, as be detailed in the current section.

A series of general stratigraphic relations can be established for different locations on the volcano, based on the observations of the recent (1999 - 2013 and 1970's) and prehistoric deposits. Considered in order of distance from the vent, different regions on the volcano will have a characteristic stratigraphy. The area occupied by the vent has remained mostly inaccessible throughout the duration of the study due to the eruptive activity, but from distant observations, and a few close range observations (e. g. figure 2.43) it can be gathered that the main deposit types consist of lava and ultraproximal fall deposits (bombs, spatter, scoria, etc.). Subsurface intrusions and additional complexities are likely to be also present. Although not considered by Vessel and Davies (1981), this region would be equivalent to the "central vent facies association" described at Ruapehu by Hackett and Houghton (1989). For Fuego volcano this region is currently very small, centered on the active vent and extending to a distance of $\sim 200 \mathrm{~m}$.

Deposits produced by the low level background activity during the 1999 to 2013 period consisted mainly of lava flows and colluvium from hot rockfall avalanches, produced by the collapse of lava flow fronts and the impact of ballistics from small explosive eruptions (see section 2.5, and particularly figure 2.12). The material is confined to the "proximal active areas" and transitions from the lava dominated upper reaches, to the clastic material dominated lower reaches. Airfall tephra is also important in this region, but many times is remobilized from the steep slopes, becoming part of the rockfall-avalanche continuum. The geomorphology of this area is dominated by the active area channels, bounded by the much less active planezees. This is equivalent to the "volcanic core facies" defined by Vessel and Davies (1981). This region extends to a distance of $2 \mathrm{~km}$ from the vent, and includes slopes between $30^{\circ}$ to $40^{\circ}$. These will be named "proximal cone facies"

Larger than background eruptions during the 1999 to 2013 period, and similar size explosive eruptions in the 1970's, produced pyroclastic flows and lava flows that advanced beyond the "proximal active areas", flowing into well defined, and deeply entrenched Barranca channels. Field mapping on the upper reaches of those channels show that on higher slopes $\left(>15^{\circ}\right)$ the stratigraphy is dominated by both lava and pyroclastic flow deposits, and to less extent by airfall tephra. Lahar deposits on such high slopes are minimal, as lahars are usually very erosive in such an environment, removing, rather than depositing material, as this is part of their source region. Most of the activity observed on this region happened within the Barranca channels. Although erosive potential is high, the common presence of lava flows provides some resistance 
to the erosion, limiting the depth of some channels; this results in a high channel density, forming a geomorphologic pattern of alternating channel and ridge relief (see figure 3.19). This region would be roughly equivalent to the "proximal volcaniclastic facies" of Vessell and Davies (1981), and it extends, with some variation depending on which flank of the volcano is being considered, to distance of $\sim 3.5-5 \mathrm{~km}$ from the vent, over channel thalweg slopes between $15^{\circ}-30^{\circ}$, and will be named "medial cone facies".

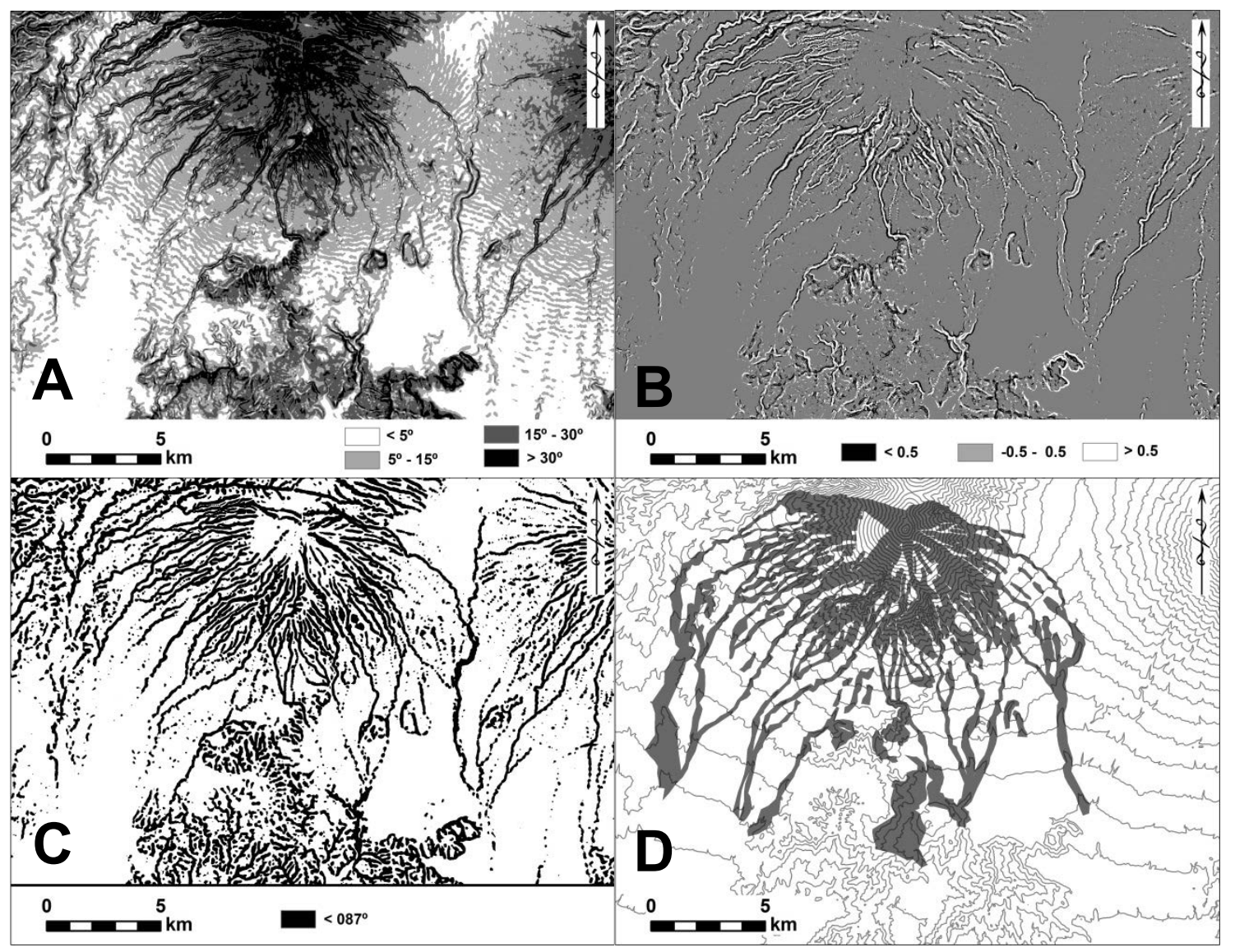

Figure 3.21. Geomorphologic properties of Fuego's terrain. A Slope map, showing the transitions between slopes ranges discussed for different facies associations in the text. The strong striped pattern can be seen around the transition $5^{\circ}$, reflecting an interpolation artifact inherited from original the elevation contour dataset from which is what generated. B Profile curvature map, for the same area as in A. Notice the strong pattern displayed by the channels $(>0.5)$ and ridges (<0.5). C Positive topographic openness map (Yokoyama et al., 2002) for the same area as in A. Notice again the strong patter displayed by channels (openness $<87^{\circ}$ ), making it easy to isolate them. D Map of areas classified morphologically as channels (in gray). The terrain geomorphology changes with distance from the vent, from a channel and ridge dominated region (completely gray) corresponding with the proximal cone facies, to an alternating channel and interfluvial terrain (alternating gray and white) geomorphology, corresponding with the pyroclastic flow apron facies. All images created by the author. 
Pyroclastic flows, especially those associated with larger eruptions, are much more mobile than lava flows, extending farther within the Barranca channels and on to lower slopes; this has a direct impact in the depositional environment, resulting in a region where the stratigraphy is dominated by pyroclastic flow deposits. In this region the deposits are intercalated with airfall tephra, and only occasionally with lava flows. Although discriminating lahar from pyroclastic flow deposits in the field can be challenging, as discussed earlier in this chapter, the observations about lahar generation during the 1999 - 2003 and 1970's eruptive periods suggests that lahars are generally erosive in this region, presumably due to the slope of the channels $\left(5^{\circ}\right.$ to $\left.15^{\circ}\right)$ and the lahar generation mechanism, and therefore lahar deposits are uncommon in this region. It is the presence of abundant, non-indurated pyroclastic flow deposits in this region what actually fuels the lahars associated to normal rainfall, making this the main source region for the lahars. This process results in a very unique geomorphology, dominated by large Barranca channels alternating with the relatively gentle interfluvial terrain, to form a "pyroclastic flow apron" (see figure 3.19).

The activity is confined to the channels, unless the magnitude of the event (i. e. pyroclastic flow) exceeds the channel capacity, causing channel avulsion and deposition of pyroclastic flow material on the interfluvial terrain. Subsequent lahar erosion will either re-establish a similar sized channel in the same location, if there was no avulsion, or at a different location if avulsion happened. In this interpretation, it is through the avulsion - channel shifting process that this part of the volcanic edifice is built over time. A key feature that has to be highlighted in this model is that the processes of channel avulsion and erosion are driven by two fundamentally different agents: pyroclastic flows drive the deposition process, while lahar flow drives the erosion process. As such, the coupled avulsion and channel erosion process should be considered as a category on its own, among other volcanic-alluvial-fluvial processes, i. e. in contrast to the alluvial avulsion and erosion processes, which are part of a continuum driven by water flow, the pyroclastic flow avulsion and laharic erosion process requires the interaction of two very different driving agents.

In the context of the 1970's vs. the $1999-2013$ eruptive periods, it is very likely that the much larger and frequently recurring pyroclastic flows during the 1970's did not allow the channels system to recover, entering a positive feedback loop in which larger flows diminished the channel cross sections and therefore cause a widespread distribution of pyroclastic flows, at least on the Alotenango and Barranca Seca - Santa Teresa fans. During the 1999 - 2013 period in comparison, the channel cross sections were much larger and remained so during most of the activity period, contributing to the limited extension of the pyroclastic flow deposits. 
This region transitions into the next "laharic and fluvial plain", and defining a boundary is as difficult as discriminating between lahar from pyroclastic flow deposits in the mapping process, but from the observations and mapping of eruptive products from the recent eruptions, the pyroclastic flow apron will extend from the transition with the proximal cone $(\sim 3.5-5 \mathrm{~km})$ to distances of $8-12 \mathrm{~km}$ from the vent, where it transitions into the laharic and alluvial plain. The facies in this region would also be part of the proximal volcaniclastic facies defined by Vessell and Davies (1981), as they do not make the distinction between lava and pyroclastic flow vs. pyroclastic flow only, dominated facies.

Arguably, if erosion is capable to remove most of the material deposited by pyroclastic flows before the next event happens, as seems to have been the case for some of the studied eruptions, the long term addition of pyroclastic material by this mechanism would be minimal, but the existence of pyroclastic flow apron itself is a prove that pyroclastic material addition to the area has so far outweighed the erosive redistribution of that material. The recognition of a pyroclastic flow apron not only stresses the importance that pyroclastic flows have in building the volcano, but it also highlights their importance as a hazard, since many of the villages surrounding the volcano are located on this facies region.

As lahars transport material through lower slope terrain their behavior transforms from predominantly erosive to depositional. This creates a stratigraphy dominated by lahar deposits, equivalent to the medial volcaniclastic facies defined by Vessell and Davies (1981), extending from the transitional region with the pyroclastic flow apron $(8-12 \mathrm{~km})$ to the transition into predominantly fluvial facies, e. g. the distal volcaniclastic facies. These facies extend to the lowest slopes on which laharic transport will commonly occur, but due to the continuum spectrum for water-sediment flow phenomena, that transition is rather gradual, as has been also documented for Fuego by Davies et al. (1979), and dilution of the flow as it enters larger order streams, further complicates the picture. Taking the study by Davies et al. (1979, figure 10), the mean grain size of deposits on the river channels draining Fuego fall from $0.3-0.4 \mathrm{~m}$ at $\sim 20 \mathrm{~km}$ from the volcano to $<0.01 \mathrm{~m}$ at $\sim 30 \mathrm{~km}$, reflecting the change from laharic - hyperconcentrated flow dominated regime to normal fluvial sediment transport, coincident with slopes $<1^{\circ}-2.5^{\circ}$. This will be denominated the "lahar plain facies".

This classification of facies is mapped and presented in figure 3.20. As discussed in this section, the boundaries between facies are in many cases transitional rather than abrupt, such that the limits shown in the map have to be taken as only indicative. The obvious asymmetry resulting from the presences of other relief forms (e. g. Acatenango volcano to the north and the tertiary 
volcanic complex to the south) complicate the shape of the polygons defining the facies association regions, which for a more symmetric volcano (e. g. the adjacent Agua volcano) would result in more circular shaped zones.

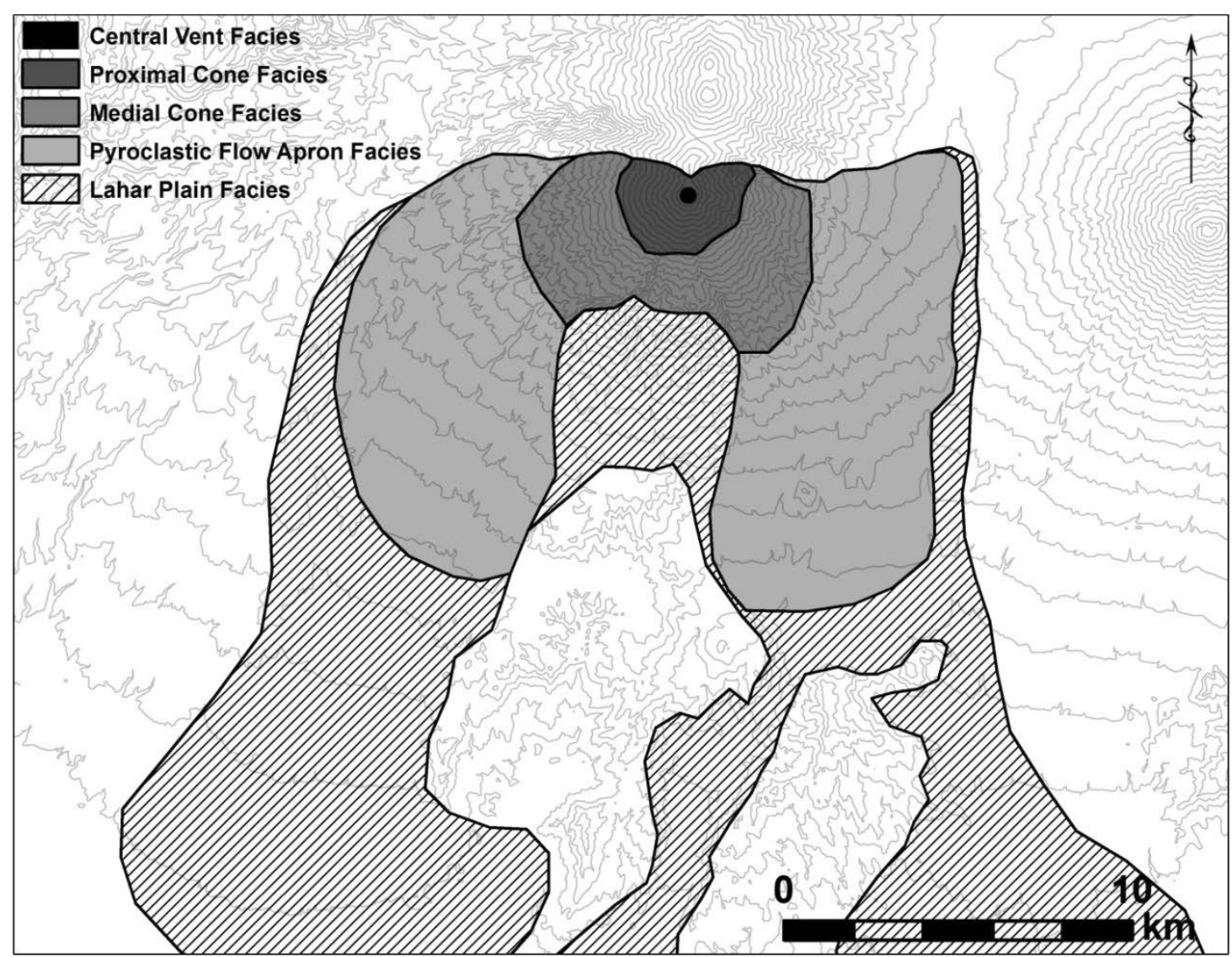

Figure 3.22. Spatial distribution of the different facies associations.

The main difference with the facies model originally developed and presented by Vessell and Davies (1981) is the identification and highlighting of the pyroclastic flow apron, as a distinctive facies association, associated to the complex interplay between pyroclastic flow deposition and laharic erosion, and with a unique geomorphologic expression. Volumetrically, from the perspective of the processes operating to build the volcanic edifice, and from a hazards assessment point of view, the importance of the pyroclastic flow apron facies becomes clear, and in the case of the hazards, will be discussed in more detail in chapter 5 .

By considering several new pieces of information in the facies model, some of the relationships between the process and the deposits, in the context of the local geomorphology are also 
explained. This allows a generalized spatial representation of the facies associations to be conveyed in a map.

\subsection{Evolution of Fuego volcano through time.}

The eruptive activity of Fuego has been documented in several historical sources of information, covering as far back as the early $16^{\text {th }}$ century. This information has been compiled into several catalogs of eruptions, e. g. the catalog compiled by the Global Volcanism Program (GVP). However, the catalogs are incomplete and many of the entries are uncertain, and the quality of the catalog degrades as records go back in time to the earlier periods covered in the catalogs. Not only is it uncertain whether some of the eruptions happened or not (some entries could be eruptions at other volcanoes, only earthquakes, etc.), but the dates, and perhaps more importantly their magnitude is also very difficult to assess. Because of these issues the information contained in the historical documents that were used as a basis for the eruption catalogs was revisited. This required tracking back the original references that describe the volcanic eruptions in documents going as far as the early $16^{\text {th }}$ century, and including the transcripts (and translations in most cases) of the relevant documents. The compilations of these transcripts can be found in appendix 3.3.

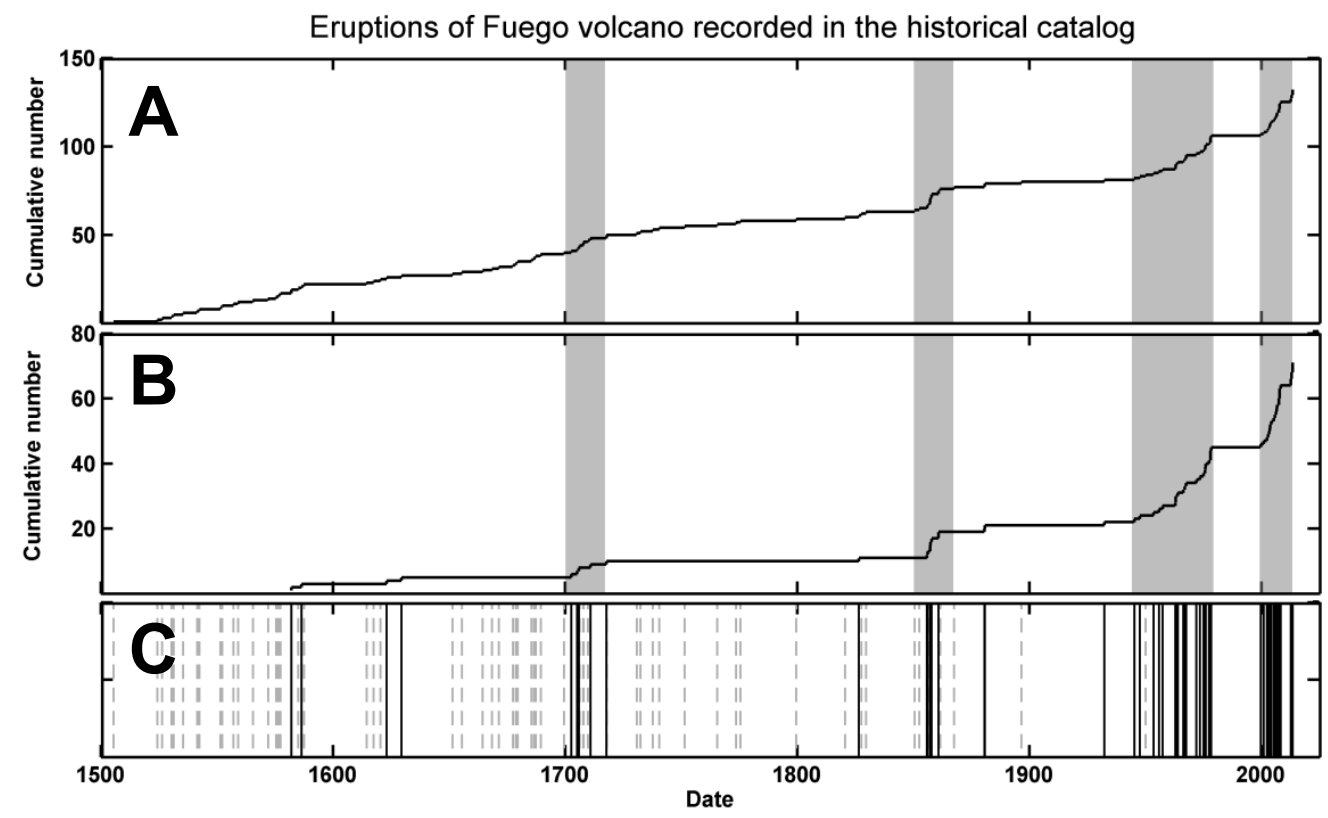

Figure 3.21. Historical records of eruptions at Fuego volcano. A Cumulative plot of eruptions for the entire catalog, including those eruptions that are uncertain. Clusters of eruptions are 
highlighted by the gray vertical bars. B Cumulative plot of eruptions including only those eruptions that are certain. Clusters of eruptions are highlighted by the gray vertical bars. C Plot of eruptions vs time. Uncertain eruptions are represented by gray dashed lines, while certain eruptions are represented by black vertical lines.

The reliability of the eruptions reported in the catalog was assessed based on those documents, and despite the limitations imposed by the data quality, a basic statistical analysis can be performed, similar to the analysis at the end of chapter 2. Figure 3.21 shows the record of eruptions compiled from the historical documents, and catalogs like the one published by the GVP. Both the entire catalog of eruptions, including those eruptions that are uncertain (figure 3.21 A), and the catalog that includes only the eruptions for which there is substantial documentation and proof (figure $3.21 \mathrm{~B}$ ) show clear signs of clustering, around the $1700-1717 \mathrm{AD}, 1850-1860$ AD, $1944-1979$ AD, and the 1999 - 2013 period; this partially confirms previous ideas about the activity at Fuego (e. g. Martin and Rose, 1981), however the results of fitting the data to probability distributions shows that the differences between the datasets can be very important.

Figure 3.22 shows the probability distribution fits for the catalog considering all the possible eruptions. The dataset is best fitted by a Weibull distribution on the longer end of the intereruption intervals, but is better fit by a Log-logistic distribution on the shorter end of intervals. The situation however is very different when only the certain eruptions are taken into account, as can be seen in figure 3.23. This second dataset is better fit by a Weibull distribution. 

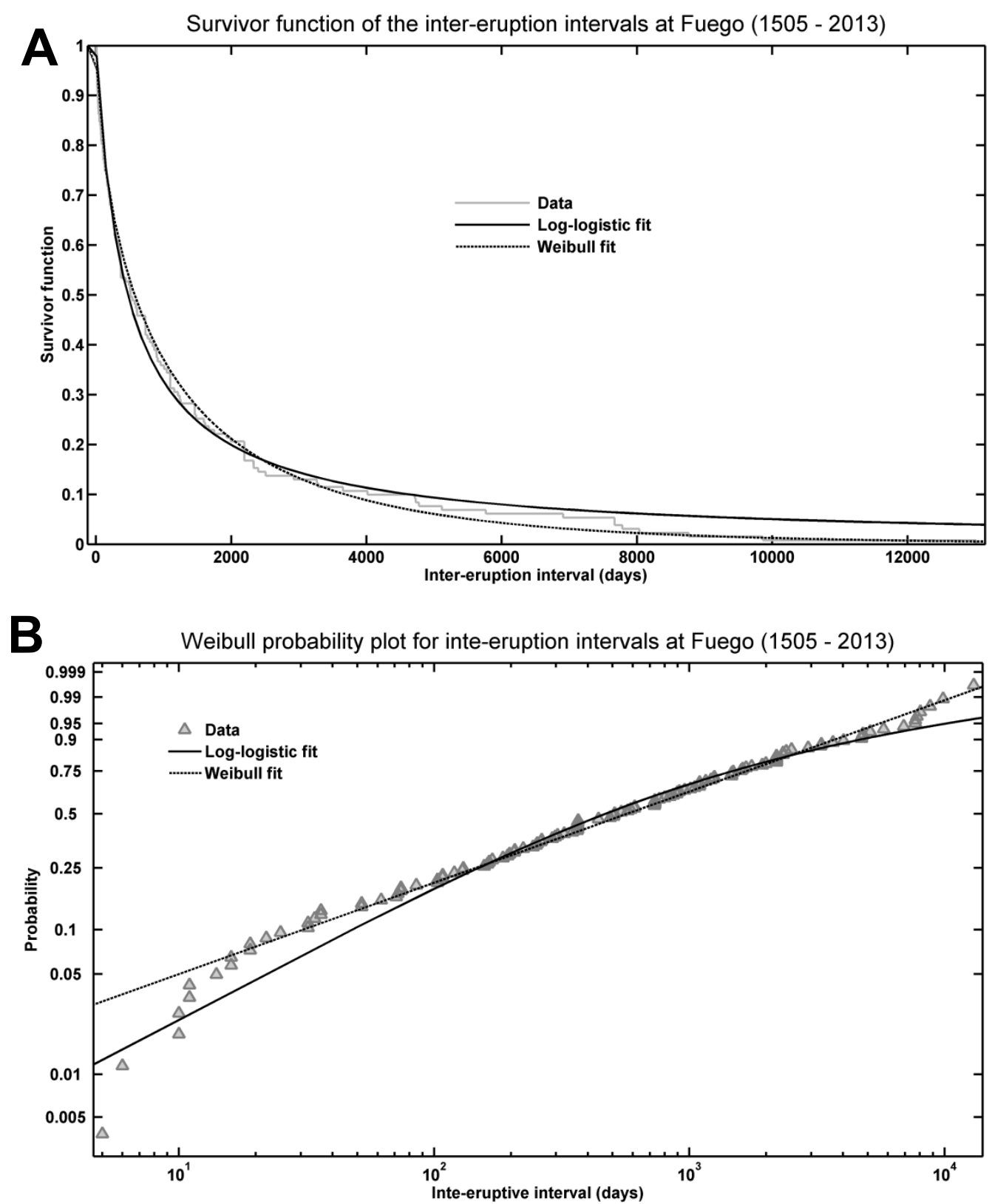

Figure 3.22. Log-logistic and Weibull fits to the entire catalog of eruptions (including uncertain eruptions). A Survival function fit. B Weibull probability plot. 

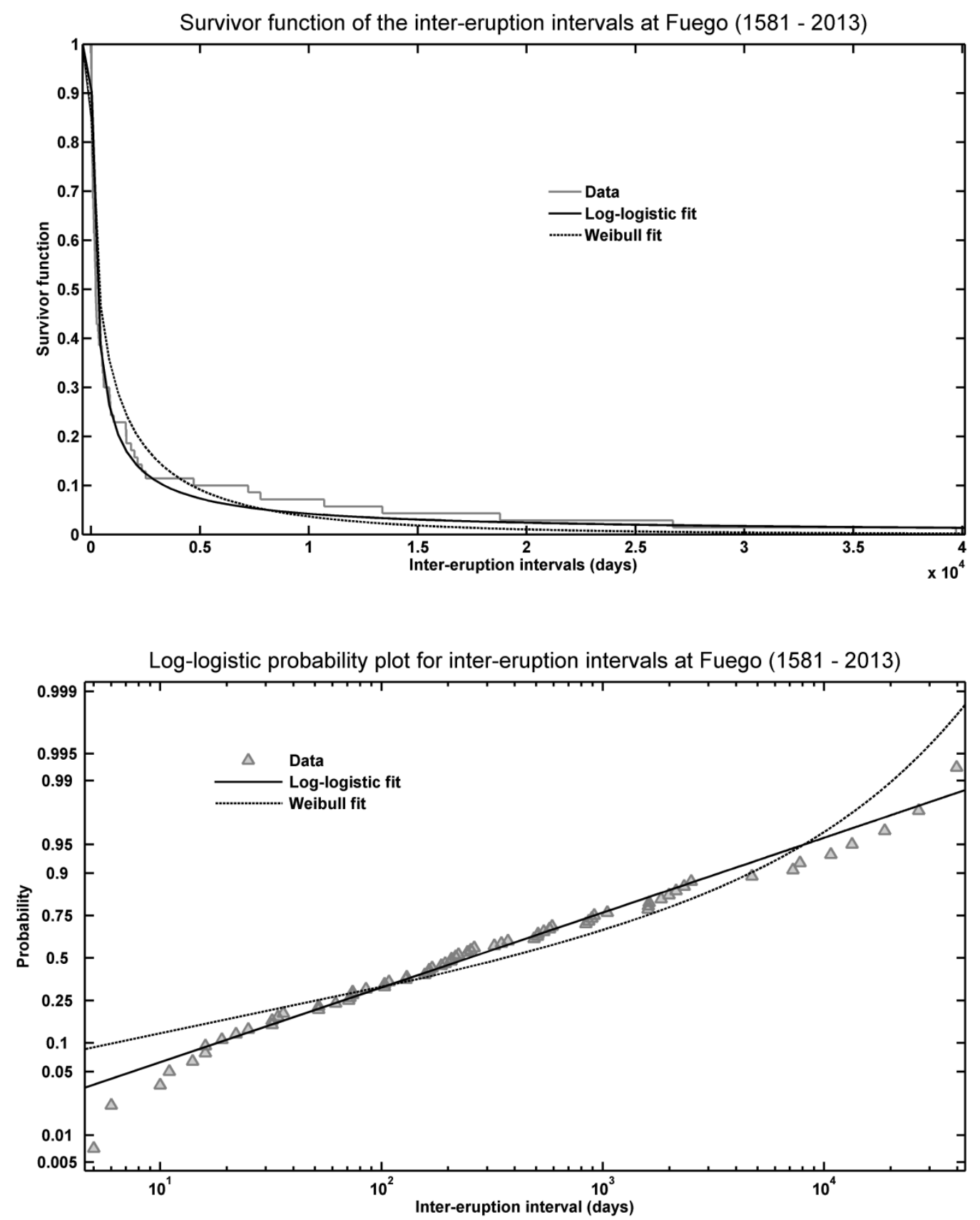

Figure 3.23. Log-logistic and Weibull fits to the catalog of eruptions including only certain eruptions. A Survival function fit. B Weibull probability plot. 
Fuego's eruptive activity beyond the historical record and the radiocarbon dates presented here is poorly constrained. Vallance et al. (2001) reported two ${ }^{40} \mathrm{Ar} /{ }^{39} \mathrm{Ar}$ ages from La Meseta, of $234+/-$ $31 \mathrm{ka}$ and $18+/-11 \mathrm{ka}$, which may imply that Fuego is mostly younger than $18+/-11 \mathrm{ka}$.

However, if Fuego's and Meseta's activity overlapped in time, the age of Fuego wouldn't be constrained by the Meseta age. The radiocarbon dates shown in this work are very young, for instance compared with the dates obtained for Acatenango by Basset (1996), but this may just be result of the very high level of activity of Fuego during the last few thousand years, which could have led to the burial of most older deposits by younger ones; the sampling done for this work only penetrated few hundreds of meters into the stratigraphic sequence of Fuego's edifice, and as such the early history of Fuego may not have been sampled. Further dating, especially of older lavas to the South of the volcano may help to better assess the older ages of Fuego's initial stages.

Volumetrically however, the sampled section could be significant. Taking Fuego's average radial profile, extracted from a DEM and rotating it to form and idealized (radially symmetric) volcanic edifice allows us to get an idea of how the summit elevation changes in relationship to the edifice volume. This calculation is based on some simplifying assumptions, including a flat basement for on which the volcanic edifice is built. In reality the pre-volcanic edifice basement is very complex, approximately sloping down from the highlands north of the volcano, to the lowlands south of it, but as a first order approximation, this model illustrates the main characteristics of the elevation volume relationship. Figure 3.24 A shows the smoothed (by a fourth order polynomial) average profiles of Fuego volcano, together with the corresponding edifice volume values. As it can be seen from the figure the relationship between summit elevation above the base and volume is not linear; as the edifice height increases the base radio increases at a much faster rate, due to the profile concavity, even faster than for a cone. For instance, increasing the edifice height above the base by $500 \mathrm{~m}$, from 1000 to $1500 \mathrm{~m}$ increases the edifice volume from 2 to $9 \mathrm{~km}^{3}$. But increasing the height $500 \mathrm{~m}$ from 3000 to $3500 \mathrm{~m}$ increases the edifice volume from 164 to 550 $\mathrm{km}^{3}$.

This has two immediate implications: first it implies that for a constant eruption rate, the edifice summit elevation slows down through time (see figure $3.24 \mathrm{~B}$ ). This may help to explain the reason why the volcanoes only attain a maximum height between 3500 and 4200 masl. The second implications of the elevation - volume relationship is that the upper few hundred meters of the stratigraphic section of a volcano may represent a large percentage of the edifice volume. Following this logic, the ca. $200-400 \mathrm{~m}$ that were accessible for sampling within the barranca channels may correspond to the youngest $\sim 50 \%$ of the volcano's volume. 

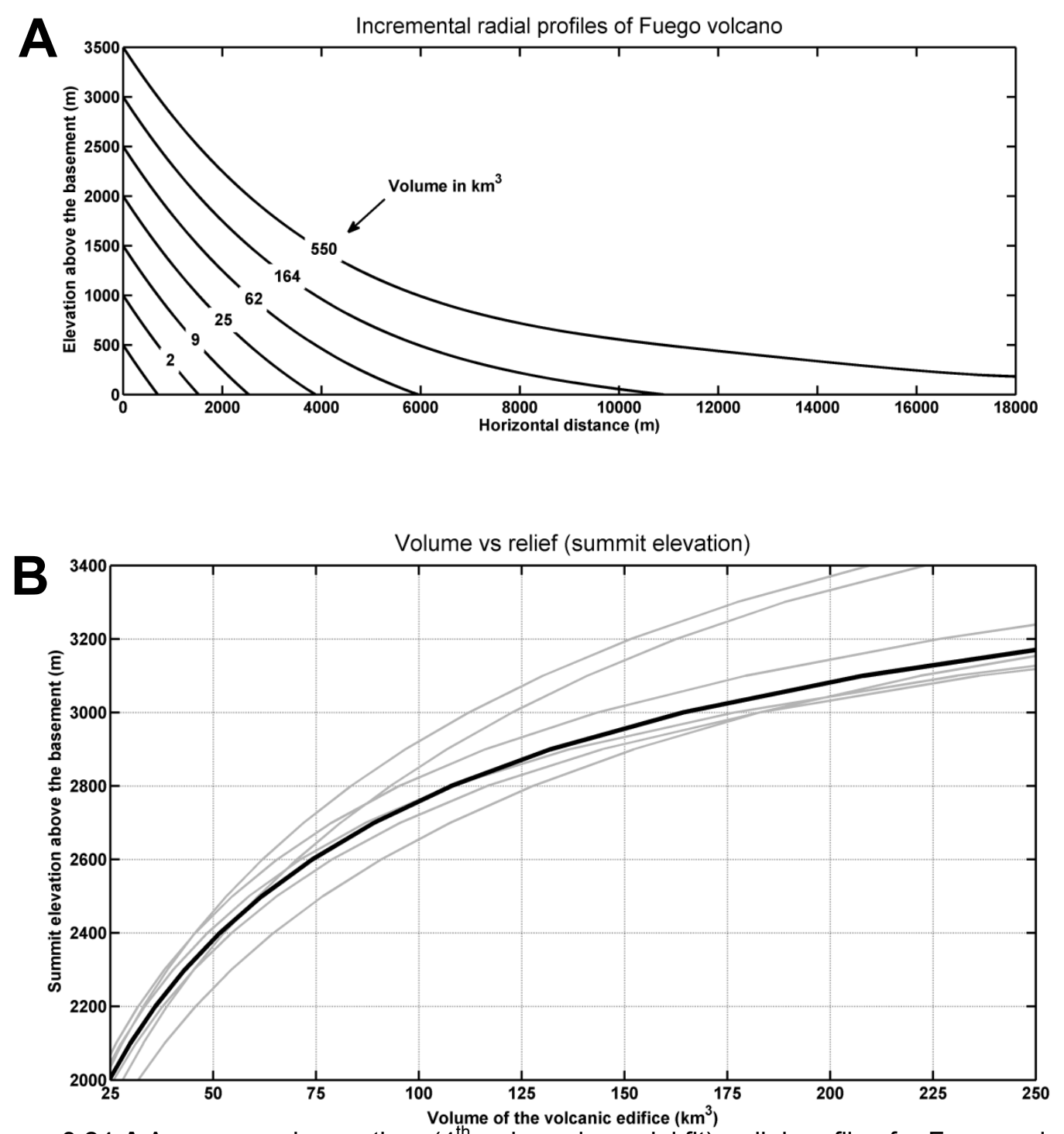

Figure 3.24 A Average and smoothen $\left(4^{\text {th }}\right.$ order polynomial fit) radial profiles for Fuego volcano showing the corresponding edifice volume values. B Relationship between edifice volume and summit elevation above the base for Fuego volcano (black thick line) and other large stratovolcanoes on the Guatemalan volcanic front.

In addition to the volumetric argument, as Vessell and Davies (1981) had originally proposed, and has been shown in both chapters 2 and 3 , the erosion and transport of erupted material, especially pyroclastic flow deposits, can quickly remove large volumes from the upper and medial sections of the cone, and redistribute that volume to the lower (ring plain or laharic plain) part of 
the volcanic - alluvial system. This would be enhanced as the cone grows in stature, and would further slowdown the growing process. Finally, in the case of tephra fall, most of the erupted volume is not even deposits on the volcanic edifice per se (see figure 3.2). Based on these arguments it can be seen that a significant fraction (perhaps as large as $50 \%$ ) of the Fuego edifice volume could have been emplaced in the last $5 \mathrm{ka}$, and in that case a young age for the whole edifice, as has been suggested before (e. g. $<18$ +/- $11 \mathrm{ka}$ ) may not be unreasonable.

\subsection{Conclusions}

The eruptive activity prior to the current (1999 - 2013) episode at Fuego volcano shares many characteristics with the activity since 1999, but the scale of some of the eruptions (e. $\mathrm{g}$. September 1971, February - March 1973, and October 1974) exceeds at least by one order of magnitude any of the events happening during the $1999-2013$ period, in terms of the volume of the pyroclastic flow and airfall tephra deposits. Lava flows, although not well documented, also happened during the 1950's to 1960's, at a scale comparable to lava flow effusion during the 1999 to 2013 period (e. g. the January 9 - 10, 2004 and December 15 - 16, 2007 lava flows). The impact of laharic activity following large eruptions in the 1970's, quantified by the area covered by sediments during those years, was also much larger than laharic activity occurring during the 1999 - 2013 period, including the activity related to extreme rainfall events.

Although some volcanic processes during previous (pre-1999) eruptions have no analogy during the current eruptive episode, the similarity of products and visual observations in case of the historical eruptions, suggest that many of the volcanic phenomena share a common mechanism, and therefore the inferences drawn from observing the volcanic processes during the current eruptive episode may be generalized to older, and perhaps much larger occurrences of the same phenomena. Airfall tephra produced by the large eruptions in the 1970's, reaching a subplinian level require a fundamentally different eruptive mechanism than the relatively minor ash eruptions seen since 1999, but pyroclastic flows which form very similar deposits, despite the difference in scale, may share a common generation mechanism, even when such mechanism is not clearly understood at this time (e. g. column collapse, "boiling over", fountain collapse, lava flow collapse, etc.). Lahar activity also seems to have a common origin despite the size of the deposit from which they originate, and the generating mechanism, e. g. due to normal vs. extreme rainfall.

The similarities of the deposits are also shared by those produced during prehistoric eruptions. A systematic stratigraphic pattern emerges from observing the prehistoric deposits, associated to the paleo-topography at the time the deposits were emplace; e. g. packets of tephra fall layers 
occur in the interfluvial terrains, whereas interleaved airfall tephra and pyroclastic flow deposits tend to occur on channel filling environments. Radiocarbon dating of pyroclastic flow deposits shows that the explosive activity at Fuego has been recurrent over the last $\sim 5 \mathrm{ka}$, producing several larger deposits well into the historical (post XVI century) period. These deposits are widespread, and in some cases the overbank facies of these young deposits are today the location of villages; the consequences today of eruptions similar to those generating such deposits could be catastrophic.

Combining the observations on the general stratigraphy, with the processes that generate and transport the volcanic materials, and with the local geomorphic characteristics of the terrain, an expanded model of facies associations for the Fuego eruptive and laharic products is proposed, focusing on the identification of a particularly significant facies, dominated by pyroclastic flow deposits. 


\section{People's expectation of future eruptive crises at Fuego volcano and their willingness to evacuate}

\subsection{Introduction}

Volcanic risk, as is the general case for risk associated with any natural or human caused hazard, confronts people with the decision of whether or not to take specific action to reduce it; a decision problem arises because in general there is a cost or some other negative aspects that must be assumed from taking the risk reduction actions (Fischhoff et al. 1983). Volcanic risk is often dealt with during crisis conditions as an eruption is imminent or already ongoing, and the relevant risk reduction decision to be made by people exposed to the volcanic hazard is whether or not to evacuate, especially in cases when the population is exposed to lethal hazards that are impossible to manage otherwise. In such a situation the perceived likelihood of suffering the potentially damaging consequences of an eruption have to be weighed against the perceived cost or otherwise negative effects of evacuating.

This is the case of Fuego volcano in Guatemala, where people may be faced with the decision to evacuate during a crisis, a decision that will depend on how the population perceives the risk, but also depends on how they perceive the potential cost or negative effects associated with an evacuation. People's decisions to evacuate under different crisis scenarios is investigated through the application of a survey, and focus especially on the issue of the perceived negative effects of a potential evacuation, comparing them to other common variables that usually are considered as driving human behavior in the face of risk.

\subsubsection{Risk and evacuations at Fuego volcano}

Fuego volcano has had a long history of large and violent explosive volcanic eruptions, the last one happening in October 1974 (Bonis and Salazar, 1973; Davies et al. 1978; Rose et al, 1978); however, several moderate size eruptions have also happened since 1999 (Lyons et al. 2009; this thesis chapter 1). Many of these eruptions have triggered crisis responses involving the national civil protection agency, local authorities and the general population of the villages closest to the volcano. From a volcanological perspective the possibility of large pyroclastic flows (mixtures of hot gases, rocks and dust moving at high speed across the landscape) reaching populated areas near the volcano during a large eruption would be the main motivation to call for an evacuation during a crisis. The last of such eruptions happened at the time of writing of this report, producing relatively large pyroclastic flows, a sizable ash cloud and triggering the evacuation of several 
thousand people from the communities on the SW flanks of Fuego. This recent crisis is therefore the first of such large scale evacuations since the 1974 eruptions.

The experience gained by the author as part of his work with the Guatemalan Government Coordination Agency for Disasters Reduction (CONRED) since 2001 and following fieldwork as part of this doctoral research, has allowed him to gain a general picture on the recent crises and people's response to it. During the large eruptions that happened in the 1970's, most people in the villages on the South-West flanks of the volcano spontaneously evacuated out of the area of heavy tephra (ash and sand) fall. Evacuations were much more reduced in other areas not affected as strongly by tephra fall, although these areas were most likely in a similar level of exposure to the pyroclastic flow hazards. However, even in the villages that were evacuated not all the population left during those crises, as groups of men were organized to stay in the evacuated villages and take care of the buildings and property, mainly to protect the property from looting and keep the roofs free of tephra to avoid their collapse. This choice was obviously made at the expense of exposing those who stayed in the villages to the hazard of tephra fall, and much more importantly, to the hazard of pyroclastic flows, although this last consideration may have been less clear to people at the time. Women, children and the rest of the men evacuated to communities outside of the zone most affected by tephra fall.

The logistics of evacuation were complicated by the lack of vehicles to transport all people, the difficulty of transit in areas that were already affected by heavy tephra fall (vehicles became stuck in the loose tephra), and the lack of a planned response, especially regarding the accommodation of large quantities of evacuees, which led to very poor sheltering conditions for the evacuees. The hardship faced during those evacuations is still remembered vividly by many people in the villages around Fuego volcano.

Both CONRED and the National Institute of Seismology, Vulcanology, Meteorology, and Hydrology (INSIVUMEH) have had a long standing presence in the area of the surveyed villages. CONRED has collaborated with volunteers who usually belong to the community level disaster reduction committee, and operate a radio link and early warning base for CONRED in the area. Since 2001 CONRED has engaged with the villages, first through the PREVOL project aimed to raise awareness about the volcanic risk and to organize the local disaster reduction committees (Sanchez, 2002), and since 2007 through a project to develop a more comprehensive early warning system to deal with volcanic crises. In this context CONRED and INSIVUMEH with financial support from the Japanese government through the Japanese International Cooperation Agency (JICA) have joined efforts with the local population to organized a series of risk 
awareness and preparedness building activities, including frequent meetings with the local emergency committees to discuss emergency protocols during crisis, workshops on volcanic risk management, volcanic crisis simulations, and evacuation route signaling.

INSIVUMEH has operated two small volcanological observatories in the villages of Panimache I and Sangre de Cristo, these observatories employ one or two local individuals to perform visual observations of the volcanic activity and communicate them to the central headquarters in Guatemala City. The presence of these observatories has created an important link between INSIVUMEH and those communities. INSIVUMEH has also had a key role in the projects developed by CONRED, as INSIVUMEH is officially the technical agency responsible of advising CONRED on the scientific and technical aspects of the volcanic phenomena.

\subsubsection{The villages near Fuego volcano}

Fuego volcano is surrounded by several small villages and plantations located at distances between 7 and $12 \mathrm{~km}$ (see Figure 4.1). The villages are set in a rural environment, with agriculture representing the main economic activity of their population. Villages on the south-west flank of the volcano originated either as settlements from groups of people who migrated from the highlands throughout the $19^{\text {th }}$ century, or as large scale plantations, mainly dedicated to coffee and sugar, established by foreigner investors at the end of the $19^{\text {th }}$ century (this thesis chapter 2 ). Most of these plantations were later partitioned and distributed among the local population, to constitute some of the current villages.

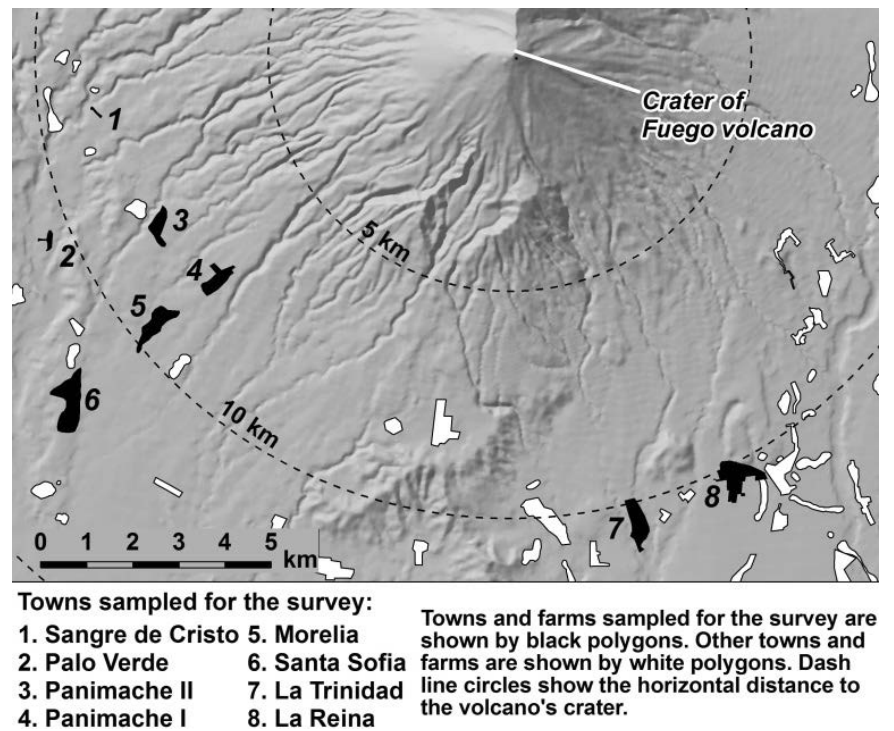

Town

Sangre de Cristo 30

Palo Verde $\quad 25$

Panimache I $\quad 281$

Panimache II $\quad 150$

Morelia $\quad 1458$

Santa Sofia $\quad 1586$

La Trinidad $\quad 576$

La Reina $\quad 286$

Figure 4.1. Location map of the communities included in this study 
Villages on the south-east flank of the volcano may have had a similar origin, but were transformed recently by population resettlement policies and programs, including land distribution programs for ex-war refugees who returned from refugee camps in Mexico after the end of the 36 year long Guatemalan civil war (e. g. Cruz Estrada, 2006).

In terms of the socioeconomic development and poverty level indicators, the population in the surveyed villages and the region in general is poor and lacks access to many basic resources and services. This is reflected in Table 4.1 by the literacy levels and household conditions in the surveyed villages and their respective counties, as shown by the data from the 2002 national census. Here we translate the Guatemalan term "Municipalidad" as county, since this seems the territorial administrative unit with the closest match to the equivalent Guatemalan territorial administrative unit. The villages of La Trinidad and La Reina are part of the Escuintla County, while the villages of Morelia, Panimache I, Panimache II, Santa Sofia, Palo Verde, and Sangre de Cristo, are part of the Yepocapa County.

Table 4.1. Literacy and household conditions at the village and county levels ${ }^{a, b}$

\begin{tabular}{lccccc}
\hline Place & Literacy & \multicolumn{4}{c}{ Household conditions } \\
\cline { 2 - 6 } & & $\begin{array}{c}\text { Direct access to } \\
\text { potable water }\end{array}$ & $\begin{array}{c}\text { Access to } \\
\text { electricity }\end{array}$ & $\begin{array}{c}\text { Dirt } \\
\text { floor }\end{array}$ & $\begin{array}{c}\text { Occupants } \\
\text { per room }\end{array}$ \\
\hline La Trinidad & 81 & 64 & 16 & 1 & 2 \\
La Reina & 66 & 67 & 69 & 73 & 5 \\
Escuintla County ${ }^{\text {c }}$ & 74 & 56 & 79 & 10 & 3 \\
Morelia & 69 & 88 & 94 & 22 & 4 \\
Panimache I & 71 & 85 & 89 & 29 & 4 \\
Panimache II & 73 & 93 & 69 & 48 & 4 \\
Santa Sofia & 62 & 88 & 95 & 25 & 4 \\
Yepocapa County ${ }^{\text {c }}$ & 58 & 60 & 66 & 22 & 4 \\
\hline a Source: INE (2002). All the values are in \% except for the last column (Occupants per \\
room). b Percentages for counties are the average values of all the populated \\
centers within that county. \\
County. Morelia, Panimache I, Panimache II, and Santa Sofia are part of the Yepocapa \\
County.
\end{tabular}

Poverty and other development measures are available at the county but not at the village level. According to INE (2011) for the year 2002 19\% of the population of the Yepocapa County lived in extreme poverty, considered to be a per-capita food consumption equivalent to a market value of 
less than 3,206 Guatemalan Quetzales (Q) per year, (USD 416 per year, at an exchange rate of 7.708 Q/USD, Guatemalan National Bank, March 14, 2012), while 74\% of the population in the county lived under the general poverty line, considered to be a per-capita food consumption equivalent to a market value of less than USD 853 (at the exchange rate cited before). For the Escuintla County the corresponding data showed that $4 \%$ of the population lived under the extreme poverty line, and $30 \%$ under the general poverty line. The relatively low percentages of people living in poverty in the Escuintla County can be explained at least in part due to the presence of a the large urban center in the Escuintla County (the City of Escuintla); therefore in the context of our study, we consider that the true conditions of poverty in the survey villages that are part of the Escuintla County is closer to that of the other villages which are part of the Yepocapa County.

Although the minimum monthly wage for agricultural activities is ca. USD 200 (MINTRAB, 2012), the national average monthly income from agricultural activities is close to USD 163 (INE, 2011). Agriculture and small livestock for self-consumption are also an important contribution in the local household economy, developed usually on land plots owned individually or communally. Land plots are usually located near or in the community, but in some cases they may be much closer to the volcanic vent and at a relatively higher exposure to the hazards.

\subsection{Literature review}

The human behavior in the face of risk can be analyzed from a variety of perspectives. Approaches focused on risk perception and based on the psychometric paradigm (Slovic, 2000), have been incorporated into general models that attempt to explain human adjustment to natural hazards (Burton et al. ,1993), as well as specifically in the case of volcanic risk (Chester, 1993).

This perspective has been criticized for ignoring the socioeconomic and political context in which decisions pertaining risk are made (Hewitt, 1983), therefore implying that people's exposure to risk is a result of their poor choices, derived from a lack of understanding and rationality about the risks they face, rather than resulting from structural and external socioeconomic and political forces that constrain their options.

Alternative explanations of human behavior, such as the cultural theory paradigm (Douglas and Wildavsky, 1982) have been put forward as a competing theoretical framework; however they as well are based on the idea that behavior is determined by risk perception. A fundamentally different approach has been presented by several authors (e. g. Wisner et al., 2004), which 
considers the broader socioeconomic and politic context, and bring people's vulnerability to the forefront of the discussion about the causes of risk.

Applied to volcanic risk (Gaillard and Dibben, 2008) the different approaches have highlighted a variety of variables that influence risk behavior. Although risk perception is still considered a crucial variable for explaining people's behavior regarding volcanic risk in many situations (e. g. Paton, 2008; Perry and Lindell, 2008; Gavilanes-Ruiz, et al., 2009; Lopez-Vazquez, 2009), several case studies of volcanic areas in a variety of settings (e. g. Dibben, 1999; Paton et al., 2001; Haynes et al., 2007; Gaillard, 2008; Lavigne, 2008; Haynes et al., 2008; Tobin et al., 2011) have shown that variables other than risk perception also influence people's attitude and behavior towards volcanic risk, including the difficulties of implementing the risk reduction measures and the threat to people's livelihoods.

Cases like the 1999 eruptive crisis at Tungurahua volcano in Ecuador (Lane et al., 2004; Tobin and Whiteford, 2002; Whiteford and Tobin, 2009), and the long term volcanic crisis at Colima volcano in Mexico (Cuevas-Muñiz, 2005), illustrate how short term concerns related to the hardship of evacuation, and longer term concerns related to threats to peoples livelihoods, weigh heavily in the decision making process to adopt different risk reduction measures.

Among the variety of possible strategies to manage volcanic risk, early warning systems focused on evacuation of the population exposed to hazards during volcanic crises has been one of the main, and in many cases the de facto, mitigation strategy (Chester, 1993; Blong, 2000; Newhall, 2000; De La Cruz-Reyna et al., 2000). Research about behavior regarding evacuations has been extensive for other natural hazards, including hurricanes and flooding (Perry, 1979; Sorensen and Mileti, 1988; Baker, 1991; Dash and Gladwin, 2007; Sorensen and Sorensen, 2007), but very few studies to date cover the decision making process leading to evacuation during volcanic crisis.

Volcanic crises have unique characteristics, as volcanic evacuations can happen over prolonged time periods, and the uncertainty in predicting the magnitude and severity of the eruptions and associated hazards are with very few exceptions very large. In many cases explosive and potentially disastrous eruptions alternate with periods of relative minor background activity, making the forecasting of threatening events highly uncertain, and giving ambiguous environmental cues to the general public. These and other differences hinder the direct application of the results from research on evacuations caused by other hazard areas (e. $\mathrm{g}$. hurricanes) to evacuations caused by volcanic crises. 
However, despite the differences with other types of hazards, it is possible to adapt general models of protective actions behavior and specifically of behavior during evacuations, to the volcanic case. One such a model, the Protective Action Decision Model or PADM (Lindell and Perry, 2004; Lindell and Perry, 2011) has been proposed as a general framework to explain people's behavior in the face of risk, including scenarios of crisis that required an evacuation.

\subsection{The PADM model}

The PADM incorporates different theoretical paradigms as well as the findings of empirical research on risk related behavior, gathered from a wide range of studies. It also considers the influences in the decision making and risk reduction implementation process, of protective actions (e. g. an evacuation) that may have negative consequences for the exposed population (e. g. hardship in shelters, threats to livelihoods, etc.), despite the occurrence of the hazardous event (e. g. a disastrous volcanic eruption).

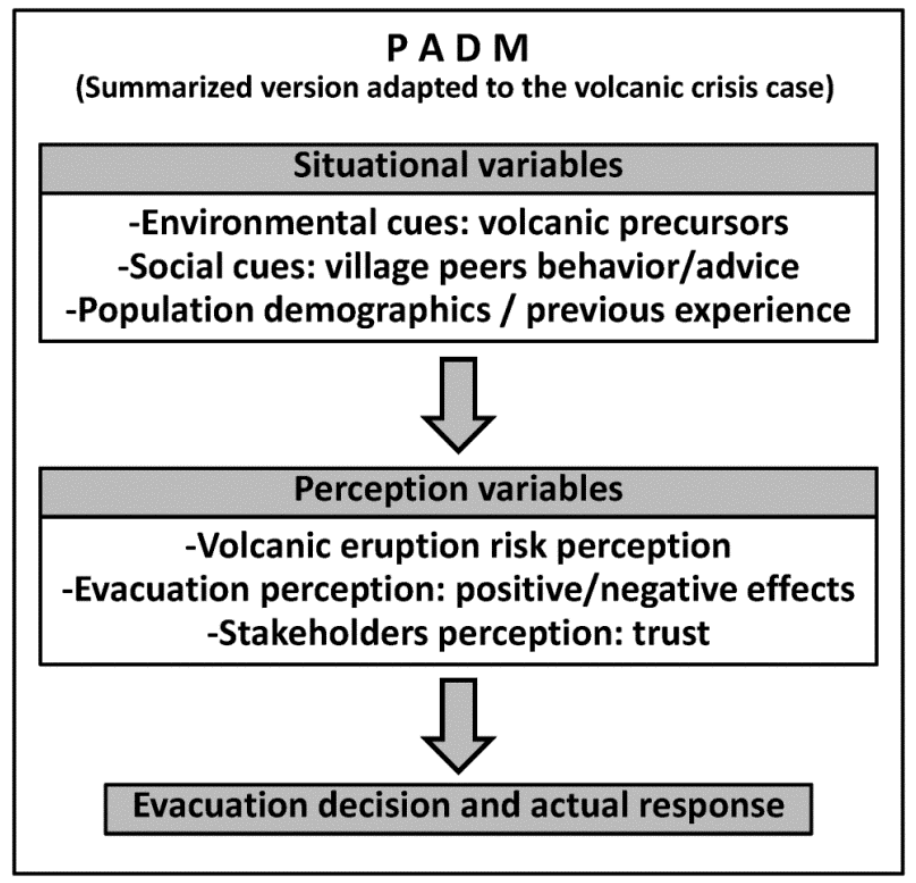

Figure 4.2. The PADM model (adapted from Lindell and Perry, 2004, and Lindell and Perry, 2011) adapted to the volcanic crisis case, showing the relevant variables explored in this study, especially the perception of potentially negative effects associated to the evacuation. 
The PADM considers the information generated and transmitted through an array of processes and variables that influence the final outcome of the decision on whether to take or not a specific protective action. In our case we will focus on the evacuation during a volcanic crisis as the protective action. In Figure 2 we show a diagram of the model that includes only those variables which are relevant for our case; the diagram has been adapted from the general model diagram by Lindell and Perry (2004), and Lindell and Perry (2011).

Initially, information about a potentially damaging event is generated in the form of environmental and social cues, e. g. an increase in volcanic activity, or the warning given by the authorities or neighbors that the volcanic activity is increasing. These are considered situational variables (first box in Figure 4.2) that are external to the perception and decision making process of the individual, but are key to determine the individual's behavior regarding the specific risk. A wider set of variables which can be considered the "receiver characteristics" in the classical warning theory (e. g. Drabek, 1999), and which for our case we chose to be represented by the population demographics and their previous experience with crises and eruptions, can also be grouped as situational variables along with environmental and social cues.

This information is received by the individual, at which point a series of psychological processes are triggered. After a pre-decision process (not shown in Figure 4.2) the individual is faced with the decision process per se, which in turn is fundamentally influenced by a series of perception variables (second box in Figure 4.2) which correspond to the "Core perceptual objects" of the general PADM model. This set of variables describe how the individual perceives, not only the risk associated to a potential hazard (a volcanic eruption in our case), but also the potential protective actions that could be taken to avoid or minimize the risk (an evacuation in our case). The perception of the evacuation (the protective action), considering both the positive and negative aspects is fundamental to understand people's behavior in the face of risk, and as it will be shown in this paper, it may be as important as the risk perception. A third subset of perception variables include the perception that the individual has about the roles that the different stakeholders should or could play associated to the protective actions; in our case we chose the variable or trust in authorities to be the relevant variable, as it may determine whether or not people may follow an evacuation advice or order.

According to the PADM, the decision making process in itself consists of a series of processes, including the risk identification and assessment, protective action search and assessment, and protective action implementation. Such a decision process ultimately leads to a behavioral response, i. e. to take a specific protective action or not, which in our case would be the 
evacuation. The actual behavior is further constrained by situational impediments and facilitators, those variables that will ultimately make possible or not to take the intended protective actions, e. g. logistical resources and physical means to perform a given action. In our case, such variables could include the access to transportation and shelter for an evacuation, the availability of security for the property left behind, etc.

In our diagram (Figure 4.2) we ignore the individual processes of the decision making, and group this category with the actual response category as a single group of variables. For the present study we focus on the two main categories of variables in the model, which are those variables that we are able to measure through the survey, i. e. the situational and perception variables, and therefore choose not to consider the other variables of the model in more detail, other than a brief description of the anecdotal evidence of prior eruption crisis and evacuation behavior by the population of the studied villages.

The PADM has the potential to be used as a framework to analyze the intended behavior regarding a possible evacuation during a volcanic crisis, and especially, the perceived importance of "negative effects of an evacuation", as this can be incorporated in the model as part of several components. Simultaneously, the relative importance of risk perception can be considered together with the importance of other variables that have been found to be relevant to the volcanic case in the literature, including the trust in authorities (Haynes, 2007). Consequently, the effects that situational variables have on these perceptions can also be assessed.

Many authors, especially those who have conducted studies on warning systems and evacuations in the US, have tended to overlook the importance of the perceived negative effects of evacuations in the decision making (e. g. Sorensen and Sorensen, 2007). This is also the case for the role that the negative aspects of mitigation plays within the PADM, mainly because as Lindell and Perry (2011) describe it, the effect of such negative aspects has been non-significant as seen in the studies conducted in that area so far.

However, this seems in contradiction with extensive evidence that in general people do consider the negative effects of mitigation actions when choosing among risk reduction alternatives, as has been previously discussed. The relative low importance assigned to the negative effects of evacuations in previous studies is in part due to the nature of these evacuations and the environment in which the studies have been carried out, as many of them have been carried out in developed countries. Crucial characteristics of the studied evacuation cases, mainly the duration and the severity of the negative effects (real or perceived) of the evacuations, were 
possibly less extreme than it is the case for many evacuation during volcanic crises in developing countries. As Lindell and Perry (2011) warn, the studies that don't find the negative effects of the mitigation to be important, have mainly considered hazards adjustments that were rather modest and required only small resource investment, and as such, may not be generalized to the more extreme cases.

In the specific case of evacuations due to volcanic crisis, the direct influence of "negative effects" variables on the decision to evacuate has been considered at a general level. Many studies have touched on the topic of the tradeoff between facing the risk and taking protective action during volcanic crises (e. g. Haynes et al., 2008; Gaillard, 2008; Lavigne, 2008) describing the effects they have in general on peoples choices regarding whether to seek protective actions or not in the face of volcanic risk.

Studies by Lane et al. (2004) and Whiteford and Tobin (2009) analyze the negative effects of the evacuation caused by the eruptive activity of Tungurahua volcano in Ecuador, including the prolonged hardship faced in the shelters and the losses and impact in peoples livelihoods caused by the evacuation. Tobin and Whiteford (2002) discuss in detail how the negative effects associated to the evacuation of the rural populations, influenced peoples' decision to remain evacuated in shelters, and whether the evacuation had been necessary in the first place.

From such studies it becomes clear that the negative effects of an evacuation are important, and at least a posteriori, they have a profound impact in peoples general perception of the whole problematic associated to the risk. Communities that recently had to face such negative effects may have a completely different response to a new evacuation in the near future. This perceptual element needs to be incorporated into the PADM for cases that are similar to those mentioned in the previous paragraphs. And even at a more general level, the perception of the negative effects of evacuations may be more important than other variables (e. g. a priori risk perception) that play more prominent roles in classic models that attempt to explain human behavior in the face of risk, and in particular in the decision process leading to an evacuation. To this end it is important to further explore and describe the a-priori importance of the perceived negative effects of evacuations, and incorporate them as more robust components in the models that attempt to describe human behavior in response to volcanic crises (e. g. the PADM), especially regarding their impact in peoples' likelihood to evacuate.

One of the challenges to conduct a study to incorporate the aspect of the "negative effects" of an evacuation into a model like the PADM is how to formally define such "negative effects", and how 
to empirically test their importance within the model, especially in the case of volcanic crisis and evacuations. The complexity of a crisis development, and the infinity of possible paths that it can take, added to the countless candidates for "negative effects" to be considered demand a very careful design of how such a study could be conducted.

One option that seems feasible is to borrow from methods used in other fields, like hurricane evacuation research (Dow and Cutter, 2000; Whitehead et al., 2000), and given the similarly complex context for decision making about evacuations during a volcanic crisis, use a series of hypothetical crisis scenarios, in which the survey participants have to decide whether to evacuate or not. In this way the effects on the decision making process of not only the potential catastrophic loss due to the eruption, but also the potentially negative effects associated to the evacuation could be explored. It is also important to notice that the work done in analogous evacuation cases highlights the issue that, although expressed evacuation intentions are not always a good predictor of actual behavior, the correlation between both is usually high (Dow and Cutter, 2000; Whitehead et al., 2000).

To test the importance of the a-priori perceived negative effects of an evacuation in the decision of whether to evacuate or not during a crisis, compared to other perception variables in the PADM, (risk perception and trust in authorities), as well as the role of situational variables in defining such perceptions, we investigate the case of the communities around Fuego volcano in Guatemala. This population includes individuals with a wide range of previous experiences with volcanic crises, and is representative of similar groups of rural population exposed to volcanic hazards in developing countries around the world. There is also anecdotal evidence suggesting that perceived negative effects of the evacuations may have been crucial in people's decision making about whether to evacuate or not during past crises at Fuego.

We investigate the variables' influence on the decision of whether to evacuate under different crisis scenarios, through the administration of a questionnaire containing a set of scenarios in which the respondents are faced with the decision to evacuate under different conditions that could be considered as negative effects of the evacuation per se.

\subsection{Research design}

An initial round of interviews focused on people's previous experiences with volcanic crisis and their expectations of future events was conducted with 38 individuals in the communities. The analysis of the interviews was used as input for the design of a 36 item survey questionnaire. The 
author's experience working with the community from 2001 to 2005, and a series of visits as part of the fieldwork activity allowed complementing the survey information with direct field observations, and anecdotal information relayed by collaborators and counterparts.

Survey respondents were chosen by convenience sampling. Due to a general feeling of mistrust towards outsiders by people in some of the villages, I choose to ask for the assistance of one or two local collaborators per village, who were either local volcanological observers from INSIVUMEH, or local disaster reduction committee members (associated to CONRED). The local collaborators helped approaching potential survey respondents. People in the streets and in their houses were approached as we walked through the villages, and were asked to participate in the survey. The respondents were given an explanation of the aim of the study, making clear that their participation was anonymous and completely voluntary, that they could choose to answer only those questions they felt comfortable with, and that they could interrupt the survey at any moment. We expected high illiteracy levels and therefore we deemed it to be more appropriate to administrate all the survey questionnaires orally. All the approached individuals accepted to participate. The convenience sampling approach may have introduced some bias, as we discuss at the end of this section, however the effect on the responses is believed to be minor.

The survey questionnaire contained 36 questions and was administered to 155 adults from the eight villages selected for the study (see Figure 4.1). The questions covered six broad topics: demographic data (Tables 4.4, 4.5 and 4.6, appendix Tables A4.1 through A4.7); people's previous experiences with eruption, crises and the government agencies that have the mandate to assist the population during such crises (Table 4.7); volcanic risk perception (Table4. 8); trust in authorities, (Table 4.9); people's perception of self-efficacy (Table 4.10); and the potential negative effects that an evacuation could have (Table 4.11). The research was approved by the Michigan Technological University Institutional Review Board (Approval number M0724).

The topics covered in the survey can be considered as inputs to the PADM model, ultimately affecting decision making during a volcanic crisis (see Figure 2). The specific variables considered in Figure 4.2 reflect a choice between variables that have been described as relevant for the volcanic case in the literature, and those that were considered relevant for the specific case by the authors.

As part of the questions in the survey, we present the respondents with a series of hypothetical crisis scenarios, in which they have to decide whether to evacuate or not given the different circumstance described as part of the scenario. Based on the information gathered from the 
survey, and using the PADM as a framework to analyze the intended behavior regarding a possible evacuation during a volcanic crisis, we explore peoples' decisions on hypothetical evacuations.

The survey sample was selected from 8 villages located within 8 and $12 \mathrm{~km}$ from the active crater (see figure 4.1). The population of the sampled villages ranged between 67 and 746 inhabitants for 2002, according to the national census (INE, 2002).

Tables 4.4 and 4.5 in this section and A4.1 to A4.8 in the appendix show a comparison of the demographic data from the sample of population included in the survey with equivalent data categories reported in the 2002 Guatemalan national census. The age composition of the sampled population seems to be significantly different from the demographic structure reported in the 2002 census data. Table 4.4 shows an under-sampling of population in the $18-30$ years age range of our survey $(20 \%)$ as compared to the village and county level data from the 2002 census $(40 \%)$. As expected, the sample contains a disproportionately large percentage of old age individuals. The reasons for this sampling bias are not entirely clear, but it is important to consider this bias when considering variables like age or previous experience in our analysis; e. g. detect differences in the responses between different age groups, and which could bias the total percentages of responses for other questions and make them not representative for the whole population. We don't see any obvious reason that the main results and conclusions of our study, presented in the following sections could be seriously compromised by this issue.

Table 4.2. Comparison of age data

\begin{tabular}{|c|c|c|c|}
\hline \multirow[b]{3}{*}{ Age } & \multicolumn{2}{|c|}{2002 Census } & \multirow{3}{*}{$\begin{array}{c}\text { Survey } \\
\text { respondents } \\
\text { Freq. (\%) }\end{array}$} \\
\hline & Counties & Villages & \\
\hline & Freq. (\%) & Freq. (\%) & \\
\hline $18-30$ & $32,249(41)$ & $811(40)$ & $31(20)$ \\
\hline $31-40$ & $16,789(21)$ & $405(20)$ & $28(18)$ \\
\hline $41-50$ & $12,414(16)$ & $330(16)$ & $45(29)$ \\
\hline $51-60$ & $8,250(11)$ & $202(10)$ & $25(16)$ \\
\hline$>60$ & $9,001(11)$ & $264(13)$ & $26(17)$ \\
\hline Total & $78,703(100)$ & $2,012(99)$ & $155(100)$ \\
\hline
\end{tabular}


The previously described bias could affect other demographic variables, but Tables A4.1 and A4.2 in the appendix show that although there are small differences between the survey sampled and 2002 census percentage data for other demographic variables, these differences are much smaller, usually $10 \%$ or less, and $15 \%$ at most. This strengthens our confidence in the representativity of our sample and the validity of the results and conclusions presented further down.

Table 5 shows that the main productive activities in the surveyed villages are related to agriculture and livestock production, as has been noted in the introduction and would be expected for the rural villages.

Table 4.3. Comparison of occupation data

\begin{tabular}{lccc}
\hline & \multicolumn{2}{c}{2002 Census } & \multirow{2}{*}{$\begin{array}{c}\text { Survey } \\
\text { respondents }\end{array}$} \\
\cline { 2 - 3 } Occupation & Counties & Villages & Freq. \\
& Freq. (\%) & Freq. (\%) & Freq. (\%) \\
\hline Agriculture and livestock & $10,539(13)$ & $770(38)$ & $74(48)$ \\
Other economic activities & $32,006(41)$ & $142(7)$ & $17(11)$ \\
Not working & $36,158(46)$ & $1,100(55)$ & $64(41)$ \\
\hline Total & $78,703(100)$ & $2,012(100)$ & $155(100)$ \\
\hline
\end{tabular}

Other demographic variables from the survey data are compared with the values reported in the 2002 census, and are reported in Tables A4 through A7 in the appendix.

\subsection{Results}

\subsubsection{Situational variables}

\subsubsection{Social cues}

As shown in table 4.4, most individuals (81\%) would follow a recommendation to evacuate by CONRED or INSIVUMEH (a social cue), even if there are no strong environmental cues, and a similar majority (76\%) would also follow CONRED's and INSIVUMEH's evacuation recommendation, even against the recommendation to stay by local population (a competing social cue). Only $39 \%$ of the people would follow an evacuation recommendation by the local population in the absence of other social (official warnings by CONRED or INSIVUMEH) or environmental cues, while $54 \%$ would not do so. 
Table 4.4. Response frequencies (percentages) for questions related to environmental and social cues.

\begin{tabular}{|c|c|c|c|c|c|c|}
\hline Question & $\begin{array}{c}\text { Strongly } \\
\text { agree }\end{array}$ & Agree & Neutral & Disagree & $\begin{array}{c}\text { Strongly } \\
\text { disagree }\end{array}$ & $\begin{array}{c}\text { Total } \\
\text { number }\end{array}$ \\
\hline $\begin{array}{l}\text { You would follow the } \\
\text { recommendation to evacuate } \\
\text { given by INSIVUMEH or } \\
\text { CONRED, even if from what } \\
\text { you can see, the volcano } \\
\text { seems quiet. }\end{array}$ & $102(67)$ & $21(14)$ & $6(4)$ & $10(6)$ & $14(9)$ & $153(100)$ \\
\hline $\begin{array}{l}\text { You would follow the } \\
\text { recommendation to evacuate } \\
\text { given by INSIVUMEH or } \\
\text { CONRED, even if people you } \\
\text { trust in your community } \\
\text { (relatives, friends, neighbors, } \\
\text { local leaders) recommend } \\
\text { you to stay. }\end{array}$ & $93(60)$ & $24(16)$ & $7(4)$ & $9(6)$ & $22(14)$ & $155(100)$ \\
\hline $\begin{array}{l}\text { If the people in your } \\
\text { community decides to } \\
\text { evacuate, even if } \\
\text { INSIVUMEH or CONRED } \\
\text { have not given a warning, } \\
\text { and from what you can see } \\
\text { the volcano doesn't seem to } \\
\text { be ready to erupt, would you } \\
\text { evacuate anyway with the } \\
\text { rest of the community? }\end{array}$ & 30 (19) & $31(20)$ & $10(7)$ & $28(18)$ & $56(36)$ & $155(100)$ \\
\hline $\begin{array}{l}\text { You and your family are at } \\
\text { risk when the volcano is } \\
\text { erupting and large quantities } \\
\text { of sand and ash are falling on } \\
\text { other communities, but } \\
\text { nothing is falling on yours. }\end{array}$ & $106(68)$ & $23(15)$ & $7(5)$ & $10(6)$ & $9(6)$ & 155 (100) \\
\hline $\begin{array}{l}\text { You and your family are at } \\
\text { risk when the volcano is } \\
\text { erupting and you see that hot } \\
\text { material (sand and rocks) is } \\
\text { rushing down the } \\
\text { "barrancas", even if it no sand } \\
\text { or ash is falling in your } \\
\text { community. }\end{array}$ & $131(85)$ & $13(8)$ & $0(0)$ & $7(4)$ & $4(3)$ & 155 (100) \\
\hline
\end{tabular}

\subsubsection{Environmental cues}

In terms of the specific hazards that could endanger people and how they manifest during a crisis, a majority of the survey respondents $(83 \%)$ agree that they would be at risk during a large eruption even if one of the strongest environmental cues, heavy tephra fall, does not directly 
affect their community. They also recognize some of the specific characteristics related to pyroclastic flows, as $93 \%$ of them agree that they would be in danger if a phenomenon with such characteristics happened during an eruption, even if they are not being directly affected by heavy tephra fall. People are aware of subtle but very important environmental cues that would allow them to recognize specific hazardous circumstances during a crisis.

\subsubsection{Population previous experience and demographics}

Most respondents have had firsthand experience with volcanic eruptions and crisis (see Table $4.5)$ although experiences vary across a wide range of cases. A majority $(83 \%)$ lived through the moderate eruptions that happened in the last 10 years, and $57 \%$ also witnessed the much larger eruptions that happened in the 1970's. A similar percentage of people $(55 \%)$ has also evacuated due to a volcanic eruption at some point in their lives. Surprisingly on the other hand, the knowledge about the agencies in charge or managing a potential future crisis at Fuego is relatively low, with only about half of the respondents (54\%) are aware of the work done by INSIVUMEH, and $66 \%$ stating that they know the work done by CONRED. Most people have had firsthand experiences with previous eruptions and direct experience with volcanic crisis in the area, but a significant percentage doesn't know the role of the government agencies that have the mandate to assist in the crisis management (i. e. CONRED and INSIVUMEH). 
Table 4.5. Response frequencies (percentages) for questions related to previous experience with crises and knowledge of the government authorities involved with the crisis management.

\begin{tabular}{lccc}
\hline Question & Yes & No & Total number \\
\hline $\begin{array}{l}\text { Have you lived through any of the Fuego } \\
\text { volcano eruptions that have happened in the }\end{array}$ & $127(83)$ & $27(17)$ & $154(100)$ \\
last 10 years? & & & \\
$\begin{array}{l}\text { Have you lived through any of the larger } \\
\begin{array}{l}\text { Fuego volcano eruptions that happened } 35 \text { or } \\
40 \text { years ago? }\end{array}\end{array}$ & $68(57)$ & $155(100)$ \\
$\begin{array}{l}\text { Have you had to evacuate due to an eruption } \\
\text { from Fuego volcano? }\end{array}$ & $85(55)$ & $70(45)$ & $155(100)$ \\
$\begin{array}{l}\text { Have you thought or felt that you wanted to } \\
\text { evacuate due to an eruption from Fuego } \\
\text { volcano? }\end{array}$ & $94(61)$ & $59(39)$ & $153(100)$ \\
$\begin{array}{l}\text { Have you been told to evacuate by authorities } \\
\text { during an eruption from Fuego volcano in the } \\
\text { past? }\end{array}$ & $66(43)$ & $89(57)$ & $155(100)$ \\
$\begin{array}{l}\text { Do you know what kind of work INSIVUMEH } \\
\text { does? }\end{array}$ & $83(54)$ & $72(46)$ & $155(100)$ \\
$\begin{array}{l}\text { Do you know what kind of work CONRED } \\
\text { does? }\end{array}$ & $102(66)$ & $53(34)$ & $155(100)$ \\
\hline
\end{tabular}

\subsubsection{Volcanic risk perception}

People have a strong awareness of the risk associated with Fuego volcano eruptions (see Table 4.6). Most survey respondents ( $89 \%)$ agree that the volcano could become dangerous during a large eruption and $69 \%$ agree that such an eruption will happen in the next 35 or 40 years.

Moreover, $97 \%$ of the respondents acknowledges that there would be a high risk to their lives and those of their families during such an eruption and $99 \%$ of them agree that their property and sources of income could be lost to such a large eruption. It is therefore evident that in general people acknowledge the risk associated with large eruptions. 
Table 4.6. Response frequencies (percentages) for questions related to risk perception.

\begin{tabular}{|c|c|c|c|c|c|c|}
\hline Question & $\begin{array}{c}\text { Strongly } \\
\text { agree }\end{array}$ & Agree & Neutral & Disagree & $\begin{array}{l}\text { Strongly } \\
\text { disagree }\end{array}$ & $\begin{array}{c}\text { Total } \\
\text { number }\end{array}$ \\
\hline $\begin{array}{l}\text { The volcano could become } \\
\text { dangerous during a large } \\
\text { eruption, like those that } \\
\text { happened } 35 \text { or } 40 \text { years ago. }\end{array}$ & $103(66)$ & $35(23)$ & $10(6)$ & $4(3)$ & $3(2)$ & $155(100)$ \\
\hline $\begin{array}{l}\text { A large eruption, like the once } \\
\text { which happened } 35 \text { or } 40 \\
\text { years ago, will happen again } \\
\text { during the next } 35 \text { or } 40 \text { years. }\end{array}$ & $44(28)$ & $63(41)$ & $26(17)$ & $15(10)$ & $7(4)$ & 155 (100) \\
\hline $\begin{array}{l}\text { If a large eruption (like the } \\
\text { once which happened } 35 \text { or } 40 \\
\text { years ago) happens again at } \\
\text { Fuego volcano, you and your } \\
\text { family would be at risk of } \\
\text { dying. }\end{array}$ & $139(90)$ & $11(7)$ & $0(0)$ & $2(1)$ & $3(2)$ & 155 (100) \\
\hline $\begin{array}{l}\text { If a large eruption (like the } \\
\text { once which happened } 35 \text { or } 40 \\
\text { years ago) happens again at } \\
\text { Fuego volcano, you could lose } \\
\text { your property (house, crops, } \\
\text { animals) or your source of } \\
\text { income. }\end{array}$ & $149(96)$ & $4(3)$ & $1(1)$ & $0(0)$ & $1(1)$ & $155(100)$ \\
\hline
\end{tabular}

\subsubsection{Evacuation perception}

The evacuation intention for different scenarios varies depending on the negative effects associated to the scenarios (see Table 4.7). Only about half of the respondents (45\%) would leave behind their property (houses, land, etc.) to follow an evacuation recommended by CONRED or INSIVUMEH if no one stays behind to provide security or take care of their property and livelihood, and only $59 \%$ would evacuate if there was no available transportation or shelter. This is in strong contrast with some of the results shown in Table 4.4, for scenarios that don't include such negative effects, as the majority ( $81 \%$ ) would evacuate if told to do so by CONRED or INSIVUMEH even if they didn't see clear signals from the volcano suggesting that a dangerous eruption is imminent, and $76 \%$ say they would evacuate even if trusted people from their community advise them not to do so.

The hardship associated to a hypothetical evacuation is clearly recognized by the majority of the population as show also in Table 4.7, as 95\% agree that they will face hardship if they have to evacuate to a shelter or any other place outside of their communities. Moreover, $44 \%$ disagree that they would find an alternative mean of transportation, shelter and food during an evacuation, if neither CONRED nor any other institution provided such resources. 
In summary, people are aware of the potentially negative effects that an evacuation can have on their livelihoods and personal wellbeing, and seem to take this into consideration when deciding whether to evacuate or not under different scenarios.

Table 4.7. Response frequencies (percentages) for questions related to evacuation perception.

\begin{tabular}{|c|c|c|c|c|c|c|}
\hline Question & $\begin{array}{c}\text { Strongly } \\
\text { agree }\end{array}$ & Agree & Neutral & Disagree & $\begin{array}{l}\text { Strongly } \\
\text { disagree }\end{array}$ & $\begin{array}{c}\text { Total } \\
\text { number }\end{array}$ \\
\hline $\begin{array}{l}\text { You would leave your property } \\
\text { behind and unattended if } \\
\text { CONRED or INSIVUMEH give } \\
\text { the order to evacuate, even if no } \\
\text { one stays behind to take care or } \\
\text { provide security for them. }\end{array}$ & $59(38)$ & $11(7)$ & $12(8)$ & $33(21)$ & $40(26)$ & $155(100)$ \\
\hline $\begin{array}{l}\text { You and your family would } \\
\text { evacuate if CONRED or } \\
\text { INSIVUMEH orders you to do so, } \\
\text { even if there is no transport } \\
\text { available to take you to a safe } \\
\text { place, nor a shelter with food to } \\
\text { receive you. }\end{array}$ & $55(36)$ & $37(24)$ & $5(3)$ & $21(13)$ & 37 (24) & 155 (100) \\
\hline $\begin{array}{l}\text { You and your family would face } \\
\text { hardship if you had to evacuate } \\
\text { from your village to a shelter, or } \\
\text { any other place outside of your } \\
\text { community. }\end{array}$ & $130(84)$ & $17(11)$ & $3(2)$ & $4(3)$ & $1(0)$ & $155(100)$ \\
\hline $\begin{array}{l}\text { If neither CONRED nor any other } \\
\text { institution provides } \\
\text { transportation, shelter, and food } \\
\text { for the evacuees, would you and } \\
\text { your family have a place to go, } \\
\text { and a way to get shelter and } \\
\text { food in case that you had to } \\
\text { evacuate? }\end{array}$ & $57(37)$ & 27 (17) & $3(2)$ & $17(11)$ & $51(33)$ & $155(100)$ \\
\hline $\begin{array}{l}\text { If after two weeks of being } \\
\text { evacuated the volcano has not } \\
\text { erupted, and from what you can } \\
\text { see it doesn't seem that it is } \\
\text { going to erupt soon, would you } \\
\text { and your family return to the } \\
\text { community, to take care of the } \\
\text { house, the animals, the land, } \\
\text { etc., even if CONRED or } \\
\text { INSIVUMEH advices the } \\
\text { communities that it is still } \\
\text { dangerous to return and that } \\
\text { they should remain evacuated? }\end{array}$ & $89(58)$ & $36(23)$ & $2(1)$ & $8(5)$ & $20(13)$ & 155 (100) \\
\hline
\end{tabular}




\subsubsection{Stakeholder perception: trust in authorities and perception of self-efficacy}

The degree of trust in authorities can be considered on two levels: trust in their advice on an evacuation and in providing security to the evacuated community. Trust in the authorities' evacuation advice is relatively high as previously discussed in section 4.1 (see also Table 4.4), with a majority (81\%) saying they would evacuated if told to do so by CONRED or INSIVUMEH, even in the absence of strong environmental cues that would suggest that a dangerous eruption is going to occur, as can be seen from Table 4.6 . Similarly, $76 \%$ say they would evacuate if told to do so by CONRED or INSIVUMEH, even if other people in the community tell them not to do so. However responses shift when people are asked about their level of trust in the police or the army to provide security to the evacuated villages. Only $38 \%$ of respondents trust these security forces to provide security to the evacuated villages, and $48 \%$ say they would not trust them on that task.

The surveyed people have an optimistic outlook about the possibility to manage a future volcanic crisis (see Table 4.8), with a large majority (89\%) believing that they can do something to save their lives and those of their families from the risk of a large eruption. However a similarly high percentage ( $88 \%$ ) also believe that they may need the advice of someone with more knowledge to tell them when the volcano becomes dangerous. Believes about how likely strong precursory signals will be before the next large eruption vary, between those who strongly agree (46\%) that there will be such clear signals, and those who strongly disagree $(39 \%)$ that the volcano will give clear signals before an eruption. In summary, although a majority of the people acknowledge the expertise and legitimacy of the government technical experts in advising during a crisis, the level of trust in the government security forces is much lower. 
Table 4.8. Response percentages (frequencies) for questions related to the perceived feasibility to manage a crisis and the related self-efficacy.

\begin{tabular}{lcccccc}
\hline & $\begin{array}{c}\text { Strongly } \\
\text { agree }\end{array}$ & Agree & Neutral & Disagree & $\begin{array}{c}\text { Strongly } \\
\text { disagree }\end{array}$ & $\begin{array}{c}\text { Total } \\
\text { number }\end{array}$ \\
\hline $\begin{array}{l}\text { If the volcano produced a } \\
\text { large eruption that puts your } \\
\text { community at risk, do you } \\
\text { believe that you could do }\end{array}$ & $85(56)$ & $50(33)$ & $7(5)$ & $3(2)$ & $8(4)$ & $153(100)$ \\
$\begin{array}{l}\text { something to save your life } \\
\text { and those of your family? }\end{array}$ & & & & & & \\
$\begin{array}{l}\text { The volcano will give clear } \\
\text { signals that a large eruption } \\
\text { is going to happen, before }\end{array}$ & $36(23)$ & $36(23)$ & $23(15)$ & $24(16)$ & $36(23)$ & $155(100)$ \\
the large eruption starts. & & & & & & \\
$\begin{array}{l}\text { You don't know when the } \\
\text { volcano becomes } \\
\text { dangerous, and you need } \\
\text { someone else with more } \\
\text { knowledge to tell you when } \\
\text { you should evacuate. }\end{array}$ & $101(66)$ & $34(22)$ & $4(3)$ & $7(4)$ & $8(5)$ & $154(100)$ \\
\end{tabular}

\subsection{Discussion}

The variation in the percentages of people who would evacuate under different scenarios, which incorporate different negative effects of an evacuation, provide evidence that the decision to evacuate is sensitive to the perception of such potentially negative consequences, and the willingness to evacuate varies depending on the conditions under which the evacuation takes place. From large percentages of people willing to evacuate when advised to do so by CONRED or INSIVUMEH under very general conditions, the responses change to only about half of the population or less willing to evacuate if they perceive that an evacuation will be a threat to their property or livelihoods, e. g. if their property and livelihoods will be exposed to looting and damage by the tephra fall; or if they expect to face excessive hardship related to the evacuation, e. g. if there is no transportation, nor shelter and food for the evacuees. This agrees with the notion put forward by other authors that variables other than risk perception drive the decision making during volcanic crises, including factors that are related to other potential collateral effects (e. g. Dibben, 1999; Paton et al., 2001; Haynes et al., 2007; Gaillard, 2008; Lavigne, 2008; Haynes et al., 2008; Tobin et al., 2011).

This perhaps intuitively expected result has important theoretical ramifications, as it stresses the importance that perceived negative effects of mitigation actions can have on the decision making process, beyond the perception of risk and other variables that have usually played major roles in models that attempt to explain human decision making with regards to risk management; i. e. risk 
perception, trust in authorities, perceived self-efficacy, etc. Compared to the Tungurahua (Lane et al., 2004; Tobin and Whiteford, 2002; Whiteford and Tobin, 2009), and Colima (Cuevas-Muñiz, 2005) cases, the Fuego volcano crises could potentially involve a variety of factors that overlaps with the low trust in authorities case of Colima and the perceived hardship and loss of livelihood of Tungurahua.

Despite the high level of awareness about the risk associated to large eruptions from Fuego volcano among the survey respondents, including the explicit acknowledgement of the possibility that their lives, the lives of their families, and their property and livelihoods may be destroyed by large eruptions in the future, the willingness of many of these people to evacuate is conditioned by the circumstances in which the evacuation may take place. The relatively low importance given to the perceived negative effects in the PADM model (Lindell and Perry, 2004; Lindell and Perry, 2011) is not consistent with the results at Fuego.

In a similar sense, there is also a widely shared view that people can do something to manage the risk associated to large eruption scenarios, which reflects a perceived sense of self-efficacy, and a general lack of fatalistic views regarding the volcanic risk; but such relatively optimistic on the people's agency and capacity to cope with a crisis do not imply that people will always be willing to evacuate when given the advice to do so.

The implicit trust in CONRED's and INSIVUMEH's advice during an evacuation, as inferred from the generally large percentages of population that would be willing to follow an evacuation recommendations by these institutions, may be again only a necessary but not sufficient conditions for such an evacuation to actually take place, as such a decision may depend strongly on the other variables described previously. In this respect, guaranteeing the security of the evacuated areas seems to be a key element to a convince significant percentage of the population to evacuate, and the government security forces could play a key role in this sense during the crisis management; unfortunately both the police and the army are seen with distrust by a large percentage of the survey respondents.

At this point it is important to clarify the rationale behind deploying the security forces to guarantee the integrity of private property and the livelihoods of the people from the communities. The presence of the security forces to secure the property in the evacuated area in general would also be limited to a level or risk that would be deemed unacceptable to the population but manageable by the security forces, beyond such a risk level even the security forces should evacuate to avoid them also being subject to lethal hazards. Furthermore, at this point the threat 
to property and livelihoods is not from looting or the accumulation of tephra on roofs, but from the direct impact of the most lethal hazards (e. g. pyroclastic flows), such that neither the presence of the security forces nor the local population would serve any purpose. Despite this limitation it is assumed that the presence of the security forces instead of the local population to secure the evacuated areas would involve a smaller number of people exposed, with a much faster response capability to leave the dangerous area (e. g. transportation and communication equipment) than the local population, and would therefore be a partial solution to handle the crisis.

The distrust in the state security forces could arise in some cases from the complex and sometimes very rough relationship that the police, and especially the army has had with the people living in some of these villages, as was specifically the case of the returned war refugees in the villages of La Trinidad (Cruz Estrada, 2006); but it may also just reflect the general level of distrust that the population of Guatemala have in the state security forces.

It is interesting to notice that some of the scenarios that describe situations which would be expected to discourage following evacuation advice actually do not seem to have such a large impact in their decision to evacuate. This is the case in which there is an absence of strong environmental cues (see Table 6), e. g. the population receiving an evacuation recommendation without them directly noticing any precursory signs of an imminent dangerous eruption; and it is also the case were they receive conflicting advice about the need to evacuate (see Table 6), e. g. the population receiving an evacuation recommendation, as they receive competing messages from other community members advising them not to evacuate.

From the practical perspective of risk reduction and crisis management the results from the survey also have important ramifications. If the answers percentages previously described in the results section and shown in Table 6 reflect the actual intention to evacuate, high percentages of the population (perhaps half of it) could be expected not to evacuate under similar scenarios in the future. As previously mentioned, the variables described as situational impediments (real or perceived) in the PADM, can tip the balance to decide against an evacuation, as threats to people's property and livelihoods arising due to an evacuation will not be considered lightly when deciding whether to evacuate or not. Strategies to encourage the following of evacuation recommendations may therefore include the provision of resources to guarantee, within the limits of what is practically possible, the integrity of the property and livelihoods left behind in the evacuated communities (but also considering the limitations of trust in the police and the army mentioned before). Similarly, a strategy to encourage compliance with an evacuation recommendation could include all those actions which will reduce the potential hardship that 
people may face during an evacuation, such as the availability of adequate transportation, sheltering and other services for the evacuees.

\subsection{Conclusions}

People's willingness to evacuate from villages close to Fuego volcano during an eruptive crisis will depend on the condition under which such an evacuation happens. Factors that may have a high impact on people's willingness to evacuate include their perceived threat to livelihoods and properties from looting, and the potential of roof collapse damage due to the accumulation of tephra; both issues may lead people to choose not to evacuate, but instead remain in their villages and protect their property and livelihood from such threats. Another potential deterrent for people to evacuate during a volcanic crisis is the prospect of hardship and poor conditions related to the evacuation and sheltering, especially the potential lack of transportation and good shelter conditions.

This study stresses the importance of some the "perceived negative effects" of the protective action (i. e. the evacuation) in terms of the PADM model, in contrasts with previous studies which emphasize other variables to explain people's choices on whether to evacuate or not, e. g. risk perception, self-efficacy, environmental and social cues, etc. Trust in authorities plays a complex role in the case here explored, although there is a high level of trust in the technical and scientific advice given by governmental agencies like CONRED and INSIVUMEH with regards to an evacuation, there is a general low level of trust in the role of government security forces (the National Civil Police and the Army) to provide security to people's property in the evacuated areas, complicating a possible solution to the problem of people's perceived threat to livelihoods and property from looting previously discussed.

The "perceived negative effects" considered in this study are only a few of many of such possibly perceived effects, as different negative effects perceptions could arise in other cases and under other circumstances. The identification of these particular issues (the perceived threat to livelihood and property from leaving the communities and facing hardship during an evacuation) came in part from the literature review on similar volcanic crisis situations and from the author's previous experience and background research on the communities near Fuego volcano. Research on other areas may reveal different negative effects perceived by people as being associated to evacuations, and even for the Fuego volcano area, further research could expose other perception elements not identified in this study. 
Considering the impact that the perceived negative effects could have on people's choice to evacuate or not during a crisis, it is of great importance to address this issue as part of any comprehensive effort to manage the volcanic crisis, and risk in general, through an early warning system at Fuego volcano. The additional finding of the generalized distrust in the government security forces adds to the challenge to address this problem.

Given the limitations inherent in testing the behavioral intentions via surveys versus observing the actual behavior it is necessary to further validate the results from this study by other means. Such an opportunity could from the recent crisis (on September 13, 2012) that triggered the evacuations of thousands of inhabitants from the villages that were surveyed in this study. A post crisis assessment, focusing on the reasons that lead people to make the choice to evacuate or not, could help to confirm the results presented here, and probably expand the perspectives on the complex issue of evacuations during eruptive crises at Volcan de Fuego.

An important policy implication from this work is that any attempt to manage the volcanic risk by ta government agency, through an early warning system in that region, will require providing a minimum of conditions for the evacuees, including transportation, shelter, and food, but also to provide security for the left behind property, within the limits that exposure of the security forces personal themselves can be deemed as an acceptable risk. But without first building trust of the population in the security forces, this will not be possible. 


\section{Elements for building a risk model at Volcan de Fuego: final considerations about risk, early warning and hazards.}

\subsection{Risk conceptualization and definition.}

How should risk associated to the eruptive activity at Fuego volcano be conceived, defined, and assessed? The answer to this question is not trivial, and it is fundamental in constraining the possible way in which the risk may be managed (Fischhoff et al 1981). The literature on risk analysis and management includes a large number of possible approaches to defining and assessing risk (e. g. Slovic 2000), but it is ultimately up to the stakeholders in a risk management problem, to decide what conception of risk is more relevant to their situation (Wisner et al. 2005).

Traditional views on risk, as a concept applied to potential loss due to natural phenomena like volcanic eruptions, have been heavily influenced by a the "human ecology" schools of thought (Burton et al. 1993), to the point of being called the "dominant approach" in the western risk and disaster research community (Hewitt, 1983; Chester, 1993). Originating from this approach, risk is also often considered to be a function of two main variables: hazard and vulnerability (Blong, 2000). This definition is useful in separating natural (non-human) from anthropic elements in a risk model, and has guided the way in which risk assessments are done.

In the dominant approach tradition, people individually and society collectively respond to natural hazards to adjust or adapt to the hazard. Adjustment can be accomplished by a variety of means, but assumes a rational decision model under uncertainty, in which the cost and the benefits of the different alternatives to manage the risk are weighed in the decision process (Burton et al. 1993). The adjustment actions respond then to a decision process, sometimes treated an expected utility maximization problem, or through a bounded rationality model (Slovic et al. 2000). Within that context, the perception that the individual or the society has about the risk becomes central in explaining their behavior regarding the management of the risk. According to that logic risk perception drives (or not) risk management, and the decision process therein.

The implicit assumption that people at risks act as unconstrained agents, focusing only on risk perception, and without considering the structural constraints imposed on them by their social, political, economic, cultural, and general context, was criticized by the founders of an alternative paradigm (O'Keefe et al. 1976). The criticism, developed into its own school of thought about natural hazards and risk, which has been called by some the "radical approach" (Susman et al. 1983; Chester, 1993), and which argues that those other factors are the real cause of the risk, and not the natural phenomena triggering them. These ideas developed further into what has 
become known as the "vulnerability approach", which stresses the importance of the concept of people's vulnerability (Wisner et al, 2005).

The concept of vulnerability then focusses on how people in daily life and within the bounds and structural constraints imposed on them, may be more or less prone to suffer losses due to the occurrence of natural phenomena (the hazards). This new proposal also involves a shift from the predominantly natural sciences dominated hazards focus, to a more social sciences driven perspective, in which the human element plays a complex role (Bankoff et al. 2007).

Each different approach relies on a particular theoretical framework, in which the conceptualization and definition of risk, and related terms, becomes part of the respective theoretical foundation. Despite the diversity of perspective in conceptualizing risk, a series of common elements tend to be present behind the most general idea of risk (Kelman, 2003). In a very general sense we can define risk as:

The probability $\boldsymbol{X}_{1}$ that a vulnerable element $\boldsymbol{X}_{2}$ experiences a loss $\boldsymbol{X}_{3}$, due to a hazard $\boldsymbol{X}_{4}$, at a place $\boldsymbol{X}_{5}$, and during a time $\boldsymbol{X}_{6}$.

Variables $\boldsymbol{X}_{1}$ though $\boldsymbol{X}_{6}$ may be formally defined or not, and can either be explicitly or implicitly considered in the risk conceptualization. Of course, there are other ways of conceptualizing risk, but in this case we loosely base our analysis, more than on the above definition, on recognizing the importance of $\boldsymbol{X}_{1}$ though $\boldsymbol{X}_{6}$, which constitute the elements for building a risk model.

The probability in $\boldsymbol{X}_{\mathbf{1}}$ does not necessarily have to be rigorous and formally defined entity, and in practice most of the time it is not, but in this context indicates only that the assumed likelihood of a potential loss is explicitly or implicitly a central element to the idea or risk. As seen in chapter 4 , people's perception of the likelihood of an eruption may influence their response to different crises scenarios, and in that context the probability may rather be seen informally and intuitively as how likely it is of having a given outcome of a crisis.

The identification or choice of the vulnerable element $\left(\boldsymbol{X}_{2}\right)$ is crucial in establishing the importance of the risk problem, i. e. what are we going to potentially lose? The above could be human lives, material goods, etc. It also determines the metric of the loss in the risk assessment, e. g. number of human lives, amount of value of property, etc. Moreover, identifying who will experience the loss is fundamental for establishing what possible risk management alternatives there may be. The magnitude or level of the potential loss $\left(\boldsymbol{X}_{3}\right)$ is equally important to establish the magnitude of 
the potential consequences of the risk, e. g. how many human lives, or economic costs, etc., could be lost. It is important not to equate the identification of the vulnerable elements with the much broader and complex scope of the vulnerability analysis in general, but it is the starting point for such an analysis.

The identification of the hazard $\left(\boldsymbol{X}_{4}\right)$, both in space $\left(\boldsymbol{X}_{5}\right)$ and time $\left(\boldsymbol{X}_{6}\right)$ is in some sense a prerequisite for choosing the other three $\left(\boldsymbol{X}_{1}\right.$ through $\left.\boldsymbol{X}_{3}\right)$ variables, as people will effectively not be vulnerable to a hazard to which they are not exposed.

Symbolically, risk can be expressed as a function of these variables, meaning that an assessment of the risk requires knowing something about $\boldsymbol{X}_{\boldsymbol{i}}$ :

$\mathbf{R}=f\left(x_{1}, x_{2}, x_{3}, x_{4}, x_{5}, x_{6}\right)$

Where $\mathbf{R}$ is the risk and $f$ is a function, not yet defined. Assessing the risk in a formal way, requires defining $f$ and $X_{1}$ through $X_{3}$ in some meaningful way. It is important to realize that our risk function is only a model representing usually some highly uncertain aspect of reality, and as such, it needs validation to be credible and useful for those who will use it. How well the model actually represents the reality will therefore depend on what variables, and if applicable, also what metrics we are going to consider as elements to build the risk model.

The first element of risk that needs to be defined is the vulnerable element; i. e. who will be the focus of the risk assessment, as being potentially exposed to the disaster impact. In this study the vulnerable element will be the communities located near to Fuego volcano. The analysis in chapter 4 gave us some insight into their experience with previous volcanic crises, their expectations about potential future crises, and their general attitude to the volcanic risk. The analysis does not pretend to be a vulnerability assessment, but it gives some important insight into some key aspects for potential crisis management scenarios, and we will focus on those findings, adapting them to the discussion in this chapter. Although risk is multidimensional and complex (Slovic, 2000), and the potential losses that may be suffered due to the volcanic by people in the communities near to Fuego can also extend to a variety of elements (life, livelihood, etc.), to simplify the analysis the focus will be only on the potential loss of life. It is important to clarify that although the focus of the analysis is on potential life loss, it will also consider other potential losses that people may face due to the available risk management options, not from the perspective of such losses being part of the risk per se, but rather exploring how they influence the risk management process and therefore how the ultimately influence the potential loss of life. 
The next elements to consider are the hazards, and their occurrence in space and time. The volcanological literature on hazards is extensive, and many of the methods have to some extent become standard practice (e. g. Newhall, 2000; De La Cruz et al. 2000; Blong 2000). The studies presented in chapters 2 and 3 are the input into the hazard considerations, and are complemented with models of volcanic processes. Among the different volcanic phenomena that could potentially impact the villages around Fuego volcano, and based on the information presented in chapters 2 and 3, pyroclastic flows and lahars seem to be the most severe and lethal hazards to which people may be exposed, while tephra may be much less lethal, but still highly damaging, as previous eruptions have shown. Those hazards have also been chosen by other authors assessing Fuego's hazards (Rose et al, 1988; Vallance et al. 2001). A more detailed discussion on some aspects of both hazards and vulnerability in the context of early warning systems will be presented.

\subsection{Risk management through early warning systems.}

Assessing the risk sets the stage for its intervention and ultimately its management. In general, interventions to reduce or mitigate the risk will demand the use of resources, i. e. will have a cost, whether economic, or otherwise (e. g. social). Therefore a risk reduction action will only be justified if the perceived benefit from taking that action and reducing the risk, results in a benefit ( $\mathrm{i}$. e. the avoidance of the loss associated to the risk) that is bigger than the value of the resources being used; in a general sense this is a cost-benefit analysis problem (Burton et al. 1993). The problem acquires further complexity due to the uncertainty in the possible outcomes, from both the potential hazardous event, and the available intervention options. Due to this the problem turns into one of decision making in the presence of uncertainty. This can be represented graphically through a payoff matrix (see figure 5.1). Arguably the worst case scenario is when risk reduction does not happen but the hazardous event does, materializing the risk in disaster (lower left square of the payoff matrix in figure 5.1), and the best case scenario corresponds to risk reduction actions being taken and the hazardous event happening, which should results in the reduction of the impact. But there is one other scenario that can unfold, when risk reduction actions are taken, but no hazardous event happens, and a posteriori the cost of the risk reduction action could be seen as unnecessary, although at the time the decision was made it may have seemed as the best choice. 


\section{Hazardous event}

Yes No

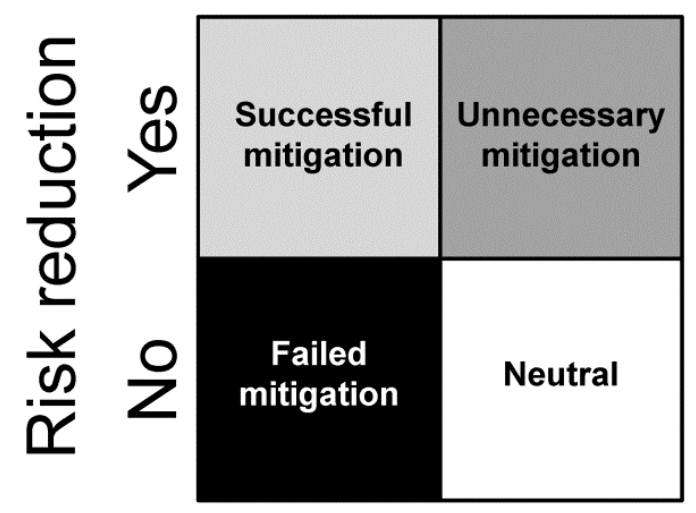

Figure 5.1 Payoff matrix for the decision to whether risk should be reduced vs the potential occurrence of a hazardous event (Adapted from Burton et al. 1993).

The decision making is effectively constrained by the available information on the risk, and by the available intervention alternatives. A minimum level of awareness is necessary to even consider the risk as a problem that requires a solution, and the more (relevant) information there is, the better the decisions are that can be taken, to the extreme that when uncertainty is reduced enough, the decision may become trivial. But the availability of means to effectively reduce the risk also constrains the decision. It is the recognition that such constrains may play a dominant role in dictating the behavior of the people in risk, what sets apart the vulnerability from the dominant approach. When choosing among the available risk reduction alternatives the decision maker has to consider the constrains related to both the hazard, and the human context. Figure 5.2 shows the flow chart that could be used while considering volcanic hazards and the available risk reduction alternatives. A particular volcanic hazard, e. g. pyroclastic flow hazard would be highly lethal or very severe if it reaches a community, therefore the in situ mitigation would seem not effective, and the only realistic alternative to reduce the risk would be to reduce the exposure of the population to the hazard. Such exposure reduction can be permanent, if it is viable through available resources, resulting in a relocation of the towns in areas judged to be exposed to the hazard. In many cases the resources for a relocation are not available and proposed solution is to limit the exposure to the hazard only temporally, when the hazard is very high, but alternative has to be questioned in the light of how effective it is (can the hazard be timely forecasted to avoid exposure?), in which case the risk is reduced via an early warning system. 


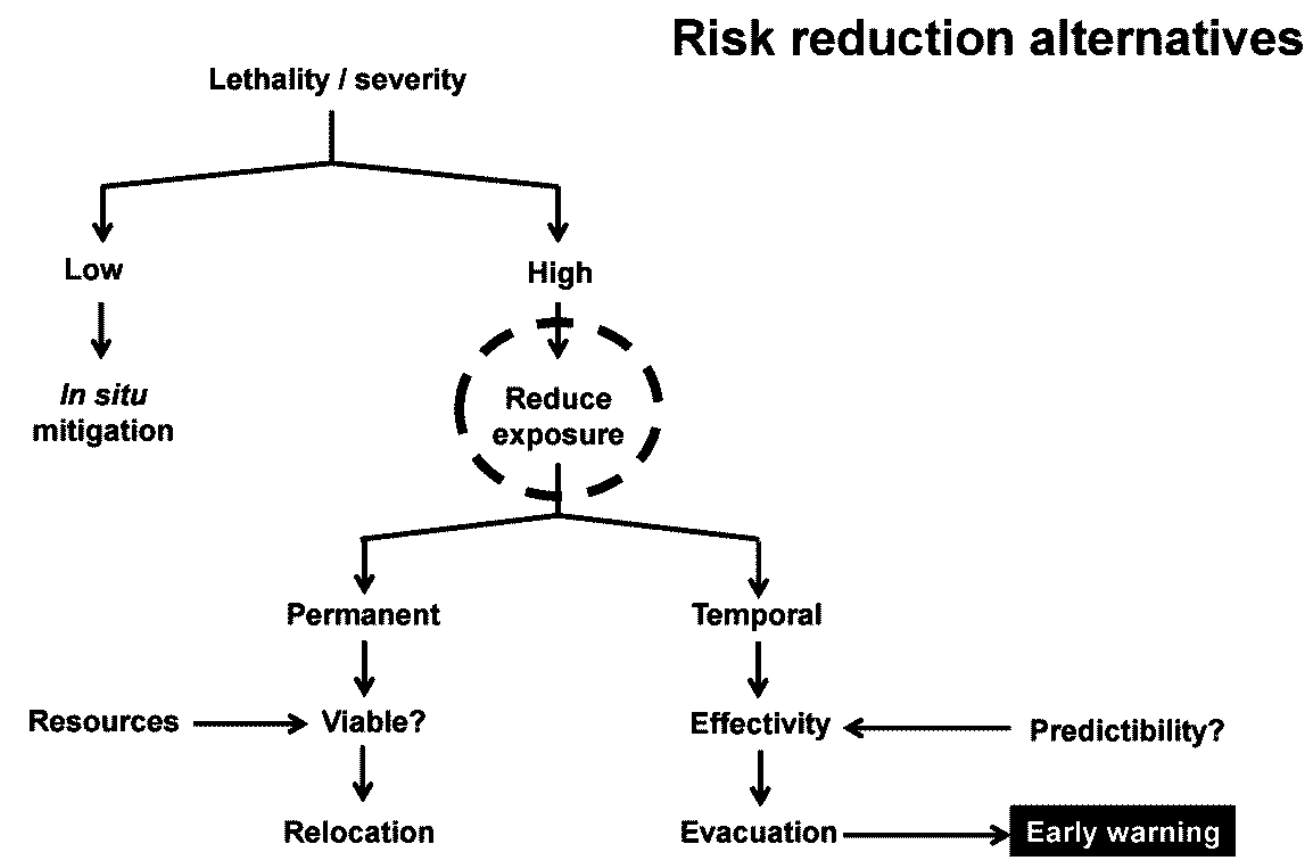

Figure 5.2. Flow chart for the selection of a risk reduction alternative based on the characteristics of both the hazard and the available reduction alternatives.

In such a context it is informative to consider the specific case of the hazards at Fuego. While it has been proposed that hazards like tephra fall could be mitigated in situ (Bonis and Salazar, 1973), more severe or lethal hazards, like pyroclastic flows and lahars require reducing the physical exposure, and the de facto choice in the case of Fuego has been early warning systems. Although it is apparent that the amount of resources that would be needed to relocate people currently living in areas potentially exposed to pyroclastic flow hazards at Fuego would be enormous for Guatemalan conditions, it is not clear how effective the alternative, the early warning system, may be.

The fundamental idea behind an early warning system is that the occurrence of a hazardous event can be "predicted" or "forecasted" before it happens, such that affective measures can be taken to avoid or reduce the damage from that event (Newhall, 2000). In the volcanic case and for the most severe hazards (e. g. pyroclastic flows) the most important action is usually the evacuation of people living in an area judged to be exposed to the hazard. But the unpredictability of the volcanic activity the human response to the crisis, make real case warnings much more complex, as has been explored in chapter 4 . 


\subsection{People's vulnerability in the context of an early warning system.}

The complexity of risk discussed at the beginning of the chapter is in part related to the variety of hazards, but is also intimately linked to the diversity of possible loss types. An individual facing a risk decision will generally not limit the possible loss assessment to only one specific kind of loss; loss or cost assessments, as well as possible benefits are many times not definable in a straightforward and commensurable way. The loss of a good or property cannot simply be equated to its market value, because the (intrinsic) relative value of that good or property depends on situational variables for every different individual, e. g. losing a house and a land plot for someone who doesn't live of that land plot and has many resources or ready access to them, does not represent the same that the loss of a house and a land plot for someone who only has those properties as a livelihood. To reduce the complexity of this problem the focus will be on a very specific kind of loss, the loss of human lives. It should be apparent that this type of loss will hardly be commensurable with any other type of cost of benefit, especially when it is the life of the own decision maker which is on the line. Nevertheless we will approach this problem following the previously discussed decision framework.

Early warning systems require the participation of different organizations and individuals who contribute to monitor the volcanic activity, detect possible precursors, assess the long and short term hazard, provide advice in the decision making process to call for an evacuation, provide logistical resources and material support for the evacuation and help to establish when a crises should end (Maskrey, 1997; Basher, 2006; Newhall, 2000; De La Cruz-Reyna et al. 2000; and Blong, 2000). On a broad level these activities area developed by four types of institutions: 1 volcanological observatories in charge of monitoring the volcanic activity, identify potential precursors, and assess the hazards, 2 civil defense organizations in charge of advising local authorities in the decision making process for a potential evacuation, and potentially issuing alerts, as well as providing logistical resources to support the evacuation, 3 local, regional and national civil authorities to provide resources and their respective levels, to assist in the evacuation efforts, and of course, 4 the actual population.

INSIVUMEH and CONRED are in charge of the observatories and the civil protection tasks respectively, as described in chapter 4 . The national, departamental, municipal governments and the local development committee represent the civil authority at different levels. Besides one seismic station and sporadic $\mathrm{SO}_{2}$ measuring campaigns, the monitoring done by INSIVUMEH is mainly based on the visual observations reported by the local observatories in Panimache I and Sangre de Cristo. The observers are locals hired and trained by INSIVUMEH who report to the 
Guatemala City headquarters several times a day, and keep continuous (24 hours) duty shifts at the observatory. The head of the volcanology department in Guatemala City produces daily activity bulletins, which are sent to CONRED and are also uploaded to INSIVUMEH's web page (http://www.insivumeh.gob.gt/geofisica.html (in Spanish)). During crisis episodes the observers increase the frequency of reports to Guatemala City, and depending on the situation, the head volcanologist from Guatemala City may go to the field to help assess the situation.

CONRED is organized to match the different levels of government with a Coordination Committee at each level, from the local to the national levels. The Coordination Committees are in charge of coordinating all the logistics and resources to manage risk during non-crisis time, and to manage the crisis once it has been declared. CONRED is supposed to pool from both private and public resources to this end, but the availability of such resources is usually very limited. For the Fuego case, CONRED with the support of the Japanese International Cooperation Agency has invested significant resources and effort to establish the basis for an early warning system, including risk awareness outreach, organization of local crisis Committees, and basic planning for the management of a potential crisis. CONRED develops generic crisis management plans (response plans) that then are adapted to the specific conditions of each crisis. A large part of the plans are focused on CONRED's internal procedures and their interaction with other organizations during the crisis, and specific eruptive crises plans are not defined. CONRED also has a small operative and logistics response team that can be quickly deployed to a crisis are to assist in crises management. The regional and departmental CONRED delegations also include personnel who can be deployed to assist in the crisis management task, and in some instances they have a small cache of food and water supplies to cover small crises over a period of 72 hours.

Regarding the volcanic crises at Fuego, the focus is usually in providing shelter, and to a lesser extent transport, but not security for the left behind property of the evacuees. This may be a critical aspect for the successful evacuation of the most hazards exposed areas, as it has been shown in chapter 4 . The distrust that most likely the population will feel towards the security forces if they were to be assigned to take care of the evacuated areas further complicates the situation. But such a solution was possible, the logistics and related planning for having security forces deployed in the evacuated areas will be a challenge in itself, because as the crisis deepens there will be a point at which the risk is not acceptable to keep such security forces in the evacuated zone, and they too will have to leave. The rationale behind deploying the security forces to the evacuated areas is that they could be a much smaller number of individuals than if a large fraction of the male population in the areas stays in the evacuated areas to avoid looting 
and clean the roofs. The security forces would also have a much higher logistic capacity to quickly leave the exposed area if the risk increases rapidly.

Given the constant level of background activity and the usually rapid ( $<24$ hours) shift of the activity from background into a crisis state, there is little time to plan an prepare for a potentially larger eruption, once the crisis started, at least if it were to follow the typical activity escalation pattern see during the $1999-2013$ eruptive episode. The question remains of whether a larger eruption (or an eruption producing a larger pyroclastic flow) would follow a similar pattern or if it would show a longer and more intense period of unrests. Although in theory a protocol of communications and decision making regarding and evacuation, and the issuing of volcanic warnings exists between CONRED and INSIVUMEH, all the major recent eruptions at Fuego left little opportunity to issue a warning in advance of an eruption. Out of the four larges pyroclastic flow producing eruptions, two were not recognized as events that were associated with large pyroclastic flows until after the events (May 21, 1999 and June 29, 2003), and two were only recognized during the event itself (July 17, 2005 and September 13, 2013)

Considering the ideas about the costs and benefits of implementing risk reduction actions discusses at the beginning of this section, we can apply the "decision making under uncertainty" framework to the early warning idea. Figure 5.3 . shows the possible outcomes of a volcanic crisis managed through an early warning system. This figure contains information that is similar to the one contained in a payoff matrix, but shown in an event tree format, and it additionally includes a branch corresponding to the non-occurrence of precursors, but which could still, perhaps unavoidably, lead to a failed alarm. The trigger for the crises is some potential precursor activity, confronting the decision maker with the choice of whether to evacuate or not. As discussed in chapter 4 , the strength of the precursor activity could be decisive in convincing people to evacuate. 


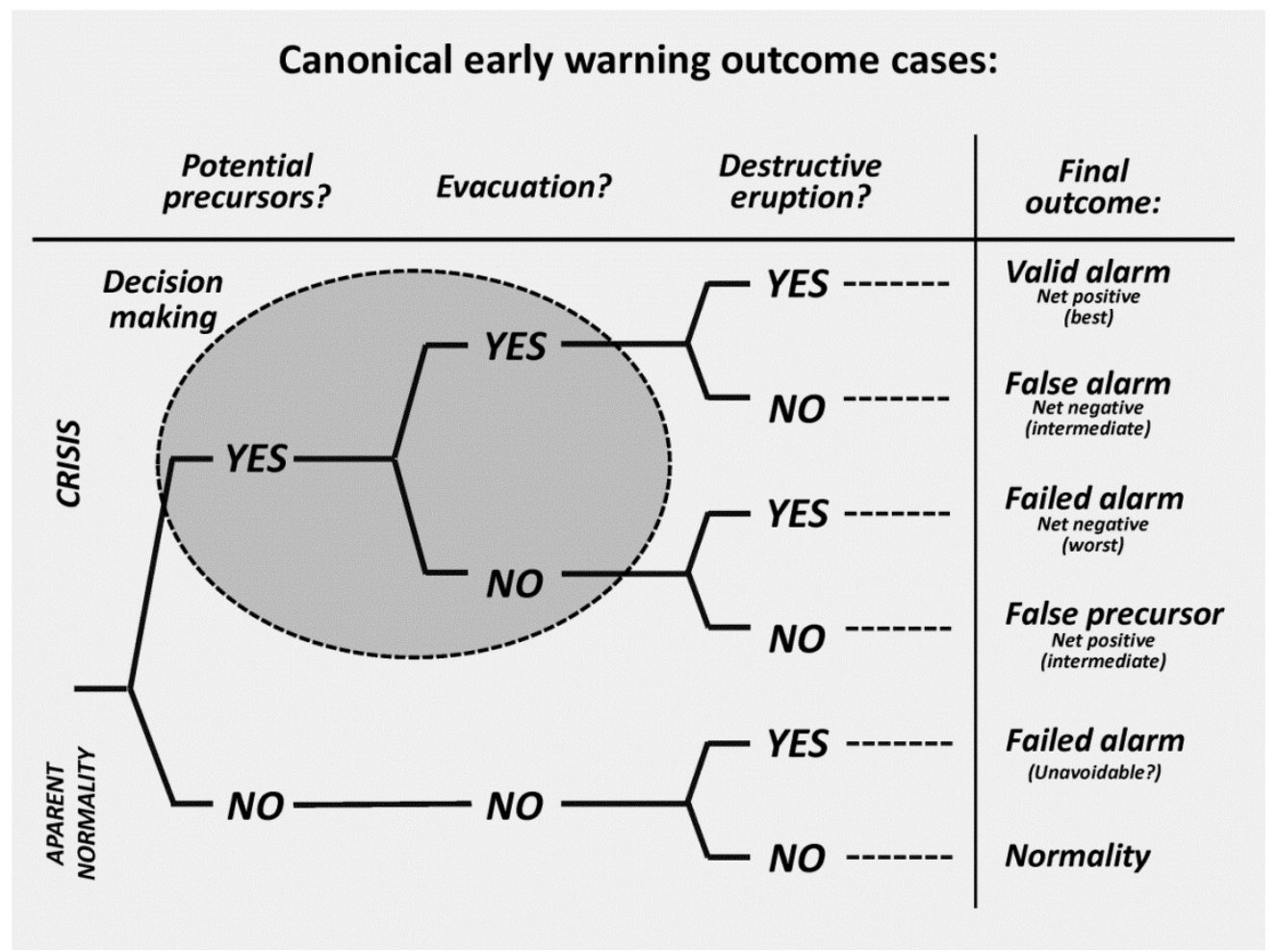

Figure 5.3. Generic early warning outcomes.

In this generic early warning process, the outcomes can be divided into two extreme cases, death or life. In between these two extremes one could consider a continuum spectrum of intermediate outcomes, e. g. measured by different degrees of injury, but for the purpose of this analysis only the two extreme cases will be considered; people then are faced with a decision that could potentially led to life or death. From the results show in chapter 4 for the case of the communities near to Fuego, it seems that people do not subscribe to fatalistic views, i. e. the perception that nothing can be done about the imminent risk and that therefore nothings should be done (e. $\mathrm{g}$. Blong, 2000). Although people seem to perceive a high level of self-efficacy when it comes to volcanic risk and crises, they also seem to be aware and recognize the potentially lethal effects that a large eruption could have on the communities near to Fuego. All these lines of evidence suggest that people will have strong motivations to take action (e. g. evacuate) if they perceive the situation to become too dangerous, and this also corresponds with the results shown in chapter 4 . The two critical questions then become: 1 . under what circumstances will people evacuate during a crisis?, and 2 . will that be early enough?

The lack of a rigorous study for the Fuego case leaves only room for anecdotal evidence and some speculation. The case of the September 13, 2012 eruption can be used as an example to 
illustrate a real case of evacuation. On the morning of September 13, 2012 Fuego entered into an "above background" eruptive phase. Like many other similar eruptions since 1999 the activity increased over several hours, prompting the response of the INSIVUMEH observatories and CONRED crisis team to more closely monitor the activity. Suddenly, close to 9:47 am a series of large $\left(\sim 2.5 \times 10^{7} \mathrm{~m}^{3}\right.$, see chapter 2 for more details $)$ pyroclastic flows and ash cloud surges were produced in rapid succession, reaching a distance of more than $8 \mathrm{~km}$ within the Barranca Ceniza channel, within approximately 8 minutes. The large pyroclastic flows produced a co-pyroclastic ash cloud that quickly spread over the nearby towns, causing light $(\sim 5 \mathrm{~mm})$ ashfall, reducing visibility and causing partial darkness. This event triggered a series of spontaneous evacuations by people in villages on the SW flank of Fuego, the area most affected by the ash fall. As the evacuation had started, CONRED jumped into action to support the thousands of evacuees. The crisis only lasted a few hours, and the ash cloud dissipated in a matter of hours. Similar anecdotes are part of the local oral tradition in the area surrounding Fuego, especially regarding the much larger eruptions in the 1960's and 1970's. The important points to observe in the description of the September 13, 2012 eruption is the very sudden onset of the most critical part of the eruption (the generation of large pyroclastic flows), the very quick and spontaneous response to the eruption by the local population, and the relative strength of the environmental cues (ashfall and darkness) that triggered the event.

It could be argued that the precursors to the pyroclastic flows started during the early hours of that day, and $\sim 5$ hours before the flows were generated, but at that point in time the eruption looked very similar, at least to the local population, to any of the other 26 eruptions that happened between 1999 and 2013 at Fuego (see chapter 2 for more details on this), but from those 26 eruptions, only 4 produced pyroclastic flows that propagated far enough to have the potential of impacting inhabited areas. I. e. the rate of "false alarms" would be very high if an evacuation happened any time that Fuego starts an "above background" eruption, and even the four cases in which large pyroclastic flows were generated could be counted as "false alarms" because the flows didn't cause any direct damage. Could a potentially deadly pyroclastic flow (one that could reach a populated area) develop as suddenly and quickly? Could the early warning system, either spontaneously led by the people in the villages, or called by INSIVUMEH and CONRED, have any chance of warning people with enough time to escape the impact of the flows?

The evolution through time of the risk perception can be represented schematically by a curve that is either obtained through formal sophisticated models representing the probability of a catastrophic or lethal event (e. g. Marzocchi and Woo, 2007), or more loosely and broadly defined as some other metric or proxy for the risk perception (e. g. Tilling, 2008). Figure 5.5 shows the 
schematic development of different "risk perception curves" paths through time for different crises scenarios. The vertical axis represents some metric (or proxy) for risk perception and the horizontal axis represents the time. The four curves show different paths for the risk perception proxy, as it evolves through time for different scenarios. A low value of the variable (close to zero) means that the perceived probability of the lethal event happening is very low, and a high value (close to one) means that the perceived probability of the lethal event happening is very high. The development of the September 13, 2013 event can perhaps be best represented by the highly convex curve I: the curve has initially a very small value (the perception is that the lethal event is very unlikely) but suddenly the perception changes over a very short time period (as short as a few minutes during the September 13, 2013 eruption), due to a very intense environmental cue, in this case the start of the pyroclastic generating phase and the related co-pyroclastic flow ash fall. As time progresses not only does the risk of the lethal event increase, but the opportunities to take actions are also reduced. The obvious difference with the actual crises is that luckily a lethal event never happened (the pyroclastic flow didn't reach any populated area).

\section{Crisis time path (development) posibilities}

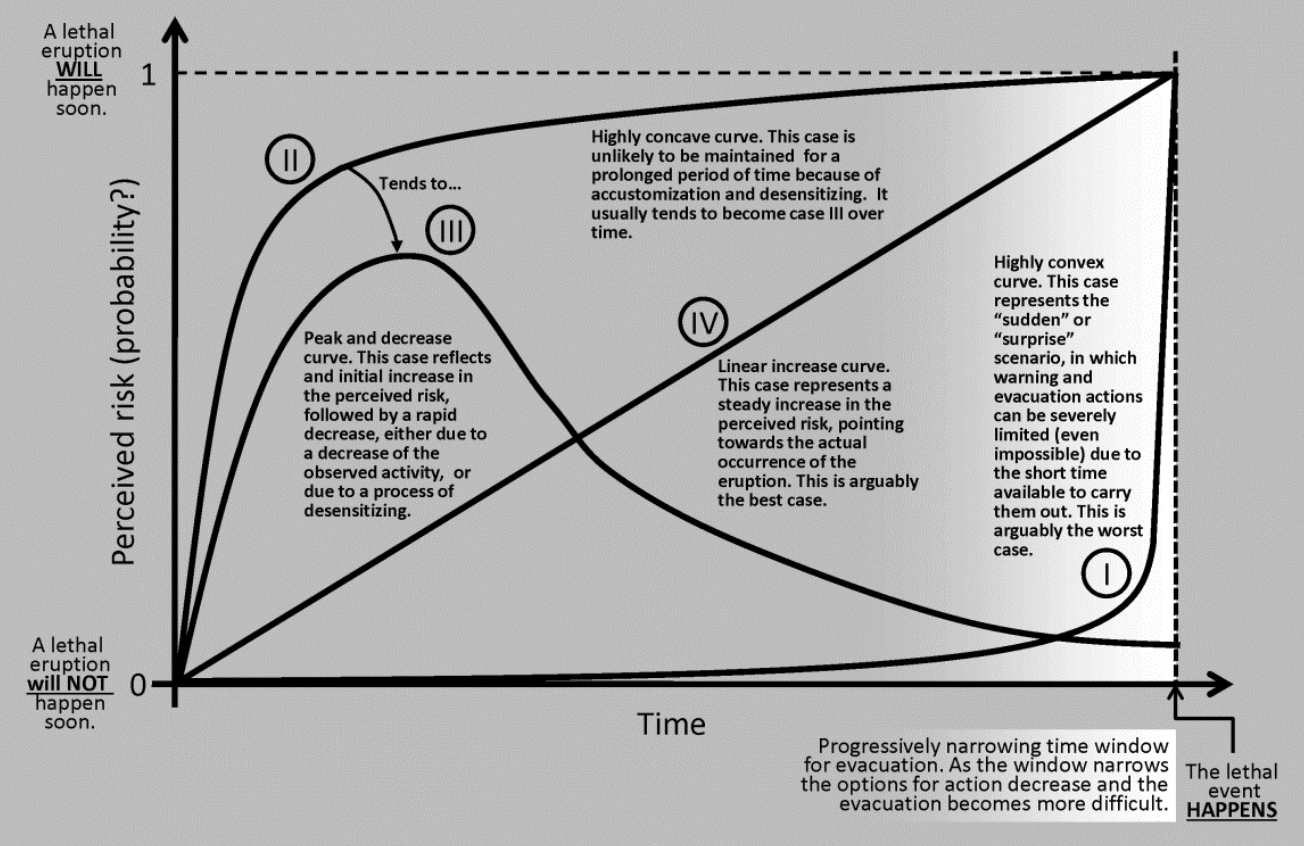

Figure 5.5 Risk perception evolution curves through time. 


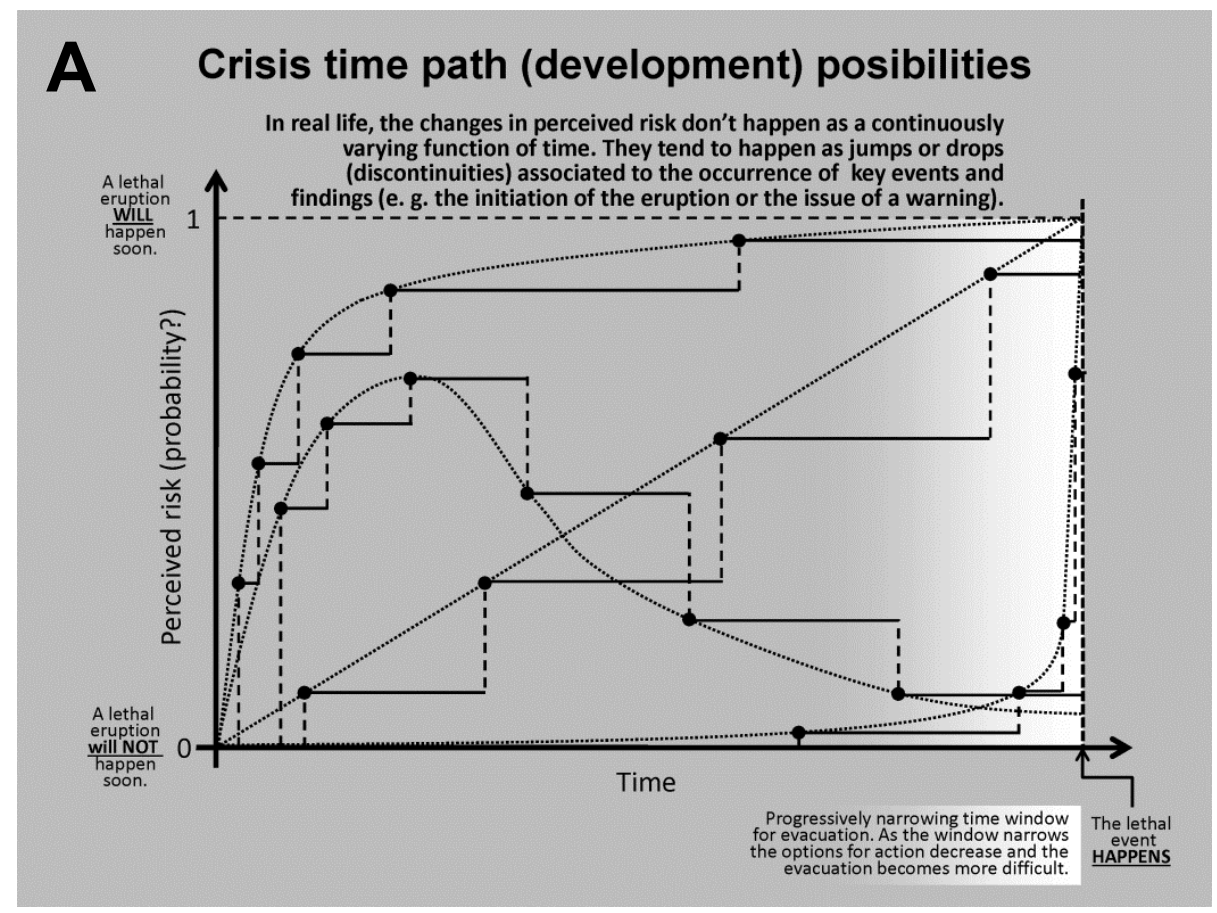

B Crisis time path (development) posibilities

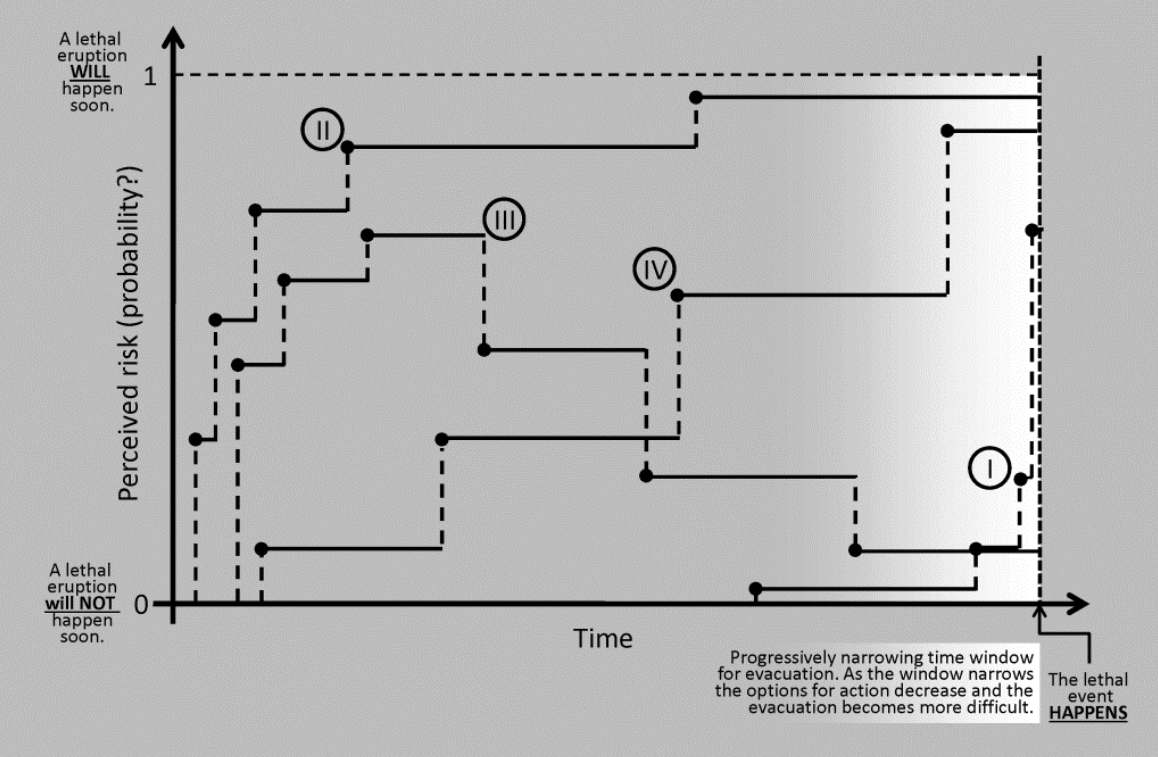

Figure 5.6 Risk perception evolution curves through time. A Continuum and smooth curves shown in figure 5.5 together with the abrupt (discrete) jump lines representation, which may be more appropriate to show the effect caused by strong individual "signals". B Same as A but showing only the abrupt jump lines. 
A second possibility is to experience a rapid increase of what could be perceived as a strong indicator that a catastrophic event is very likely happening in near future as depicted in curve II, but which remains at a high level for an extended period of time (see also Tilling, 2008; figure 3b). In reality and for most risk perception (or their proxies) curve II will tend to become III as times passes on, even if the original indicator that suggested a high probability of a lethal event happening does not change with time. This happens because people become accustomed and desensitized to the heightened levels of activity (or of the parameters that is being observed). Perhaps the simplest path in the diagram would be a straight line, in which the risk perception increases linearly through time until it reaches the moment when the actual event happens, as the curve value becomes 1 (certainty of the occurrence of the event). But this is a very unlikely scenario. Many other shapes for this curve are possible, increasing the complexity and uncertainty in the evacuation decision making process (e. g. Tilling, 2008).

But the changes in risk perception are probably more abrupt, as many times risk perception is dominated by discrete events that can be considered "signals" (Slovic, 1987) and which can significantly alter the risk perception (e. g. the start of a more intense eruption phase, or the start of heavy ashfall). This representation can be seen in figure 5.6.

All these curves only focus on the perceived risk as the determinant for make a decision whether or not to evacuate and may be adequate to describe the evolution of the perceived risk during the most extreme cases, when all other considerations become irrelevant, i. e. when the risk perception curve gets very close to have a value of 1 . Anecdotal evidence from the large eruptions from the 1970's suggest that such a threshold may be very high for some people, especially by the roles they could play within the community, e. g. during some of the large eruptions in the 1970's some of the men stayed behind in the villages to protect them from looting and to sweep the roofs to avoid their collapse. The fact that many of these men stayed in the villages throughout the thickest of the tephra fall, to fulfill their roles leaves little room for stronger cues to warn them that perhaps a pyroclastic flow could reach them, which is a very worrisome observation. 


\subsection{Hazard elements to consider as part of a risk model for Fuego volcano}

Two hazard assessments have been published for Fuego. Rose et al. (1988) published a hazard assessment, including a written report and a series of maps depicting areas subject to pyroclastic flow, lahar and air-fall tephra hazards (see figure 5.7). Their assessment was heavily based on the activity observed during the 1971 to 1974 eruption cluster and other recent eruptions, which is reflected in their choice of the areas considered to be under threat by pyroclastic flows and lahars. Pyroclastic flow hazard areas are mostly confined to the active channels, as has been observed during recent eruptions. Vallance et al. (2001) also produced a hazard assessment including a report and a series of maps, but they took a more general approach, examining the longer term eruptive history of the volcano, and therefore their maps show in general larger areas as being subject to pyroclastic flow, surge and lahars hazards, including large swaths of interfluvial terrain. In some sense both hazard assessments could be seen as depicting different scenarios of activity, with the assessment by Rose et al. (1988) corresponding to an event for which pyroclastic flows and lahars are confined to channels (smaller flows), and the assessment by Vallance et al. (2001) corresponding to a probably much larger eruption, for which the pyroclastic flows (and surges) and lahars are not confined to the channels (larger flows).

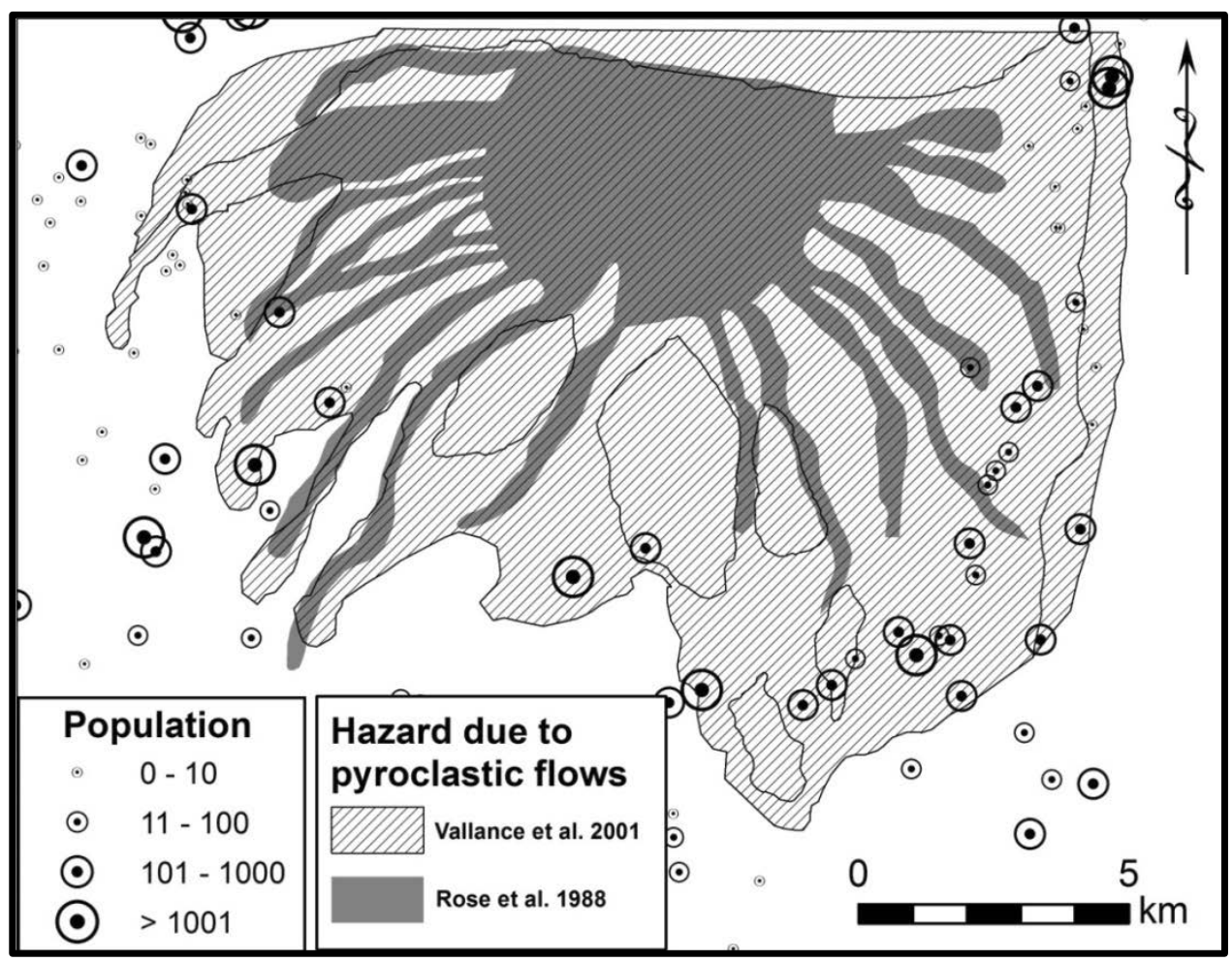

Figure 5.7. Comparison of areas considered to be exposed to pyroclastic flows and surges by Rose et al. (1988) and Vallance et al. (2001). 
Most significant in figure 5.7 is the fact that while the hazard map by Rose et al. (1988) only includes a few populated centers, the map of Vallance et al includes many more, making both maps very different in terms of the risk they portray. In the case of a civil defense official or a and inhabitant in one of the towns included in the map of figure 5.7, the critical question to ask is, under what circumstance would one of the other map apply? During a crisis one of the crucial questions to answer is which map should be used, if any at all. Choosing a map, or in general a scenario as the relevant scenarios is not easy.

The uncertainty in what will be the next event to happen has been approached from the perspective of probabilities. This arises from the uncertainty in the hazards assessment, as many aspects of volcanic phenomena are impossible to predict (Sparks, 2003). Probabilistic models have been applied to the occurrence of volcanic events since at least the 1960's, with Wickman's seminal papers on stochastic volcanic phenomena, setting the foundation for further studies on the topic (Wickman, 1966). Currently the development of probabilistic and statistical models for volcanic phenomena encompass a wide range of applications (e. g. Mader et al, 2006), including volcanic risk analysis.

Combining these elements into a meaningful risk model can be challenging (e. g. Fischhoff et al. 1981). It is possible to combine the different elements by consider many scenarios of how a potential hazard may impact the exposed vulnerable element, and estimate the potential loss for each, and one approach to do so, is to borrow methods developed in the fields of engineering, like fault and event trees (Pate-Cornell, 1984). Newhall and Hoblitt (2002) applied the concept of probabilistic event trees to the analysis of volcanic risk, with later authors expanding the model to include more sophisticated approaches, e. g. Bayesian event trees (Marzocchi et al. 2006), and applying the idea to real cases of risk assessment (e. g. Neri et al. 2008; Kushendratno et al. 2012). The chapter will use the event tree tool to illustrate how some key factors specific to the Fuego risk case, in both the hazard and the vulnerability elements, may determine the outcome or the risk analysis.

From the information presented on chapters 2 and 3 it becomes apparent that pyroclastic flows exhibit complex behavior that is impossible to display in a single map. As recognized already by Bonis and Salazar in 1973, and further confirmed by this study, the pyroclastic flow hazard is strongly influenced by the presence of channels with a large enough cross sectional area, to contain and route the flow. Most Barranca channels draining Fuego have large cross sectional areas (e. g. see figure 2.18), but this can be an ephemeral condition, especially during periods 
with frequent pyroclastic flow generation, as pyroclastic flow deposition within the channel can lead to subsequent over spilling and avulsion.

How to incorporate such observations into a formal risk assessment is not clear. Preliminary pyroclastic flow modeling gives poorly constrained results, i. e. a very wide range of results can be obtained by adjusting the poorly constrained model parameters, and therefore their results are not very informative. Perhaps expert elicitation methods (e. g. Aspinall, 2006) could be used for that purpose in this case.

Using the event tree formalism, we can explore the importance of some of the hazard and vulnerability related issues discussed in previous chapters. Figure 5.8 shows a typical, hypothetical event tree for a given location near Fuego, e. g. the village of Panimache I. Highlighted by the gray box is one of the typical nodes in such type of tree analysis, and this node corresponds to the question: Do the pyroclastic flow reach the community?

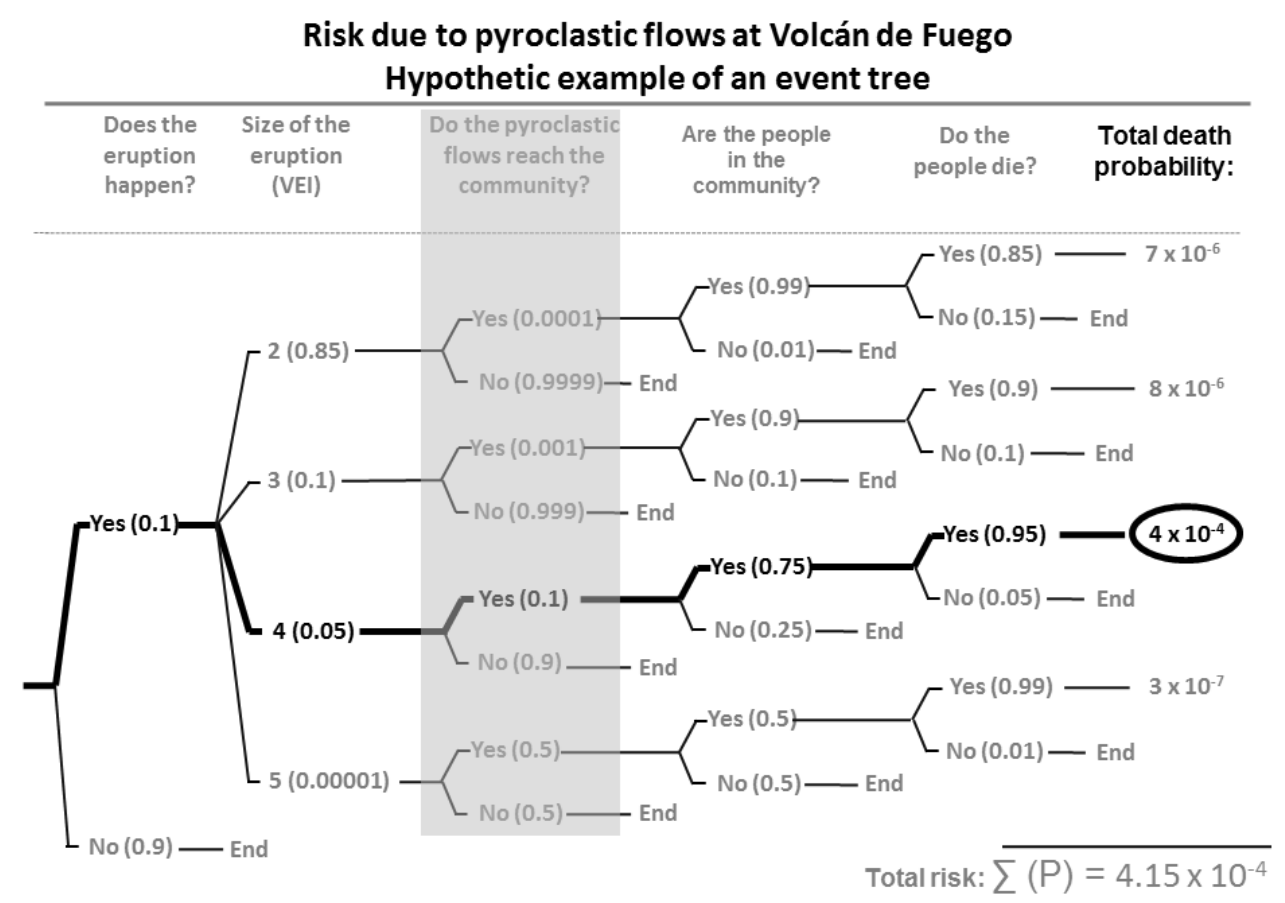

Figure 5.8. Hypothetical event tree for a village near Fuego volcano. Highlighted in the gray box is the standard pyroclastic flow node that will be expanded into more nodes in figure 5.9. 
In their original paper, Newhall and Hoblitt (2002) only consider a direction (a sector of the volcano) and a distance from the vent. However, from the information presented in chapters 2 and 3 it is clear that direction and distance alone are not a good way of characterize the pyroclastic flows at Fuego. In fact, large pyroclastic flows have propagated beyond the $7-8 \mathrm{~km}$ distance at which the closest villages are located from the vent, but flowing next to them, confined in the deep barranca channels (e. g. the pyroclastic flows on barranca Taniluya during the 1970's). Maximum run-out is an important parameter to characterize how hazardous a pyroclastic flow is, but the control of the topography over which the flow propagates may be equally important.

If a pyroclastic flow has a run-out longer than the distance at which the communities are located from the vent, a natural question to ask would be: does the pyroclastic flow overspill the barranca channel? This question is a complex one, as it depends on multiple factors. The size of the channel cross section is important in controlling the likelihood of flow overbanking, and can change significantly if previous pyroclastic flows have deposited in the channel, or if intense laharic erosion has cut through it. Channel constrictions, or more likely a reduction in the channel depth, can cause overflow as a specific location.

The characteristics of the flow itself are also important, and in the general, how dense or inflated the flow is will be an important factor controlling the cross sectional area of the flow: a dense and relatively compact granular flow will have a much smaller cross sectional area than a highly expanded and low density flow. But as the flow density decreases the influence of gravity becomes less important, and gas expansion and initial momentum become more important. In the extreme case the flow becomes a surge, on which the topography exerts little control. On the other extreme we have dense, particle interaction (frictional and collisional) dominated grain flow, for which Reynolds' dilatancy may account for only a few percentage volume expansion. At Fuego the termini and distal segments of the pyroclastic flows are probably close to the dense end of pyroclastic density current spectrum, but in the upper and media reaches of the areas affected by pyroclastic flows, many times there are also ash cloud surges produced simultaneously, which are much less constrained by the topography, but don't propagate too far away from the channels.

In the case of dense pyroclastic flow, the cross sectional area is controlled mainly by the volumetric flow rate and the velocity: a large volumetric flow rate and a low velocity will result in a very large flow cross sectional area, that can exceed the channel cross sectional area, leading to overflow, that could be the case of a very large flow pulse which quickly decelerates if the channel 
slope drops quickly, or the sinuosity of the channel results in large energy and velocity loss. Of course, for a large enough volumetric flow rate, all the other parameters (velocity, channel cross section, etc.) will be irrelevant and the flow will overspill anyway, but the geologic record and the recent events seem to suggest that such a situation is rather unlikely. Another condition that would promote flow overbanking is the progressive sedimentation within a flow pulse (somewhat analogous to the flow pulse deceleration), or the progressive deposition of a sequence of flow pulses during a single eruption. Finally, a flow can also spill out of a barranca channel due to the inertial effects cause by rapid changes in the flow direction, at sharp turns or in the presence of obstacles in the barranca channel, analogous to the inertial superelevation effect on water in curved streams channels.

The specific way in which these factors control the flow, and how they determine whether the flow will overbank or not are complex and difficult to assess. Ideally a physical flow model could be used to assess such behavior for different sets of the relevant input parameters (e. g. topography, flow physical characteristics, etc.), but the probability that each specific set of conditions will happen cannot be given by the model, it has to be estimated independently. The conditions could be estimated by a group of experts, through an expert elicitation method, and all the factors could be considered by expanding the node related to the pyroclastic flows in the event tree, into a series of nodes and branches describing all the different options (see figure 5.9) for a specific location.

\section{Given the occurrence of pyroclastic flow, what is the likelihood that a flow will overbank and impact a populate area adjacent to the channel?}

\begin{tabular}{ccccc}
\hline $\begin{array}{c}\text { Channel cross } \\
\text { sectional area } \\
\left(\mathrm{m}^{2}\right)\end{array}$ & $\begin{array}{c}\text { Averageflow } \\
\text { velocity }(\mathrm{m} / \mathrm{s})\end{array}$ & $\begin{array}{c}\text { Volumetric flow } \\
\text { rate }\left(\mathrm{m}^{3} / \mathrm{s}\right)\end{array}$ & $\begin{array}{c}\text { Channel cross } \\
\text { sectional area } \\
\text { reduction due to } \\
\text { previous flow } \\
\text { deposits }(\mathrm{m} 2)\end{array}$ & $\begin{array}{c}\text { Overbanking } \\
\text { flow reaches the } \\
\text { community }\end{array}$ \\
\end{tabular}

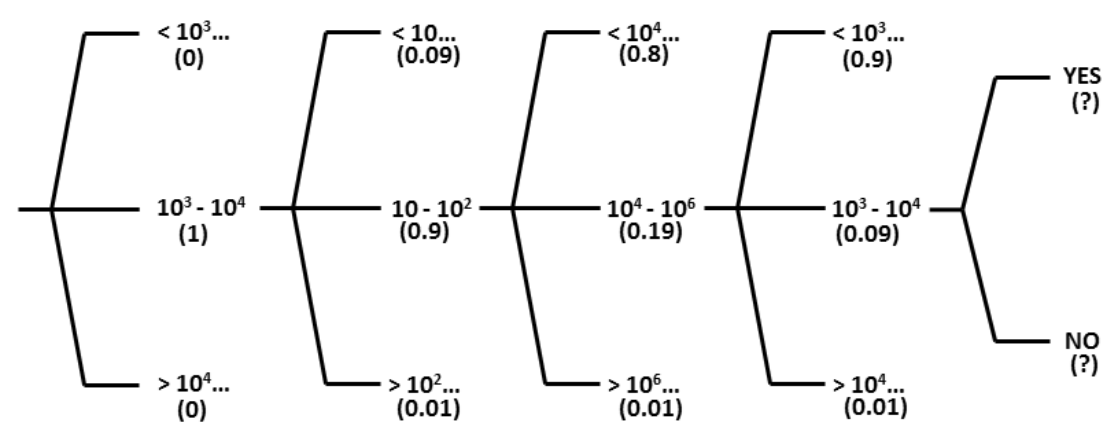

Figure 5.9. Event tree for conditions that may cause a pyroclastic flow overbanking. 
A similar approach could be applied to the question of whether people will be in the exposed areas, i. e. the node highlighted with a gray box on figure 5.10 .

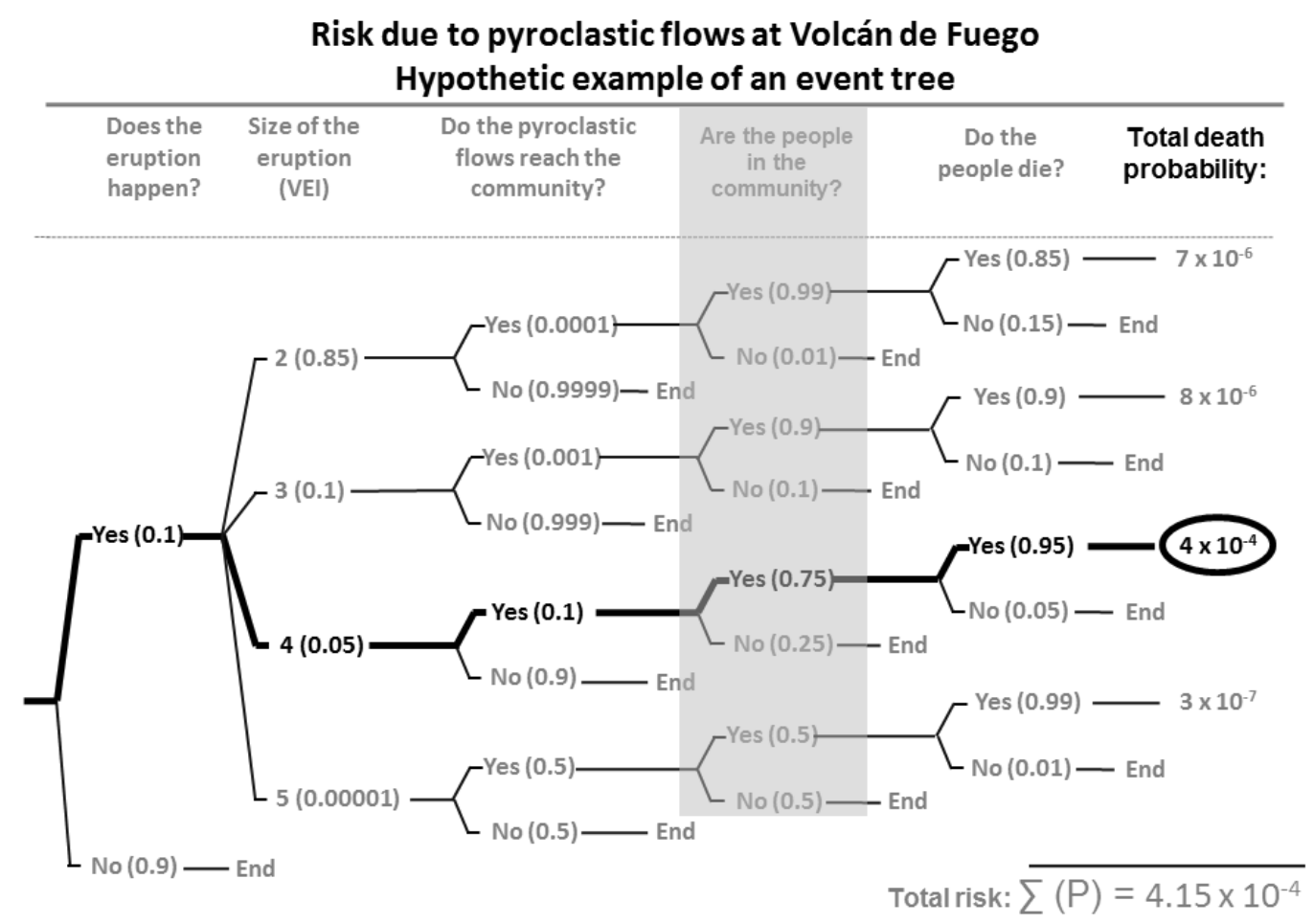

Figure 5.10. Hypothetical event tree for a village near Fuego volcano. Highlighted in the gray box is the standard "people present in the exposed area" node that will be expanded into more nodes in figure 5.11 .

In that case the details explored in chapter 4 could be also expanded into an event tree, representing the conditions under which a potential evacuation could take (or not) place. This is shown in figure 5.11. Environmental cues, as well as circumstantial conditions during the evacuation are shown as nodes in the tree. Estimating these probabilities may be challenging, but again, expert elicitation could be used to get a rough value for each node. 
How likely is it that people will evacuate during a crisis?

\begin{tabular}{|c|c|c|c|c|}
\hline $\begin{array}{l}\text { Environmental } \\
\text { cues }\end{array}$ & $\begin{array}{l}\text { Will there be } \\
\text { an evacuation } \\
\text { order? }\end{array}$ & $\begin{array}{c}\text { Will } \\
\text { transportation, } \\
\text { food and } \\
\text { shelter be } \\
\text { provided? }\end{array}$ & $\begin{array}{l}\text { Will security be } \\
\text { provided to } \\
\text { guard the } \\
\text { property in the } \\
\text { evacuated } \\
\text { towns? }\end{array}$ & $\begin{array}{l}\text { Will people } \\
\text { evacuate? }\end{array}$ \\
\hline
\end{tabular}

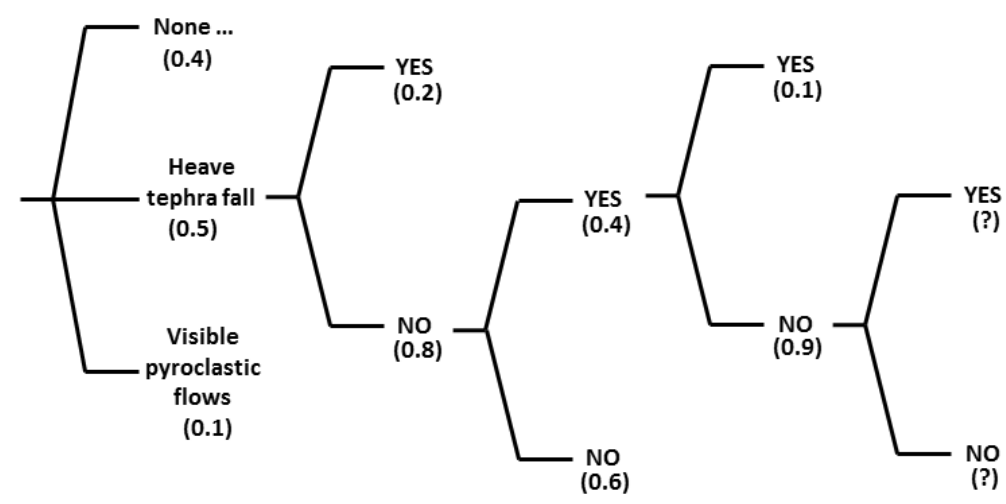

Figure 5.11. Event tree for the evacuation probability under different crisis conditions.

\subsection{Concluding remarks on potential future crises, and opportunities and challenges to manage them.}

Future crises at Fuego volcano will likely happen in the future, and the population and authorities will have to manage them within the constraints of resource availability and uncertainty described in this work. Improving monitoring and forecasting capacity at Fuego could help reduce the uncertainty during a crises, facilitating the decision making process, for instance related to issuing evacuation orders. A better assessment of some of the specific hazard issues explored in this work, including the potential for pyroclastic flow overbanking, should also be done. But equally important is to also provide the best possible conditions for an evacuation, as this will most likely encourage people to evacuate when an evacuation order is issued. Further assessing the impact of the negative aspects of evacuations could help clarify this issue. 


\section{References}

Alvarado, G. E., \& Soto, G. J. (2002). Pyroclastic flow generated by crater-wall collapse and outpouring of the lava pool of Arenal Volcano, Costa Rica. Bulletin of volcanology, 63(8), 557568.

Andronico, D., Scollo, S., Caruso, S., \& Cristaldi, A. (2008). The 2002-03 Etna explosive activity: Tephra dispersal and features of the deposits. Journal of Geophysical Research, 113(B4), B04209.

Andronico, D., Cristaldi, A., Del Carlo, P., \& Taddeucci, J. (2009). Shifting styles of basaltic explosive activity during the 2002-03 eruption of Mt. Etna, Italy. Journal of Volcanology and Geothermal Research, 180(2), 110-122.

Bagnold, R. A. (1966). An approach to the sediment transport problem from general physics. US Geol. Surv. Prof. Paper, 422, 231-291.

Bagnold, R. A. (1977). Bed load transport by natural rivers. Water Resources Research, 13(2), 303-312.

Baker, E. J. (1991). Hurricane evacuation behavior. International Journal of Mass Emergencies and Disasters, 9(2), 287-310.

Bankoff, G., Frerks, G., \& Hilhorst, D. (Eds.). (2004). Mapping vulnerability: disasters, development, and people. Earthscan. $236 \mathrm{p}$.

Basset, T. S. (1996). Histoire éruptive et évaluation des aléas du volcan Acatenango (Guatemala) (Vol. 3). Université de Genève. 309 p.

Behncke, B., \& Neri, M. (2003). The July-August 2001 eruption of Mt. Etna (Sicily). Bulletin of Volcanology, 65(7), 461-476.

Behncke, B. (2009). Hazards from pyroclastic density currents at Mt. Etna (Italy). Journal of Volcanology and Geothermal Research, 180(2), 148-160. 
Blong, R. (2000). Volcanic hazards and risk management. In H. Sigurdsson, B. Hughton, S.R. McNutt, H. Rymer, J. Stix (Eds.), Encyclopedia of Volcanoes, Academic Press, San Diego (2000), pp. 1215-1227.

Bonadonna, C., Connor, C. B., Houghton, B. F., Connor, L., Byrne, M., Laing, A., \& Hincks, T. K. (2005). Probabilistic modeling of tephra dispersal: Hazard assessment of a multiphase rhyolitic eruption at Tarawera, New Zealand. Journal of geophysical research, 110(B3), B03203.

Bonis, S., \& Salazar, O. (1973). The 1971 and 1973 eruptions of volcan Fuego, Guatemala, and some socio-economic considerations for the volcanologist. Bulletin Volcanologique, 37(3), 394400.

Borgia, A., Linneman, S., Spencer, D., Morales, L. D., \& Andre, J. B. (1983). Dynamics of lava flow fronts, Arenal volcano, Costa Rica. Journal of volcanology and geothermal research, 19(3), 303-329.

Borgia, A., \& Linneman, S. R. (1990). On the mechanisms of lava flow emplacement and volcano growth: Arenal, Costa Rica. In Lava flows and Domes (pp. 208-243). Springer Berlin Heidelberg.

Bronk-Ramsey, C. B. (2009). Bayesian analysis of radiocarbon dates. Radiocarbon, 51(1), 337360.

Burton, I. Kates, R.B., and White, G.F. (1993). The environment as hazard. Guilford Press. 290 p.

Calder, E. S., Cole, P. D., Dade, W. B., Druitt, T. H., Hoblitt, R. P., Huppert, H. E., ... \& Young, S. R. (1999). Mobility of pyroclastic flows and surges at the Soufriere Hills Volcano, Montserrat. Geophysical Research Letters, 26(5), 537-540.

Calder, E. S., Luckett, R., Sparks, R. S. J., \& Voight, B. (2002). Mechanisms of lava dome instability and generation of rockfalls and pyroclastic flows at Soufriere Hills Volcano, Montserrat. Geological Society, London, Memoirs, 21(1), 173-190.

Charbonnier, S. J., \& Gertisser, R. (2008). Field observations and surface characteristics of pristine block-and-ash flow deposits from the 2006 eruption of Merapi Volcano, Java, Indonesia. Journal of Volcanology and Geothermal Research, 177(4), 971-982. 
Chester, D. K. (1993). Volcanoes and society. E. Arnold. 351 pp.

Cigolini, C., Borgia, A., \& Casertano, L. (1984). Intra-crater activity, aa-block lava, viscosity and flow dynamics: Arenal volcano, Costa Rica. Journal of volcanology and geothermal research, 20(1), 155-176.

Clarke, A. B., Neri, A., Voight, B., Macedonio, G., \& Druitt, T. H. (2002). Computational modeling of the transient dynamics of the August 1997 Vulcanian explosions at Soufriere Hills Volcano, Montserrat: influence of initial conduit conditions on near-vent pyroclastic dispersal. Geological Society, London, Memoirs, 21(1), 319-348.

Cole, P. D., Calder, E. S., Druitt, T. H., Hoblitt, R., Robertson, R., Sparks, R. S. J., \& Young, S. R. (1998). Pyroclastic flows generated by gravitational instability of the 1996-97 lava dome of Soufriere Hills Volcano, Montserrat. Geophysical Research Letters, 25(18), 3425-3428.

Collins, B. D., \& Dunne, T. (1986). Erosion of tephra from the 1980 eruption of Mount St. Helens. Geological Society of America Bulletin, 97(7), 896-905.

Cueva-Muñiz, A., \& Luján, J. L. S. (2005). Reubicación y desarticulación de La Yerbabuena. Desacatos, (19), 41-70.

Cruz-Estrada, R. (2006). Comunidad de RetornadosColonia 15 de Octubre "La Trinidad" La experiencia organizativa del Retorno y su impacto en la conformación identitaria de las nuevas comunidades. Thesis. $271 \mathrm{p}$.

Dade, W. B., \& Huppert, H. E. (1998). Long-runout rockfalls. Geology, 26(9), 803-806. Davidson, J., \& De Silva, S. (2000). Composite volcanoes. Encyclopedia of Volcanoes (Sigurdsson, H.; Hughton, BF; McNutt, SR, 679.

Dash, N., \& Gladwin, H. (2007). Evacuation decision making and behavioral responses: Individual and household. Natural Hazards Review, 8(3), 69-77.

Davies, D. K., Vessell, R. K., Miles, R. C., Foley, M. G., \& Bonis, S. B. (1977). Fluvial transport and downstream sediment modifications in an active volcanic region. in Miall, A. D., ed., Fluvial sedimentology: Calgary, Alberta, Canadian Society of Petroleum Geologists, p. 61-84. 
Davies, D. K., Quearry, M. W., \& Bonis, S. B. (1978). Glowing avalanches from the 1974 eruption of the volcano Fuego, Guatemala. Geological Society of America Bulletin, 89(3), 369-384.

De La Cruz-Reyna, S., Meli, R. P., \& Quaas, R. W. (2000). Volcanic crises management. Encyclopedia of Volcanoes, Academic Press, San Diego, USA, 1199-1214.

Deger, E. (1932). Der Ausbruch des Fuego in Guatemala am 21 Januar 1932 und die chemische Zusammensetzung seiner Auswurfmaterialien. Chemie der Erde, 7, 291-297.

Dibben, C., \& Chester, D. K. (1999). Human vulnerability in volcanic environments: the case of Furnas, São Miguel, Azores. Journal of Volcanology and Geothermal Research, 92(1), 133-150.

Dollfus, A., E. deMontserrat, (1868). Voyage geologique dans les republiques de Guatemala et El Salvator, Paris, Imperiale. 539 p.

Douglas, M., \& Wildavsky, A. (1982). Risk and culture: an essay on the selection of technological and environmental dangers. Berkeley. Cal.: Univ. of California Press. 221 p.

Dow, K., \& Cutter, S. L. (2000). Public orders and personal opinions: household strategies for hurricane risk assessment. Global Environmental Change Part B: Environmental Hazards, 2(4), 143-155.

Dozy, J. J. (1949). Some notes on the volcanoes of Guatemala. Bulletin of Volcanology, 8(1), 4767.

Drabek, T. E. (1999). Understanding disaster warning responses. The Social Science Journal, 36(3), 515-523.

Draxler, R. R., \& Rolph, G. D. (2013). HYSPLIT (HYbrid Single-Particle Lagrangian Integrated Trajectory) model access via NOAA ARL READY website (http://www. arl. noaa. gov/ready/hysplit4. html). NOAA Air Resources Laboratory, Silver Spring.

Erlund, E. J., Cashman, K. V., Wallace, P. J., Pioli, L., Rosi, M., Johnson, E., \& Granados, H. D. (2010). Compositional evolution of magma from Parícutin Volcano, Mexico: The tephra record. Journal of Volcanology and Geothermal Research, 197(1), 167-187. 
Evans, J. R., Huntoon, J. E., Rose, W. I., Varley, N. R., \& Stevenson, J. A. (2009). Particle sizes of andesitic ash fallout from vertical eruptions and co-pyroclastic flow clouds, Volcán de Colima, Mexico. Geology, 37(10), 935-938.

Farr, T. G., Rosen, P. A., Caro, E., Crippen, R., Duren, R., Hensley, S., .. \& Alsdorf, D. (2007). The shuttle radar topography mission. Reviews of geophysics, 45(2).

Fierstein, J., \& Nathenson, M. (1992). Another look at the calculation of fallout tephra volumes. Bulletin of Volcanology, 54(2), 156-167.

FINNMAP - PASCO. 2006. Plan de trabajo para la Generación Unificada Nacional de Base de Datos de GIS y Producción de Impresión de Mapas Topográficos Originales a escala 1:50,000 de la Republica de Guatemala. FINNMAP - PASCO. Guatemala. 7 p.

Fischhoff, B. (Ed.). (1984). Acceptable risk. Cambridge University Press. 185 p.

Fuchs, C. W. C. (1865). Die vulkanischen Erscheinungen der Erde. CF Winter'sche verlagshandlung. $583 \mathrm{p}$.

Fuchs, C. W. (1882). III. Die vulkanischen Ereignisse des Jahres 1880. Zeitschrift für Kristallographie, Mineralogie und Petrographie, 4(1), 51-96.

Gaillard, J. C. (2008). Alternative paradigms of volcanic risk perception: the case of Mt. Pinatubo in the Philippines. Journal of Volcanology and Geothermal Research, 172(3), 315-328.

Gaillard, J. C., \& Dibben, C. J. (2008). Volcanic risk perception and beyond. Journal of Volcanology and Geothermal Research, 172(3), 163-169.

Gavilanes-Ruiz, J. C., Cuevas-Muñiz, A., Varley, N., Gwynne, G., Stevenson, J., Saucedo-Girón, R., \& Cortés-Cortés, A. (2009). Exploring the factors that influence the perception of risk: The case of Volcan de Colima, Mexico. Journal of Volcanology and Geothermal Research, 186(3), 238-252.

Hackett, W. R., \& Houghton, B. F. (1989). A facies model for a Quaternary andesitic composite volcano: Ruapehu, New Zealand. Bulletin of volcanology, 51(1), 51-68. 
Hantke, G. (1951). Übersicht über die vulkanische Tätigkeit 1941-1947. Bulletin of Volcanology, 11(1), 161-208.

Hantke, G. (1953). Übersicht über die vulkanische Tätigkeit 1948-1950. Bulletin of Volcanology, 14(1), 151-184.

Hantke, G. (1955). Übersicht über die vulkanische Tätigkeit 1951-1953. Bulletin of Volcanology, 16(1), 71-113.

Hantke, G. (1959). Übersicht über die vulkanische Tätigkeit 1954-1956. Bulletin of Volcanology, 20(1), 3-33.

Hantke, G. (1962). Übersicht über die vulkanische Tätigkeit 1957-1959. Bulletin of Volcanology, 24(1), 321-348.

Haynes, K., Barclay, J., \& Pidgeon, N. (2007). Volcanic hazard communication using maps: an evaluation of their effectiveness. Bulletin of Volcanology, 70(2), 123-138.

Haynes, K., Barclay, J., \& Pidgeon, N. (2008). The issue of trust and its influence on risk communication during a volcanic crisis. Bulletin of Volcanology, 70(5), 605-621.

Haynes, K., Barclay, J., \& Pidgeon, N. (2008). Whose reality counts? Factors affecting the perception of volcanic risk. Journal of Volcanology and Geothermal Research, 172(3), 259-272.

Hebberger, J.J. 1977 Recent laharic and glowing avalanche sediments, Guatemala: MA Thesis, Univ. Missouri at Columbia, 117p.

Hewitt, K. (Ed.). (1983). Interpretations of calamity: From the viewpoint of human ecology (Vol. 1). Allen \& Unwin. 304 p.

INE - Instituto Nacional de Estadística (Guatemala). (2003). Censos nacionales XI de población y VI de habitación 2002. Instituto Nacional de Estadística.

Iverson, R. M. (1997). The physics of debris flows. Reviews of geophysics, 35(3), 245-296. 
Iverson, R. M., Schilling, S. P., \& Vallance, J. W. (1998). Objective delineation of lahar-inundation hazard zones. Geological Society of America Bulletin, 110(8), 972-984.

Kelfoun, K., Samaniego, P., Palacios, P., \& Barba, D. (2009). Testing the suitability of frictional behaviour for pyroclastic flow simulation by comparison with a well-constrained eruption at Tungurahua volcano (Ecuador). Bulletin of volcanology, 71(9), 1057-1075.

Kelman, I. (2003). Defining risk. FloodRiskNet Newsletter, 2, 6-8.

Kilburn, C. R. (2004). Fracturing as a quantitative indicator of lava flow dynamics. Journal of Volcanology and Geothermal Research, 132(2), 209-224.

Koch, A. J., \& McLEAN, H. U. G. H. (1975). Pleistocene tephra and ash-flow deposits in the volcanic highlands of Guatemala. Geological Society of America Bulletin, 86(4), 529-541.

Kushendratno, Pallister, J. S., Bina, F. R., McCausland, W., Carn, S., Haerani, N., Griswold, J., \& Keeler, R. (2012). Recent explosive eruptions and volcano hazards at Soputan volcano-a basalt stratovolcano in north Sulawesi, Indonesia. Bulletin of volcanology, 74(7), 1581-1609.

Lane, L. R., Tobin, G. A., \& Whiteford, L. M. (2003). Volcanic hazard or economic destitution: hard choices in Baños, Ecuador. Global Environmental Change Part B: Environmental Hazards, 5(1), 23-34.

Lavigne, F., \& Thouret, J. C. (2003). Sediment transportation and deposition by rain-triggered lahars at Merapi Volcano, Central Java, Indonesia. Geomorphology, 49(1), 45-69.

Lavigne, F., De Coster, B., Juvin, N., Flohic, F., Gaillard, J. C., Texier, P., .. \& Sartohadi, J. (2008). People's behaviour in the face of volcanic hazards: Perspectives from Javanese communities, Indonesia. Journal of Volcanology and Geothermal Research, 172(3), 273-287.

Lindell, M. K., \& Perry, R. W. (2004). Communicating environmental risk in multiethnic communities. Communicating effectively in multicultural contexts (7).

Lindell, M. K., \& Perry, R. W. (2011). The protective action decision model: theoretical modifications and additional evidence. Risk Analysis, 32(4), 616-632. 
Linneman, S. R., \& Borgia, A. (1993). The blocky andesitic lava flows of Arenal volcano, Costa Rica. Active Lavas: Monitoring and Modeling, 25.

Lodato, L., Spampinato, L., Harris, A., Calvari, S., Dehn, J., \& Patrick, M. (2007). The morphology and evolution of the Stromboli 2002-2003 lava flow field: an example of a basaltic flow field emplaced on a steep slope. Bulletin of volcanology, 69(6), 661-679.

López-Vázquez, E. (2009). Risk perception and coping strategies for risk from Popocatépetl Volcano, Mexico. Geofísica internacional, 48(1), 133-147.

Lube, G., Cronin, S. J., \& Thouret, J. C. (2011). Kinematic characteristics of pyroclastic density currents at Merapi and controls on their avulsion from natural and engineered channels.

Geological Society of America Bulletin, 123(5-6), 1127-1140.

Lyons, J. J., Waite, G. P., Rose, W. I., \& Chigna, G. (2010). Patterns in open vent, strombolian behavior at Fuego volcano, Guatemala, 2005-2007. Bulletin of volcanology, 72(1), 1-15.

Manville, V., Németh, K., \& Kano, K. (2009). Source to sink: a review of three decades of progress in the understanding of volcaniclastic processes, deposits, and hazards. Sedimentary Geology, 220(3), 136-161.

Marchetti, E., Ripepe, M., Harris, A. J. L., \& Delle Donne, D. (2009). Tracing the differences between Vulcanian and Strombolian explosions using infrasonic and thermal radiation energy. Earth and Planetary Science Letters, 279(3), 273-281.

Macdonald, G. A. (1972); Volcanoes. Prentice-Hall, Englewood Cliffs, NJ, (1972), 510 p.

Mader, H. M. (Ed.). (2006). Statistics in volcanology (Vol. 1). Geological Society. 285 p.

Major, J. J., \& Yamakoshi, T. (2005). Decadal-scale change of infiltration characteristics of a tephra-mantled hillslope at Mount St Helens, Washington. Hydrological processes, 19(18), 36213630.

Marzocchi, W., Sandri, L., Gasparini, P., Newhall, C., \& Boschi, E. (2004). Quantifying probabilities of volcanic events: the example of volcanic hazard at Mount Vesuvius. Journal of Geophysical Research: Solid Earth (1978-2012), 109(B11). 
Meyer-Abich, H. (1956). Los volcanes activos de Guatemala y El Salvador (América Central). Ministerio de Obras Públicas. 102 p.

Miyabuchi, Y., Watanabe, K., \& Egawa, Y. (2006). Bomb-rich basaltic pyroclastic flow deposit from Nakadake, Aso Volcano, southwestern Japan. Journal of volcanology and geothermal research, 155(1), 90-103.

Montessus de Ballore, F. (1884). Temblores y erupciones volcánicas en Centro-América. San Salvador, El Salvador. 246 p.

Montgomery, D. R., \& Buffington, J. M. (1997). Channel-reach morphology in mountain drainage basins. Geological Society of America Bulletin, 109(5), 596-611.

Moore, J. G., \& Melson, W. G. (1969). Nuees ardentes of the 1968 eruption of Mayon volcano, Philippines. Bulletin Volcanologique, 33(2), 600-620.

Mooser, F., Meyer-Abich, H., \& McBirney, A. R. (1958). Catalogue of the active volcanoes of the world including solfatara fields: Part VI. Central America. International Volcanological Association. $147 \mathrm{p}$.

Nairn, I. A., \& Self, S. (1978). Explosive eruptions and pyroclastic avalanches from Ngauruhoe in February 1975. Journal of volcanology and geothermal research, 3(1), 39-60.

Németh, K., \& Cronin, S. J. (2007). Syn-and post-eruptive erosion, gully formation, and morphological evolution of a tephra ring in tropical climate erupted in 1913 in West Ambrym, Vanuatu. Geomorphology, 86(1), 115-130.

Neri, A., Aspinall, W. P., Cioni, R., Bertagnini, A., Baxter, P. J., Zuccaro, G., .. \& Woo, G. (2008). Developing an event tree for probabilistic hazard and risk assessment at Vesuvius. Journal of Volcanology and Geothermal Research, 178(3), 397-415.

Newhall, C. G. "Volcano warnings." Encyclopaedia of volcanoes, Academic, New York (2000): 1185-1197.

Newhall, C., \& Hoblitt, R. (2002). Constructing event trees for volcanic crises. Bulletin of Volcanology, 64(1), 3-20. 
O'Keefe, P., Westgate, K., \& Wisner, B. (1976). Taking the naturalness out of natural disasters. Nature, 260, 566-567.

Palmer, B. A. (1991). Holocene lahar deposits in the Whakapapa catchment, northwestern ring plain, Ruapehu volcano (North Island, New Zealand). New Zealand journal of geology and geophysics, 34(2), 177-190.

Palmer, B. A., Purves, A. M., \& Donoghue, S. L. (1993). Controls on accumulation of a volcaniclastic fan, Ruapehu composite volcano, New Zealand. Bulletin of volcanology, 55(3), 176189.

Paté-Cornell, M. E. (1984). Fault trees vs. event trees in reliability analysis. Risk Analysis, 4(3), 177-186.

Paton, D., Millar, M., \& Johnston, D. (2001). Community resilience to volcanic hazard consequences. Natural Hazards, 24(2), 157-169.

Paton, D. (2008). Risk communication and natural hazard mitigation: how trust influences its effectiveness. International Journal of Global Environmental Issues, 8(1), 2-16.

Perry, R. W. (1979). Evacuation decision-making in natural disasters. Mass Emergencies, 4(1), 25-38.

Perry, R. W., \& Lindell, M. K. (2008). Volcanic risk perception and adjustment in a multi-hazard environment. Journal of Volcanology and Geothermal Research, 172(3), 170-178.

Pioli, L., Erlund, E., Johnson, E., Cashman, K., Wallace, P., Rosi, M., \& Delgado Granados, H. (2008). Explosive dynamics of violent Strombolian eruptions: the eruption of Parícutin Volcano 1943-1952 (Mexico). Earth and Planetary Science Letters, 271(1), 359-368.

Prochaska, A. B., Santi, P. M., Higgins, J. D., \& Cannon, S. H. (2008). A study of methods to estimate debris flow velocity. Landslides, 5(4), 431-444.

Pyle, D. M. (1989). The thickness, volume and grainsize of tephra fall deposits. Bulletin of Volcanology, 51(1), 1-15. 
Quearry, M. W. (1975). Continental volcanic sediments in the region of Volcan de Fuego, Guatemala. Ph. D. dissertation, University of Missouri--Columbia. 105 p.

Reimer, P. J., Baillie, M. G., Bard, E., Bayliss, A., Beck, J. W., Blackwell, P. G., \& Weyhenmeyer, C. E. (2009). IntCal09 and Marine09 radiocarbon age calibration curves, 0-50,000 years cal BP.

Riedel, C., Ernst, G. G. J., \& Riley, M. (2003). Controls on the growth and geometry of pyroclastic constructs. Journal of Volcanology and Geothermal Research, 127(1), 121-152.

Rockstroh, E. (1883). Temblores y Erupcions en Centre-America, Revista del Observatorio central de Guatemala, no. 1, 1883, pp 25 - 39.

Roggensack, K. (2001). Unraveling the 1974 eruption of Fuego volcano (Guatemala) with small crystals and their young melt inclusions. Geology, 29(10), 911-914.

Rose Jr, W. I., Bonis, S., Stoiber, R. E., Keller, M., \& Bickford, T. (1973). Studies of volcanic ash from two recent Central American eruptions. Bulletin Volcanologique, 37(3), 338-364.

Rose Jr, W. I., Anderson Jr, A. T., Woodruff, L. G., \& Bonis, S. B. (1978). The October 1974 basaltic tephra from Fuego volcano: description and history of the magma body. Journal of Volcanology and Geothermal Research, 4(1), 3-53.

Rose, W.I., Mercado, R., Matías, O. and Girón, J., 1987, Volcanic hazards of Fuego volcano, Guatemala, Preliminary Report: Michigan Technological University, U.S. Geological Survey, and INSIVUMEH, $30 \mathrm{p}$.

Rose, W. I., Conway, F. M., Pullinger, C. R., Deino, A., \& Mclntosh, W. C. (1999). An improved age framework for late Quaternary silicic eruptions in northern Central America. Bulletin of Volcanology, 61(1-2), 106-120.

Rose, W. I., Self, S., Murrow, P. J., Bonadonna, C., Durant, A. J., \& Ernst, G. G. J. (2008). Nature and significance of small volume fall deposits at composite volcanoes: Insights from the October 14, 1974 Fuego eruption, Guatemala. Bulletin of Volcanology, 70(9), 1043-1067.

Rose, W. I., \& Durant, A. J. (2011). Fate of volcanic ash: aggregation and fallout. Geology, 39(9), 895-896. 
Sánchez del Valle, R. (2002). Sistematización y documentación del proyecto: Sistemas de alerta temprana en los volcanes de Pacaya y Fuego. Experiencias en Gestión Local de Riesgo en Centroamérica, 59-70.

Sapper, K. (1913). Die mittelamerikanischen Vulkane (No. 178). J. Perthes.

Sapper, K. (1925). Los volcanes de la América Central (No. 1). M. Niemeyer.

Saucedo, R., Macıas, J. L., Bursik, M. I., Mora, J. C., Gavilanes, J. C., \& Cortes, A. (2002).

Emplacement of pyroclastic flows during the 1998-1999 eruption of Volcán de Colima, Mexico. Journal of volcanology and geothermal research, 117(1), 129-153.

Saucedo, R., Macías, J. L., \& Bursik, M. (2004). Pyroclastic flow deposits of the 1991 eruption of Volcán de Colima, Mexico. Bulletin of volcanology, 66(4), 291-306.

Schwarzkopf, L. M., Schmincke, H. U., \& Cronin, S. J. (2005). A conceptual model for block-andash flow basal avalanche transport and deposition, based on deposit architecture of 1998 and 1994 Merapi flows. Journal of Volcanology and Geothermal Research, 139(1), 117-134.

Slingerland, R., \& Smith, N. D. (2004). River avulsions and their deposits. Annu. Rev. Earth Planet. Sci., 32, 257-285.

Slovic, P. E. (2000). The perception of risk. Earthscan Publications. 473 p.

Sorensen, J. H., \& Mileti, D. S. (1988). Warning and evacuation: answering some basic questions. Industrial Crisis Quarterly, 2(2), 1-15.

Sorensen, J. H., \& Sorensen, B. V. (2007). Community processes: warning and evacuation. In Handbook of disaster research (pp. 183-199). Springer New York.

Sparks, R. S. J., Wilson, L., \& Hulme, G. (1978). Theoretical modeling of the generation, movement, and emplacement of pyroclastic flows by column collapse. Journal of Geophysical Research: Solid Earth (1978-2012), 83(B4), 1727-1739. 
Sparks, R. S. J. (2003). Forecasting volcanic eruptions. Earth and Planetary Science Letters, 210(1), 1-15.

Susman, P., O'Keefe, P., \& Wisner, B. (1983). Global disasters, a radical interpretation. Interpretations of calamity, 263-283.

Taddeucci, J., Pompilio, M., \& Scarlato, P. (2004). Conduit processes during the July-August 2001 explosive activity of Mt. Etna (Italy): inferences from glass chemistry and crystal size distribution of ash particles. Journal of Volcanology and Geothermal Research, 137(1), 33-54.

Tobin, G. A., \& Whiteford, L. M. (2002). Community resilience and volcano hazard: the eruption of Tungurahua and evacuation of the faldas in Ecuador. Disasters, 26(1), 28-48.

Tobin, G. A., Whiteford, L. M., Jones, E. C., Murphy, A. D., Garren, S. J., \& Padros, C. V. (2011). The role of individual well-being in risk perception and evacuation for chronic vs. acute natural hazards in Mexico. Applied Geography,31(2), 700-711.

Valentine, G. A., \& Wohletz, K. H. (1989). Numerical models of Plinian eruption columns and pyroclastic flows. Journal of Geophysical Research: Solid Earth (1978-2012), 94(B2), 1867-1887.

Vallance, J. W. (2000). Lahars. In Sigurdsson (Ed) Encyclopedia of volcanoes. Academic Press. $1417 \mathrm{p}$.

Vallance, J. W., S. P. Schilling, O. Matías, W. I. Rose, and M. M. Howell (2001), Volcano hazards at Fuego and Acatenango, Guatemala, U.S. Geolog. Surv. Open-File Rep., 01-431, USGS/Cascades Volcano Obs., Vancouver, Wash.

Vallance, J. W., Bull, K. F., \& Coombs, M. L. (2010). Pyroclastic flows, lahars and mixed avalanches generated during the 2006 eruption of Augustine Volcano. US Geological Survey Professional Paper, 1769, 221-267.

Van Westen, C. J., \& Daag, A. S. (2005). Analyzing the relation between rainfall characteristics and lahar activity at Mount Pinatubo, Philippines. Earth Surface Processes and Landforms, 30(13), 1663-1674. 
Vessell, R. K. (1979). Recent and ancient volcaniclastic sedimentation on an active continental margin. Ph. D. Dissertation. Texas Tech University. 127 p.

Vessel, R. K., and Davies, D. K., (1981). Nonmarine sedimentation in an active forearc basin, in Ethridge, F. G., and Flores, R. O., eds.. Recent and ancient nonmarine depositional environments: Models for exploration: Society of Economic Paleontologists and Mineralogists Special Publication 31, p. 31-45.

Volcanological Society of Japan - IAVCEI (1963). Bulletin of Volcanic Eruptions No 3, Tokyo Japan. $8 \mathrm{p}$.

Volcanological Society of Japan - IAVCEI, (1964). Bulletin of Volcanic Eruptions No 4, Tokyo Japan. $10 \mathrm{p}$.

Volcanological Society of Japan - IAVCEI, (1967). Bulletin of Volcanic Eruptions No 7, Tokyo Japan. $10 \mathrm{p}$.

Volcanological Society of Japan - IAVCEI, (1969). Bulletin of Volcanic Eruptions No 9 - 1, Tokyo Japan. $19 \mathrm{p}$.

von Seebach, K. (1892). Ueber Vulkane Centralamerikas. Abhandlungen der Königlichen Gesellschaft der Wissenschaften in Göttingen, 38, 3.

Waite, G. P., Nadeau, P. A., \& Lyons, J. J. (2013). Variability in eruption style and associated very long period events at Fuego volcano, Guatemala. Journal of Geophysical Research: Solid Earth. 118 (4), 1526 - 1533.

Walker, G. P. L. (1967). Thickness and viscosity of Etnean lavas. Nature, 213, $484-485$.

Walker, G. P. (1973). Explosive volcanic eruptions-a new classification scheme. Geologische Rundschau, 62(2), 431- 446.

Webley, P. W., Wooster, M. J., Strauch, W., Saballos, J. A., Dill, K., Stephenson, P., ... \& Matias, O. (2008). Experiences from near-real-time satellite-based volcano monitoring in Central America: case studies at Fuego, Guatemala. International Journal of Remote Sensing, 29(22), 6621-6646.

Whiteford, L. M., \& Tobin, G. A. (2009). If the pyroclastic flow doesn't kill you, the recovery will. Political economy of hazards and disasters. Alta Mira Press, Walnut Creek, 155 -176. 
Whitehead, J. C., Edwards, B., Van Willigen, M., Maiolo, J. R., Wilson, K., \& Smith, K. T. (2000). Heading for higher ground: factors affecting real and hypothetical hurricane evacuation behavior. Global Environmental Change Part B: Environmental Hazards, 2(4), 133-142.

Wickman, F. E. (1966). Repose period patterns of volcanoes. Ark. Mineral. Geol, 4(8), 291-367.

Wilson, L., \& Self, S. (1980). Volcanic explosion clouds: Density, temperature, and particle content estimates from cloud motion. Journal of Geophysical Research: Solid Earth (1978-2012), 85(B5), 2567-2572.

Wilson, L., Sparks, R. S. J., \& Walker, G. P. (1980). Explosive volcanic eruptions-IV. The control of magma properties and conduit geometry on eruption column behaviour. Geophysical Journal of the Royal Astronomical Society, 63(1), 117-148.

Wilson, J. P., \& Gallant, J. C. (Eds.). (2000). Terrain analysis: principles and applications. John Wiley \& Sons.

Wisner, B. (Ed.). (2004). At risk: natural hazards, people's vulnerability and disasters. Routledge. $471 \mathrm{p}$.

Wunderman, R. L., \& Rose, W. I. (1984). Amatitlan, an actively resurging cauldron $10 \mathrm{~km}$ south of Guatemala City. Journal of Geophysical Research, 89(B10), 8525-8539.

Wolf, T. (1878). Der Cotopaxi und seine letzte Eruption am 26 Juni 1877. Neues Jb. Miner. Geol. PalaÈont, 113-167.

Yamamoto, T., Takada, A., Ishizuka, Y., Miyaji, N., \& Tajima, Y. (2005). Basaltic pyroclastic flows of Fuji volcano, Japan: characteristics of the deposits and their origin. Bulletin of volcanology, $67(7), 622-633$.

Yokoyama, R., Shirasawa, M., \& Pike, R. J. (2002). Visualizing topography by openness: a new application of image processing to digital elevation models. Photogrammetric engineering and remote sensing, 68(3), 257-266. 


\section{Appendices}

A set of appendices with complementary information is provided with this thesis. Appendix 1, containing the authorizations for use photographic material is given at end of this .pdf document (next section). Appendices 2.1 through 4 are given as electronic .zip files in the accompanying $\mathrm{CD}$ to this thesis, or can be downloaded from the online repository hosting this .pdf document.

Appendix 1 Authorization to use photographic material (transcription of Facebook and email messages)

\section{Figure 2.7}

\section{Message sent to K'ashem via Facebook by Rüdiger Escobar Wolf (April 17, 2013):}

Estimados amigos de K'ashem, mi nombre es Rudiger Escobar Wolf... y viendo la pagina de facebook de K'ashem encontre unas fotos que me interesaria poder utilizar en mi tesis....

Yo utilizaria las fotos solo para fines no comerciales, para ser publicadas en mi tesis doctoral y quizas en algunos articulos cientificos que publique en el futuro. Desde luego que en esas publicaciones yo le daria el credito correspondiente al autor de las fotos, de la forma en que el o ella me lo indique. Voy a poner un mensaje en las fotos para que ustedes sepan a que fotos me refiero. De antemano les agradecere si me pueden ayudar con esto. Saludos!

Response by K'ashem:

OK, no hay problema y en los creditos: "K'ashem - www.hastalacumbre.com" y listo. Saludos!

Figure 2.11 A and B, Figure 2.25 B:

Message sent to Ricky Lopez Bruni via Facebook by Rüdiger Escobar Wolf (February 25, 2013):

Estimado Ricky, le quiero pedir permiso para utilizar algunas de sus fotografias del volcan de Fuego, para fines no comerciales. ... quisiera utilizar algunas fotos para ponerlas en la disertacion con el fin de ilustrar ese tipo de actividad. Tambien las utilizaria en la presentacion el dia de la defensa de la disertacion. Desde luego que le dare todos los creditos de autoria y 
derechos de propiedad, e incluire cualquier nota de derechos de autor que usted me indique...

Saludos: Rudiger

Response by Ricky Lopez Bruni:

dale con gusto

Figure $2.11 \mathrm{C}$ :

Message sent to Ivan Castro Peña via Facebook by Rüdiger Escobar Wolf (November 12, 2012):

Estimado Ivan, le quiero pedir permiso para utilizar algunas de sus fotografias del volcan de Fuego, para fines no comerciales... quisiera utilizar algunas fotos para ponerlas en la disertacion con el fin de ilustrar ese tipo de actividad; tambien las utilizaria en la presentacion el dia de la defensa de la disertacion. Desde luego que le dare todos los creditos de autoria y derechos de propiedad, e incluire cualquier nota de derechos de autor que usted me indique...

Saludos: Rudiger

\section{Response by Ivan Castro Peña:}

Hola Rudiger que alegre por tu disertación te felicito por eso y claro que las puedes usar, si pudieras mostrarme lo que hagas te lo agradecería, un abrazo que estés bien, gracias por escribir

\section{Figure 2.25 A:}

Message sent to Estuardo Archila via Facebook by Rüdiger Escobar Wolf (July 19, 2013):

Hola Estuardo, como le va? Queria pedirle permiso para utilzar una de sus fotos del volcan de Fuego en mi tesis. La foto es del 2002 y en la tesis le daria es credito respectivo. Gracias! Saludos!

\section{Response by Estuardo Archila:}

con todo gusto y si se puede tener una copia electronica del documento se lo agradeceria mucho 
Figure 2.26 A and B:

Message sent to Vinicio Bejarano via Facebook by Rüdiger Escobar Wolf (September 27, 2012):

Estimado Sr Bejarano, mi nombre es Rudiger Escobar Wolf, y soy un estudiante del doctorado en volcanologia en la Michigan Tech University, y mi tema de investigacion es sobre el volcan de Fuego. He tenido la oportunidad de ver algunos de sus videos y fotografias sobre la actividad eruptiva del volcan de Fuego, que Usted ha publicado en el internet (en youtube, facebook, etc.) y me interesaria poder utilizar parte de este material con fines de investigacion (no lucrativos), obviamente dandole a Usted todo el credito que le corresponde... Saludos: Rüdiger

\section{Response by Vinicio Bejarano:}

Gracias por la comunicacion y el interés... y claro que se pueden usar y publicar, o darle el uso que usted necesite... Saludos y a las ordenes

Figure 2.43 A, B, C, D:

Message sent to Gustavo Chigna from INSIVUMEH via email by Rüdiger Escobar Wolf (January 10, 2012):

Estimados Gustavo... queria pedir permiso para utilizar las fotografias que ustedes y otros compañeros del INSIVUMEH han tomado de la actividad volcanica y del volcan. En todas las fotos que yo utilice estare dando los creditos respectivos al autor y al INSIVUEMH...

\section{Response by Gustavo Chigna:}

Hola Rudiger

Por mi parte no hay problema para utilizar fotos y si necesita mas me avisa, estamos en contacto (por correo).

Saludos. 
Figure 2.43 E and F:

Message sent to Yojana Miner from SECONRED via email by Rüdiger Escobar Wolf (January 10, 2012):

Estimada Yojana... quiero utilizar fotos y video del volcan de Fuego que fue tomado por CONRED, asi que necesito el respectivo permiso...

\section{Response by Yojana Miner:}

Por este medio le autorizo a utilizar las fotografías y video tomados por personal de la SECONRED, en publicaciones académica y cientificas, siempre y cuando sea para fines no comerciales...

Atentamente Yojana Miner

Figure $2.43 \mathrm{G}$ :

Message sent to Janelle Haapala via email by Rüdiger Escobar Wolf (November 29, 2012): Janelle... You took some pictures of a Guatemalan volcano (see attached pictures) that I want to use in my dissertation and so I would like her permission to publish the pictures...

Saludos: Rüdiger

\section{Response by Janelle Haapala:}

Rudiger, You may use those pictures. I would send higher resolution pictures but all my pictures are slides, so it is more troublesome.

Let me know if you want to borrow the slides.

Janelle

\section{Figure $2.43 \mathrm{H}$ and $\mathrm{I}$ :}

Message sent to Edwin Wilfredo Cabnal Hernández from SINIT / SEGEPLAN via email by Rüdiger Escobar Wolf (November 19, 2012): 
Estimados Sres SINIT / SEGEPLAN... Resulta que estoy escribiendo mi disertacion doctoral sobre el volcan de Fuego en la Michigan Tech University, y como parte de la investigacion yo he utilizado la informacion de la IDE, y entre otras cosas he utilizado las ortofotos como fondo de varias figuras (mapas). Mi pregunta es si necesito algun permiso especial para publicar dicha informacion. El uso de la informacion es de caracter no comercial, especificamente para usos de investigacion. Obviamente yo le doy los creditos respectivos al SINIT / SEGEPLAN, y al IGN, incluyendo la URL del sitio web de la IDE.

Le agradezco de antemano su atencion y estare a la espera de su respuesta.

Saludos: Rudiger

\section{Response by Wilfredo Cabnal Hernández:}

Estimado Rudiger, buenos días.

Son suficientes con dar los créditos a SEGEPLAN y a las otras instituciones de donde proviene la información.

Saludos.

\section{Figure $2.43 \mathrm{H}$ and $\mathrm{I}$ :}

Message sent to Raul Salguero via email by Rüdiger Escobar Wolf (July 19, 2013):

Dear Raul, I am writing to ask for permission to use one of your photographs of Fuego volcano on my dissertation. You could grant me permission via email, if that is OK for you. Thanks.

Saludos: Rüdiger

\section{Response by Raul Salguero:}

Dear Rudiger,

You have my permission to use the photograph on your dissertation.

Best regards,

Raúl Salguero 
Figure 3.11 A and B:

Message sent to Ken Wilson via email by Rüdiger Escobar Wolf (November 19, 2012):

Dear Mr Wilson, my name is Rüdiger Escobar Wolf, I'm a PhD student at Michigan Tech

University, and my dissertation is about Fuego volcano... shared some photographs of an eruption from Fuego volcano that I understand were taken by your father, Mr. Ned Wilson, in $1947 \ldots$

I would also like to ask you for permission to give these pictures a non-commercial use, by including them in my dissertation and possibly in a subsequent scientific article. I would of course give your father the due credits for the authorship.

Thanks!

Saludos: Rüdiger

\section{Response by Ken Wilson:}

Dear Rudiger,

I think that with proper credit, our family would be quite happy to have these photographs used in a dissertation or article. I am copying my siblings on this email. 